\title{
REDUCED FOULING OF ULTRAFILTRATION MEMBRANES \\ VIA SURFACE FLUORINATION
}

By R. H. Sedath, S. F. Yates and N. N. Li

March 1993

Work Performed Under Contract No. FC07-891D12904

\author{
Prepared for the \\ U.S. Department of Energy \\ Under DOE Idaho Field Office \\ Sponsored by the Office of the Assistant Secretary \\ for Conservation and Renewable Energy \\ Office of Industrial Technologies \\ Washington, D.C. \\ Prepared by \\ Allied-Signal Research and Technology \\ Des Plaines, IL 60017
}


Surface fluorination can affect significantly the performance of an ultrafiltration membrane used to concentrate a food-related stream. Membranes which have been fluorinated under appropriate conditions and tested as flat sheets exhibit higher initial fluxes, and do not foul as rapidly as untreated membranes. We link this improvement to increased hydrophilicity of the surface, as shown by the decrease we observe in contact angle with water. This increased hydrophilicity, in turn, we link to the addition of fluorine and oxygen to the surface.

Our pilot plant study did not show the clear difference in membrane flux and fouling that we observed in the flat sheet study. Instead, fluorinated and unfluorinated modules behaved in a substantially similar manner. Fouling by the potato waste feed was severe, and resulted in the formation of an extensive gel layer within the module on the surface of the membrane. XPS, SEM and FTIR studies combine to indicate that some build up of organic material occurred on both the fluorinated and unfluorinated membranes, but SEM indicates that a fibrous mat of material was observed only on the nonfluorinated membrane. We conclude that in the pilot study, membrane fouling and gel formation were so extensive that the surface interaction effect on whici: our approach is based was overwhelmed. 


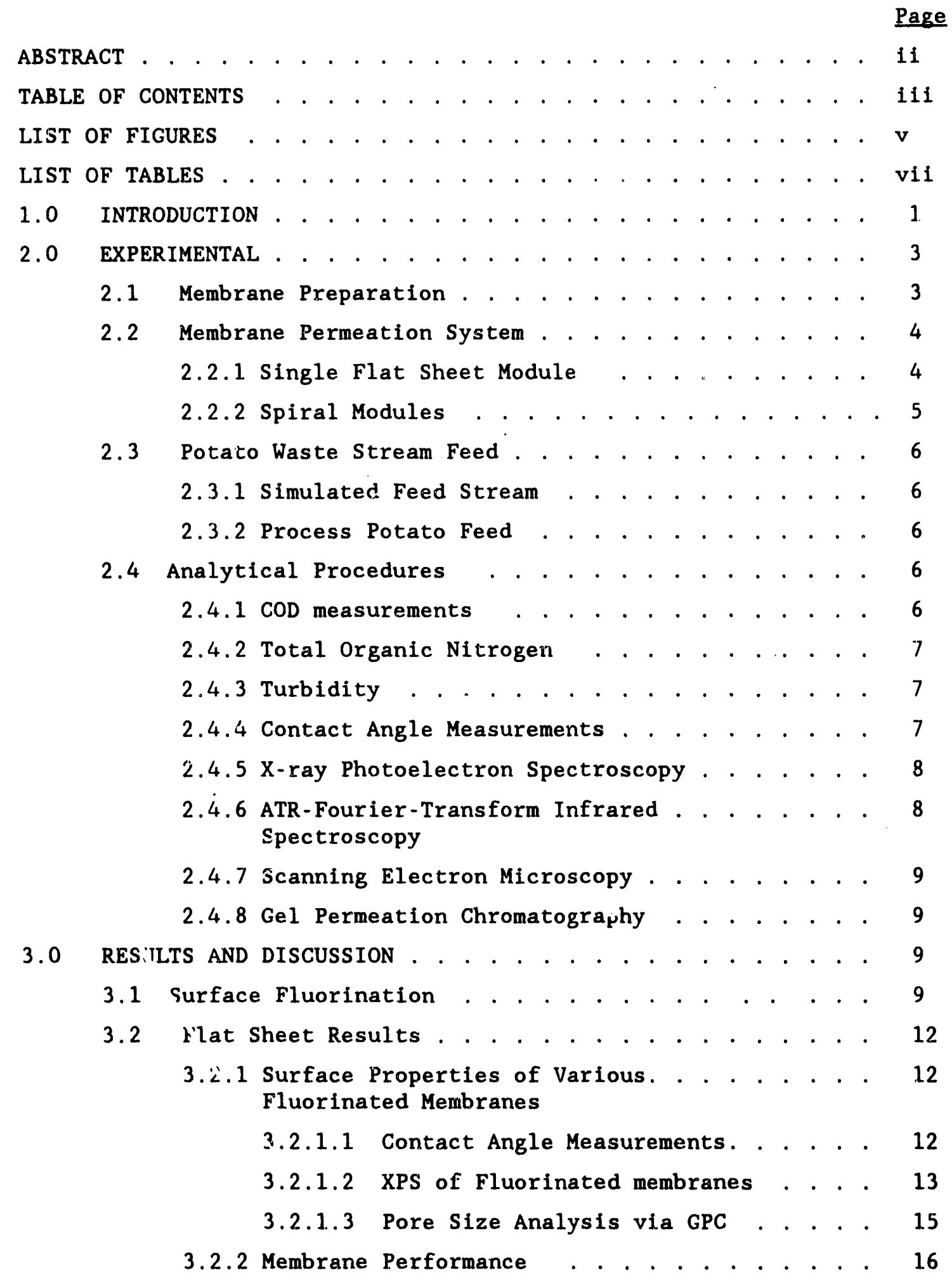


3.2.2.1 Permeate Flux... . . . . . . . . 16

3.2.2.2 COD and Nitrogen Rejection . . . . 17

3.2.3 Summary - Flat Sheet Experiments . . . . . . . 18

3.3 Cleaning Study . . . . . . . . . . . . . . . . . . 18

3.4 Scale-up to Spiral Module . . . . . . . . . . . . . . 19

3.4.1 Membrane Performance . . . . . . . . . . 20

3.4.1.1 Permeate Flux .. . . . . . . . . 20

3.4.1.2 Turbidity, COD and . . . . . . . . 23 Nitrogen Rejection

3.4.1.3 Gel Permeation Chromatography . . . . 25 Analysis of Process Potato Starch

3.4.2 Surface Properties . . . . . . . . . . . . . 26

3.4.2.1 Final Appearance . . . . . . . . . 26

3.4.2.2 SEM Micrographs . . . . . . . . . . . 26

3.4.2.3 XPS Analysis of Fouled . . . . . . . . 27 Surfaces

3.4.2.4 ATR-FTIR Analysis of Surface . . . . . 27

3.4.3 Summary - Spiral Wound Module Study . . . . . . 28

3.5 Economic Analysis . . . . . . . . . . . . . . . . . . 29

4.0 CONCLUSIONS AND RECOMMENDATIONS . . . . . . . . . . . . 31

5.0 ACKNOWLEDGEMENTS . . . . . . . . . . . . . . . . . . . . . 33

6.0 REFERENCES . . . . . . . . . . . . . . . . . . . . . . . . 34

\section{TABLES}

FIGIIRES

APPENDICES

A. Flat Sheet Data... . . . . . . . . . . . . . Al

B. Spiral Module Pilot Plant Data . . . . . . . . . B1

C. XPS Survey Spectra of Fluorinated Membranes . . . . C1

D. Economic Analysis of Ultrafiltration Systems . . . D1 


\section{LIST OF FIGURES}

Page

Figure 1: Schematic of Ultrafiltration Membrane Separation . . . . . . . 37

Figure 2: Flowsheet of a Typical Potato Processor' . . . . . . . . . . . 38

Figure 3: Schematic of the Fluorination Apparatus . . . . . . . . . . . 39

Figure 4: Schematic of a Test System with a Single . . . . . . . . . . . 40 Ultrafiltration Cell

Figure 5: Diagram of Unrolled Spiral-Wound Membrane Module . . . . . . . 41

Figure 6: Flowsheet of the Spiral Module Pilot Plant . . . . . . . . . . 42

Figure 7: Photograph of the Spiral Module Pilot Plant . . . . . . . . . 43

Figure 8: Definition of Contact Angle $\theta$ at Water-Solid Interface . . . . 44

Figure 9: Comparison of DI Water Flux Through Pretreated Membranes . . . 45

Figure 10: Contact Angle Measurements of Untreated and . . . . . . . . . 46 Fluorinated Polysulfone Membranes

Figure 11: Contact Angle Measurements of Untreated and . . . . . . . . . 47 Fluorinated Polyethylene Membranes

Figure 12: Atomic Ratios for Untreated and Fluorinated . . . . . . . . . 48 Polysulfone Membranes as Determined by $\mathrm{X}$-ray

Photoelectron Spectroscopy.

Figure 13: Gel Permeation Chromatograms of Low Molecular Weight . . . . 49 Dextran Feed Through Untreated and Fluorinated Polysulfone Membranes

Figure 14: Gel Permeation Chromatograms of High Molecular . . . . . . . 50 Weight Dextran Feed Through Untreated and Fluorinated

Polysulfone Membranes

Figure 15: Performance Results of Untreated and Fluorinated . . . . . . . 51 Polysulfone Membranes In Flat Sheet Study

Figure 16: Performance Results of Untreated and Fluorinated . . . . . . . 52 Polysulfone Membranes In Pilot Study \#1

Figure 17: DI Water and Permeate Flow Rates (15 Minute) of . . . . . . . 53 Untreated and Fluorinated Polysulfone Membranes In Pilot Study \#1

Figure 18: Performance Results of Untreated and Fluorinated . . . . . . . 54 Polysulfone Membranes In Pilot Study \#2 
Figure 19: DI Water and Permeate Flow Rates (15 Minute) of . . . . . . . 55 Untreated and Fluorinated Polysulfone Membranes In Pilot Study \#2

Figure 20: Comparison of Untreated Polysulfone Membranes From . . . . . . 56 Pilot Studies \#1 and \#2

Figure 21: Comparison of Fluorinated Polysulfone Membranes From . . . . . 57 Pilot Studies \#1 and \#2

Figure 22: Gel Permeation Chromatograms of the Degradation of . . . . . . 58

the Industrial Potato Waste Feed During Run

Figure 23: Gel Permeation Chromatograms of Industrial Potato Feed . . . . 59 Through Untreated and Fluorinated Polysulfone Membranes (30 Minute Reading)

Figure 24: Gel Permeation Chromatograms of Industrial Potato Feed . . . 60 Through Untreated and Fluorinated Polysulfone Membranes (Fina1 Reading)

Figure 25: Photographs of Opened Spiral Modules at Conclusion . . . . . . 61 of Pilot Study. The Left and Right Photographs are the Untreated and Fluorinated Membranes of Pilot Study \#1, Respectively.

Figure 26: Photographs of Opened Spiral Modules at Conclusion . . of Pilot Study. The Left and Right Photographs are the Untreated and Fluorinated Membranes of Pilot Study \#2, Respectively.

Figure 27: SEM Micrographs of the Untreated Membrane at the . . . . . . . 63 Conclusion of Pilot Study \#1.

Figure 28: SEM Micrographs of the Fluorinated Membrane at the . . . . . . 64 Conclusion of Pilot Study \#1.

Figure 29: ATR-FTIR Spectra of the Non-Fouled Untreated Membrane . . . . . 65

Figure 30: ATR-FTIR Spectra of the Fouled Untreated Membrane . . . . . . . 66

Figure 31: ATR-FTIR Spectra of the Non-Fouled Fluorinated Membrane . . . . 67

Figure 32: ATR-FTIR Spectra of the Fouled Fluorinated Membrane . . . . . . 68 


\section{LIST OF TABLES}

Table 1: XPS Analysis of Fluorinated Polysulfone Membranes . . . . . . 68

Table 2: XPS Analysis of Fluorinated Polyethylene Membranes . . . . . . 69

Table 3: XPS Analysis of Fluorinated Cellulose Acetate Membranes. . . . 70

Table 4a: Surface Appearance of Clean and Fouled Membranes . . . . . . . 71

Table 4b: XPS Analysis of Washed Polysulfone Membranes . . . . . . . . . 72

Table 5: XPS Analysis of Final Pilot Study Membranes . . . . . . . . . 73

Table 6: Operating Conditions For Pilot Study . . . . . . . . . . . . . 74 


\subsection{INTRODUCTION}

Fouling of ultrafiltration membranes is a critical problem in the food processing industry ${ }^{1.5}$. Membrane fouling decreases flux and shortens membrane lifetimes, making them less economical to food processors for concentrating process streams. Membranes foul with organic material (e.g. lipids during soy processing ${ }^{6}$ and proteins from processing cheese whey ${ }^{7}$ ) and this results in a significant decline in flux. The fouling of the membranes may also be irreversible even with extensive cleaning, and as a result membrane lifetime is also decreased.

If fouling could be minimized, membrane separation would be a more economical and energy saving method for concentrating aqueous streams ${ }^{1,2}$. Presently, the food processing industry consumes 28 of the total national energy usage'. Most of the processes which consume this energy are thermally driven separations and concentrations where the process streams contain dilute solutions of organic matter. These process streams consist of recyclable organic material such as starch and protein. Present thermal concertration methods inherently use large amounts of energy to concentrate these process streams, due to the latent heat of vaporization of water.

Fouling of the membrane can be changed either by varying the hydrodynamics over the membrane or by varying the physico-chemical interaction between the foulant and the membrane ${ }^{8-11}$. By varying hydrodynamics (i.e. increasing the crossflow velocity), foulant can be swept away from the membrane before adsorption can occur. This is illustrated in Figure 1. Alternatively, the adsorption of foulant may be reduced by decreasing the physico-chemical interaction between foulant and membrane thus allowing the foulant to diffuse away and be swept from the surface.

Various pretreatments of the membrane surface have been used to modify the interactions between the foulant and membrane. These treatments were intended to produce membranes with more hydrophilic surfaces that would interact less strongly with proteins. Membranes have been modified via plasma treatment to make the surface more hydrophilic by introducing more hydroxyl groups to the surface $e^{12}$ or by polymerizing monomeric substrates to the surface of the membranes to produce a thin 
layer of hydrophilic polymer on top of the hydrophobic membrane ${ }^{13}$. The latter approach reduced the permeate flux through the membrane, perhaps by decreasing the effective pore size of the membrane. This might have occurred because of coating of the inside surface of some pores with the hydrophilic polymer or occlusion of the smallest pores by the polymer.

In another approach, Speaker et $a 1^{14}$ used a fluorinated amphiphilic surfactant to coat the surface of membrane. This treatment increased the hydrophilicity of the surface and reduced fouling at the surface, but the surfactant treatment also severely reduced permeate flux through the membrane. In one study, a surfactant treated membrane had substantial fouling reduction, but the permeate flux decreased to nearly zero. In another study's, this flux decline was avoided by using a nonionic surfactant. All surfactant-based approaches, however, suffer the disadvantage that the surfactant is consumed, and must be replenished periodically.

Fluorination has been used to modify polymer surfaces ${ }^{1622}$. The goal of these studies was to change the permeation rates of gases through the polymer by changing the solubility of the gases inside a thin layer at the polymer surface. This change in solubility was reported to have had a direct influence on the permeability of gases through the membrane. Fluorination has also been used to improve the wettability of fibers ${ }^{2}$. The authors attributed the increase in wettability to partial fluorination of the membrane surface.

Our study reports on an investigation of the effect of surface fluorination on the fouling characteristics of membranes prepared from non-fluorinated polymers. Fluorination of the membrane chemically modifies the physico-chemical interaction between solution species and the membrane, and this modification can result in a decrease in fouling characteristics of the membranes. At the same time, fluorination should also help improve the lifetime of the membrane by providing an easier surface to clean during the cleaning cycle.

Spiral wound modules can be prepared more easily by the use of surface fluorination on a non-fluorinated membrane than by the use of fluorinated polymers directly. Casting membranes using perfluorinated polymers is a difficult process ${ }^{23}$. 
Further processing of fluorinated membrane into industrial type configurations is also difficult due to the non-wetting nature of the fluorinated polymer. Surface treatments are often necessary to allow adhesives to bond with these polymers in the construction of spiral modules ${ }^{24}$. The fluorination process in this study affects only the surface of the membrane without changing the bulk properties of the underlying polymer. Surface fluorination can be used to treat controlled areas, such that further processing is easily accomplished. The surface-fluorinated membranes investigated in this study can be incorporated easily into currently available membrane modules if fluorination is introduced as a pre-treatment to the membranes before the construction of modules.

Ultrafiltration of potato-processing waste is a process where fouling has been noted. A schematic of the typical overall potato process is shown in Figure 2. The potato processing industry produces 25 billion gallons of potato waste annually, and this aqueous waste stream contains about 0.6 \& solids, mainly starch, protein and ash'. A significant amount of energy would be needed to concentrate this dilute stream by thermai concentration. Presently, the waste is treated at a secondary waste water treatment center or sprayed onțo farm fields. With increased environmental concerns about biological oxygen demand (BOD) of waste products, waste streams must be pretreated before effluent can be released to any secondary waste water treatment. Membrane concentration appears to be an energy-efficient way of concentrating the potato waste streams.

\subsection{EXPER IMENTAL}

\subsection{Membrane Preparation}

Various membranes were fluorinated at the onset of this study. The membranes fluorinated were polyethylene, polysulfone and cellulose acetate. The polyethylene membranes were DuPont Tyvek T-988 membranes and the polysulfone and cellulose acetate membranes were manufactured by Allied-Signal Fluid Systems (San Diego). The polyethylene membrane was received and stored dry. The polysulfone and cellulose acetate membranes were received and stored wet. The pore sizes of the membranes varied significantly. The polyethylene membrane had a pore size distribution that 
could exclude 99.68 of 0.624 micron latex spheres. The molecular weight cutoff of the untreated polysulfone membrane was typically 100,000 daltons while the molecular weight cutoff of the cellulose acetate membrane was typically 50 daltons. This study will primarily focus on the effects of fouling on polysulfone ultrafiltration membranes, but the effects of surface fluorination on the other membranes surface properties will be noted.

The various membranes to be fluorinated were cut to size from larger sheets of stock membrane. Since membranes must be dried to undergo the fluorination process, the polysulfone and cellulose acetate membranes were first pretreated with an aqueous methanol solution and subsequently dried. The methanol pretreatment aided in recovering permeate flux in the dried polysulfone membranes as will be discussed in Section 3.1.

Membranes were fluorinated at a facility in Allied-Signal's Morristown Laboratories by the Exploratory Research Group. The process for all three membranes used elemental fluorine mixed with nitrogen. Oxygen was excluded from the reaction mixture. A schematic of the fluorination reactor is given in Figure 3 . The dry membranes were placed inside the reactor and treated at various residence times from 0 to 120 minutes and concentrations from 0.0125 to 0.05 fluorine in nitrogen. The flow rate of reaction mixture in the reactor was $4 \mathrm{liter/minute} \mathrm{at} \mathrm{ambient} \mathrm{pressure.}$ The high flow rate of gas guaranteed that the concentration of fluorine in the atmosphere over the membrane was constant. After fluorination, the treated membrane was quickly exposed to air. One large sheet of membrane was treated at each set of fluorination conditions and the treated sheets were used for both the performance experiments and further surface analysis.

\subsection{Membrane Permeation System}

\subsubsection{Single Flat Sheet Module}

Potato-waste filtration was carried out at room temperature in a standard closed-loop filtration system of three or six cells mounted in series, each with an effective cross-sectional area of $3 \mathrm{in}^{2}$. A schematic of a related system containing 
one membrane module is shown in Figure 4. Filtrate and permeate were recycled to insure that feed composition remained constant. The feed tank contained 3 liters of potato feed. To reduce concentration polarization and minimize gel-layer formation (14), the unit was run in a cross-flow configuration with Reynolds number greater than 1600 for turbulent flow. The applied trans-membrane pressure was 100 psi.

\subsubsection{Splral Modules}

Spiral modules were constructed by Fluid Systems from large sheets of membrane prepared as described above. The fluorinated membrane used in the pilot studies was fluorinated with $0.025 \mathrm{~F}_{2}$ in $\mathrm{N}_{2}$ for 30 minutes. Fluorinated and untreated membrane sheets were built into spiral mod ies with an average effective surface area of 87 $\mathrm{in}^{2}$. The thickness of the feed st ermeate spacers were 0.031 and 0.018 inches, respectively. A schematic of a typical spiral module is shown in Figure 5 . The spiral modules tested in the pilot plant were run in parallel, as shown in the schematic in Figure 6. A photograph of the completed bench-scale spiral module

pilot plant is shown in Figure 7. The spiral modules were placed inside the stainless steel housings, and the filtrate and permeate were recycled to ensure that the feed composition was not concentrated due to permeation. The feed tank for the pilot study contained 18.9 liters ( 5 gallons) of feed. The flow rate through each spiral was one liter/minute during the first pilot study and three liters/minute during the second. The trans-membrane pressure drop in the spiral module was 20 psi and the trans-spiral pressure drop was $2 \mathrm{psi}$ at 11 iter/minute, and 6 psi at 3 liter/minute. The pilot plant was run on a twenty-four hour cycle for five days a week. During such a run, the pilot plant was on-line approximately 21 hours and then cleaned for 3 hours. The cleaning procedure will be discussed in Section 3.3. On weekends, the pilot plant was cleaned and subsequently filled with DI water for storage over the weekend. 


\subsection{Potato Waste Stream Feed}

\subsubsection{Simulated Feed Stream}

The simulated potato waste stream was prepared by blending 432 grams of washed unpeeled potatoes with 1 liter of DI water in a Waring blender at high speed for three minutes. The blend was then heated to $60^{\circ} \mathrm{C}$ and held at that temperature for 5 minutes. This step was intended to solubilize a portion of the potato starch. Subsequently, the mixture was strained through cheese cloth and the resulting filtrate was stored in the refrigerator until used. The total solids of this master batch was 0.958 . The feed used in the filtration unit was prepared by dilution of this master batch to a value of 0.6 total solids.

\subsubsection{Process Potato Feed}

Basic American Foods (Blackfoot, ID) kindly provided an industrial potato waste stream from water-gun slicing of potatoes. The total solids of the waste stream was $1.1 \mathrm{wt}$. 8. The potato waste was kept in cold storage until the feed was to be tested. Even with cold storage, the potato waste in the flat cell study degraded, resulting in a drop of $\mathrm{pH}$ from 6.7 to 3.9 between shipment and end use. Before an experimental run, the waste water was treated with $200 \mathrm{ppm}$ sodium benzoate as a preservative to prevent further degradation. For the pilot study, fresh feed (25 gallons) was shipped by overnight air on the Friday preceding each week's run. The potato feed during the first pilot study was prefiltered with a $50 \mu \mathrm{m}$ filter the morning of the run to prevent end plugging of the spiral module, while the potato feed during the second pilot study was prefiltered with a $25 \mu \mathrm{m}$ filter.

\subsection{Analytical Procedures}

\subsubsection{COD measurements}

Chemical oxygen demand (COD) measurements were made using a colorimetric method, following digestion with potassium dichromate ${ }^{25}$. The COD measurement is an indirect analysis of the amount of organic carbon present in the retentate and 
permeate. The axalysis was done with a commercially available HACH COD digestion reactor with the appropriate reagents for a particular COD range. COD results were read directly from a HACH DR 100 Colorimeter.

\subsubsection{Total Organic Nitrogen}

The total organic nitrogen of the permeate and feed streams were measured using a chemiluminescence technique (ASTM method D 4629-86). Total organic nitrogen is a direct measure of total protein in this study.

\subsubsection{Turb1dsty}

Turbidity of the permeate samples was measured with a DRT-15C Portable Turbidimeter from H F Stuntific Inc. The turbidimeter measures the nephelometric turbidity via scattered light from suspended solids present in the permeate. Measurements are reported in standardized NTU units The feed samples needed to be diluted to lower the turbidity into the measurement range of the turbidimeter.

\subsubsection{Contact Angle Measurements}

Contact angle measurements were taken with a Ramé-Hart Inc. (New Jersey) comparator microscope (NRL C.A. Goniometer 100-00) fitted with a goniometer scale for measuring the angle directly from a drop of water on the membrane. The contact angle measuret is illustrated in Figure 8 . The contact angle measurements were made on $1^{\prime \prime}$ by $1^{\text {" }}$ representative samples of membrane using de-ionized water as the boundary liquid. The reported values are the average of at least three independent measurements on the membrane where the contact angle measurement was taken on both sides of the water drop. The measurements were taken within 2 minutes of placing the drop on the membrane surface. The contact angle provides a measure of the hydrophilicity of the membrane ${ }^{26}$. 


\subsubsection{X-ray Photoelectron Spectroscopy}

$X$-ray photoelectron spectroscopy (XPS) was used to analyze the surface composition of the membranes. XPS data were recorded with an HP 5950 ESCA system. Small ectangular samples were covered with a gold plated mask, containing a window $3 \mathrm{~mm}$ by $7 \mathrm{~mm}$. Samples were introduced into the vacuum chamber and set to an angle of 38 degrees relative to the $x$-ray beam. This corresponds to an analysis depth of ca. $50 \AA$. The samples were flooded with electrons produced by a hot filament to minimize charge buildup. A survey scan of 0-1000 eV was taken to identify all the elements present on the membrane surface. Peak fitting routines were used to obtain accurate area and binding energy information for all the peaks located in the high resolution windows. Adventitious carbon is seen on the samples exposed to air and has a binding energy equal to that of graphite or hydrocarbons. The binding energies reported have offset corrections to force adventitious carbon to $284.6 \mathrm{eV}$. The atomic percentages reported were corrected for the sensitivity of the instrument to the transition of each element. The atomic percentages will be presented as ratios with respect to the total number of carbon atoms. This procedure allows us to directly compare the atomic ratios found for the various treated membranes. This assumes that the number of carbons remains constant in the $50 \AA$ layer that is being analyzed. Since no carbon is added to the surface and fluorination occurs under mild conditions, this assumption is presumed to be valid.

\subsubsection{ATR - Fourier-Transform Infrared Spectroscopy}

Attenuated Total Reflectance - Fourier-Transform Infrared Spectroscopy (ATRFTIR) was utilized to analyze the functional groups present on the surface of the starting and fouled membranes. The fouled membrane samples from the pilot study were washed for one hour in DI-water in a mechanical shaker before analysis. The DI-water was changed and the membrane was shaken for an additional hour. The samples were subsequently air dried in a hood. A $30^{\circ}$ germanium crystal was utilized with an effective penetration depth of 3.0 to $0.3 \mu \mathrm{m}$ over the infrared wavelengths of 2.5 to $25 \mu \mathrm{m}$. The spectra were measured on a Perkin-Elmer 16PC FTIR configured with the ATR specimen rig. Each specimen was scanned from 400 to $4000 \mathrm{~cm}^{-1}$ at $2 \mathrm{~cm}^{-1}$ resolution for 64 scans. The spectra were normalized and were reported in 
absorbance mode.

\subsubsection{Scanning Electron Microscopy}

The surface appearance of the membranes was analyzed via scanning electron microscopy (SEM). The fouled membrane samples for the SEM were washed as in Section 2.4.6. Additionally, the membranes were prepared by critical point drying, which is believed to conserve the integrity of the pores. The process consists of solvent exchanging the water in the pores sequentially with ethanol, amyl acetate and finally liquid carbon dioxide under high pressure. The carbon dioxide is flashed off leaving the pore structure intact.

\subsubsection{Gel Permeation Chromatography}

Gel permeation chromatography (GPC) was performed on feed and permeate samples to estimate the initial pore size distribution and the effect of fluorination on the pore size distribution of the treated membrane ${ }^{27,28}$. Two feed mixtures of a high and low molecular weight distribution of dextran were fed to the membranes in the flat cell rig and the permeate was collected at 100 psi trans-membrane pressure. The feed and permeate were analyzed with a Waters $150 \mathrm{C}$ chromatograph equipped with a refractive index detector. The column was a combination of two Shodex Ion-Pak s803 columns and one 5804 column. The mobile phase was $0.1 M$ sodium nitrate and the flow rate was $0.94 \mathrm{ml} / \mathrm{min}$. The column and injector temperature were set at $80^{\circ} \mathrm{C}$. The column was calibrated with dextran standards. The sample concentrations were 0.2 wtz.

\subsection{RESULTS AND DISCUSSION}

\subsection{Surface Fluorination}

All of the membranes which were modified in this study were fluorinated at Allied Signal's Exploratory Research Group (Morristown, NJ). Membranes were fluorinated dry as batch samples in a flow reactor through which was passed a dilute mixture of elemental fluorine in nitrogen. Oxygen was carefully excluded from the reactor during fluorination, and all fluorinations were done at room temperature in 
the dark. The principal variables studied with respect to fluorination conditions were the exposure time and concentration of fluorine in the flow gas, and the degree of fluorination was judged principally by XPS analysis of the membranes. Comparison of scanning electron micrographs of fluorinated and untreated membranes revealed no apparent surface damage due to the fluorination process.

Pretreatment of the polysulfone membranes was necessary before fluorination, since these membranes are normally shipped and stored wet. If the membrane is allowed to dry, we observe very little water flux through the membrane, even at applied pressures up to $400 \mathrm{psi}$. To aid in rewetting the membrane, the membranes were pretreated with a 508 aqueous solution of methanol and then air dried in the hood. The deionized (DI) water flux in the dry methanol-treated membrane returned to a reasonable value, as illustrated in Figure 9, while a dry untreated membrane exhibited very little flux at a trans-membrane pressure of $100 \mathrm{psi}$. The methanol treatment of the membrane is believed to prevent pore collapse in the membrane during the drying process, thus allowing the membrane to re-wetted under moderate pressures. Before use, $t ?:$ cluorinated membranes were wetted by subjecting the membranes to DI water at 100 psi for at least 15 minutes.

Elemental fluorine is a powerful electrophile, and is capable of reacting with essentially all organic compounds, including alkanes. For the polymeric materials discussed in this work, the major mechanisms for attack are assumed to be free radical halogenation and electrophilic substitution. Free radical halogenation was probably the only mechanism by which fluorine was introduced into polyethylene, and would also be the mechanism by which fluorine would be introduced into methyl or methylene groups in polysulfone and cellulose acetate. Attack is presumably initiated by hydrogen abstraction by a fluorine radical (1) and occurs by a chain reaction (1-2). Fluorination of aromatic rings presumably occurs via a carbonium ion mechanism ( 3 ).

$$
\begin{aligned}
& F^{\cdot}+R-\mathrm{CH}_{3} \rightarrow \mathrm{HF}+\mathrm{RCH}_{2} \cdot \\
& R-\mathrm{CH}_{2} \cdot+\mathrm{F}_{2} \rightarrow \mathrm{RCH}_{2} \mathrm{~F}+\mathrm{F}^{\bullet}
\end{aligned}
$$




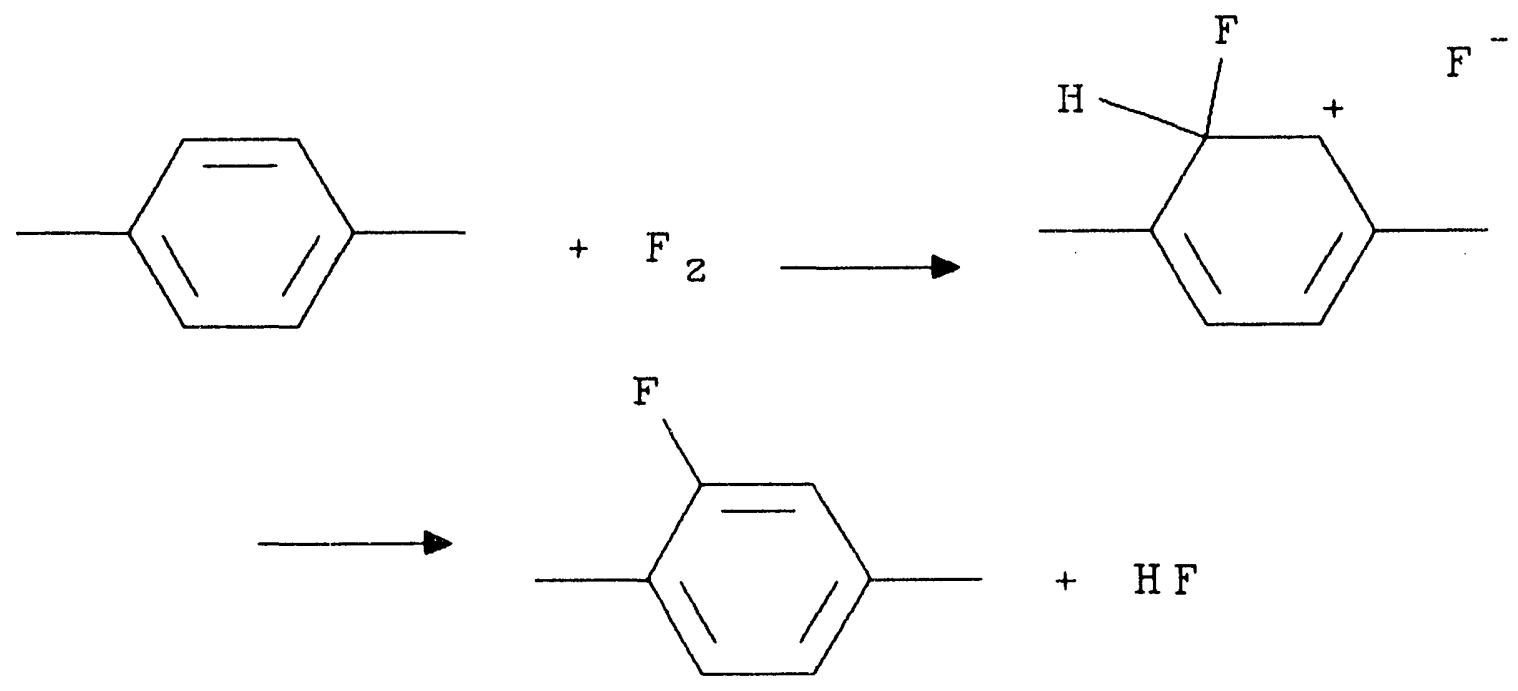

Elemental fluorine is a strong enough electrophile to cleave carbon-carbon single bonds. For a material with as much fine structure as an ultrafiltration membrane, such cleavage reactions might result in significant damage to the membrane structure. Later in this report, we will discuss experiments designed to test whether such damage occurs. The use of very dilute fluorine streams and low temperatures was designed to avoid as much carbon cleavage as possible. As a result of either carbon cleavage or homolysis of $\mathrm{C}-\mathrm{H}$ bonds, formation of relatively stable free radical sites within the membrane is possible. As we will note later in this report, these free radical sites may be implicated in the introduction of oxygenated functionality into the membrane.

Strong evidence for the formation of such stable free radical sites within the membrane and the importance of quenching them by reaction with air components was presented by an experiment in which a polysulfone membrane was carefully protected from air, not only during fluorination, but also afterwards. This membrane became extremely brittle, and shattered into numerous small pieces on handling. Our hypothesis is that the unquenched free radical sites resulted in cross-linking within the membrane structure, and this made the membrane brittle. 


\subsection{Flat Sheet Results}

\subsubsection{Surface Properties of Varlous Fluorinated Membranes}

Polysulfone, cellulose acetate and polyethylene membranes were surface fluorinated and the surface properties were analyzed via contact angle measurements and XPS. The contact angle measurements were used to quantify the hydrophilicity of the membranes, while XPS analyses provided a measure of the amount of fluorine and other elements added to the membrane. The effect of fluorination on pore size was analyzed via dextran permeation experiments.

\subsubsection{Contact Angle Measurements}

Contact angle measurements of water on the membranes were performed to provide a measure of the surface energy of untreated membranes and membranes after treatment under various fluorination couditions. The effect of fluorine treatment time on the contact angle of polysulfone is shown in Figure 10, which shows the contact angle of water on polysulfone membranes treated at $0,5,30$, and 60 minutes at 0.025 volis fluorine in nitrogen. The contact angle decreased from an initial value of $90^{\circ}$ to a value of $56^{\circ}$ after fluorine treatment for 60 minutes with a concentration of 0.025 volo fluorine in nitrogen. This observation was at first surprising, since it indicated that the membrane had become more hydrophilic, not more hydrophobic, as would have been expected if the membrane were perfluorinated.

The effect of fluorine treatment on a polyethylene membrane is shown in Figure 11. As with the polysulfone membrane, the membrane became more hydrophilic with increased fluorination treatment. The contact angle decreased from an initial value; of $99^{\circ}$ to a value of $77^{\circ}$ after fluorine treatment for 30 minutes with a concentration of 0.025 volo fluorine in nitrogen. With a more intensive fluorine treatment of 0.25 vol fluorine in nitrogen for thirty minutes, no contact angle measurement could be taken because the water wetted the surface completely, and was absorbed into the pores. 
No contact angle measurements were possible on the untreated or fluorinated cellulose acetate membranes because extensive surface damage occurred during the drying procedure. The entire surface was cracked and curled, and no representative $1 "$ by $1 "$ samples could be obtained.

\subsubsection{XPS of Fluorinated Membranes}

The surface composition of the untreated and fluorinated membranes was analyzed by XPS. XPS has previously successfully been applied to the analysis of membrane properties ${ }^{27.29,30}$. The XPS result.s on fluorinated polysulfone, polyethylene and cellulose acetate are listed in Tables 1, 2, and 3, respectively. The theoretical elemental concentrations for the untreated membranes (based on the empirical formulae of the polymers) are also listed in parentheses in the Tables. XPS is generally considered to be sensitive to a depth of $50 \AA$ into the surface examined. We assumed that the number of carbon atoms near the surface remains the same, and therefore report atomic ratios with respect to carbon in order to give a clear indication of the chemistry occurring at the surface.

For polysulfone, the atomic ratio for sulfur remains relatively constant for all treatment times as seen in Figure 12 and listed in Table 1. This indicates that the fluorination process does not remove the sulfur from the surface. The atomic ratios with respect to carbon show that the fluorine content does increase on the surface, as expected, with an atomic ratio of $0.44 \mathrm{~F} / \mathrm{C}$ at 60 minutes. Note, however, that Figure 12 also shows that the level of oxygen increases on the membrane to an atomic ratio of $0.36 \mathrm{O} / \mathrm{C}$ at 60 minutes. Since the reaction was completed in oxygen-free reaction gas, the increase in oxygen on the membrane surface must be a result of reaction with water or oxygen absorbed in the membrane present from the start of the reaction or reaction with atmospheric water or oxygen after removal from the fluorination reactor.

For the polyethylene membrane, similar surface changes were evident with increased fluorination treatment, as the concentrations of atomic fluorine and oxygen increased on the surface (Table 2). The atomic ratios with respect to carbon show that the fluorine content does increase on the surface as expected, with a 
atomic ratio of $0.235 \mathrm{~F} / \mathrm{C}$ for 30 minutes ( 0.025 volo fluorine in nitrogen), and that the level of oxygen increased on the membrane to an atomic ratio of $0.130 / C$. At a higher concentration of fluorine $(0.258)$ in the reaction mixture, the amount of fluorine on the surface did not increase substantially over the amount of fluorine present on the surface at the lower concentration, while the amount of oxygen increased almost threefold.

Untreated and fluorinated cellulose acetate membranes were analyzed via XPS and the composition of the surface is given in Table 3 . The atomic ratios with respect to carbon show that the fluorine content increased on the surface, as expected, with an atomic ratio of $0.15 \mathrm{~F} / \mathrm{C}$ at 30 minutes. The level of oxygen decreased on the membrane to an atomic ratio of $0.46 \mathrm{O} / \mathrm{C}$ versus 0.49 for the untreated cellulose acetate membrane. This decrease in oxygen on the surface may not be statistically significant.

Based on our XPS results, we can advance two possible rationales for the increase in hydrophilicity we observe in the contact angle experiments on the polysulfone and polyethylene membranes: polar interactions resulting from partial fluorination, and surface oxygenation. Fluorination of a surface can lower its hydrophilicity as the surface becomes more like a perfluorinated polymer, but, at incomplete fluorination, the hydrophilicity may increase. For example, the estimated Hildebrand interaction parameters ${ }^{31}$ for the methyl pendant group $\left(-\mathrm{CH}_{3}\right)$ of the polysulfone molecule and the related fluorine-substituted methyl groups ($\mathrm{CH}_{2} \mathrm{~F},-\mathrm{CHF}_{2}$ and $-\mathrm{CF}_{3}$ ) are $11.9,16.4,16.4$, and $13.4 \mathrm{MPa}^{1 / 4}$, respectively. We observe that, with increasing fluorination, these methyl groups first become more hydrophilic as revealed by the increase in the Hildebrand parameter, but eventually become more hydrophobic as the methyl group is perfluorinated. Similar Hildebrand parameter results are observed with the methylene groups in polyethylene.

Ring fluorination is expected to have a lesser effect on increasing the hydrophilicity of the surface. Thus, the Hildebrand interaction parameter for phenylene groups on the polysulfone molecule decreases on fluorination, which would have the effect of making a membrane more hydrophobic (1.e. $22.6 \mathrm{MPa}^{\text {th }}$ for the monosubstituted phenylene versus $24.7 \mathrm{MPa}^{1 / 2}$ for the phenylene group). 
Surface oxygenation may also play a large role on the membrane's hydrophilicity. Oxygenated species, such as acid fluorides, on the surface would greatly increase the wettability of the surface. The increase in hydrophilicity during fluorination has been observed previously by Anand et. al, ${ }^{18}$ who observed a minimum in contact angle at the maximum level of atomic oxygen on a fluorinated poly(ethylene) membrane prepared for gas separation. However, at long treatment times, the membrane surface was eventually perfluorinated and reached the maximum contact angle. Of the two effects, we suspect that the hydrophilicity of the fluorinated membrane is mainly due to the increased oxygen level in the surface. We observed this clearly in the fluorinated polyethylene membranes 1 isted in Table 2 , where the amount of fluorine added to the surface was relatively small compared to the amount of oxygen added to the surface at the higher fluorine gas concentration. The associated contact angle measurements in Figure 11 show that the membrane treated at the higher fluorine concentration had a larger decrease in contact angle than the membrane treated at the lower concentration, even though the relative amounts of fluorine on the surface did not vary drastically.

\subsubsection{Pore Size Analysis via GPC}

The effect of our fluorination treatment on the pore size of polysulfone membranes was analyzed via dextran permeation through the membrane. GPC analysis of dextran in the feeds and permeates were used to compare the pore sizes of the untreated membrane to the fluorinated polysulfone membrane. A dextran feed with a low molecular weight distribution $\left(M_{w}=5.4 \times 10^{5}\right.$ daltons and $\left.M_{w} / M_{n}=2.6\right)$ was filtered using untreated and fluorinated membranes, and the corresponding GPC chromatograms are given in Figure 13. For this molecular weight distribution of feed, the permeate GPC chromatograms show identical distributions for all the membranes, indicating that the dextran easily passed through the membrane pores. This result indicates that the pore size of the treated membranes did not decrease below $5.5 \times 10^{4}$ daltons.

A high molecular weight distribution ( $\mathrm{M}_{w}=5.3 \times 10^{6}$ daltons and $\mathrm{M}_{w} / \mathrm{M}_{n}-23$ ) dextran feed was subsequently filtered with the same untreated and fluorinated membranes and the corresponding GPC chromatograms are given in Figure 14 . The 
molecular weight distribution was bimodal with peaks at approximately $1.0 \times 10^{6}$ and $2.2 \times 10^{\mathrm{s}}$ daltons, and these GPC chromatograms show that very little of the dextran has permeated through the membrane. The molecular weight distributions of dextran that permeated through the untreated and fluorinated membranes are identical again, indicating that the pores sizes did not increase past $2.2 \times 10^{5}$ daltons during the fluorination process. We conclude that the fluorination treatment used in this study does not drastically affect the pore size distribution of the polysulfone membrane.

\subsubsection{Membrane Performance}

Membrane performance in the flat sheet study was evaluated using the permeate flux and the rejection of COD and nitrogen (protein).

\subsubsection{Permeate Flux}

The effect of fluorination treatment time on membrane performance is illustrated in Figure 15. Fluorination has a significant effect on both initial permeate flux and fouling rate. We observe that the initial fluxes of the treated membranes were higher than those of the untreated membrane. In general, we found that the initial flux increased with increased treatment time. We also note that the treated membranes had lower fouling rates when compared to the untreated membrane, as indicated by the decreasing slopes of the data on the Log(Flux) versus Log(Time) plot of Figure 15. In general, the fouling rate of the fluorinated membranes decreased with increasing treatment time. An ideal nonfouling membrane would have a slope of zero. Overall, the fluorinated membranes exhibit better fouling properties than the untreated polysulfone membrane. Membrane performance using simulated potato feed (Section 2.3.1) is given in Appendix Al. Additional studies using other process feeds and treated membranes are given in Appendix A2.

Our observation of increased flux for the fluorinated membrane is interesting, since our dextran experiments have already shown that the pore dimension does not change significantly. The principal change is thus the change in contact angle between the water and the membrane surface, which is in turn linked to increased 
hydrophilicity. We can understand this increase in flux by remembering that our membrane has a distribution of pore sizes, and that the diameter of the smallest pore which is actively involved in flow will be given by the Cantor 6 equation (4), where $\gamma$ is the surface tension of the liquid, $\theta$ is the contact angle with that liquid, and $P$ is pressure.

$$
D=\frac{4 \gamma \cos (\theta)}{P}
$$

Thus decreasing the contact angle will decrease the minimum diameter of useful pores, increasing the total number of pores available for flow.

Increased hydrophilicity also can explain the decrease in fouling rate as shown in Figure 15. Our study is thus in agreement with others $\mathbf{s}^{9,12}$, who have observed that the rate of adsorption of hydrophobic foulants (i.e. proteins) decreased with the increase of hydrophilicity of the membrane surface. Our common interpretation is that a hydrophilic surface layer reduces the number of hydrophobic sites available on the membrane for adsorption and deposition of protein, thus reducing the observed fouling rate.

In particular, we should note that membrane hydrophilicity is likely to have a significant effect on protein adhesion due to the possibility of denaturation. For many proteins, secondary and tertiary structure is dependent on the presence of a hydrophilic external medium. Placed in contact with a hydrophobic surface, these proteins will denature, and adhere strongly to the surface. A hydrophilic surface will adsorb a surface layer of water, thus presenting to proteins which come into contact with it a surface similar to that of water. This effect was recently observed by Chmiel, et. $\mathrm{al}^{32}$.

\subsubsection{COD and Nitrogen Rejection}

COD and total organic nitrogen rejection were measured for the feed stream and permeates after three hours into the experiment. The COD and total nitrogen of the feed stream were $10,100 \mathrm{mg} / 1$ and 0.037 mass, respectively. COD rejection through 
the membranes was $42 \pm 18$ and total organic nitrogen rejection was $78 \pm 28$. The low rejection in $C O D$ is due to the large pore size of this polysulfone membrane. Rejections as measured by COD and total nitrogen were within one standard deviation of each other for fluorinated and untreated membranes, indicating that selectivity was not altered significantly by fluorination. The acceptable rejections of both COD and nitrogen for the potato waste stream need to be at least 758 . The rejection of $C O D$ and nitrogen for various potato feeds and treated membranes is given in Appendix A2.

\subsubsection{Summary - Flat Sheet Experiments}

Our initial studies with flat sheets have shown that surface fluorination can significantly affect the performance of an ultrafiltration membrane used to concentrate a food-related stream. Membranes which have been fluorinated under appropriate conditions exhibit higher initial fluxes, and do not foul as rapidly as untreated membranes. We link this improvement to increased hydrophilicity of the surface, as shown by the decrease we observe in contact angle with water. This increased hydrophilicity, in turn, we link to the addition of fluorine and oxygen to the surface. Partial fluorination can make a surface more hydrophilic due to the strong dipole moment of the C-F bond, while oxygen-containing functional groups can participate in hydrogen bonding interactions.

\subsection{Cleaning Study}

A preliminary cleaning study was performed to test the stability and cleanability of untreated and treated membranes to various typical cleaning solutions. Membranes were fouled for three hours in the filtration rig with fresh industrial potato waste under rig conditions identical to the flat sheet studies. A fouled and nonfouled membrane were each cut into three pieces and concurrently subjected to the various washes listed in Table 4 a for an hour in a shaker bath, followed by a DI-water rinse for an additional hour. The fouled membranes had a gel-like material on the surface before cleaning. The final membrane appearance was noted after cleaning and the results are listed in Table 4a. No permeate flux study was completed on the cleaned membranes. 
Membrane stability to cleaning was analyzed on the washed but not initially fouled membranes from the first portion of this study. The membranes were analyzed via XPS and the results are noted in Table 4b. We observe that, for all the washes, some of the elemental fluorine was removed from the surface. This result was expected, since surface fluorination can lead to a variety of functional groups with varying degrees of hydrolytic sensitivity. In particular, since surface oxidation of any polymer surface is inevitable, some fluorine will be attached to the polymer as -OF or - COF groups which will not survive contact with water. Similar observations have been made by Dixon and Hayes ${ }^{33}$ for fluorination of polyolefin films. Of course, hydrolysis of these groups releases hydrophilic functionality, so this reaction should cause no particular harm to our fouling resistance.

With respect to other treatments, we observed that acid washing with sulfuric acid added sulfur and oxygen to the surface. We ascribe this to surface-adsorbed sulfuric acid which was not completely washed off. The bleach wash added chlorine to the surface, perhaps due to light chlorination of the surface. It appears that the acid wash removed more fluorine from the membrane than the basic or bleach wash.

Based on qualitative appearance of the nembranes and the XPS results, we decided to use a the cleaning procedure in the spiral module pilot study involving a sodium hydroxide wash followed by a disinfecting bleach wash.

\subsection{Scale-up to Spiral Modules}

The pilot plant study was used to investigate the effects of increasing the fluorinated membrane surface area, and changing the membrane configuration. It also allowed us to observe long term fouling of membrane under realistic conditions, including a daily cleaning cycle. Two pilot studies were conducted. The first pilot study was run at a feed rate of 1 liter/minute/spiral and the second pilot study was run at a feed rate of 3 liters/minute/spiral. The second pilot study was conducted at a higher cross-flow velocity to reduce the gel formation and severe fouling observed in the first pilot study at the lower feed rate. 
The feed used in the pilot plant study was shipped fresh from a plant operated by Basic American Foods in Blackfoot Falls, ID once a week, as detailed in the experimental section. According to BAF, the feed came from the potato peeling operation in their plant, and was typical of their normal waste stream from this operation. We filtered the feed through a 50 micron filter immediately before use. Our analyses showed that the organic constituents in the feed consisted primarily of starches. With a total solids loading of 1.248 , it had a COOD of $11,500 \mathrm{mg} / \mathrm{L}$, an organic nitrogen content of 0.026 mass \& and an ash content of: 0.124 mass 8 . Based on this analysis, we can conciude that the organic components in the feed are primarily starches, with a low concentration of proteins. We estimate that the starches had an average molecular weight of $1.8 \times 10^{6}$ daltons and a dispersity of 2.7. Qualitatively, we found that this was a highly fouling feed in our system.

\subsubsection{Membrane Performance}

Membrane performance in the pilot plant study was evaluated by monitoring the change in permeate flux with time and the rejection of COD and nitrogen (protein) by the membrane. The turbidities of the initial and final permeates were also measured. Finally, the surface properties of the fouled membranes were measured on samples cut from the spiral module after it had been used in the pilot plant. These properties included visual observations, SEM observations and XPS analysis of the surface composition of the fouled membrane.

\subsubsection{Permeate Flux}

The permeate flux of the untreated and fluorinated membrane modules were monitored throughout both pilot plant studies. In the first pilot study (21 days), the feed rate was 1 liter/minute per spiral, while in the second pilot study (5 days), the feed rate was 31 iter/minute per spiral. The untreated spiral modules in the first pilot study were prepared using membrane which had been methanol treated, then dried. The untreated modules were re-wetted by placing the module into the pilot plant housing and passing a 508 aqueous methanol solution through the membrane. Each module was then rinsed thoroughly with DI water. The fluorinated 
membrane did not require this treatment to regain flux.

The permeace fluxes of the untreated and fluorinated membranes during the first pilot study are given in Figure 16. The solid and dashed 1 ines represent the permeate fluxes of the fluorinated and untreated membranes, respectively. The untreated spiral module had to be replaced after nine days; it failed when a misplaced o-ring allowed the feed to flow around the spiral module instead of through the spiral module. This misplaced o-ring resulted in a steep decline in permeate flux in the untreated membrane. We believe the the reduced flow through the untreated membrane also affected the cleanability the membrane by reducing the cross-flow velocity and allowing foulants to buila up at the surface. Also, during the cleaning cycle, less cleaning solution passed through the membrane, allowing bacteria and other solids to build up inside the permeate spacer (See Figure 5).

In all experiments, we noted that very severe drops in permeate flux of the membranes occurred early in each day's cycle. While in typical commercial membrane operation, the flux may drop to 50 of its original value by the time the cleaning cycle is begun, we observed that it fell to one third its original value within 15 minutes of the start of each cycle. These severe drops are undoubtedly due to the high concentration of starches and other foulants in the potato-derived feed.

We found that the permeate flux of the fluorinated spiral module was greater than that of the second untreated spiral module for the first six days of each spiral's operation. After six days of operation, the permeate flux of the fluorinated membrane dropped below the permeate flux of the untreated membrane. The final fluxes for both membranes were very low relative to the starting flux.

We believe that one reason for the drop in the permeate flux of the fluorinated membrane over time was the lack of effectiveness of the cleaning cycle in removing foulants from the surface. After each cleaning cycle, we passed DI water through the membrane and measured the permeate flux. The DI water flux immediately after cleaning and the permeate flux after 15 minutes of operation is given in Figure 17 for various days of the pilot study, and provides a measure of 
the effectiveness of the cleaning cycle and the fouling ability of the potato feed. We see that, in general, the trend for both membranes is that the DI permeate flux declines with the total number of cleaning cycles. In the fluorinated membrane, there is little recovery in the DI water flux after 10 days. The fluorinated membrane may have been affected by bacterial growth in the stagnant fluid in the permeate spacer in the first mis-aligned untreated module which then passed into the fluorinated spiral module. The DI permeate flux does increase on days 19, 20, and 21 in both membranes and this increase is most likely related to variations in the total foulants in the initial potato feed. We observed that the total solids and COD in the feed had decreased on those days (See Appendix B1).

The extent of fouling in the untreated and fluorinated modules by the potato feed is seen in the relative drop in permeate flux after 15 minutes. For example, the flux decline for the fluorinated membrane on the first day (Day 1) is $88 \%$, while the flux decline for the non-fluorinated membrane on the first day (Day 10) is 828 . These flux declines are very large and are probably indicative of gel layer formation at the surface.

Our flux results at the end of the first pilot plant study did not show the resistance to fouling which we had previously observed in the flat sheet studies. Comparing the two studies, we noted that the cross-flow velocity was much higher in the flat sheet studies than it had been in our spiral wound modules $(12,500 \mathrm{~cm} / \mathrm{min}$ versus $734 \mathrm{~cm} / \mathrm{min}$ ) as listed in Table 6 . Since, as we note earlier, fouling is strongly affected by both hydrodynamics and surface interactions, we ran a second pilot plant study to explore the effect of increased cross-flow velocity.

The permeate flux of the untreated and fluorinated membranes during the second pilot study are shown in Figure 18. The solid and dashed lines represent the permeate flux of the untreated and fluorinated membranes, respectively. The untreated membrane had a higher permeate flux than the fluorinated membrane for all five days of the study. The higher flux for the untreated membrane relative to the fluorinated membrane, was due to the wetting behavior of the fluorinated membrane. We believe that the fluorinated membrane was not completely wetted before the start of the run, since we saw the permeate flux through the fluorinated membrane 
increasing continuously throughout the first day of the second pilot study .

We again observed the extent of fouling by the potato feed in the relative drop in permeate flux after 15 minutes in the untreated and fluorinated modules (Figure 19). For example, the flux decline for the fluorinated membrane on the second day is 778 , while the flux decline for the fluorinated membrane on the same day is 508. These flux declines are very large and are indicative of gel layer formation at the surface.

The cleanability of the untreated and fluorinated membranes can also be deduced from Figure 19. The cleaning procedure used in this study appears to clean the untreated membrane, but does not appear to effectively clean the fluorinated surface. Tragardh ${ }^{34}$ has observed that membrane cleaning procedures are dependent on both the type of foulant and the type of membrane used.

Comparing the two pilot plant studies, the effect of the retentate flow rate on the performance of untreated and fluorinated membrane performance is shown in Figures 20 and 21, respectively. For the untreated membrane, the permeate flux increased with the increase in retentate flow rate, while for the fluorinated membrane, the permeate flux did not change with increasing retentate flow rate. The differences in the permeate flux rates for the untreated membrane may not be experimentally significant.

\subsubsection{Turbidity, COD and Nitrogen Rejection}

Turbidity, COD and total organic nitrogen rejection were measured for the feed stream and permeates at various times during both pilot studies. The numerical results for the first and second pilot studies are listed in Appendices B1 and B2, respectively. The variation in the initial daily potato feed is obvious from the change of COD, total organic nitrogen, and total solids over the duration of the pilot studies. For example, the initial COD reading varied from $6800 \mathrm{mg} / \mathrm{L}$ to 13,407 $\mathrm{mg} / \mathrm{L}$ during the first pilot study. At the same time, the COD typically decreased during a daily run for both pilot studies. For example, the COD of the feed at the start and finish of the first day in the second pilot study changed from $5250 \mathrm{mg} / \mathrm{L}$ 
to $4850 \mathrm{mg} / \mathrm{L}$, respectively. This decrease in COD may be due to degradation of the high molecular weight starches in the feed to low molecular weight starches which can easily pass through the membrane. Such degradation may result from the high shearing stresses, bacteria action, or thermal degradation ${ }^{35,36}$.

The rejections of COD and total nitrogen were similar for the fluorinated and untreated membranes, indicating that the selectivity of the membrane was not altered significantly by the fluorination treatment. For example, the COD rejections of the untreated and fluorinated membranes at the start of day one of the second pilot study were 348 and 368 , respectively. The COD rejections of the untreated and fluorinated membranes at the end of the same day were 248 and 238 , respectively. The membranes behaved identically even though the rejections decreased during the day. This decrease in rejection is a direct effect of starch degradation in the feed during the day. The acceptable rejections of both COD and nitrogen for the potato waste stream need to be at least 758. The low COD and low nitrogen rejection is due to the large pore size in this polysulfone membrane.

Finally, COD rejections for the mis-aligned untreated spiral module of the first pilot study indicate that bacterial growth or mass build-up may have occurred in the permeate spacer. The COD rejection values were very low or negative. A negative rejection would imply that mass was being produced in the permeate.

The turbidity of the feed and permeate were taken at the start and conclusion of the experiment, and the results are listed in Appendix $B$. The feed was typically very cloudy and the permeate through the membranes was visually clear. The feed turbidity varied from about 90 to $1000 \mathrm{NTU}$ and was reduced to 0.2 to 20 NTU in the permeate. The turbidity of the feed increased from the first sample to the final sample indicating that the composition of the feed did vary with time, most likely due to degradation of the feed with temperature, or degradation by bacterial growth. 


\subsubsection{Gel Permeation Chromatography Analysis of Process Potato Starch}

Feed and permeate samples from both the untreated and fluorinated spiral modules, taken at the beginning of the run (1st day, 2nd pilot study) and at the conclusion of the run, were analyzed via GPC to determine the molecular weight distribution of potato starch rejected by the membranes. The molecular weight distributions were evaluated using polysaccharide calibration standards.

The GPC chromatograms for feed samples taken at the beginning (lower curve) and end (upper curve) of the run are shown in Figure 22. The initial feed had a high molecular weight fraction at $8.4 \times 10^{6}$ daltons, while the final feed did not contain this high molecular weight component. The initial feed also had a large peak at $3.8 \times 10^{5}$, but in the final sample, this peak had increased in magnitude and shifted to longer retention times indicating that the overall molecular weight distribution had decreased. These results indicate that the feed stream degraded significantly over the $21 \mathrm{hr}$ daily run period and that degradation of the starch in the feed resulted in a decrease in the overall molecular weight distribution of the starch.

The GPC chromatograms of the permeates from each module and the feed at the start of the pilot study are shown in Figure 23. The feed had a GPC peak at $8.4 \mathrm{x}$ $10^{6}$ daltons, which did not appear in both permeate samples. The disappearance of this peak indicates that the untreated and fluorinated membranes removed the high molecular weight starch. The remaining regions of the GPC chromatograms were identical for all the curves, indicating that the lower molecular species were not rejected by the untreated and fluorinated membranes.

The GPC chromatograms of the two permeates and feed at the conclusion of the pilot study are shown in Figure 24. The GPC chromatograms are identical over all retention times, indicating that the entire molecular weight distribution had passed through both the uncreated and fluorinated membranes. Since starch degradation had eliminated the highest molecular weight starch component, a greater fraction of the starch passed through the membrane, and the rejection of the membranes decreased. This result explains our results in section 3.4.1.2, where we observed that the COD 
rejection decreased over each daily run in the pilot plant.

\subsubsection{Surface Properties}

\subsubsection{Final Appearance}

The spiral modules were dissected at the conclusion of each pilot plant study. Photographs of the front and back of the membranes from the spiral modules of the first and socond pilot study are shown in Figures 25 and 26 , respectively. A solid gel-like material is seen in the feed spacer close to the permeate tube. A greater build up of gel material occurred in the fluorinated spiral in Figure 25 . We link this increased accumulation to the longer time the fluorinated spiral module spent on-line in the filtration rig. The gel builds up preferentially near the permeate tube because this is where there is the least resistance to flow through the permeate spacer.

\subsubsection{SEM Micrographs}

SEM micrographs were taken of the untreated and fluorinated membranes after the first pilot plant study. The membrane samples were extensively washed with DI water and dried via critical point drying to preserve the pore structure. A small representative sample was cut from the final dried membranes and observed by SEM.

Micrographs of the untreated and fluorinated membranes are shown in Figures 27 and 28 , respectively. A fibrous material with a characteristic dimension of 500 $\AA$ is seen on the surface of the untreated membrane in Figure 27, which we believe is most likely an accumulation of starch. This fibrous material did not cover the surface evenly, and photographs taken from other parts of the membrane showed no sign of it. The entire surface of the fluorinated membrane is clean of the fibrous material. The fluorinated membrane does exhibit fissures in the surface, which are most likely due to the drying process. Overall, the surfaces of the untreated and fluorinated membranes have similar appearance. 


\subsubsection{XPS Analysis of Fouled Surfaces}

XPS results for the membranes from the first pilot plant study are presented in Table 5. We see that there is fluorine left on the membrane surface even after extended continuous operation. The fluorinated membrane was online for 22 days while the untreated membrane was online for 13 days. While the fluorine level appears to have dropped from about $0.12 \mathrm{~F} / \mathrm{C}$ for a cleaned membrane to $0.04 \mathrm{~F} / \mathrm{C}$ for a pilot tested membrane, this is probably an artifact of our data treatment. In earlier studies, we assumed that the number of carbon atoms in the $50 \AA$ layer being analyzed would remain constant during fluorination, but this is no longer true when carbon-containing materials adsorb on the surface (i.e. protein, starch). Any additional carbon material adsorbed would dilute the number of fluorine atoms present in the analyzed layer. The presence of this adsorbed carbon i.; clearly indicated by the $\mathrm{S} / \mathrm{C}$ ratio, which decreased after extended use.

We can also evaluate fluorine content on the surface by comparing the $F / S$ ratio of a water-washed fluorinated membrane (Table 4b) with the fluorinated membrane from the pilot study (Table 5). Since sulfur and fluorine should be present at the same depth, the amount of sulfur to fluorine would be expected to remain constant even with the fouled layer present. We observe that the $F / S$ ratio decreased from 5.2 for the water-washed fluorinated membrane to 2.4 for the fluorinated membrane from the pilot study. The decrease in $F / S$ indicates that the fluorination decreased by 50 \& over the 21 day period.

\subsubsection{ATR-FTIR Analysis of Surface}

The spectra of clean untreated and fluorinated polysulfone membranes are given in Figures 29 and 31, respectively. The peak in the region between 3100 and 3000 $\mathrm{cm}^{-1}$ is indicative of the $\mathrm{C}-\mathrm{H}$ stretch of an aromatic hydrogen and the peak in the region between 3000 and $2870 \mathrm{~cm}^{-1}$ is indicative of the C-H stretch of an aliphatic hydrogen $^{27}$. The aromatic nature of the polysulfone is confirmed by the aromatic bands at 1592 and $1492 \mathrm{~cm}^{-1}$. The $1334 / 1304 \mathrm{~cm}^{-1}$ doublet and the $1159 \mathrm{~cm}^{-1}$ are attributed to $\mathrm{RSO}_{2} \mathrm{R}$ groups of the polysulfone backbone. The spectra are in agreement with spectra of other polysulfone membranes ${ }^{27,30,31}$. 
The spectra of fouled untreated and fluorinated polysulfone membranes from the first pilot study are given in Figures 30 and 32 , respectively. The membranes were extensively washed with DI water and dried in air. The spectra exhibit all of the functional groups present in the starting polysulfone membranes. Additional peaks are observed at 3313,1663 , and $1549 \mathrm{~cm}^{-1}$ in the fouled membrane. The $3313 \mathrm{~cm}^{-1}$ peak can be associated with the $\mathrm{N}-\mathrm{H}$ stretch in proteins or with an $\mathrm{O}-\mathrm{H}$ stretch, and the 1663 and $1549 \mathrm{~cm}^{-1}$ peaks may be associated with the amide I and amide II bands ${ }^{27}$. The appearance of the amide bands is indicative that proteins have adsorbed on the surface during the pilot plant study, and that long term fouling of the membranes is controlled by protein deposition. Direct quantitative analysis of the degree of protein fouling is difficult to calculate due to the difference in run times of the various membranes used in the first pilot study.

The effect of fluorination on the polysulfone spectra can be seen by comparing Figures 29 and 31 . The decrease in the peak at $2954 \mathrm{~cm}^{-1}$ indicates that the number of aliphatic $\mathrm{C}-\mathrm{H}$ bonds has decreased, while the number of $\mathrm{C}-\mathrm{F}$ bonds has increased as indicated by the absorbance increase ${ }^{37}$ in the region of $1350-1000 \mathrm{~cm}^{-1}$. The C-F bonds are detected in the $1100-1000 \mathrm{~cm}^{-1}$ region and the $\mathrm{C}^{\prime \prime} / \mathrm{CF}_{3}$ groups show broad peaks in the region of $1350-1120 \mathrm{~cm}^{-1}$.

\subsubsection{Summary -- Spiral Wound Module Study}

Our pilot plant study does not show the clear difference in membrane flux and fouling that we observed in the flat sheet study. Instead, fluorinated and untreated modules behaved in a substantially similar manner. Fouling by the potato waste feed was severe, and resulted in the formation of an extensive gel layer within the module on the surface of the membrane. As a result, permeate fluxes

"decreased to less than 508 of their original values within the first 15 minutes of each cycle. XPS, SEM and FTIR studies combine to indicate that some build up of organic material occurred on both the fluorinated and unfluorinated membranes, but SEM indicates that a fibrous mat of material was observed only on the nonfluorinated membrane. We conclude that in the pilot study, membrane fouling and gel formation were so extensive that the surface interaction effect on which the fouling technique is based was overwhelmed. 
Reconciliation of the results of the spiral module study with those in the flat sheet study will be discussed in section 4.0 .

\subsection{Economic Analysis}

The ultimate objective of our program was to reduce energy consumption by the food processing industry by providing an alternative to evaporative concentration of aqueous streams. In order for such a process to be considered by the food processing industry, it must be reasonably low in cost, and offer significant savings to the processor in energy and other costs. In this section we analyze these costs.

Since surface fluorination represents an added treatment to an existing ultrafiltration membrane, analysis of the costs of the modified membrane is relatively simple. Conventional ultrafiltration membranes of the type used in our work are normally sold for $\$ 3.5-4.5 / \mathrm{sq}$. ft. as spiral wound modules ${ }^{38}$. Surface fluorination would most conveniently be accomplished by treating the formed, unrolled membrane with fluorine in either a batch or continuous mode. Fluorine is commercially available at $\$ 40-50 / 1 b,{ }^{39}$ and based on the amount of fluorine on the surface we estimate that this would contribute $\$ 1.3 \times 10^{-5} / \mathrm{sq}$. ft. to the cost of the membrane. The principal cost of fluorination will therefore be the capital, labor and environmental costs associated with using fluorine safely. By way of comparison, the cost of fluorinating the interior of a one gallon polyethylene container was estimated ${ }^{40}$ at $5.5-6 \&$ per container in 1978 , and this cost included a royalty fee for the proprietary process used. Clearly. surface fluorination is an inexpensive treatment and can be also be applied inexpensively to fluorinating other polymeric surfaces, including membranes.

The economics of an increase in permeate flux through a fluorinated membrane wexe analyzed ${ }^{39}$ for a hypothetical ultrafiltration plant running on a 365 day, 24 hour operating cycle which included daily cleaning of the membrane. The plant would be operated 20 to 22 hours per day with a cleaning cycle varying between 2 to 4 hours per day. A 258 increase in permeate throughput through a membrane would result in a 238 reduction in capital costs as illustrated in 
Appendix $D$. The decrease in capital costs is directly related to a decrease in both the number of modules, pressure tubes and pumps needed to provide a given plant output. In addition to reduced capital costs, operating costs would decrease as illustrated in Appendix $D$. Utility costs would also be reduced by 20-258. For example, electrical costs would decrease from $\$ 52,700$ to $\$ 39,500$ due to decreased pumping requirements. Steam and water costs were not estimated due to large regional price differences. The amount of steam used remains constant and is directly related to the total amount of feed treated. Cleaning costs would be reduced 15-208, mainly resulting from a reduction in the quantity of chemicals and water used to clean the modules. There would be no reduction in labor costs and no reduction in pretreatment procedures. Annual replacement costs of the membranes would also decrease due to the decrease in the number of membrane modules present in the ultrafiltration system for a specified permeate flux. The replacement cost of the improved membranes listed in Appendix D does not include fluorination costs.

In conclusion, the 258 increase of permeate flux decreased both the initial capital investment and the annual operating costs of the ultrafiltration plant. An original equipment manufacturer stated that a fluorinated membrane with a 258 increase in permeate flux would be attractive due to the increased efficiency it would provide to the overall membrane process.

By reducing the costs of using membranes, surface fluorination is an enabling technology for energy conservation. Fluorinated membranes can be used to reduce the energy required to concentrate final food products or aqueous waste streams in industries like those involved in meat and poultry, fruits and vegetables, dairy, and grain milling processes. Examples of food processes where membranes can be applied include ultrafiltration (UF) of poultry brine, UF fractionation of milk to produce cheese, and UF of potato waste streams. As a concentration method, our technology thus offers an alternative to evaporation and distillation, which require large quantities of energy to due to the latent heat of vaporization of water. 


\subsection{CONCLUSIONS AND RECOMMENDATIONS}

Our flat sheet study has shown that in the filtration of potato waste streams, permeate flux increased and the fouling rate of the polysulfone membrane was reduced by surface fluorination. Analysis of the fluorinated membrane showed that the fluorination process added both fluorine and oxygen to the surface. We believe that the increased oxygen and fluorine on the surface of the membrane increased the hydrophilic nature of the membrane, and this increase in hydrophilicity increased the initial flux by decreasing the contact angle in the pores of the membrane. It also decreased the fouling rate by decreasing the interactions of foulants with the membrane. Avoiding denaturation of proteins and glycoproteins on the hydrophobic surface may be important to this effect.

The permeate flux results in the spiral module pilot study did not agree with the flat sheet results. No significant difference was observed between the performance of the fluorinated module and an untreated module, and neither module worked well with the realistic feed. Analytical results with respect to degree of fluorination and contact angle, however, were similar to those in the flat sheet study.

The decrease we observed in permeate flux in the spiral module may have been due to (1) operating conditions (crossflow velocity, trans-membrane pressure, etc.) (2) cleaning procedures, or (3) changes in the composition of the potato feed. Membrane fouling was more severe in the spiral module than in the flat sheet runs as evidenced by the sharp decrease in permeate flux at the start of each run. The operating conditions of the flat sheet studies and the spiral modules runs differed since cross flow velocities in the flat sheet were greater than those in the spiral module by an order of magnitude. The increased crossflow velocity in the flat sheet study could have swept away any gels formed on the surface of the membrane, while in the spiral modules, the gels would have built up at the surface. The spiral module also contained a feed spacer which was not present in the flat sheet studies. This spacer could have aggravated gel formation by entrapping and concentrating gels that had formed inside the spacer. Spacer sizing and design are critical in controlling the build-up of 
foulants inside the module.

We found that the cleaning procedure used in this study did not effectively clean the spiral modules. This was made evident by the harderied gel that formed inside both the untreated and fluorinated modules after extended use. The long term build up of foulant would result in a short lifetime for the membrane.

In retrospect, we also believe that the feed composition also varied between the flat sheet study and the spiral module runs. Feed degradation occurred continuously on receipt of each feed sample, but the potato feed was clearly further degraded in the flat sheet study than in the spiral module study, judging from the $\mathrm{pH}$ values of the samples. Degradation results in a lower molecular weight distribution of starch, and associated with the lower molecular weight, a higher critical gel concentration. With a higher critical gel concentration, we would expect a gel layer to first occur at a higher surface concentration (or at longer filtration times), as was in fact observed in our flat sheet study.

As a result of these problems, severe gel formation on the spiral modules prevented us from observing tha effects of surface fluorination on the membrane surface in the pilot study. The permeate flux dropped over 50 in the first 15 minutes of each cycle, indicating that a gel layer formed quickly on the surface. After gel formation, the permeate flux through the membrane was probably controlled by the presence of the gel layer rather than by the membrane surface.

We recommend that further studies be completed to establish whether surface fluorination is a viable approach to reducing fouling in ultrafiltration membranes. These studies should focus on the three hypotheses described above, and determine whether each is involved, separately or in combination, in obviating the surface fluorination effect we observed in the flat sheet study. In particular, further studies should refine our identification of the foulants on or near the membrane surface. They should also define the gelling properties of potato starch and map the critical gel concentration as a function of concentration, pH, ionic strength and other factors. Membrane cleaning also 
needs a much closer examination, including pilot plant trials with alternative cleaning agents. The net effect of these studies would be a much more clearly defined picture of the benefits of surface fluorination, and a concrete resolution of the question of whether its benefits are sufficient to justify commercial development.

\section{0 ACKNOWLEDGEMENTS}

We appreciate the support and advice of Sia Mercouris, Samuel Nunez, Christopher Andren, and Edward Funk (Allied-Signal R\&T, Des Plaines, IL); John Hewes, Donald Taylor, Thomas Izod and Morris Berembaum (Allied-Signal R\&T, Morristown, NJ); George Shia and Alexander Robertson (Fluorine Products Division, Buffalo, NY); and Jim Beckman and William Light (Fluid Systems, San Diego CA).

We would like to thank Steve Gardels and Lyle Parks at Basic American Foods (Blackfoot, ID) for providing the potato waste used in the pilot studies.

We appreciate the support and adv of W. M. Sonnett (DOE Office of Industrial Technologies), G. R. Peterson (DOE Idaho Operations office) and T. W. Lawford (EG\&G Idaho, ID).

Finally, we wish to thank Peggy L. Macaluso and Maria E. Santos for typing and formating this report.

This paper was prepared with the support of the U.S. Department of Energy (DOE) Cooperative Agreement No. DE-FC07-89ID12904. However, any opinions, findings, conclusions, or recommendations expressed herein are those of the authors and do not necessarily reflect the view of DOE. 


\subsection{REFERENCES}

1. Mohr C.M., Leeper S.A., Engelgau D.E. and Charboneau B.L., Membrane Applications and Research in Food Processing: An Assessment, U.S. DOE Report DE88016250, August 1988.

2. Humphrey J.L., Seibert A.F., and Koort R.A., Separation Technologies - Advances and Priorities, U.S. DOE Report DE91010024, February 1991.

3. Lee D.N. and Merson R.L., J,Food ScI., 41, 403(1976).

4. Findley J.W., Cereal Chem., 54, 131(1977).

5. Merin U. and Cheryan M., J. Food Process and Preser., 4. $183(1980)$.

6. Cheryan M., Ultrafiltration Handbool, "echnomic Publishing, Lancaster, PA (1986).

7. Lee D.N. and Merson R.L., J. Dairy Sci, 58, 107(1975).

8. Fane A.G. and Fell C.J.D., Desalinatior, E2, 117(1987).

9. Nystrom M., J. Membr, Sci., 44, 183(1989).

10. Jonsson A. and Tragardh G., Chem. Erig, and Process., 27, $67(1990)$.

11. Bauser H., Chmiel H., Stroh N, and Walitza E., J, Membr, Sci, 27, 195(1986).

12. Jeffery C.G., McKenchnie M. T. and Perry D.L., U.S. Patent 5,028,453, July 2, 1991.

13. Nomura H., U.S. Patent 4.806.246, February 21, 1989; Masuoka T. Hirasa 0., Suda Y., Omishi M., Seita Y. U.S. Patent 4,845,132 July, 4, 1989.

14. Speaker L.M. U.S. Patent 4.554.076, November 19, 1985; Speaker L.M., Forrister W.B., Gao H., Chian E.S.K., Campbell D.P., Goebel K.D., Stern R.M., "Anti-Fouling Surface Modification for Longer-1ived Membranes with Constant Fluxes and Selectivities: AFT II" Final Report, U.S. Geological Survey Grant 14-08-0001-G1281, April 15, 1988.

15. Fane A.D., Fell C.J.D. and Kim K.J., Desalination, 53, 37 (1985). 
16. Clark D.T., Feast W.J., Musgrave W.K.R., Ritchie I., J. Polym. Sci.: Polym. Chem, Ed, 13, 857 (1975).

17. Hayes L.J., Dixon D.D., J. Appl, Poly. Sci., 22, 1007 (1978).

18. Anand M., Cohen R.E., Baddour R.F., Polymer, 22, 361 (1981).

19. Corbin G.A., Cohen R.E., Baddour R.F., J. Appl, Poly. Sci, 30, 1407 (1985).

20. Kiplinger C.L., Persico D.F., Lagow R.J., Paul D.R., J.Appl. Poly. s. 31,2617 (1986).

21. Mohr J.M., Paul D.R., Misna T.E., Lagow R.J., J, Membr, Sci., 55, 131 (1991).

22. Boultinghouse H.D., "Fluorinated Polymeric Surfaces", U.S. Patent 4.296.151. (1981).

23. Brock T.D., Membrane Filtration: A User's Guide and Reference Manual Science Tech. Inc., Madison, WI (1983)

24. Ueno S., Nomura H., Imada K., U.S, Patent 4,548,867, October 22, (1985).

25. "Oxygen Demand, Chemical (COD)", Water Analysis Handbook, Hach Co., Lovel and, CO(1989).

26. OLrani M., Schock G., J, Membrane Sci, 43, 243 (1989).

27. Kassotis J., Shmidt J., Hodkins L.T. and Gregor H.P., J, Membr, Sci, 22,61 (1985).

28. Nobrega R., De Balınn H., Aimar P. and Sanchez V., J. Membr. Sci, 45, 17 (1989).

29. Fontyn M., Van't Riet K., Bijsterbosch B.H., Colloids Surf, 54 , 331 (1991).

30. Fontyn M., Van't Riet K., Bijsterbosch B.H., Colloids Sci,, 54, 349 (1991).

31. Barton A.F.M. , CRC Handbook of Solubility Parameters and Other Cohesion Parameters, CRC Press, Boca Raton, FL (1983).

32. Chmiel H., McDonogh R.M., Bauser H., Stroh N., J. Dispersion Sci, Tech., 12, 161 (1991).

33. Dixon D.D., Hayes L.J., U.S, Patent 4,020,223 April 26, 1977.

34. Tragardh G., Desalination, 71, 325 (1989). 
35. Bayazeed A. and Tranter J., Starch, 43, 18 (1991).

36. Bayazeed A. and Tranter J., Starch 43, 262 (1991).

37. Refer to Silverstein R.M., Bassler G.C., Morrill T.C., Spectrometric Identification of Organic Compounds, 3rd ed., pp. 114, 115, J. Wiley \& Sons, N.Y. (1974).

38. Personal communication, William Loy, Allied-Signal Fluid Systems Division, San Diego, CA (1992).

39. Personal communication, George Shia, Allied-Signal Fluorine Products Division, Buffalo, NY (1992).

40. Plastics Technology, 24, September, 23 (1978) 


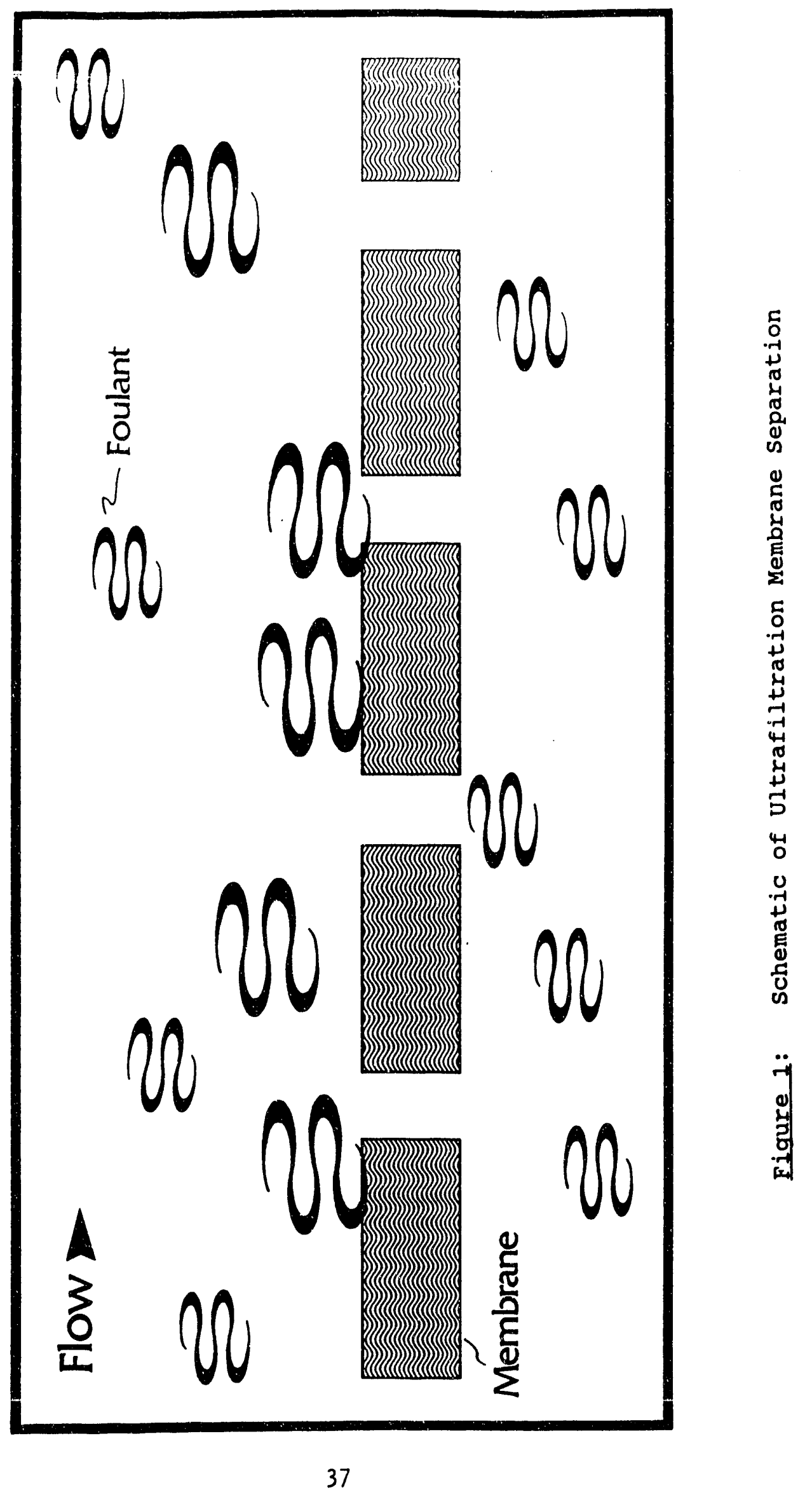




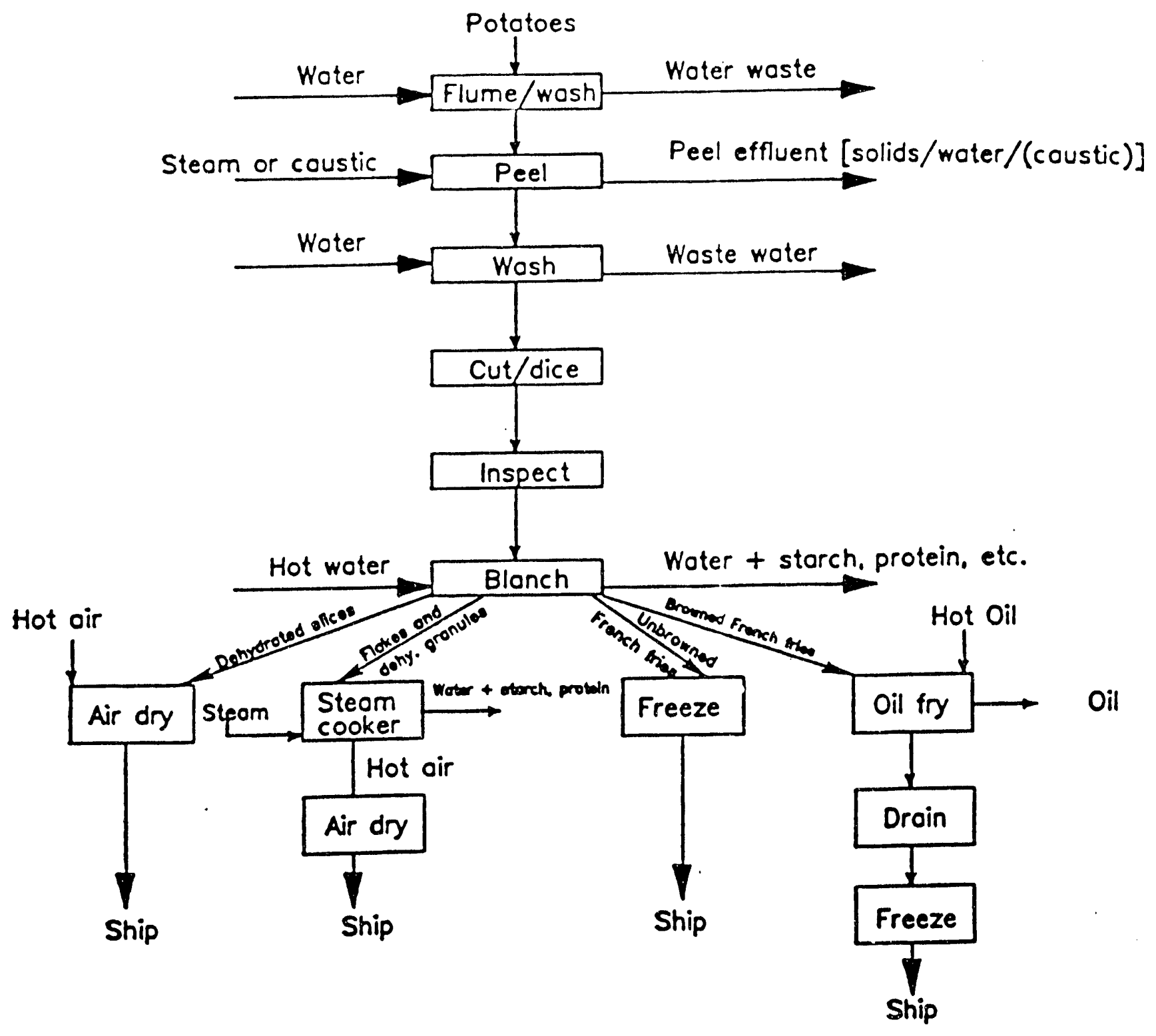

Figure 2: Flowsheet of a Typical Potato Processor 


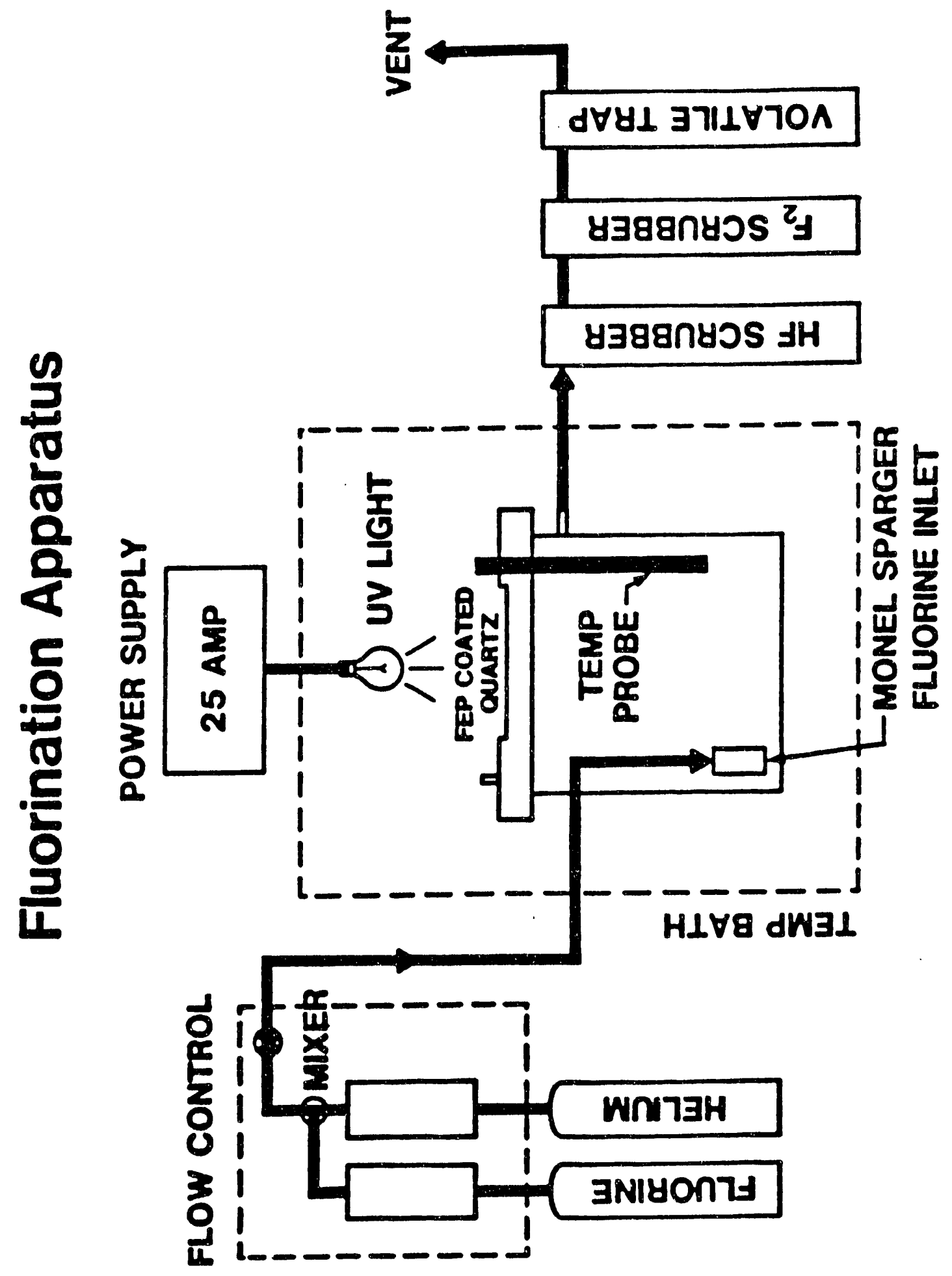




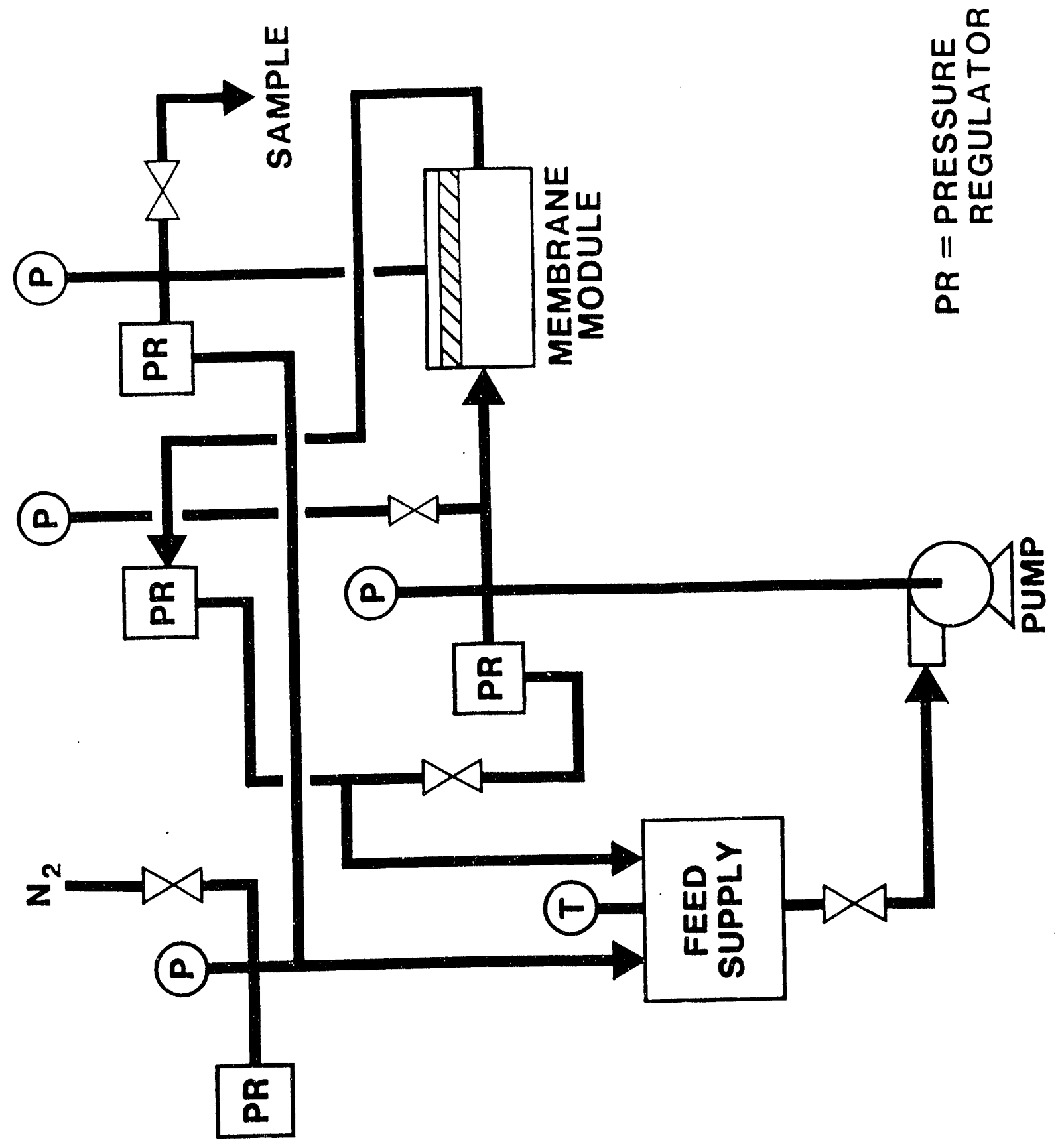

年 


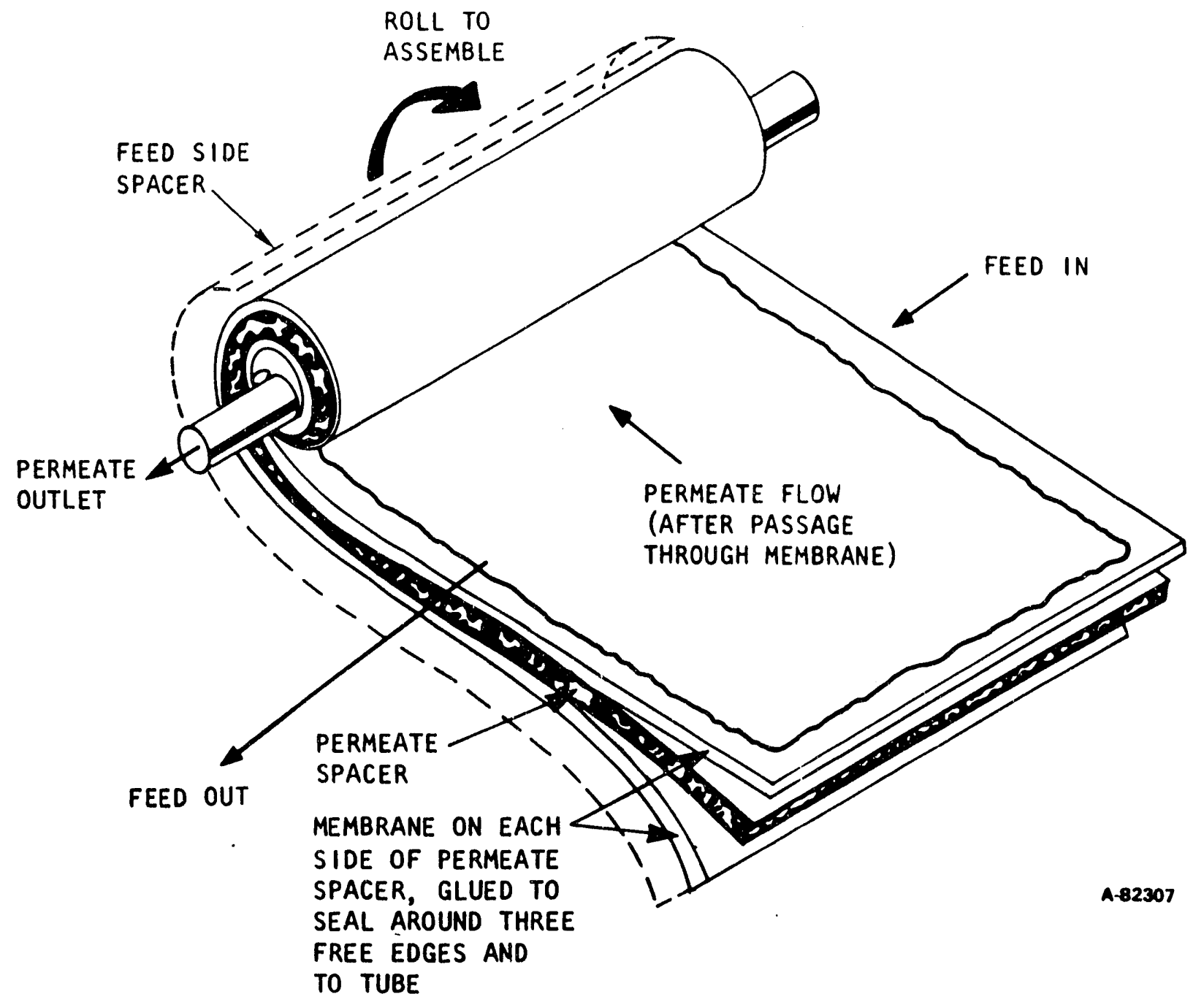

Figure 5: Diagram of Unrolled Spiral-Wound Membrane Module 


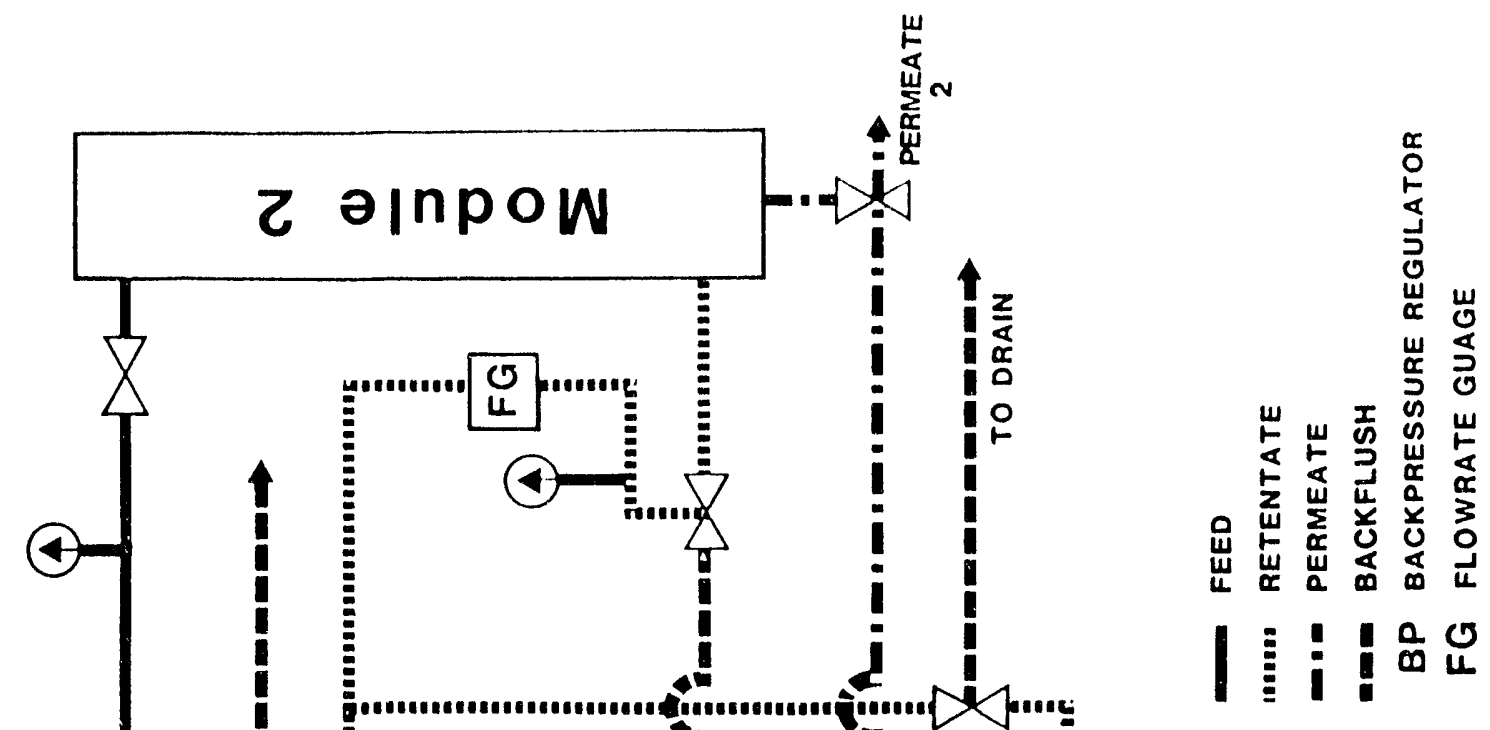

D

ํ) 


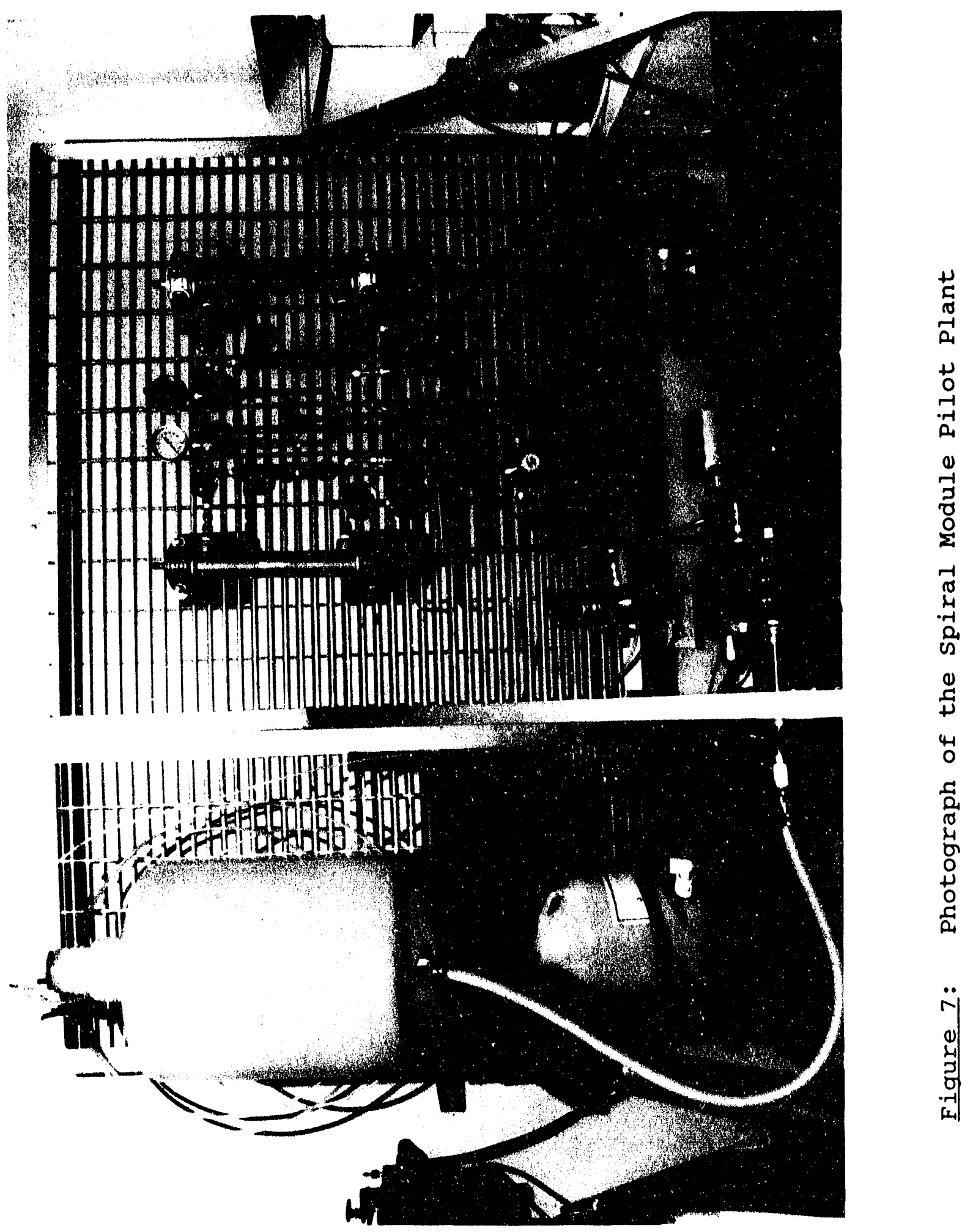



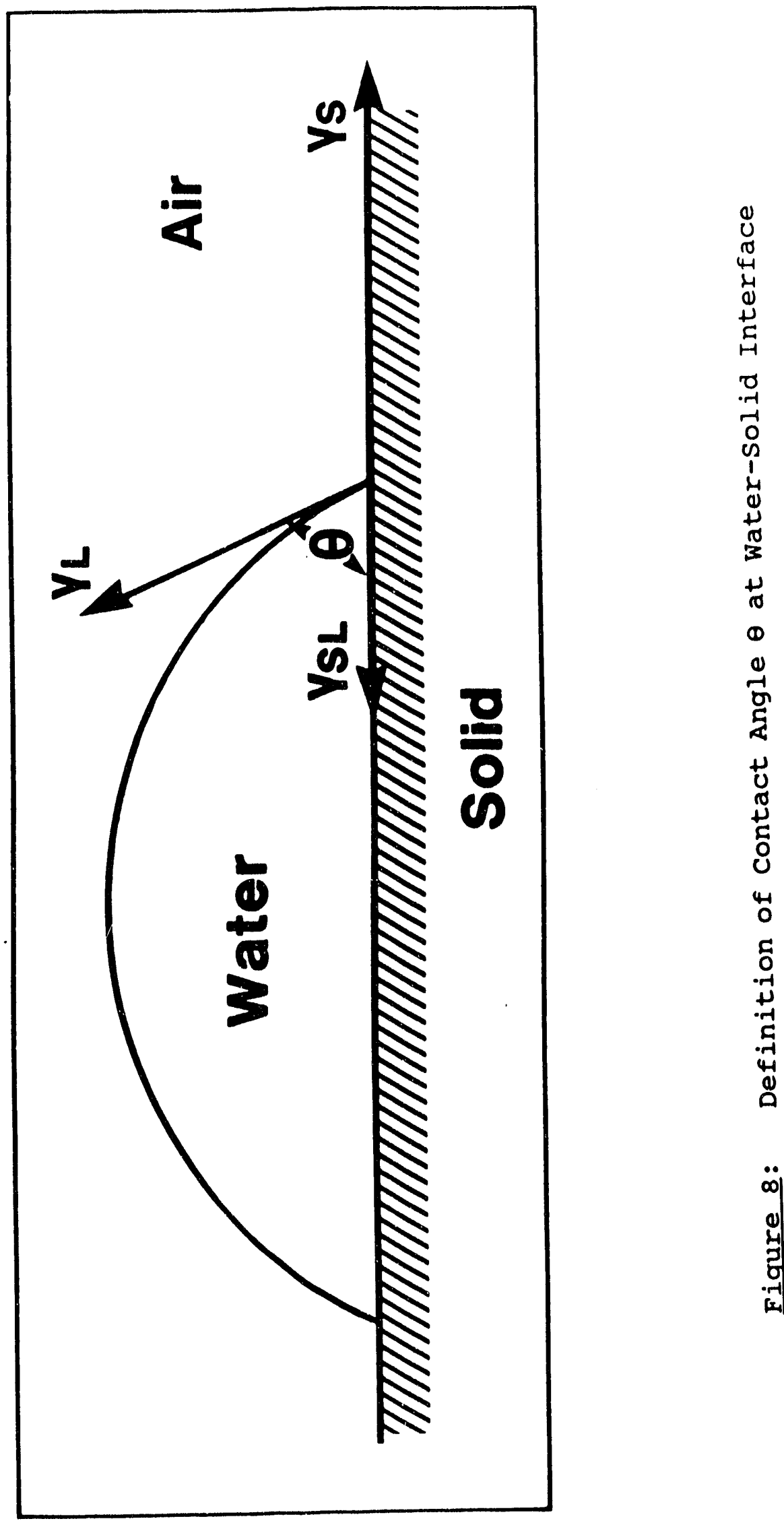


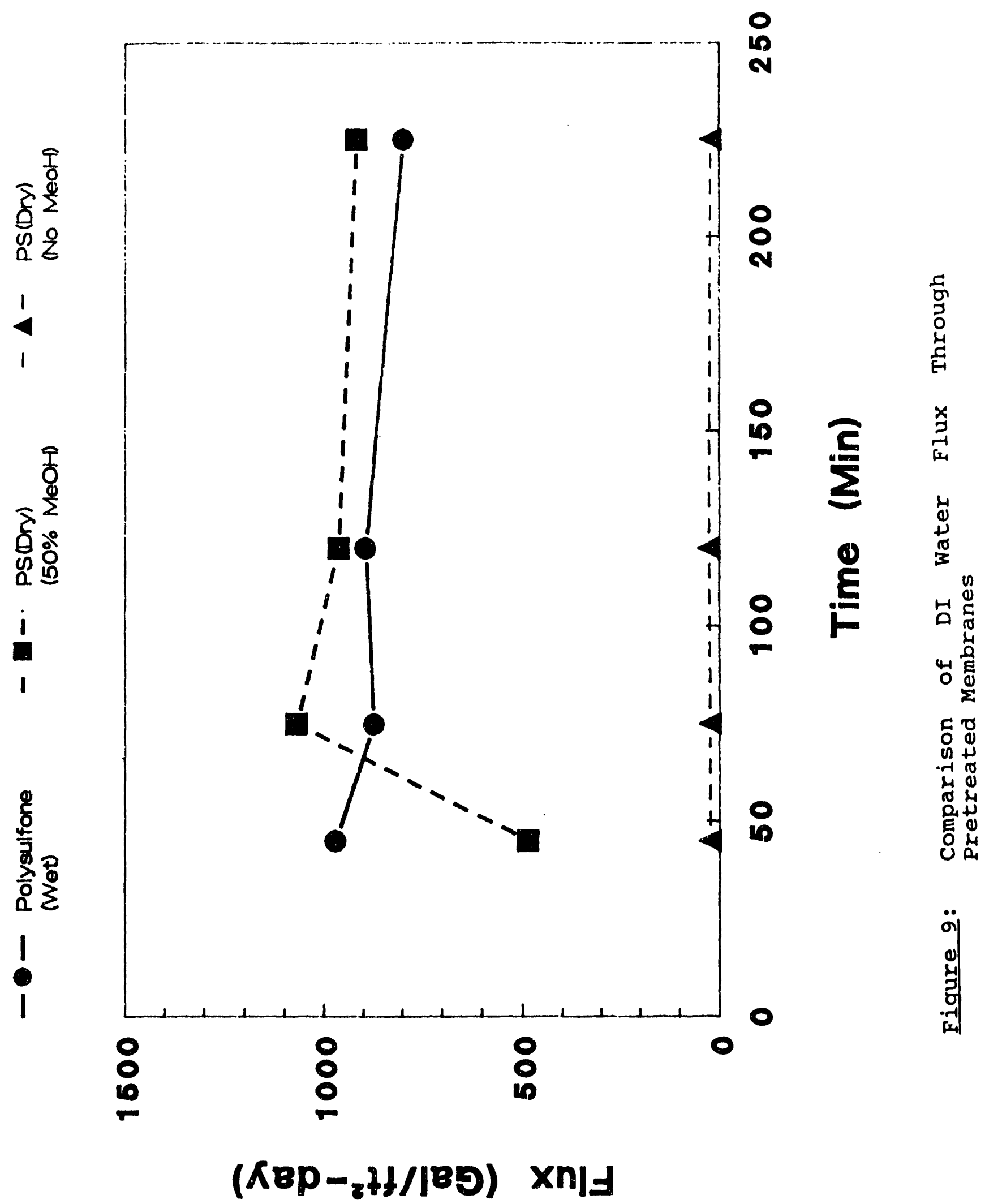




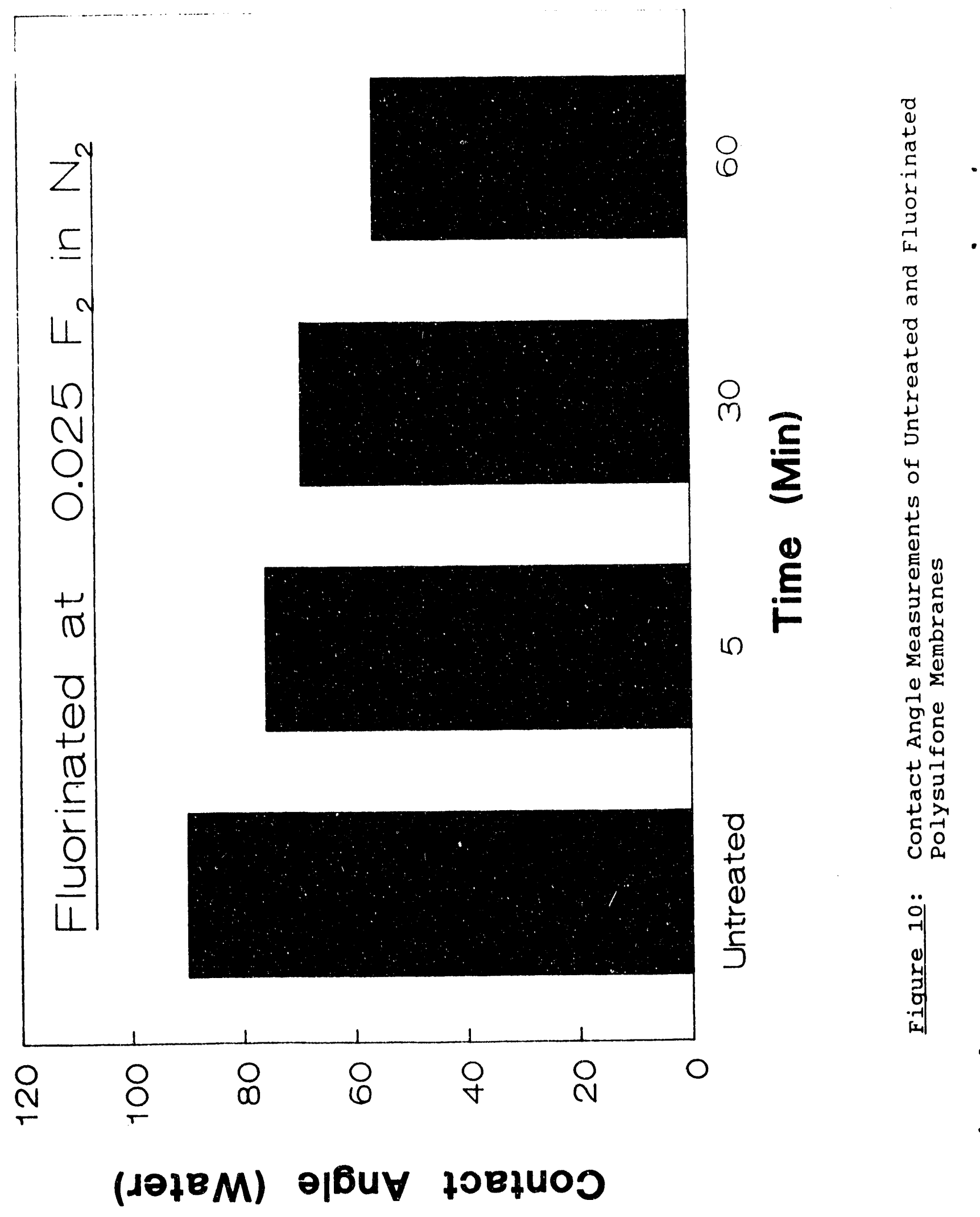




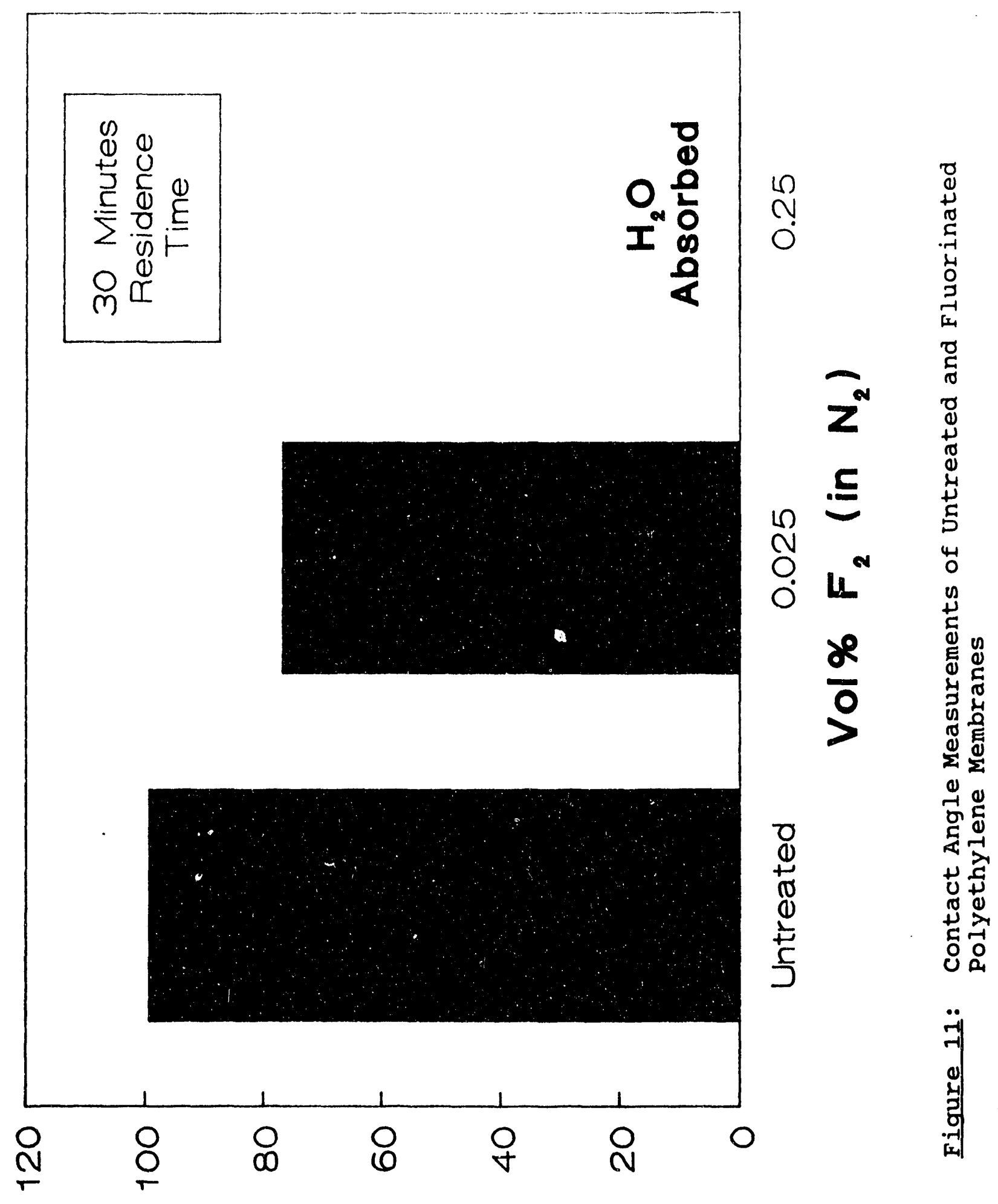

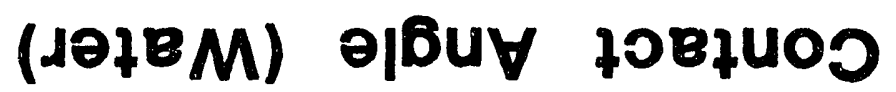




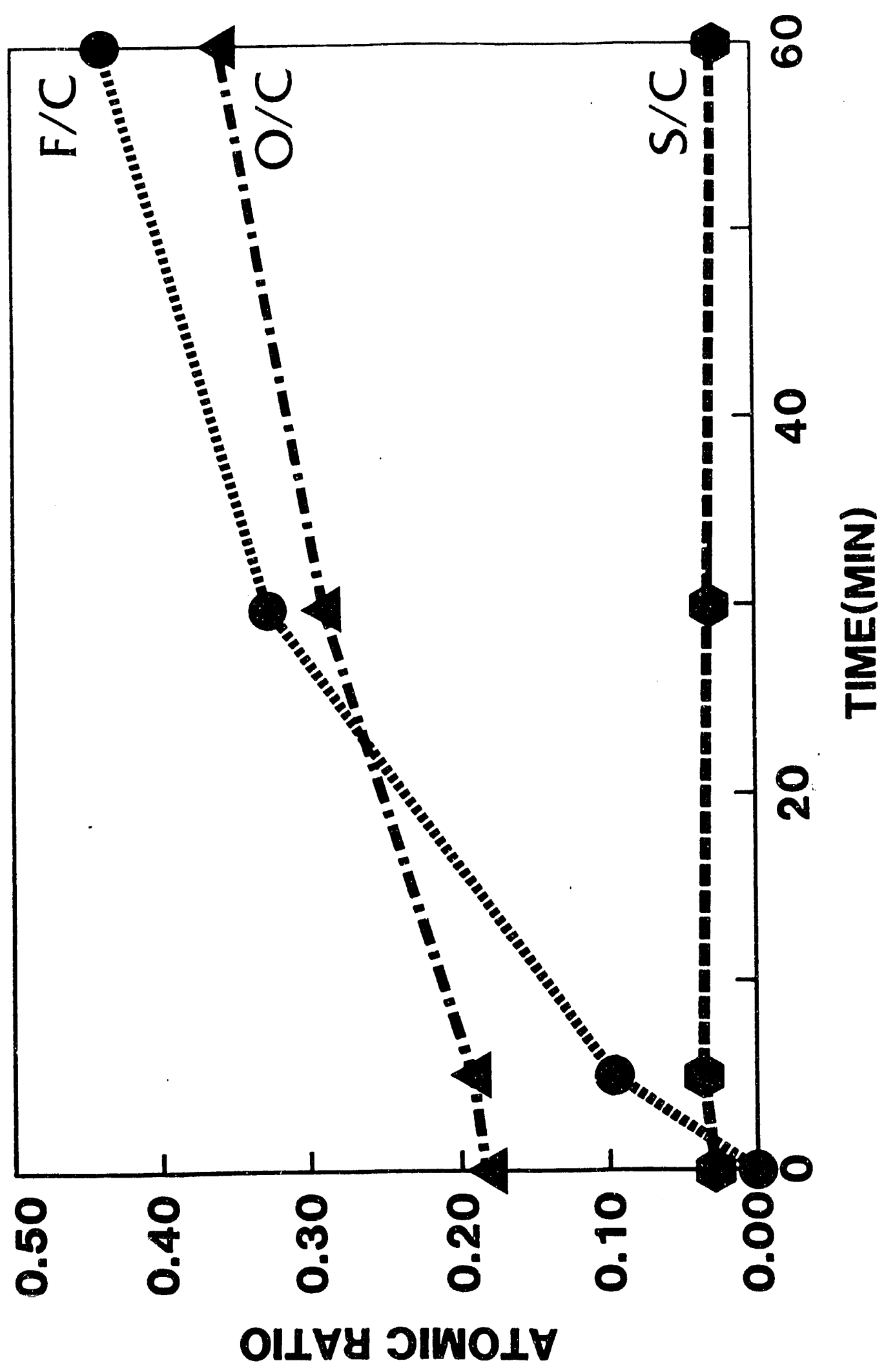




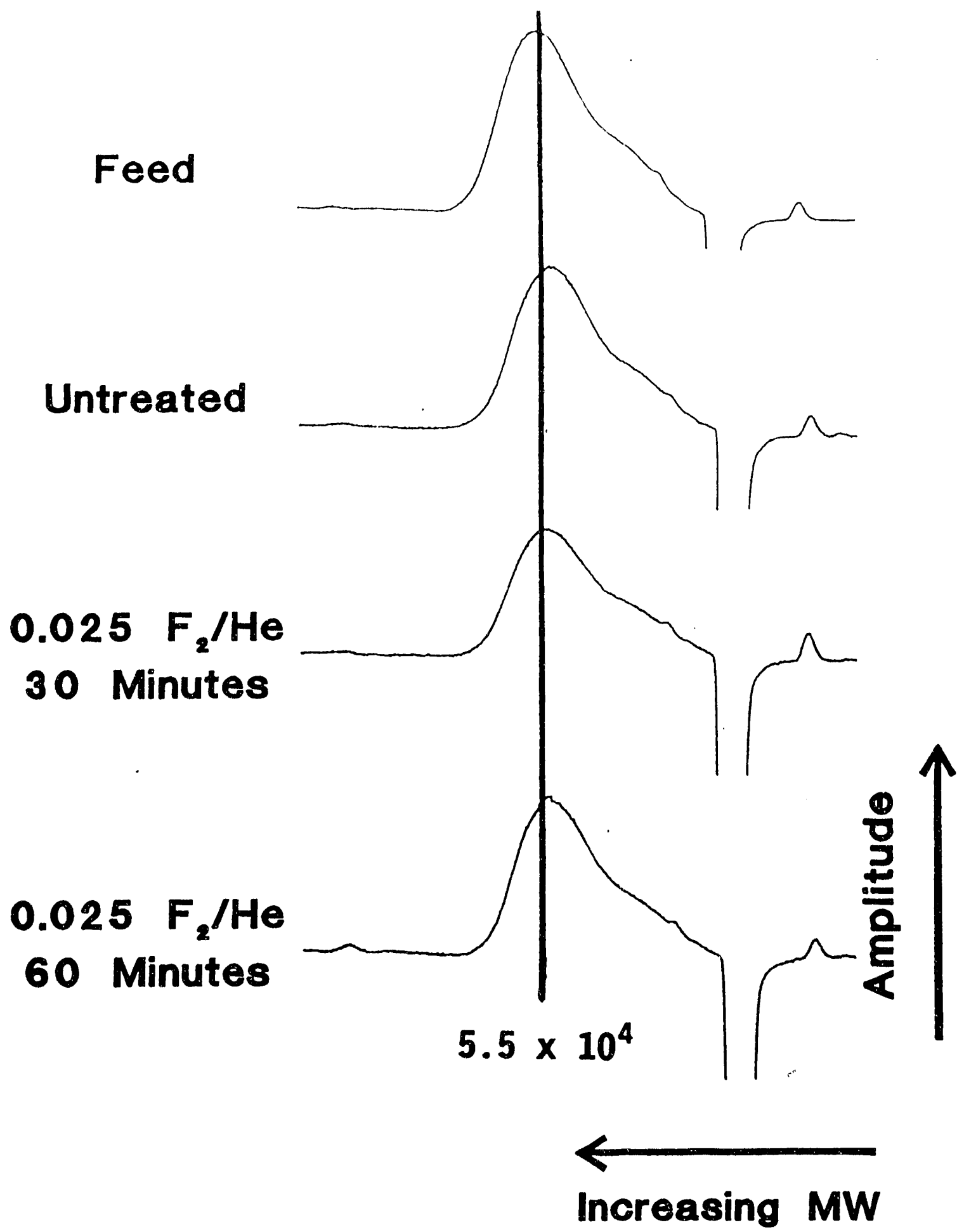

Figure 13: Gel Permeation Chromatograms of Low Molecular Weight Dextran Feed Through Untreated and Fluorinated Polysulfone Membranes 


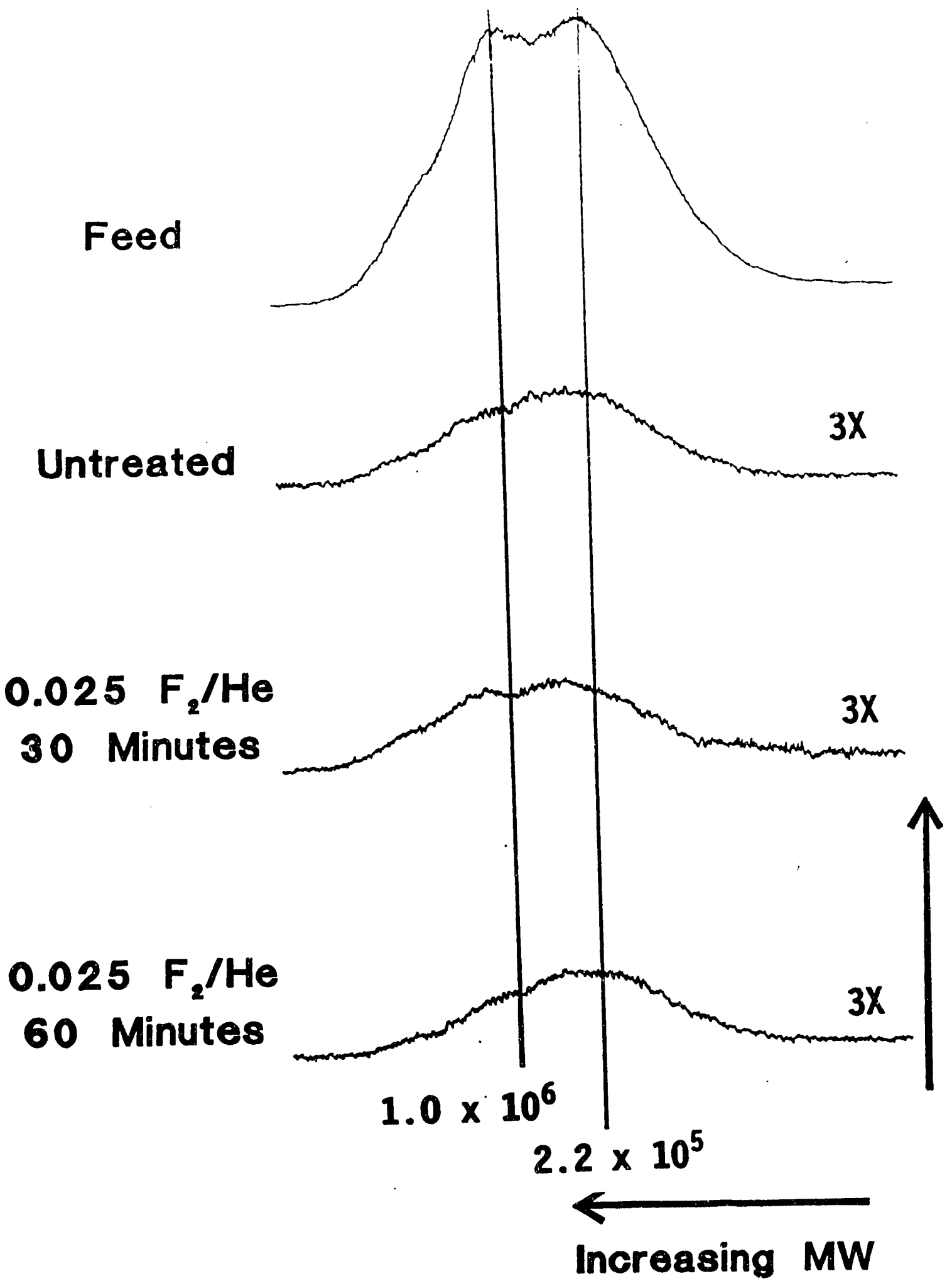

Figure 14: Gel Permeation Chromatograms of High Molecular Weight Dextran Feed Through Untreated and Fluorinated Polysulfone Membranes 


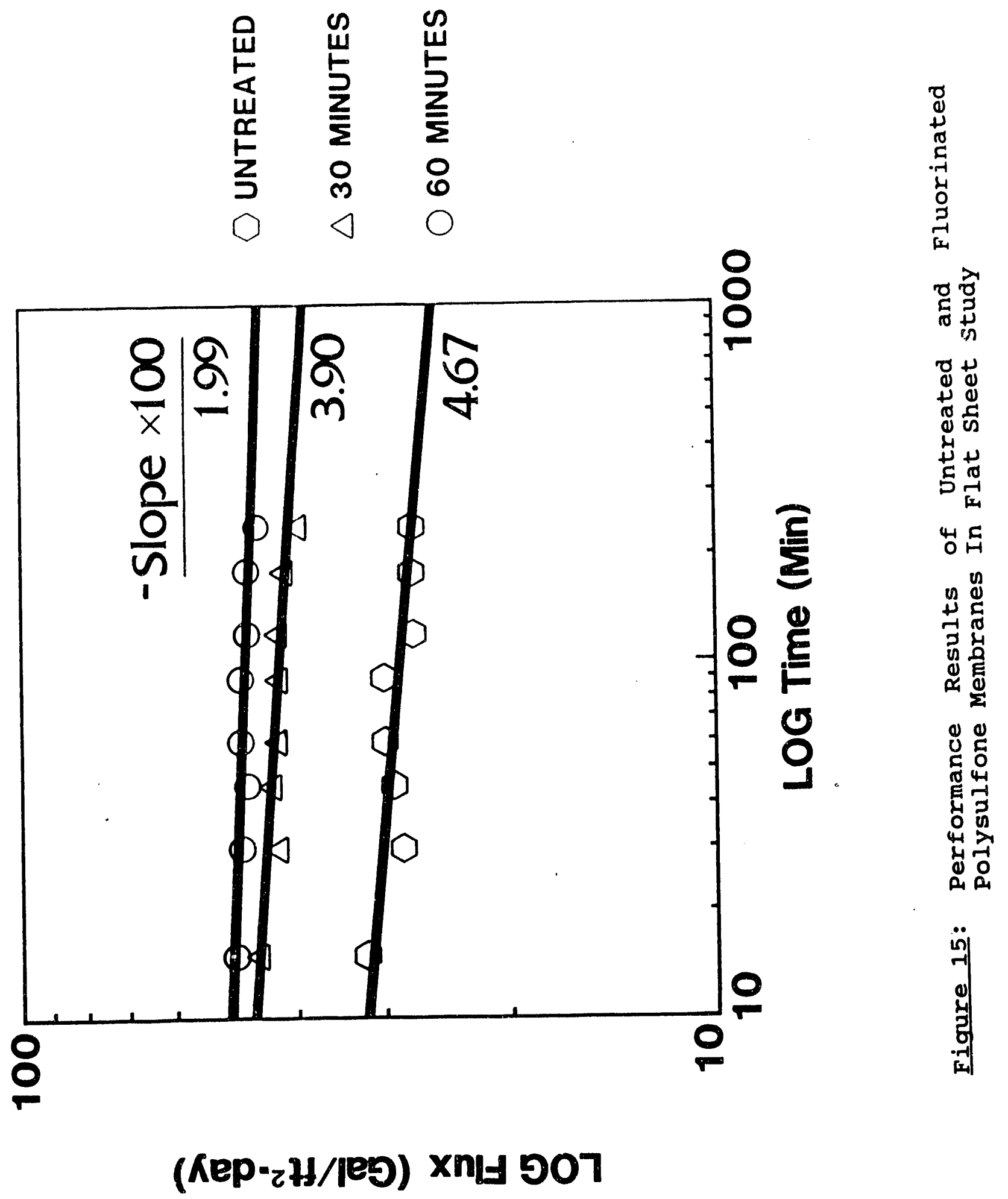




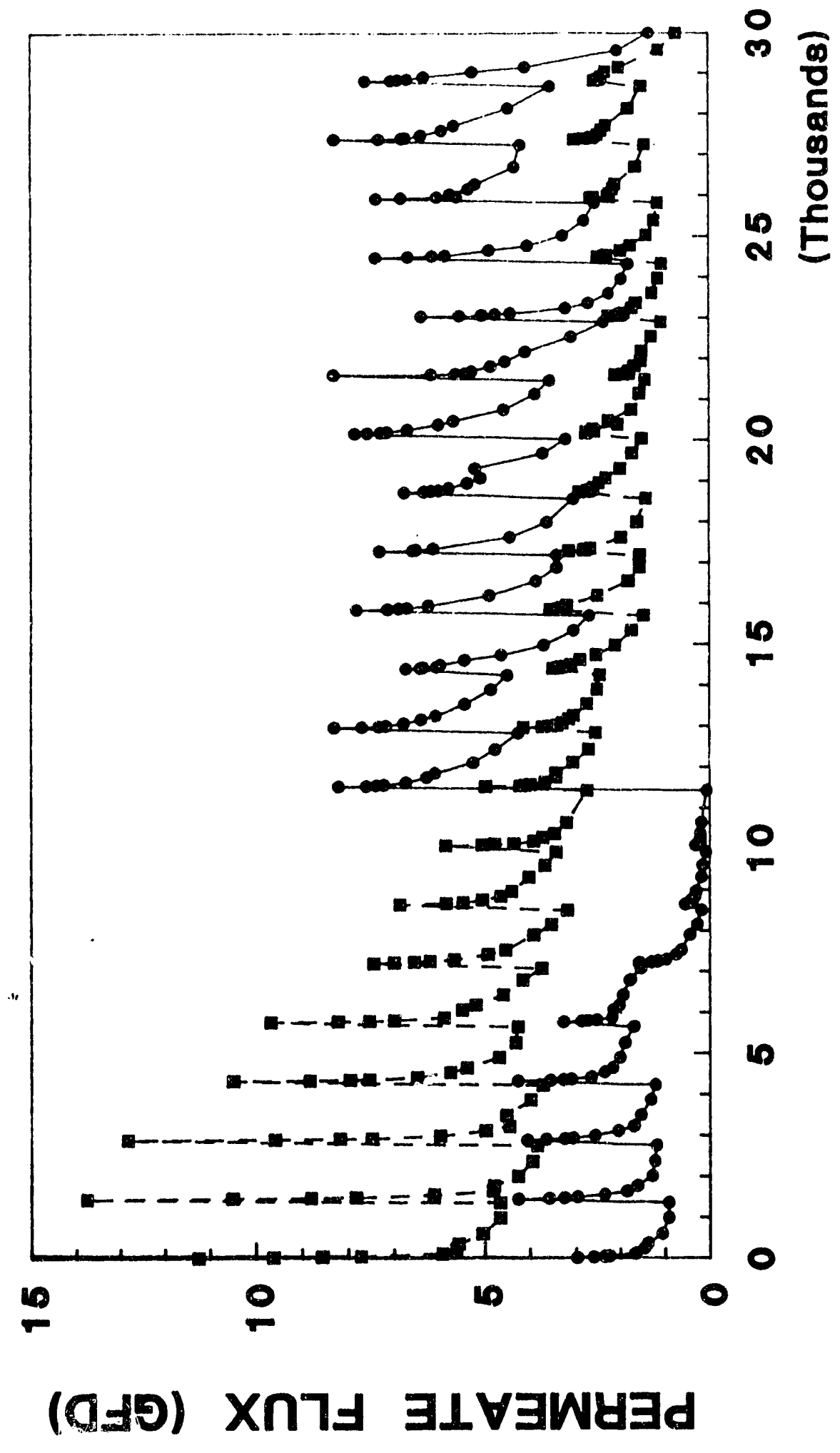

ర్

框

ชั ชิ

د.

品

(1)

ب

II

C.

प1

(1)

+

ว

U)

0

$+$

$+$

(1)

$\frac{1}{5} \frac{1}{0}$

这

() 0

U동

돈

낭 ?

$4>$

4.

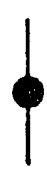

(1)

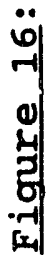



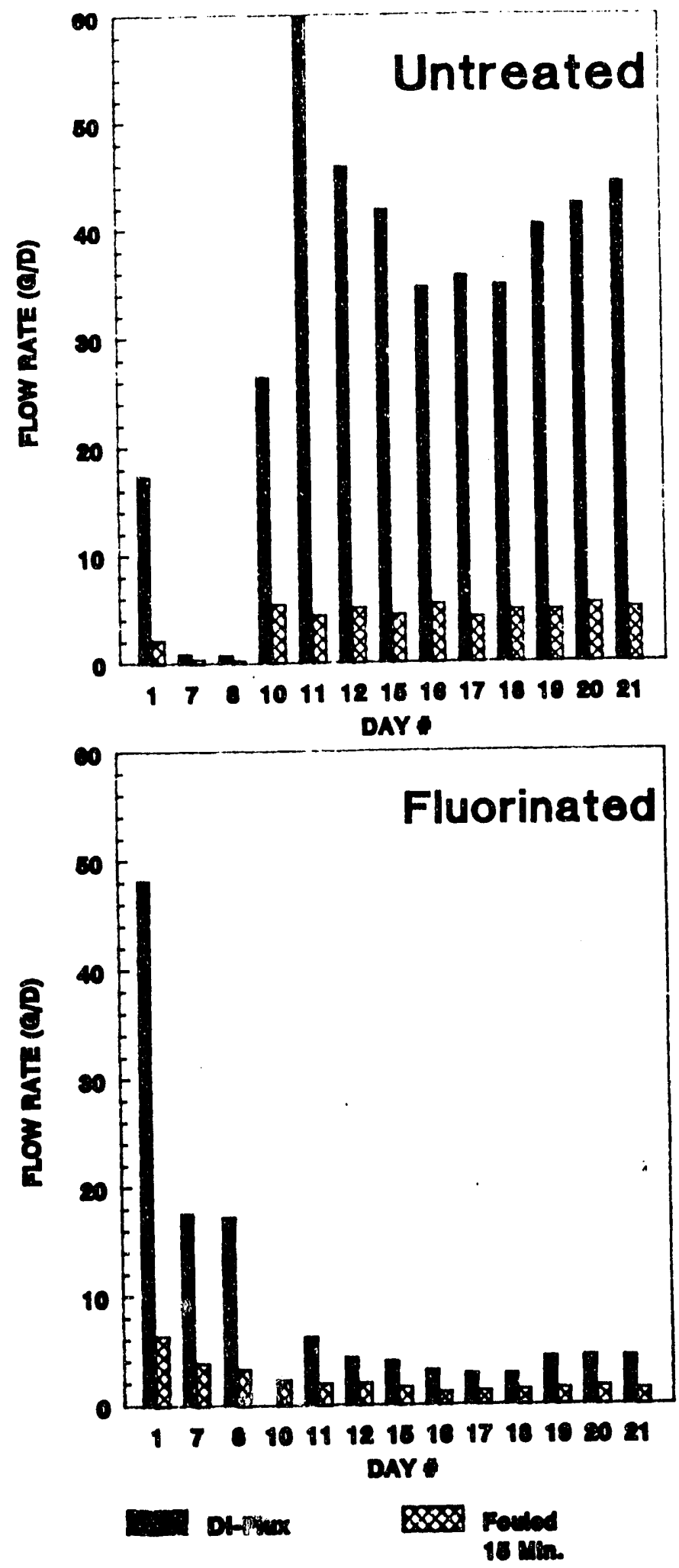

Fiqure 17: DI water and Permeate Flow Rates (15 Minute) of Untreated and Fluorinated Folysulfone Membranes In Pilot Study \#1 


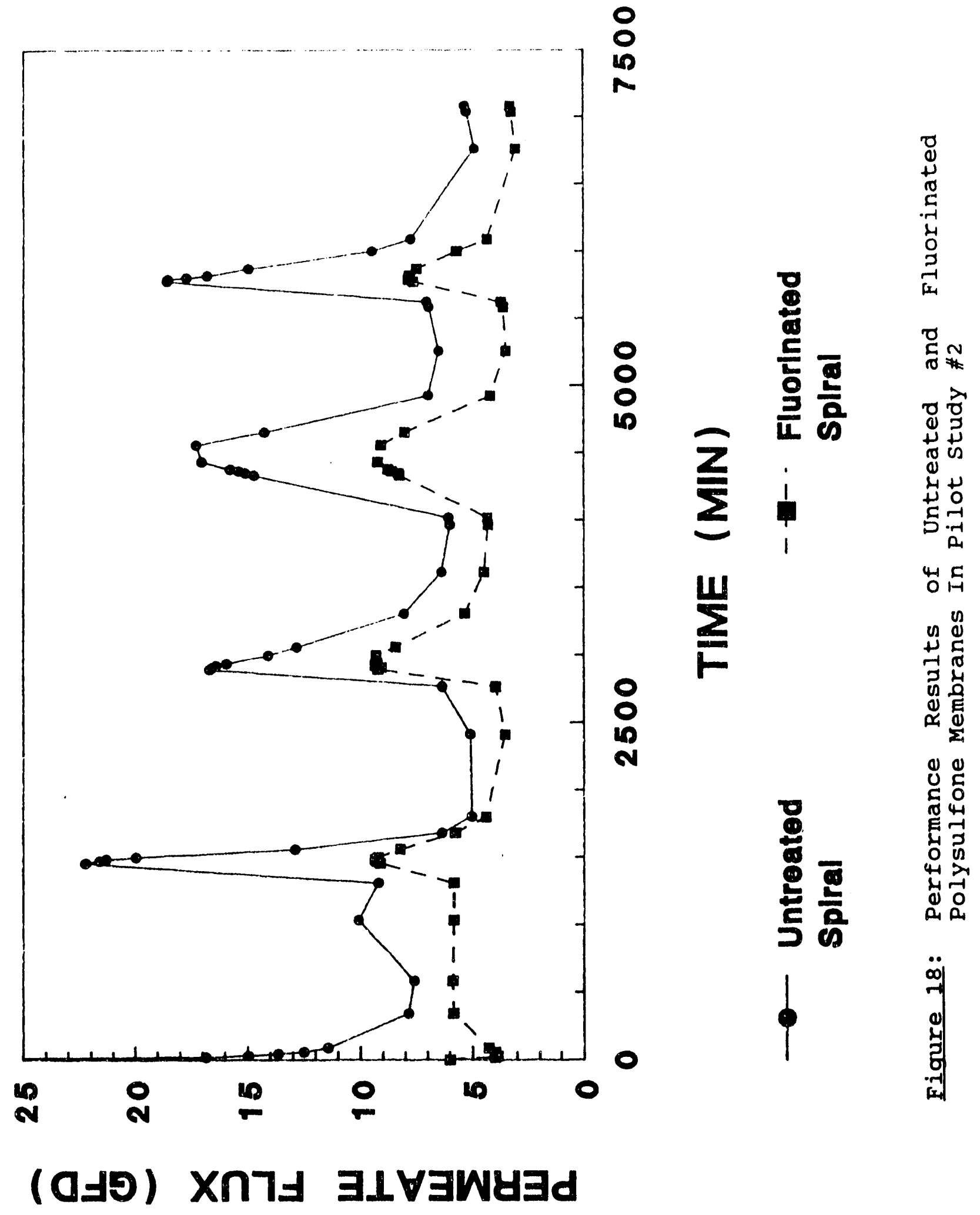




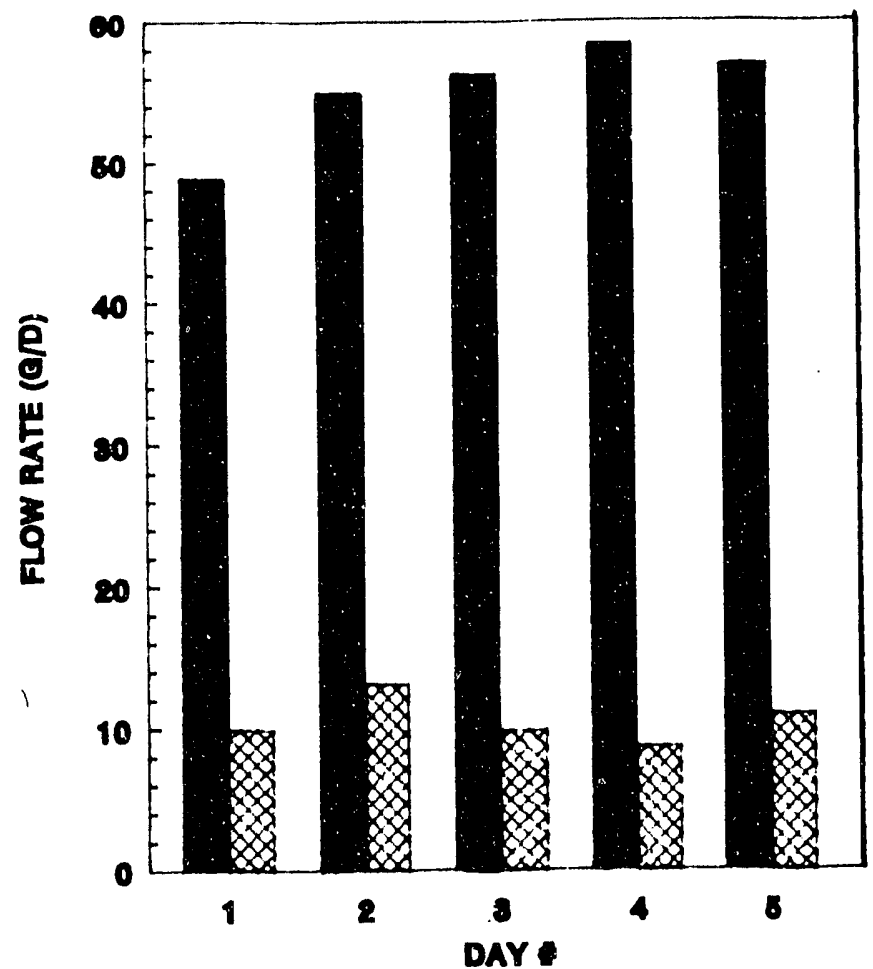

Untreated

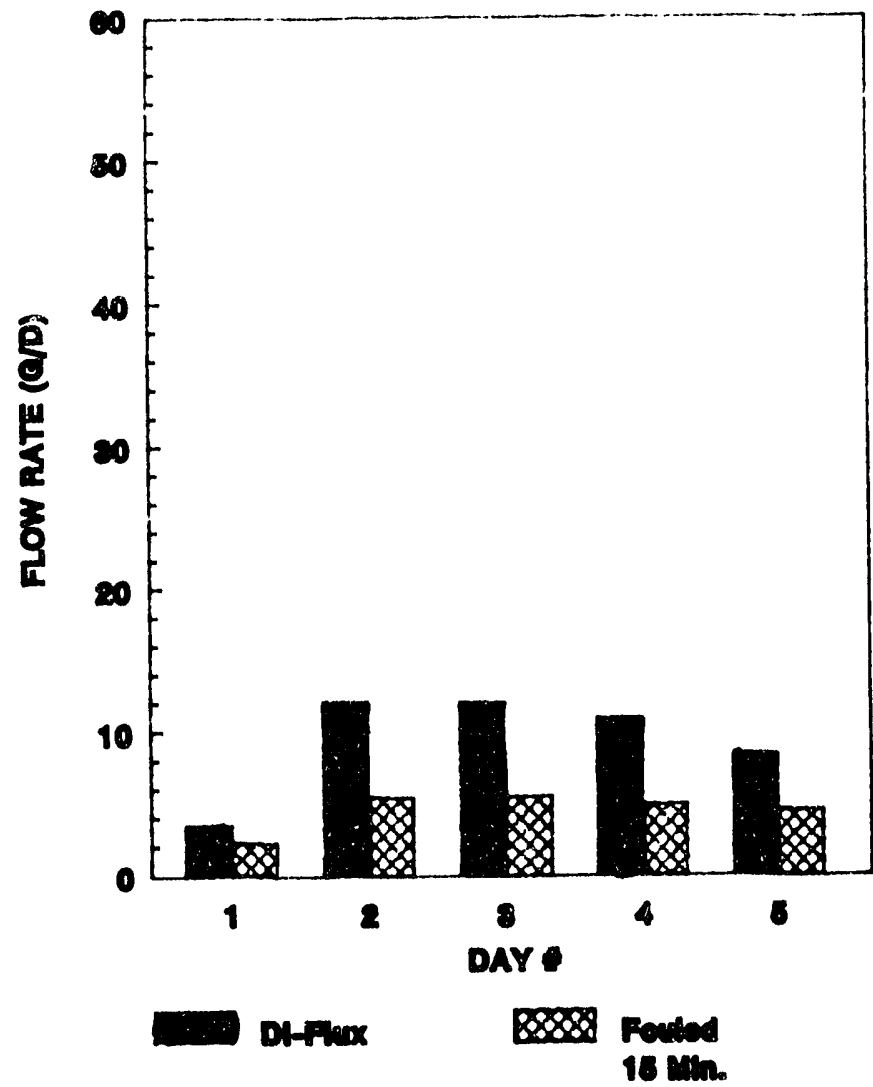

Fluorinated

Figure 19: DI Water and Permeate Flow Rates (15 Minute) of Untreated and Fluorinated Polysulfone Membranes In Pilot Study \#2 


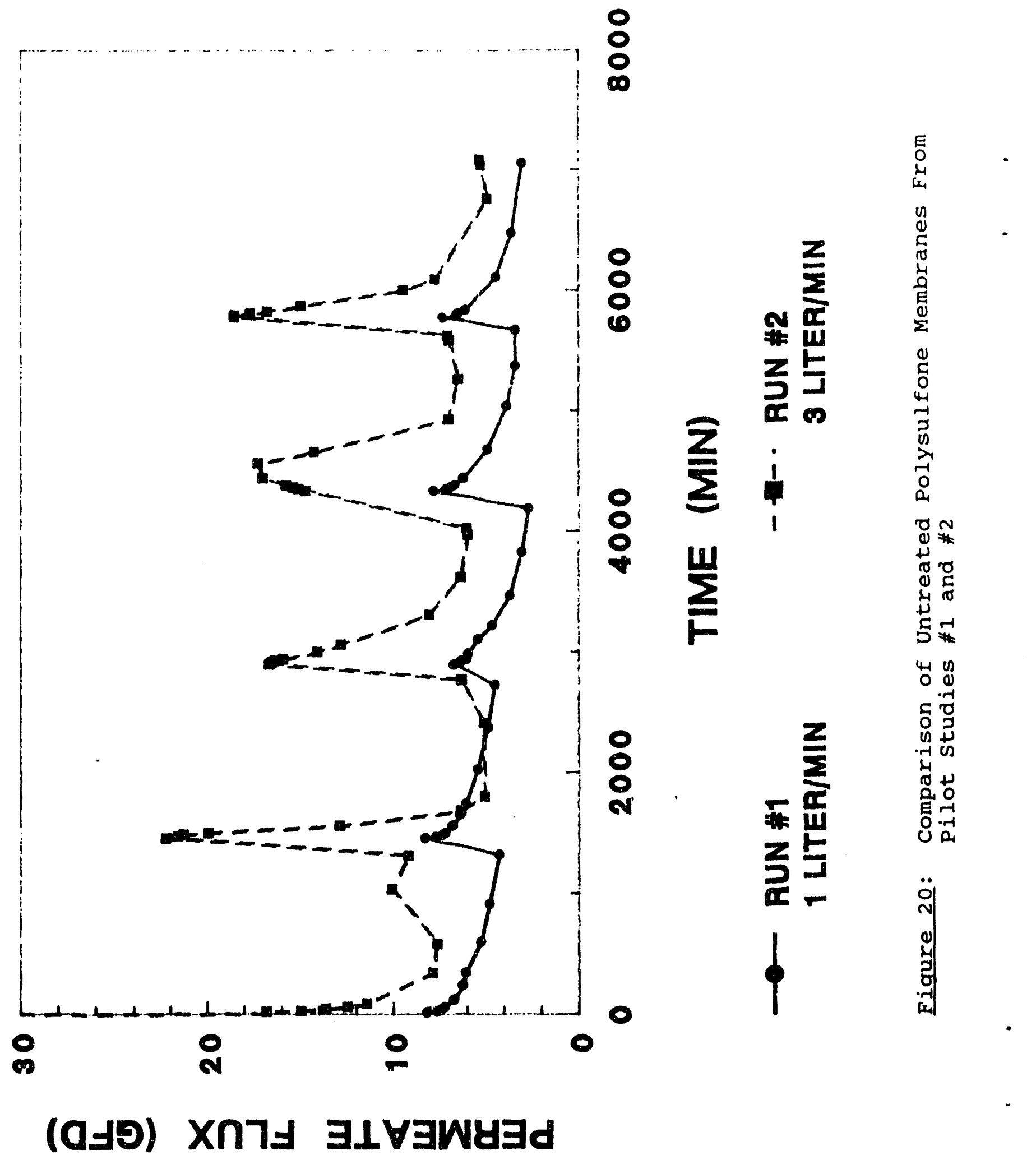




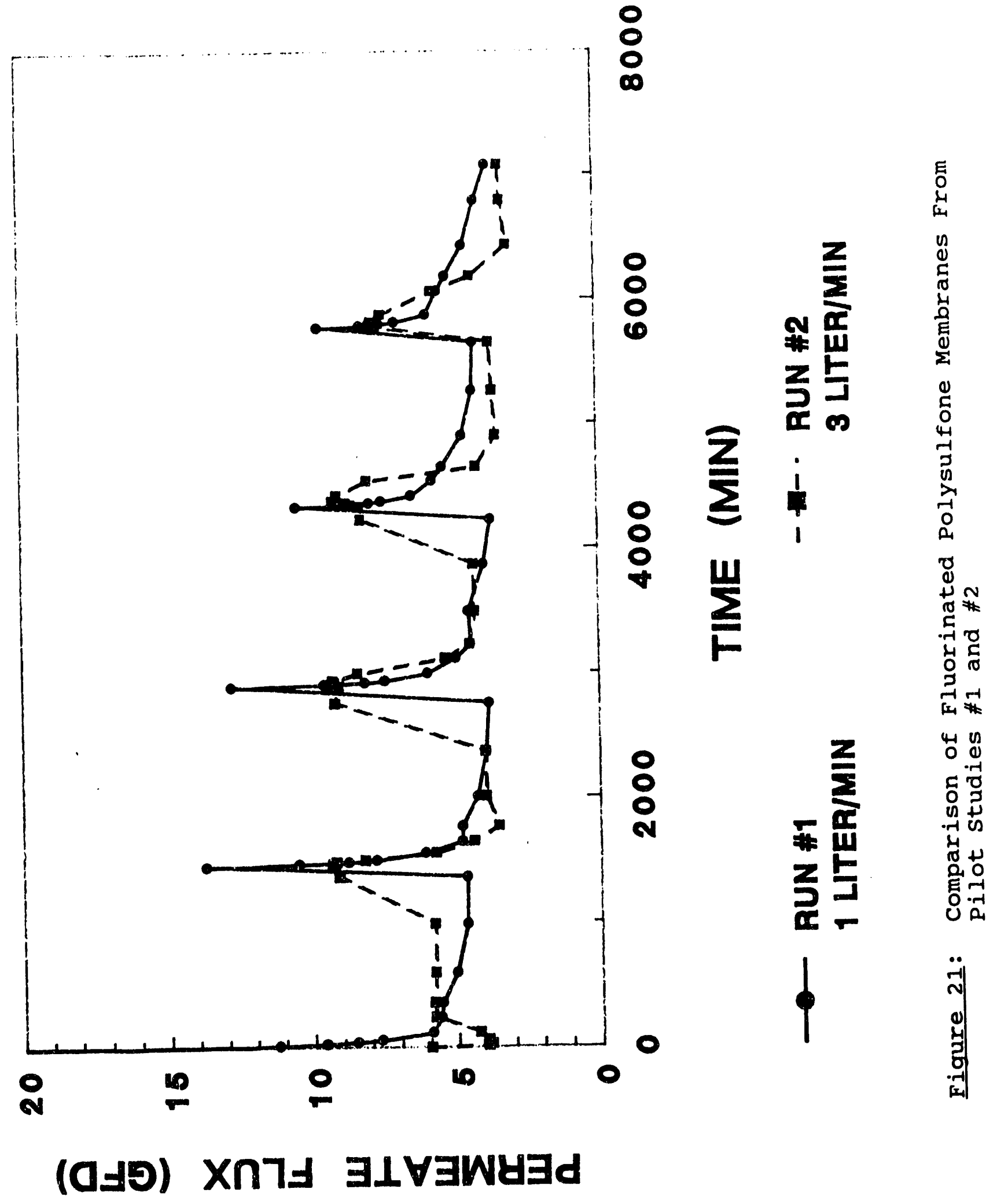




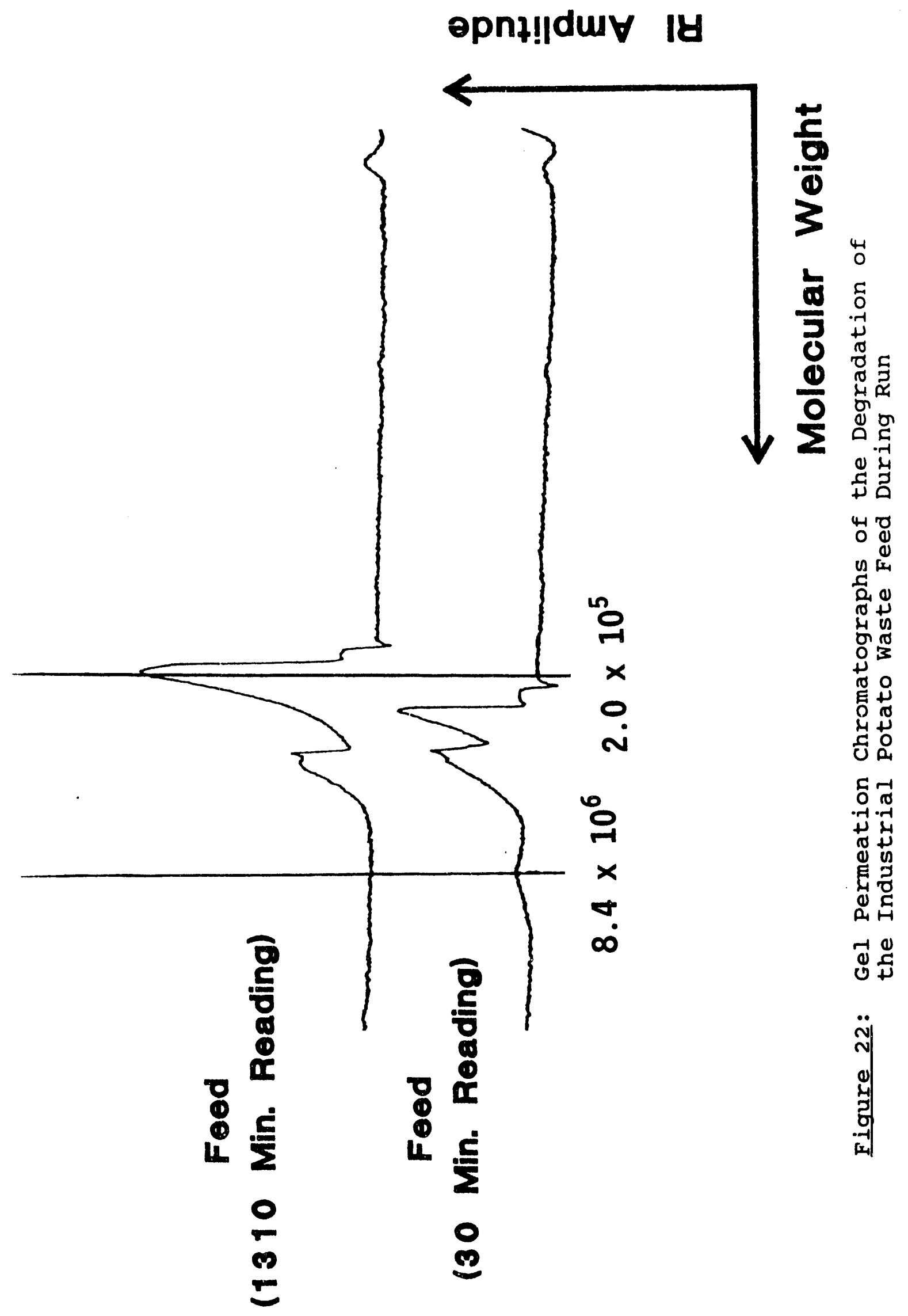




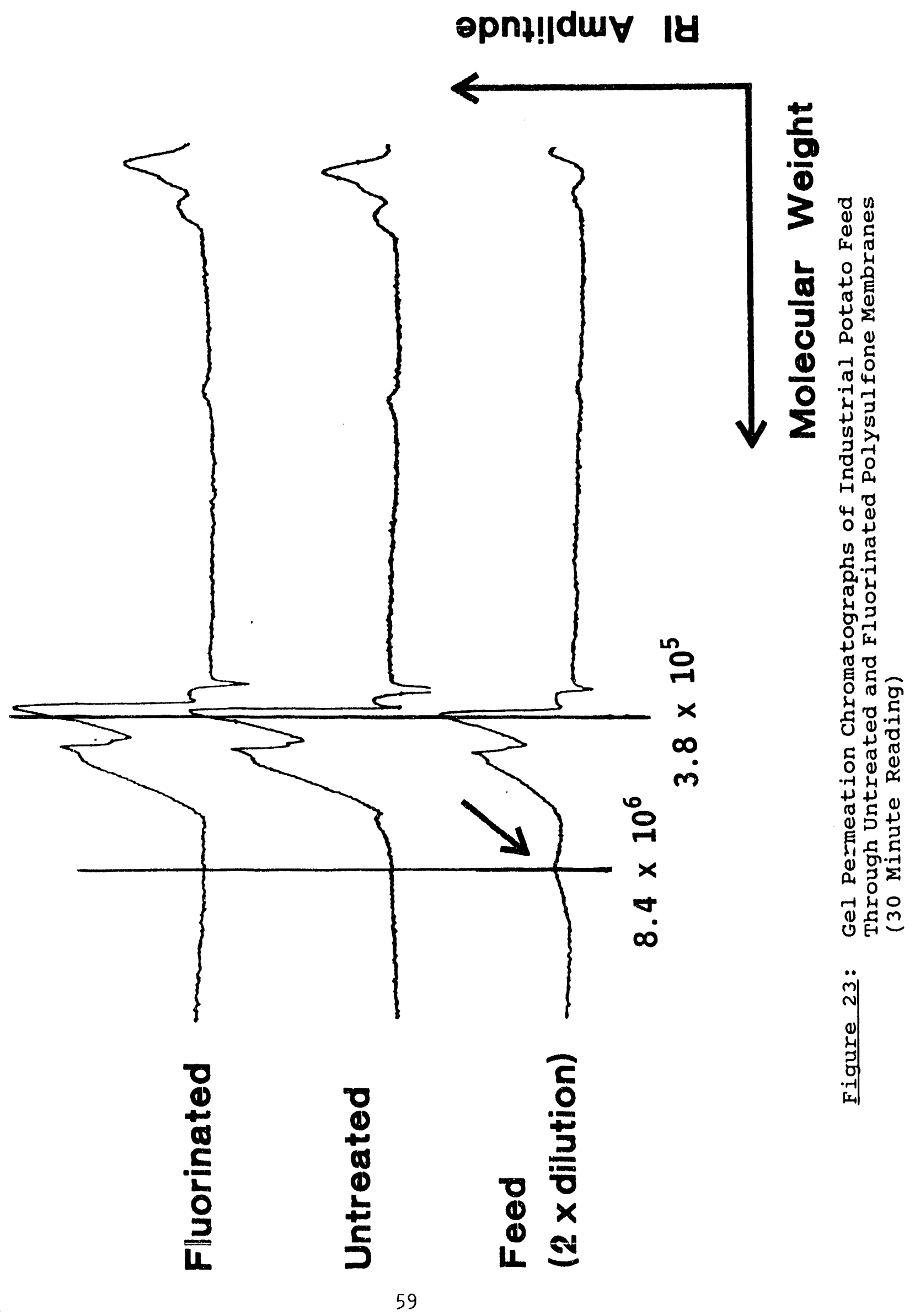




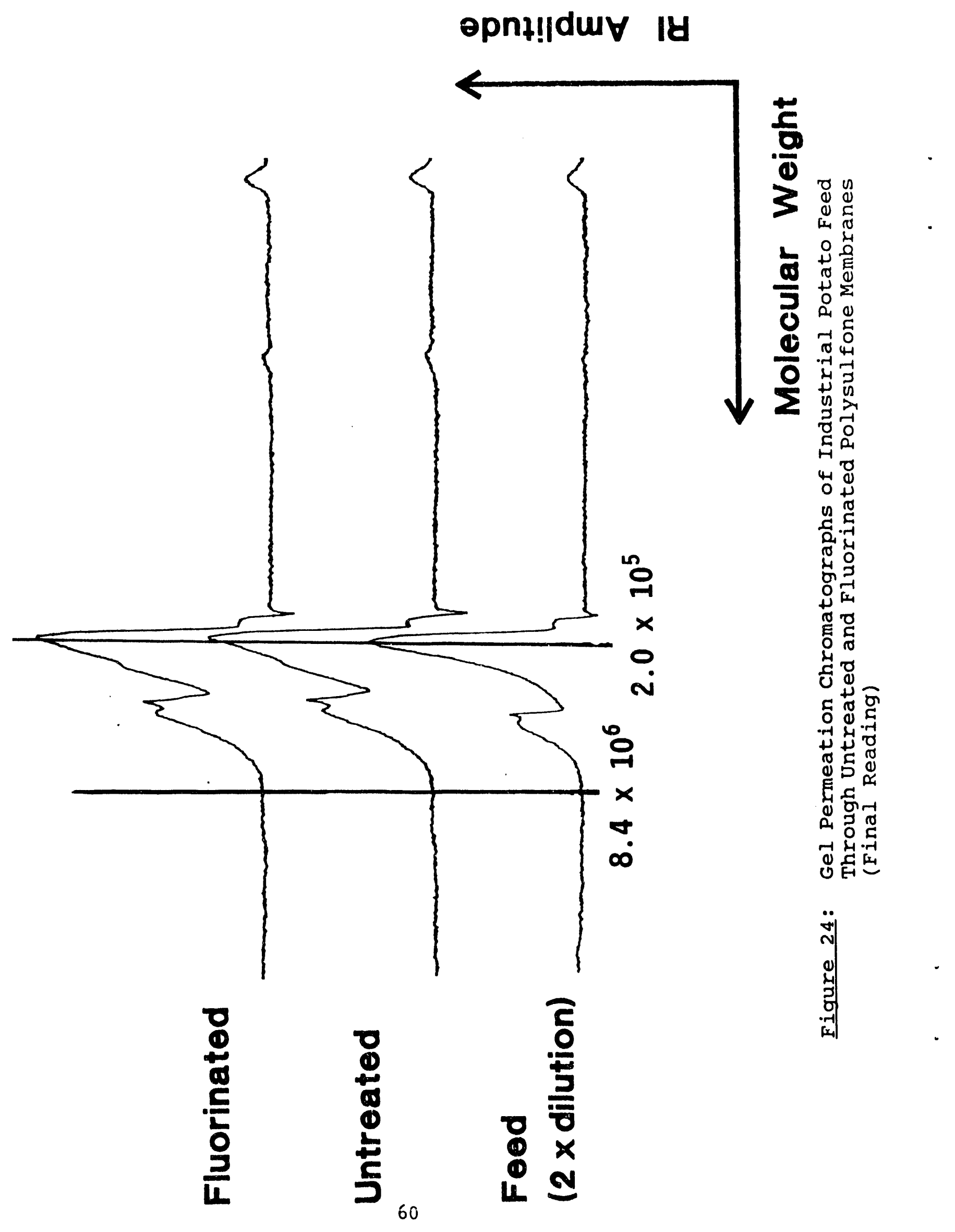




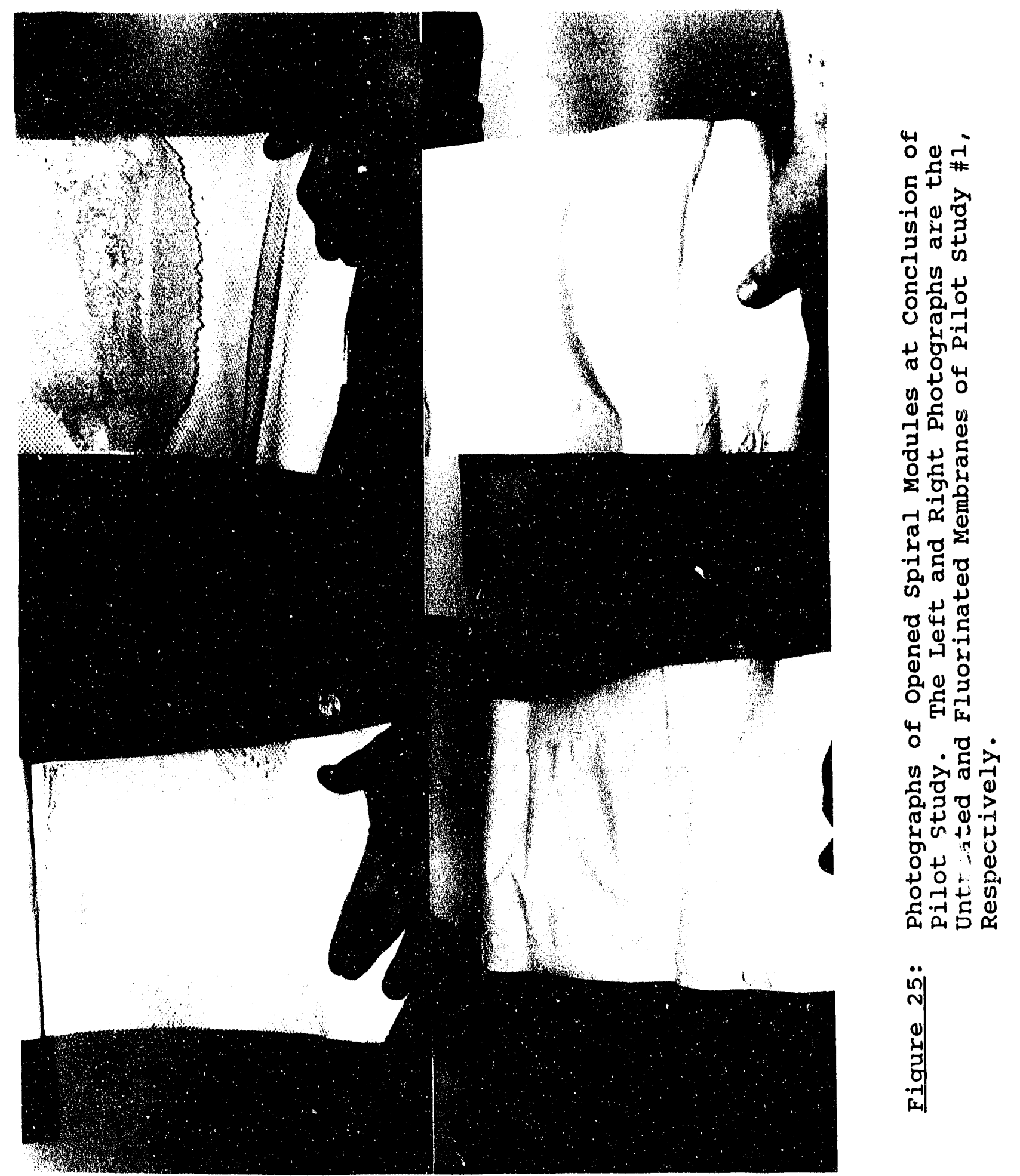




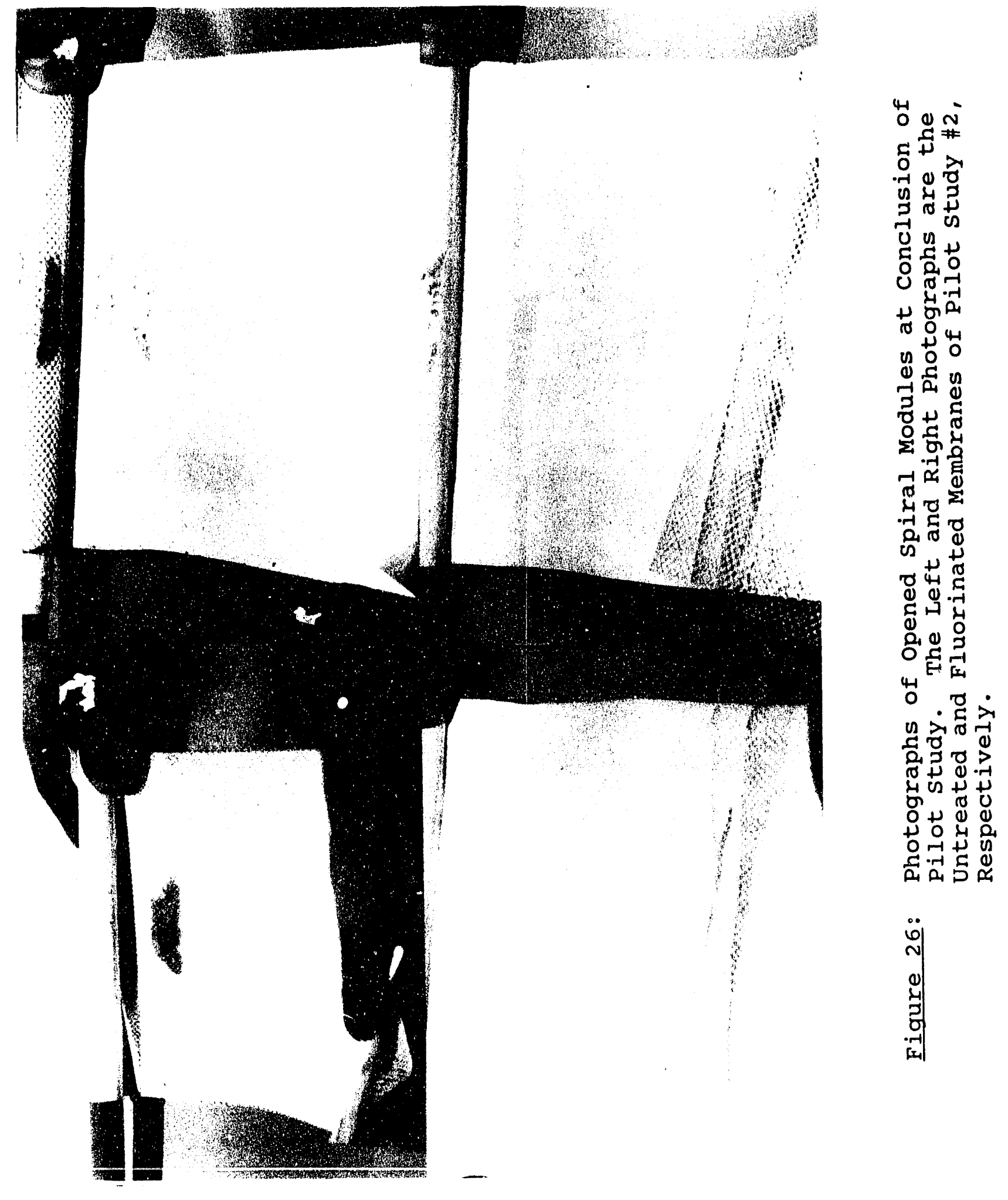



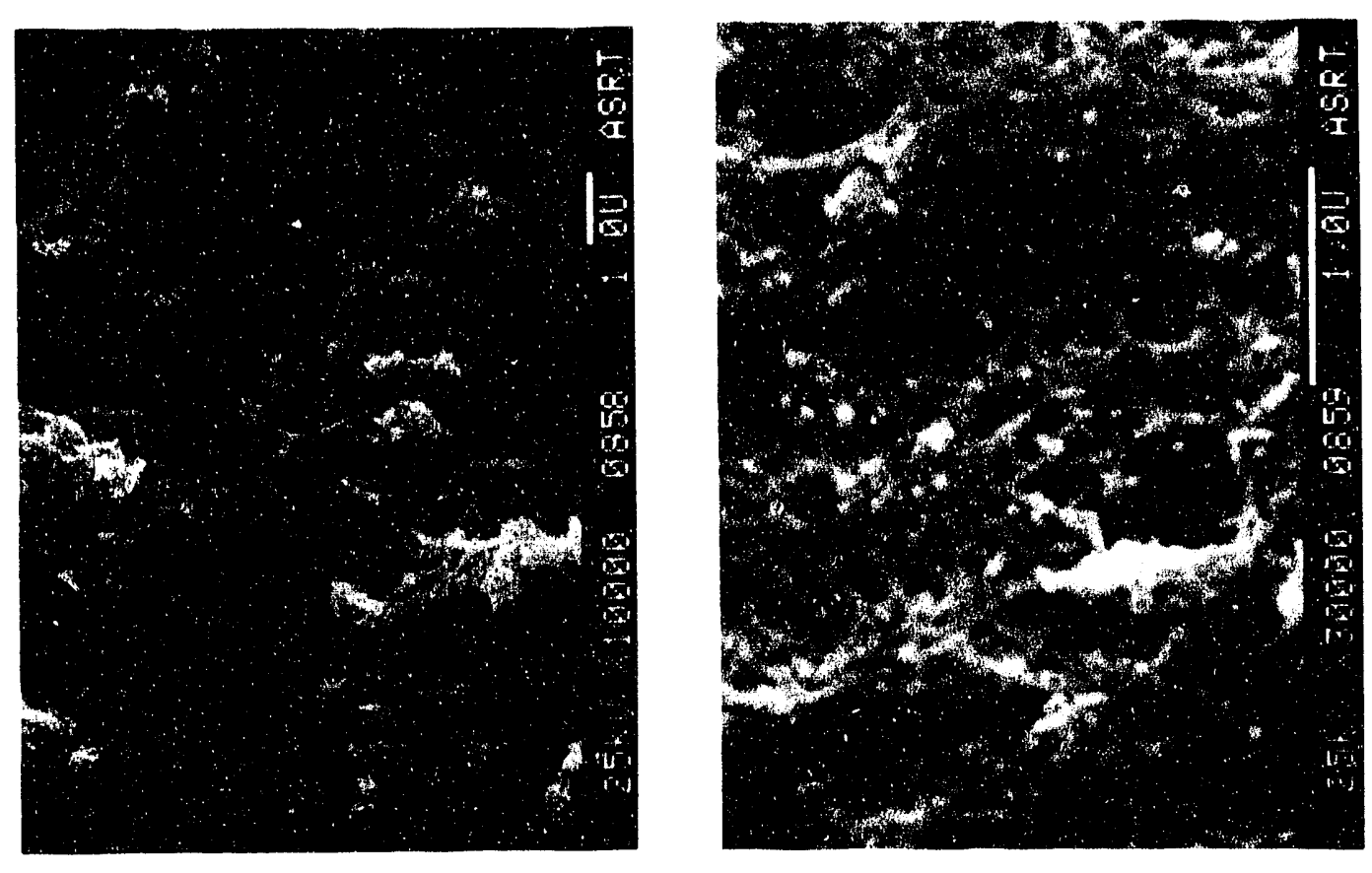

岂

ర్d

雚.

단

芯 김

ט

造
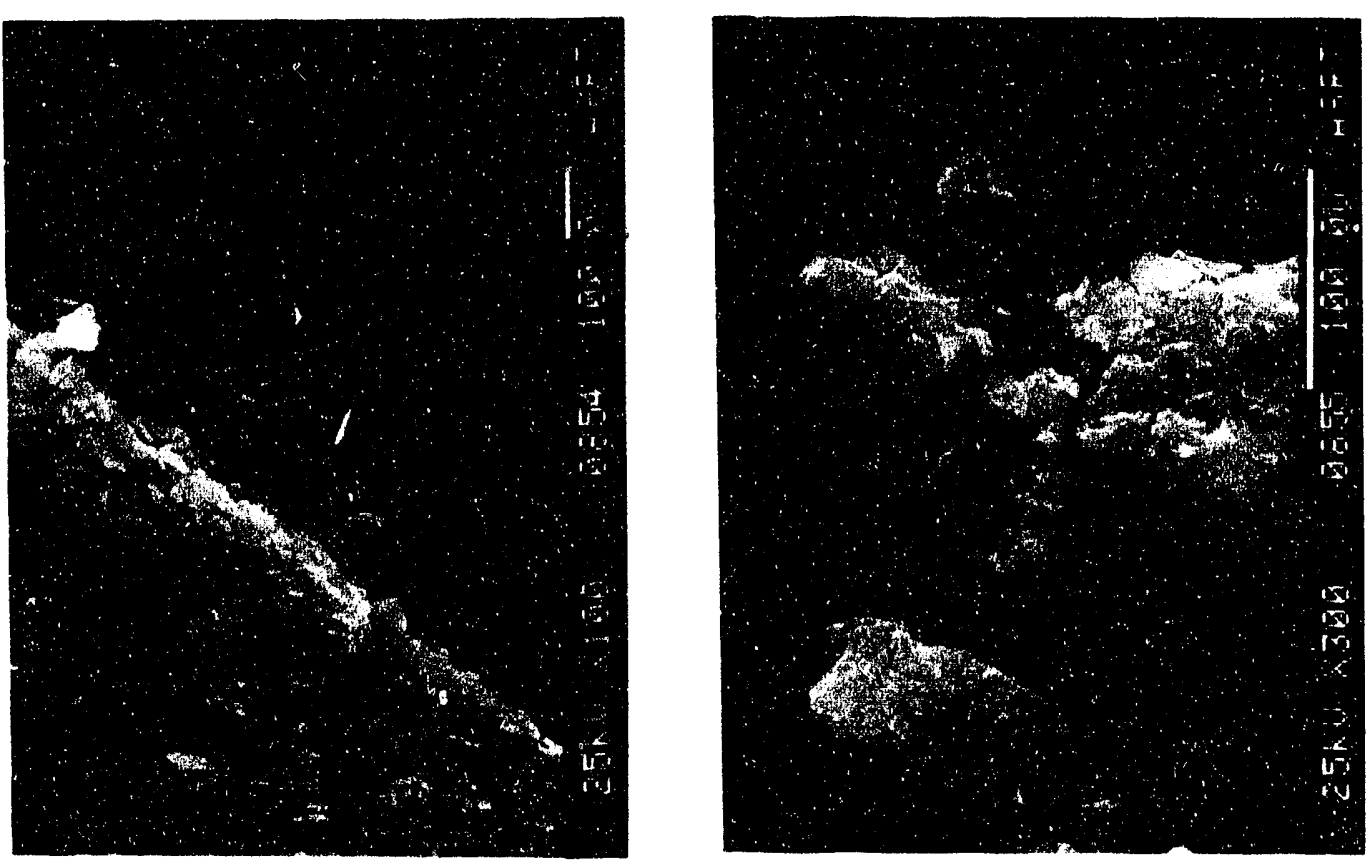

4ै 俩

u

दै

10

응

응

나. न

c) U

車

焉怘

ํ. 

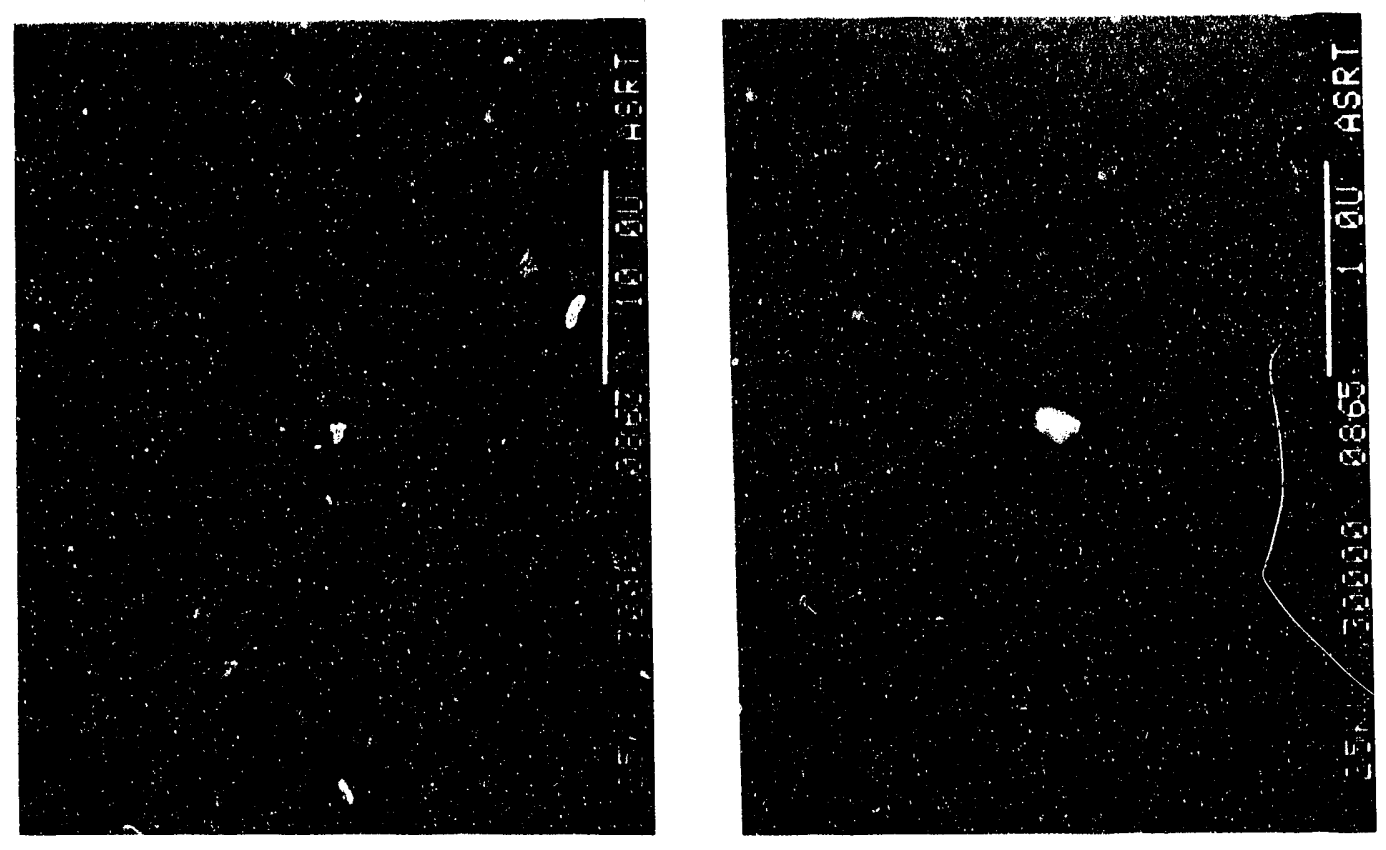

$\frac{1}{1}$

$+$

峁

ס

-

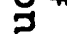

로 궁

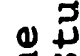
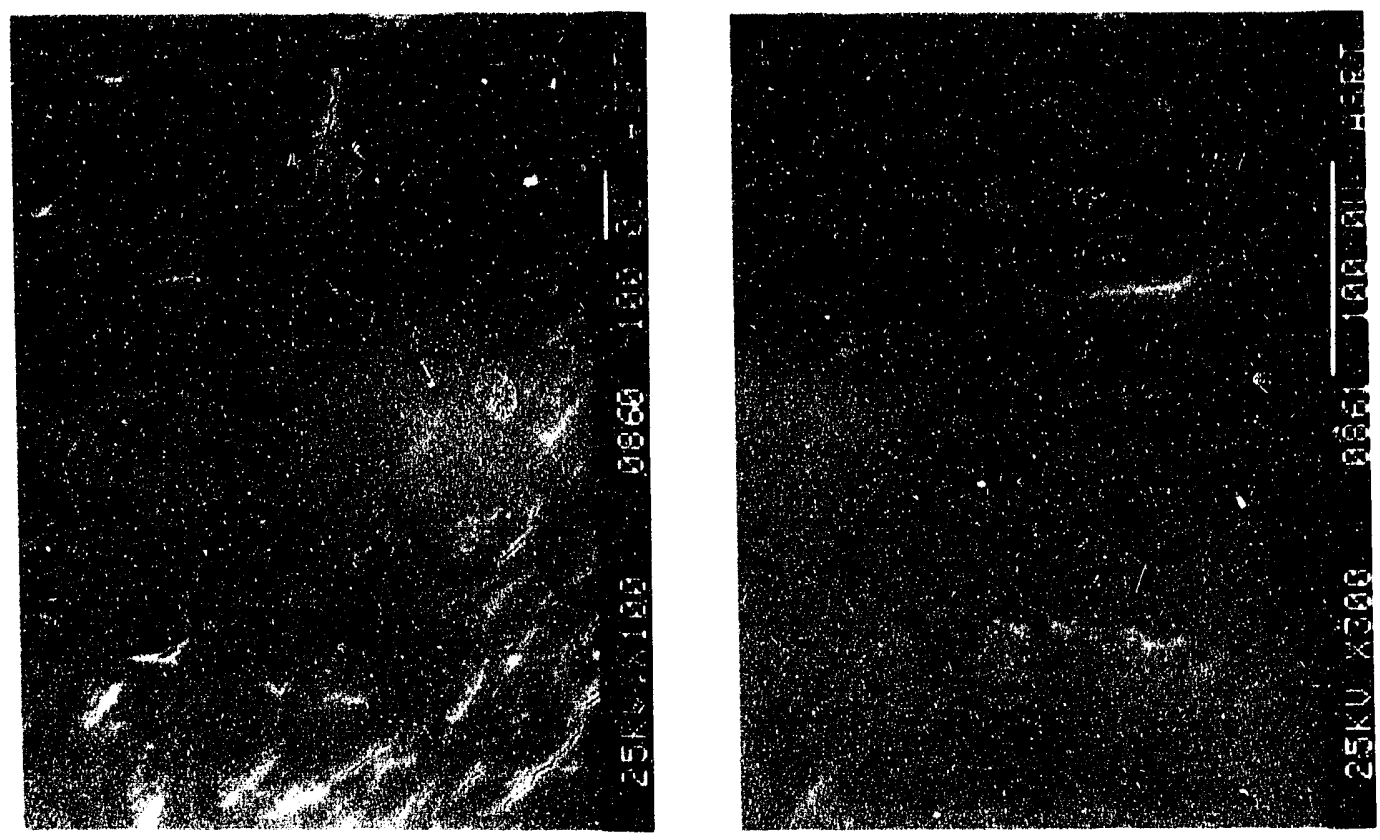

占的

4ै

U)

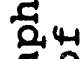

\%

茨

음

म्4.-1

- 5

20

퐁

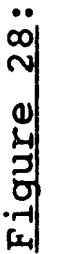




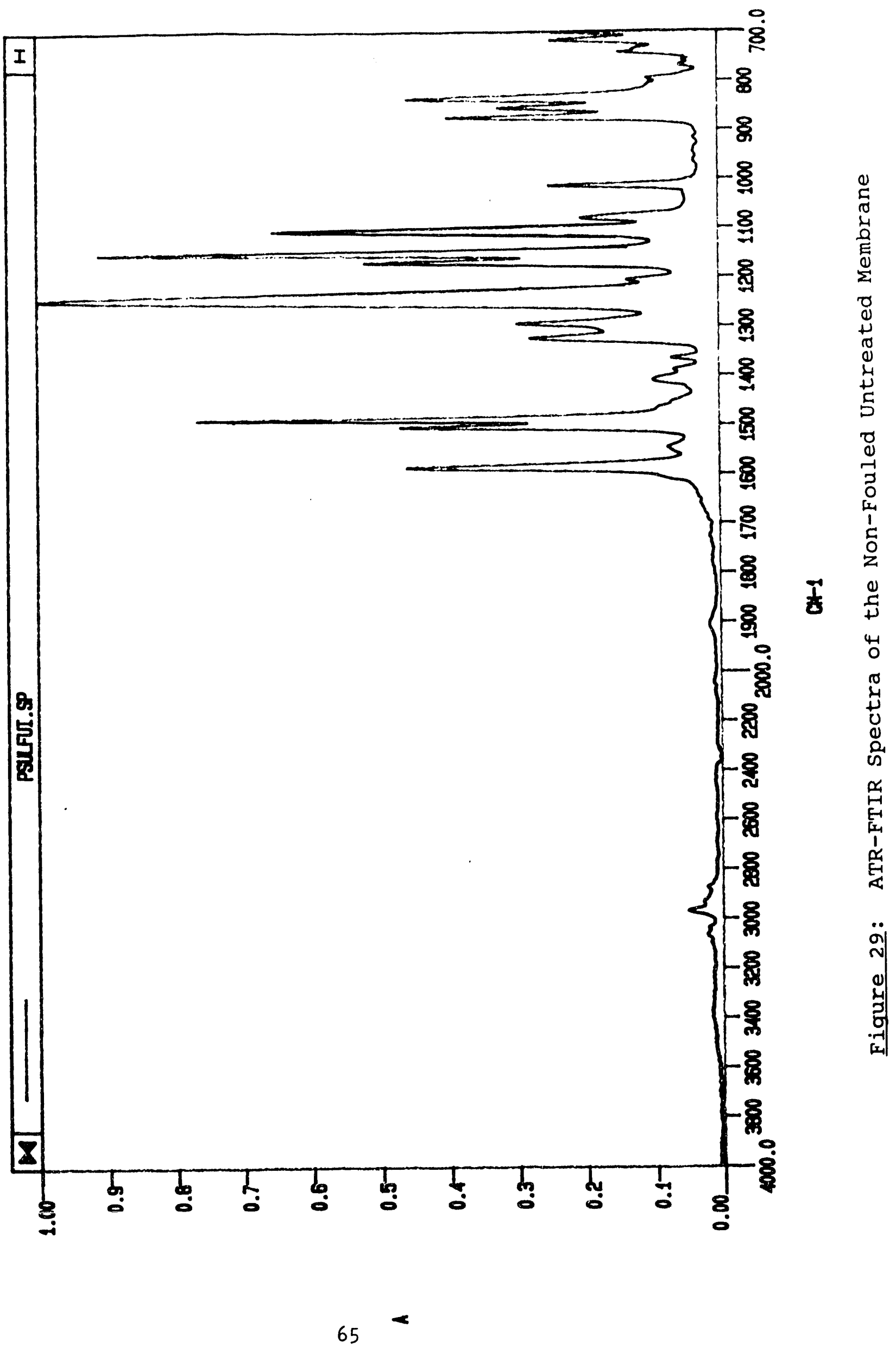




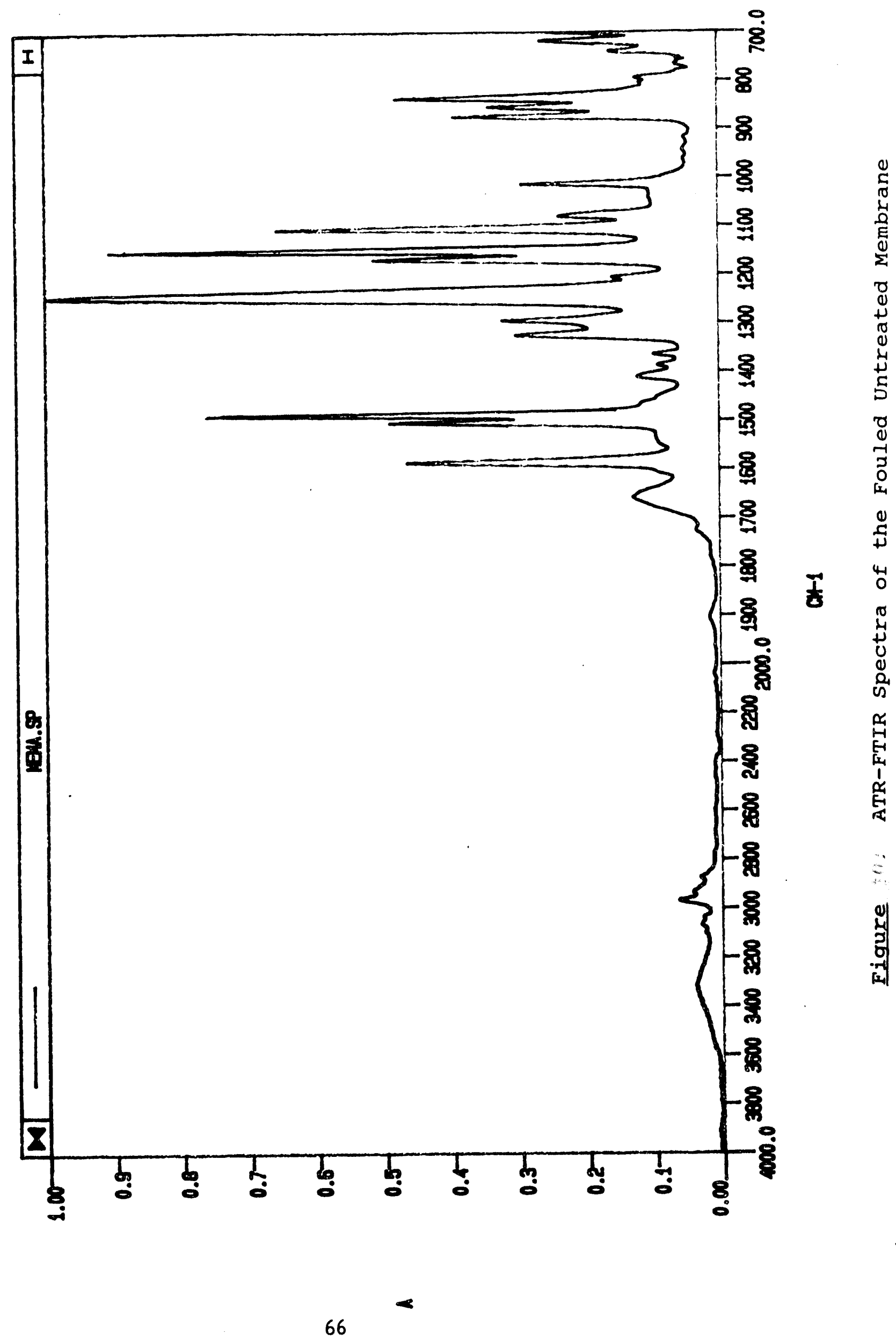




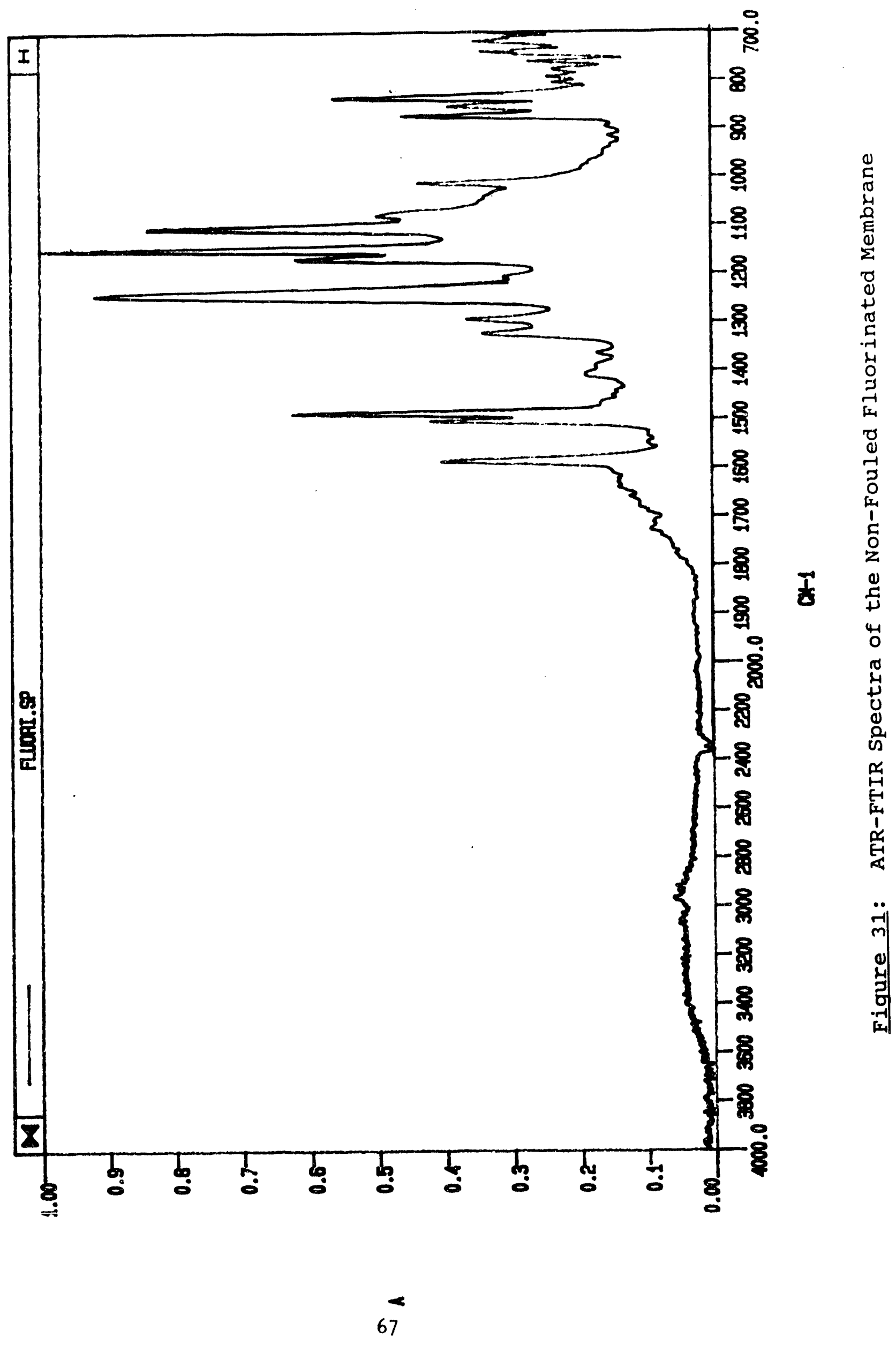




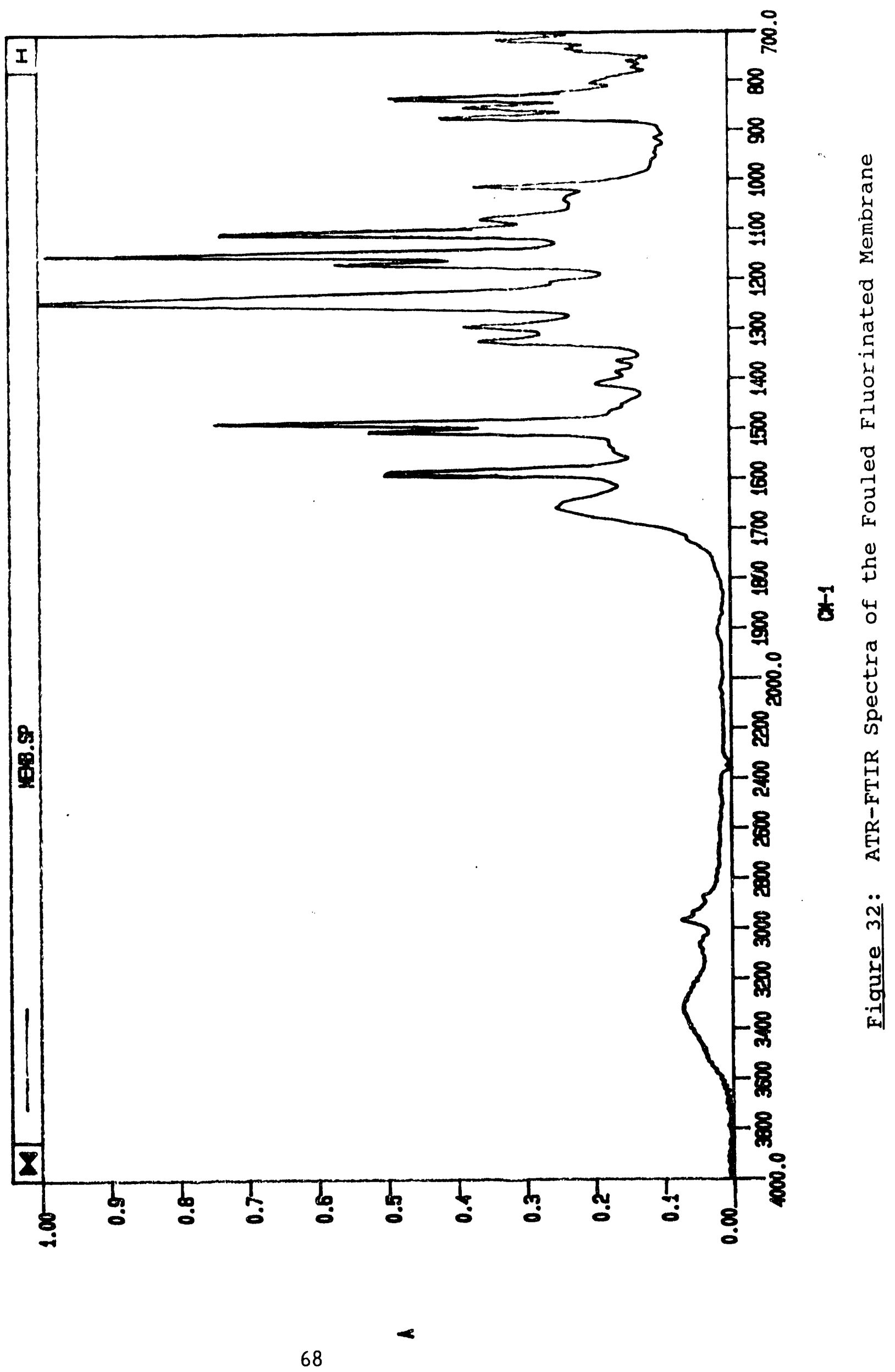




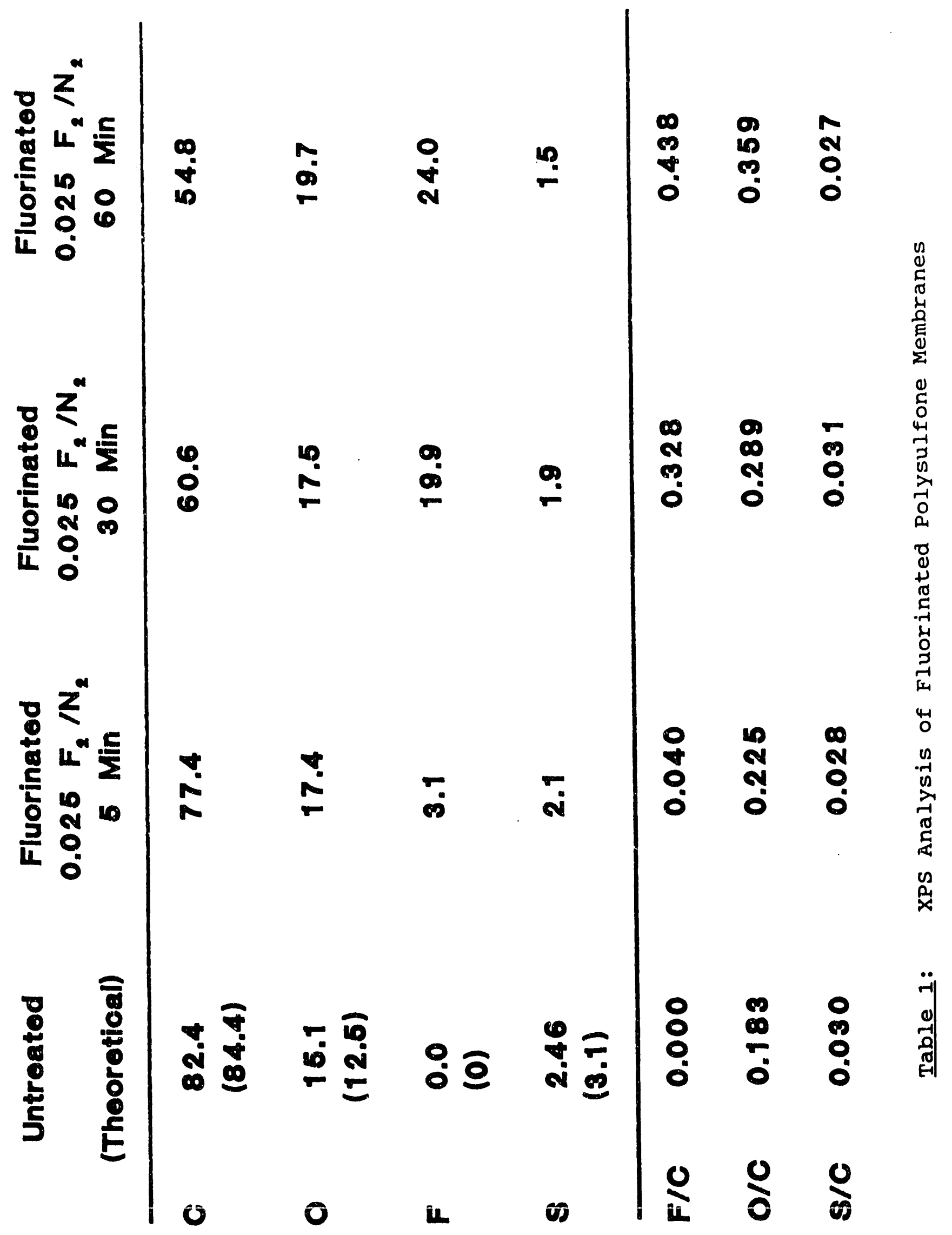



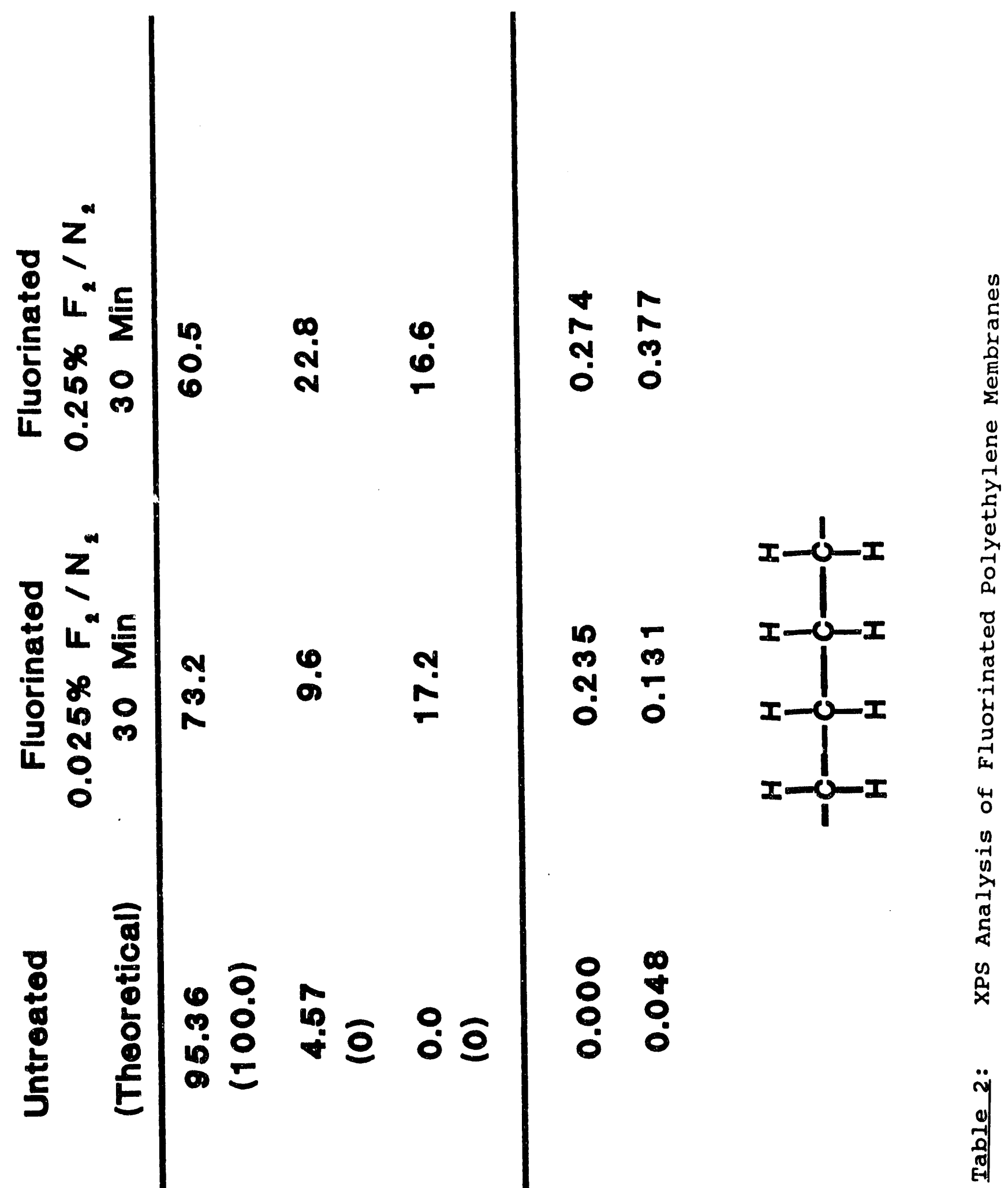

$0 \quad 0 \quad 4 \quad \frac{0}{1}$ 


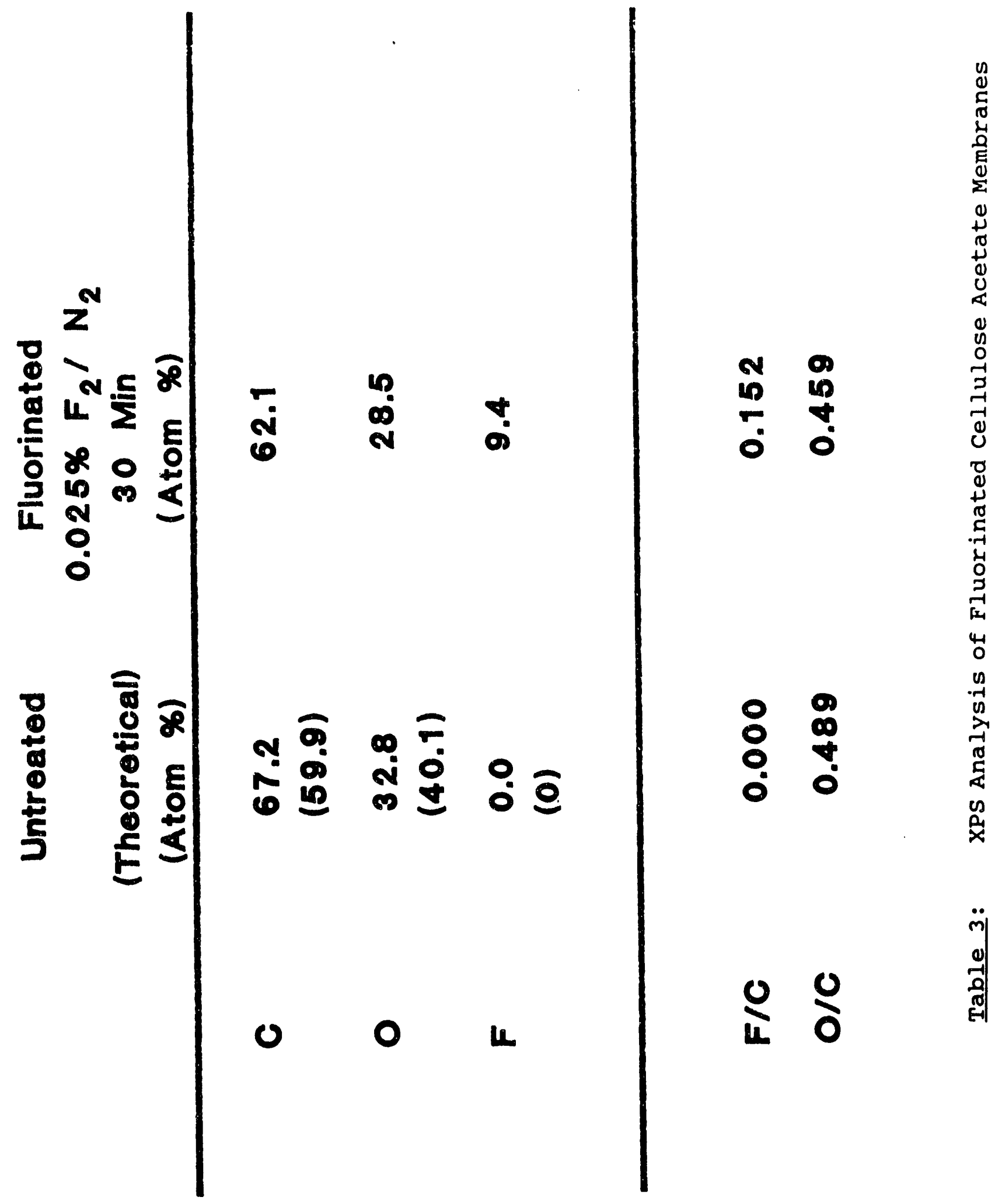


TABLE 4A: SURFACE APPEARANCE OF CLEAN AND FOULED MEMBRANES

\begin{tabular}{|c|c|c||}
\hline CLEANING PROCEDURE & $\begin{array}{c}\text { NON-FOULED } \\
\text { MEMBRANE }\end{array}$ & $\begin{array}{c}\text { FOULED } \\
\text { MEMBRANE }\end{array}$ \\
\hline $\begin{array}{c}\mathrm{H}_{2} \mathrm{SO}_{4} \\
(0.88)\end{array}$ & $\begin{array}{c}\text { CLEAN } \\
\text { GLOSSY }\end{array}$ & $\begin{array}{c}\text { CLEAN } \\
\text { POWDERY APPEARANCE }\end{array}$ \\
\hline $\begin{array}{c}\mathrm{NaOH} \\
(0.88)\end{array}$ & $\begin{array}{c}\text { CLEAN } \\
\text { GLOSSY }\end{array}$ & $\begin{array}{c}\text { CLEAN } \\
\text { GLOSSY }\end{array}$ \\
\hline $\begin{array}{c}\text { (LOROX } \\
(0.058)\end{array}$ & $\begin{array}{c}\text { CLEAN } \\
\text { GLOSSY }\end{array}$ & $\begin{array}{c}\text { CLEAN } \\
\text { SLIGHT POWDERY } \\
\text { APPEARANCE }\end{array}$ \\
\hline
\end{tabular}

TABLE 4B: XPS ANALYSIS OF WASHED POLYSULFONE MEMBRANES

\begin{tabular}{||l|c|c|c|c|c|}
\hline & CONTROL & $\begin{array}{c}\text { WATER } \\
\text { WASH }\end{array}$ & $\begin{array}{c}\mathrm{H}_{2} \mathrm{SO}_{4} \\
0.88\end{array}$ & $\begin{array}{c}\mathrm{NaOH} \\
0.88\end{array}$ & $\begin{array}{c}\text { CLOROX } \\
0.058\end{array}$ \\
\hline SULFUR & 1.7 & 2.1 & 3.5 & 2.4 & 2.0 \\
\hline CARBON & 61.0 & 69.1 & 68.1 & 72.1 & 70.9 \\
\hline NITROGEN & 1.5 & 1.7 & 1.2 & 1.9 & 1.7 \\
\hline OXYGEN & 18.1 & 16.7 & 19.6 & 15.4 & 15.6 \\
\hline FLUORINE & 17.6 & 10.5 & 7.5 & 8.7 & 8.9 \\
\hline CHI_ORINE & 0 & 0 & 0 & 0 & 1.0 \\
\hline S/C & 0.028 & 0.0291 & 0.0536 & 0.0339 & 0.0286 \\
\hline N/C & 0.0244 & 0.0252 & 0.0182 & 0.0189 & 0.0233 \\
\hline O/C & 0.2972 & 0.2419 & 0.2876 & 0.2137 & 0.2193 \\
\hline F/C & 0.2884 & 0.1514 & 0.1096 & 0.1213 & 0.1254 \\
\hline CL/C & 0 & 0 & 0 & 0 & 0.0140 \\
\hline
\end{tabular}


TABLE 5: XPS ANALYSIS OF FINAL PILOT STUDY MEMBRANES

\begin{tabular}{||l|c|c||}
\hline & $\begin{array}{c}\text { Untreated } \\
\text { Membrane }\end{array}$ & $\begin{array}{c}\text { Fluorinated } \\
\text { Membrane }\end{array}$ \\
\hline SULFUR & 1.9 & 1.2 \\
\hline CARBON & 75.3 & 68.5 \\
\hline NITROGEN & 6.3 & 7.9 \\
\hline OXYGEN & 16.0 & 19.6 \\
\hline FLUORINE & 0.0 & 2.8 \\
\hline CHLORINE & Trace & Trace \\
\hline S/C & 0.0246 & 0.0172 \\
\hline N/C & 0.0837 & 0.1159 \\
\hline O/C & 0.2128 & 0.2854 \\
\hline F/C & - & 0.0413 \\
\hline
\end{tabular}




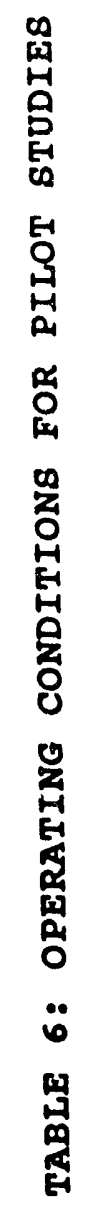

\begin{tabular}{|c|c|c|c|}
\hline 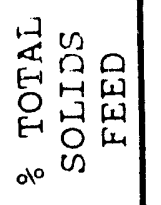 & $\begin{array}{l}a \\
0\end{array}$ & $\stackrel{\sim}{\sim}$ & $\begin{array}{l}\varphi \\
\dot{0}\end{array}$ \\
\hline 品染 & $\begin{array}{l}m \\
\dot{\sigma}\end{array}$ & $\stackrel{\text { nn. }}{\dot{n}}$ & $\begin{array}{l}0 \\
\dot{\varphi}\end{array}$ \\
\hline 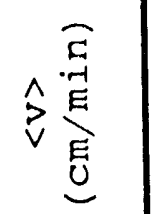 & $\begin{array}{l}0 \\
0 \\
0 \\
n \\
-1\end{array}$ & $\stackrel{m}{r}$ & $\begin{array}{l}0 \\
0 \\
\\
7\end{array}$ \\
\hline 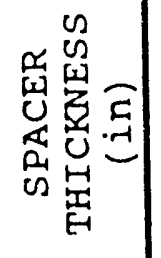 & $\begin{array}{l}0 \\
\mathbf{0} \\
\mathrm{o}\end{array}$ & $\begin{array}{l}-1 \\
0 \\
0\end{array}$ & $\begin{array}{l}-1 \\
0 \\
0 \\
0\end{array}$ \\
\hline 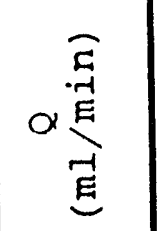 & $\begin{array}{l}0 \\
0 \\
\stackrel{n}{N}\end{array}$ & $\underset{\sim}{-1}$ & $\begin{array}{l}\text { : } \\
\stackrel{\circ}{N} \\
\text { }\end{array}$ \\
\hline 嵒拿 & $\begin{array}{l}\circ \\
\circ \\
-1\end{array}$ & $\stackrel{\text { N }}{ }$ & $\stackrel{i}{N}$ \\
\hline $\begin{array}{l}\text { 易 } \\
\text { 帠 }\end{array}$ & 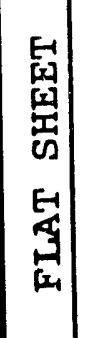 & 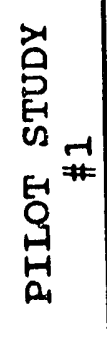 & 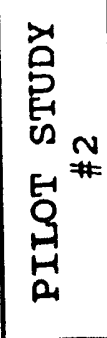 \\
\hline
\end{tabular}




\section{Appendix A}


Appendix P.1: Simulated Potato Feed

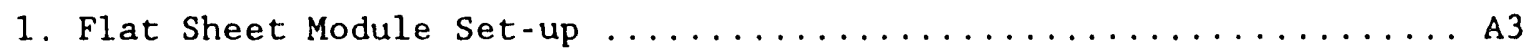

2. Initial Flat Sheet Test: Data Sheet $\ldots \ldots \ldots \ldots \ldots \ldots \ldots \ldots \ldots \ldots \ldots$

a. DI Water Flux Through Untreated and Fluorinated PS Membranes .. A4

b. Permeate Flux Through Untreated and Fluorinated PS Membranes .. A5

c. Normalized Permeate Flux through PS Membranes ............ A6

d. Log-Log Permeate Flux versus Log Time (Fouling Behavior) ...... A7

3. Flat Sheet Screening Runs I: Data Sheet $\ldots \ldots \ldots \ldots \ldots \ldots \ldots \ldots$

a. DI Water Flux Through Untreated and Fluorinated PS Membranes .. A9

b. Permeate Flux Through Untreated and Fluorinated PS Membranes. AlO

c. Log-Log Permeate Flux versus Log Time (Fouling Behavior) ..... Al1

4. Flat Sheet Screening Runs II: Data Sheet $\ldots \ldots \ldots \ldots \ldots \ldots \ldots \ldots$ A12

a. DI Water Flux Through Untreated and Fluorinated PS Membranes . A13

b. Permeate Flux Through Untreated and Fluorinated PS Membranes . A14

c. Log-Log Permeate Flux versus Log Time (Fouling Behavior) ..... A15

\section{Appendix A2: Process Potato Feed}

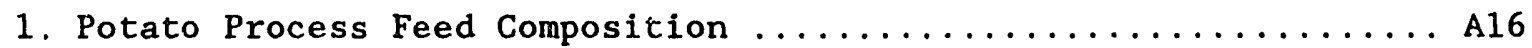

2. Industrial Feed (Slicer)

Table A2-1A: Membrane Specification (Silcer Stream).......... A17

a. DI Water Flux Through Untreated and Fluorinated PS Membranes . A18

b. Permeate Flux Through Untreated and Fluorinated PS Membranes . A19

Table A2-1B: COD and Nitrogen Rejection (S1icer Stream) ....... A20

Table A2-1C: DI Water and Permeate Fluxes (Slicer) .......... A21

3. Industrial Feed (Barre1)

Table A2-2A: Membrane Specification (Barrel Stream).......... A22

a. DI Water Flux Through Untreated and Fluorinated PS Membranes . A23

b. Permeate Flux Through Untreated and Fluorinated PS Membranes . A24

Table A2-2B: COD and Nitrogen Rejection (Barrel Stream) ....... A25

Table A2-2C: DI Water and Permeate Fluxes (Barrel) .......... A26 
4. Industrial Feed ( $\mathrm{Bl}$ ancher)

Table A2-2A: Membrane Specification (Blancher Stream)........ A27 a. DI Water Flux Through Untreated and Fluorinated PS Membranes . A28 b. Permeate Flux Through Untreated and Fluorinated PS Membranes . A29 Table A2-2B: COD and Nitrogen Rejection (Blancher Stream) ....A A30 Table A2-2C: DI Water and Permeate Fluxes (Blancher) ........A31 


\section{Flat Sheet Module Set-up}

The flat sheet module set-up consisted of 3 or 6 single cell modules (See Figure 4) connected in series. The feed stream flow went sequentially from membrane cell \#1 to membrane cell \#6 and back to the feed tank. The flow rate of feed was approximately 2.51 iters/minute. A typical permeate flow rate during a run with the potato waste was $2.2 \mathrm{ml} / \mathrm{min}$ ( $40 \mathrm{GFD}$ ) through the membrane, and the trans-membrane pressure drop was 100 psi.

\section{Initial Flat Sheet Test \\ Data Sheet}

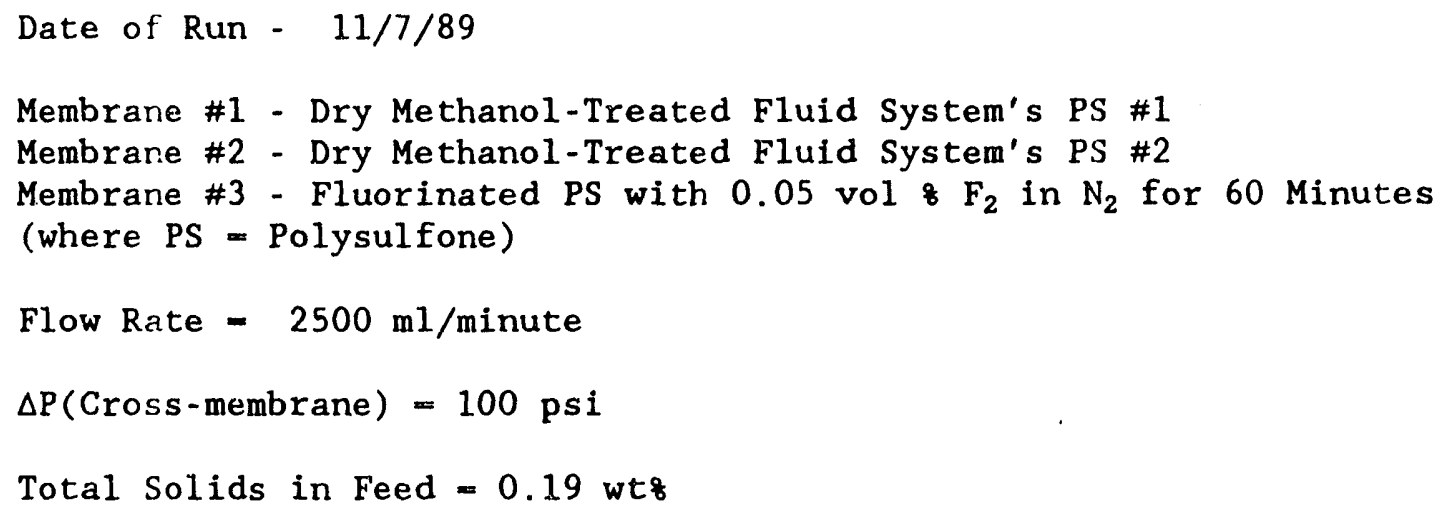




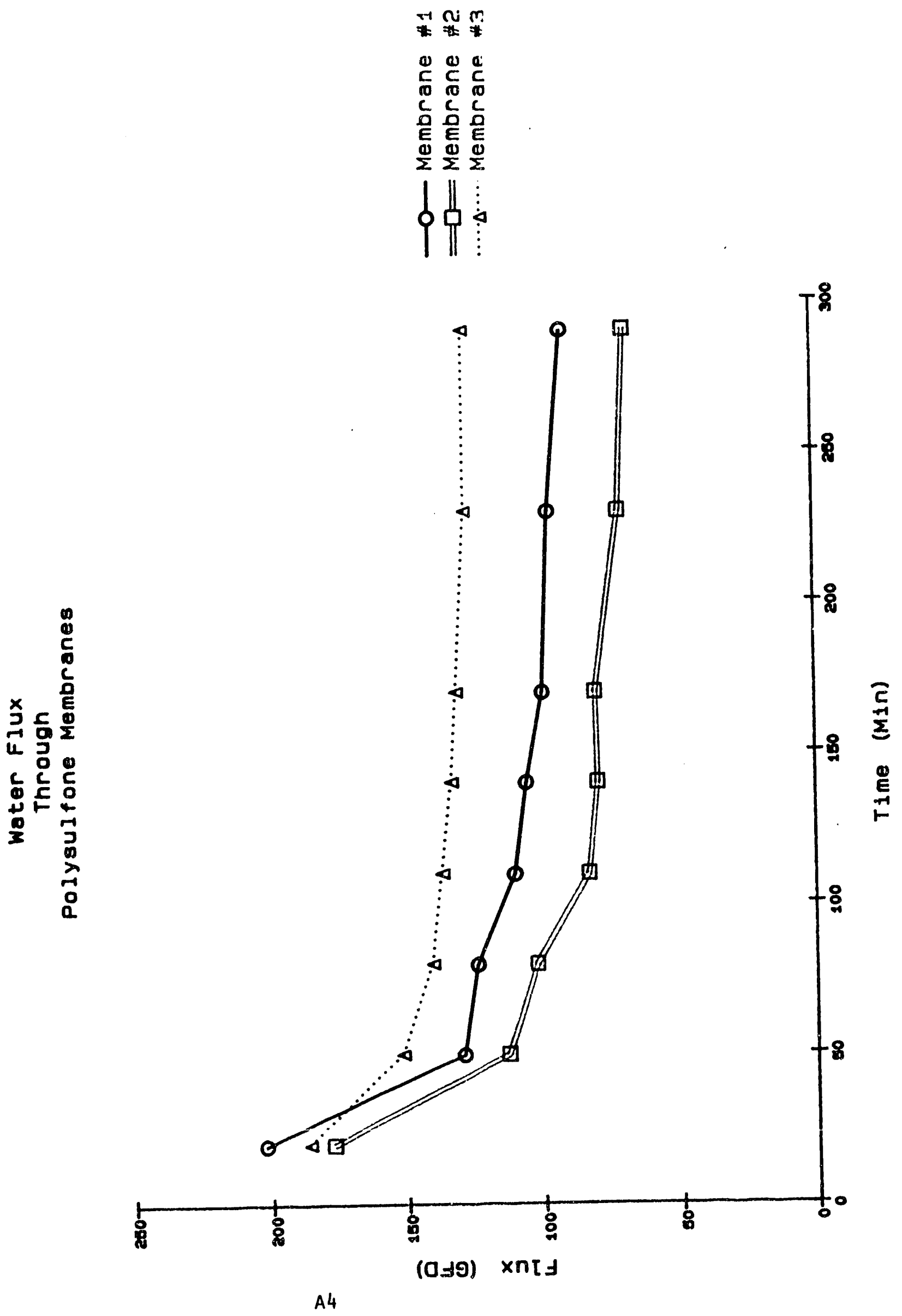




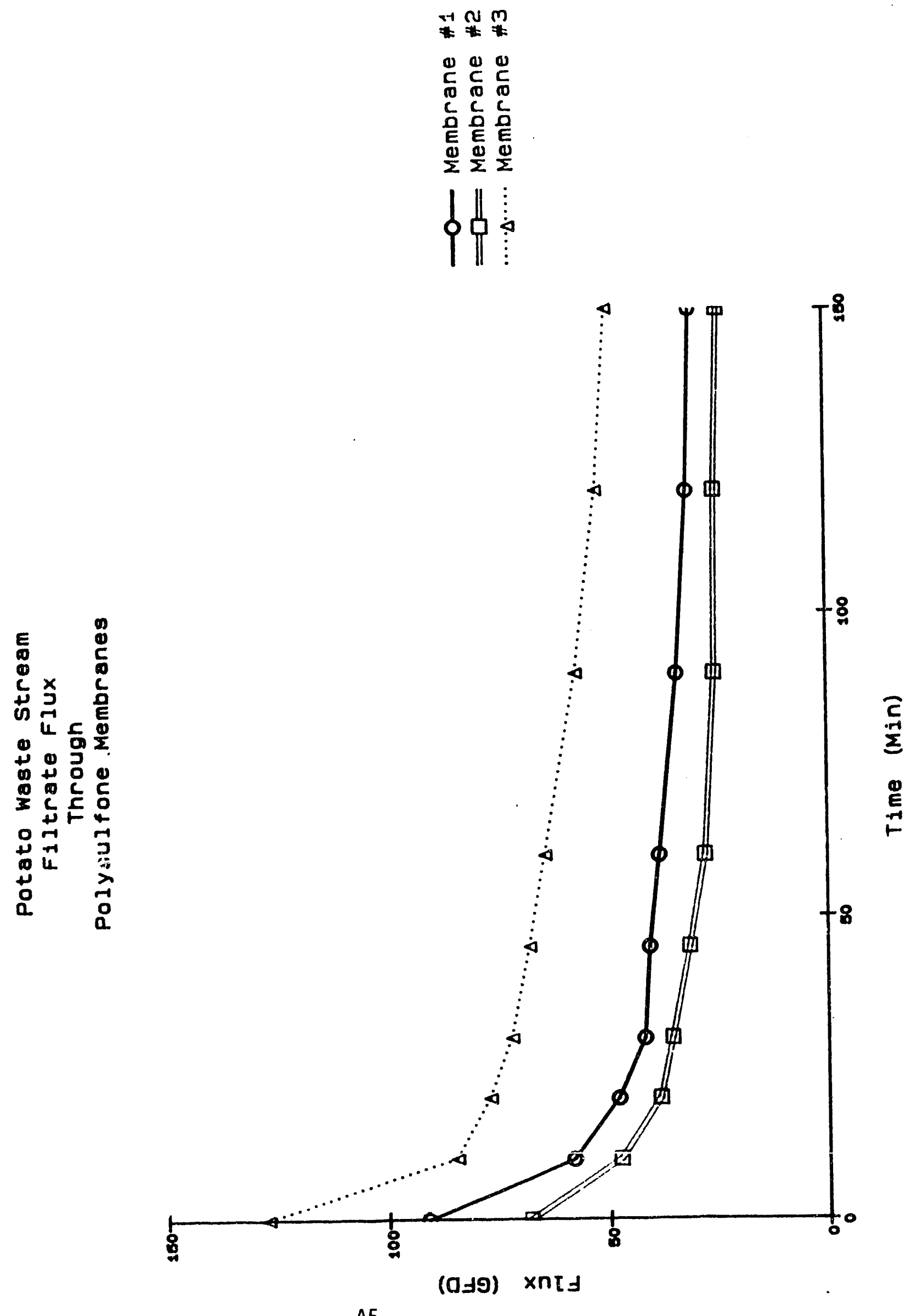




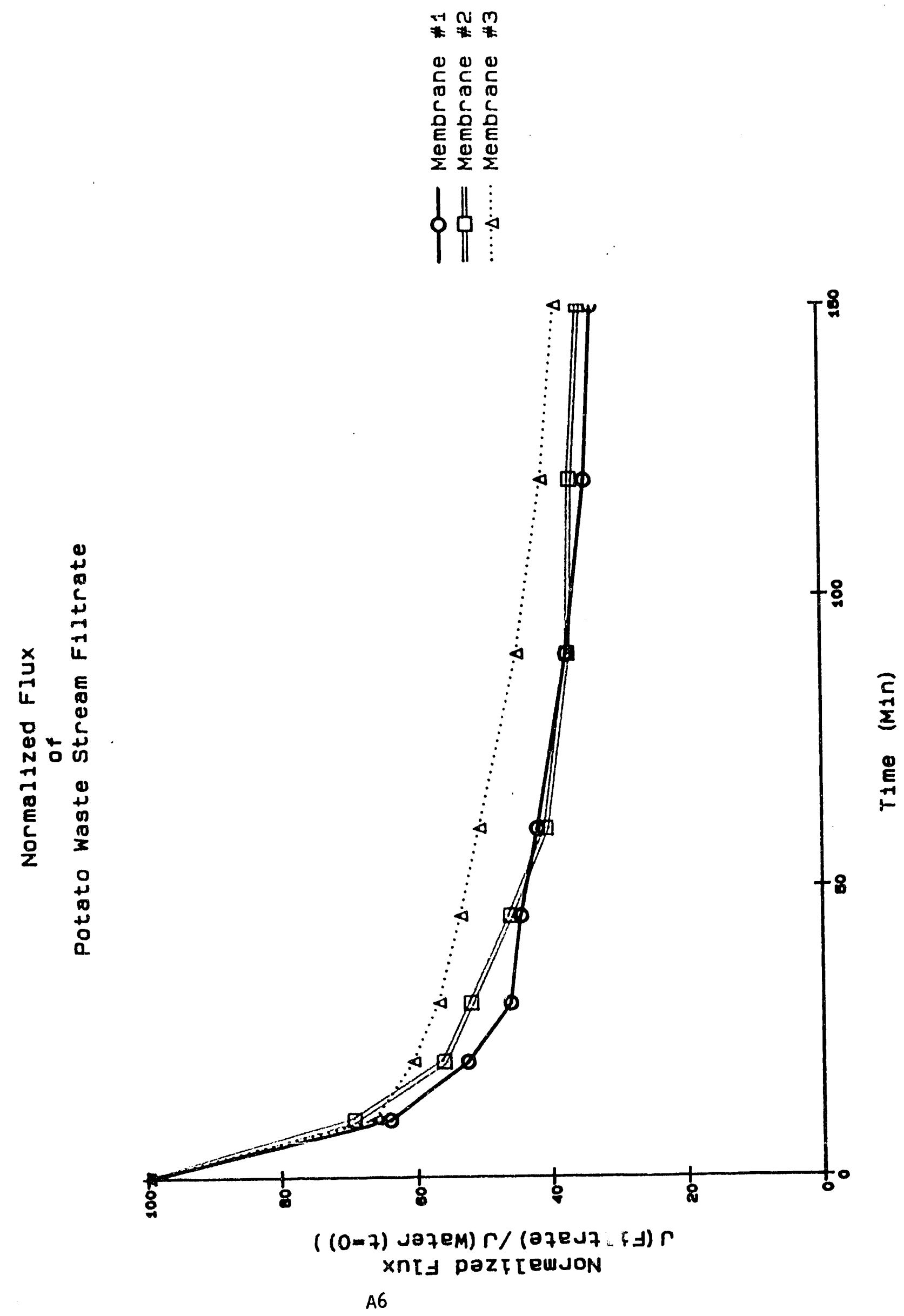




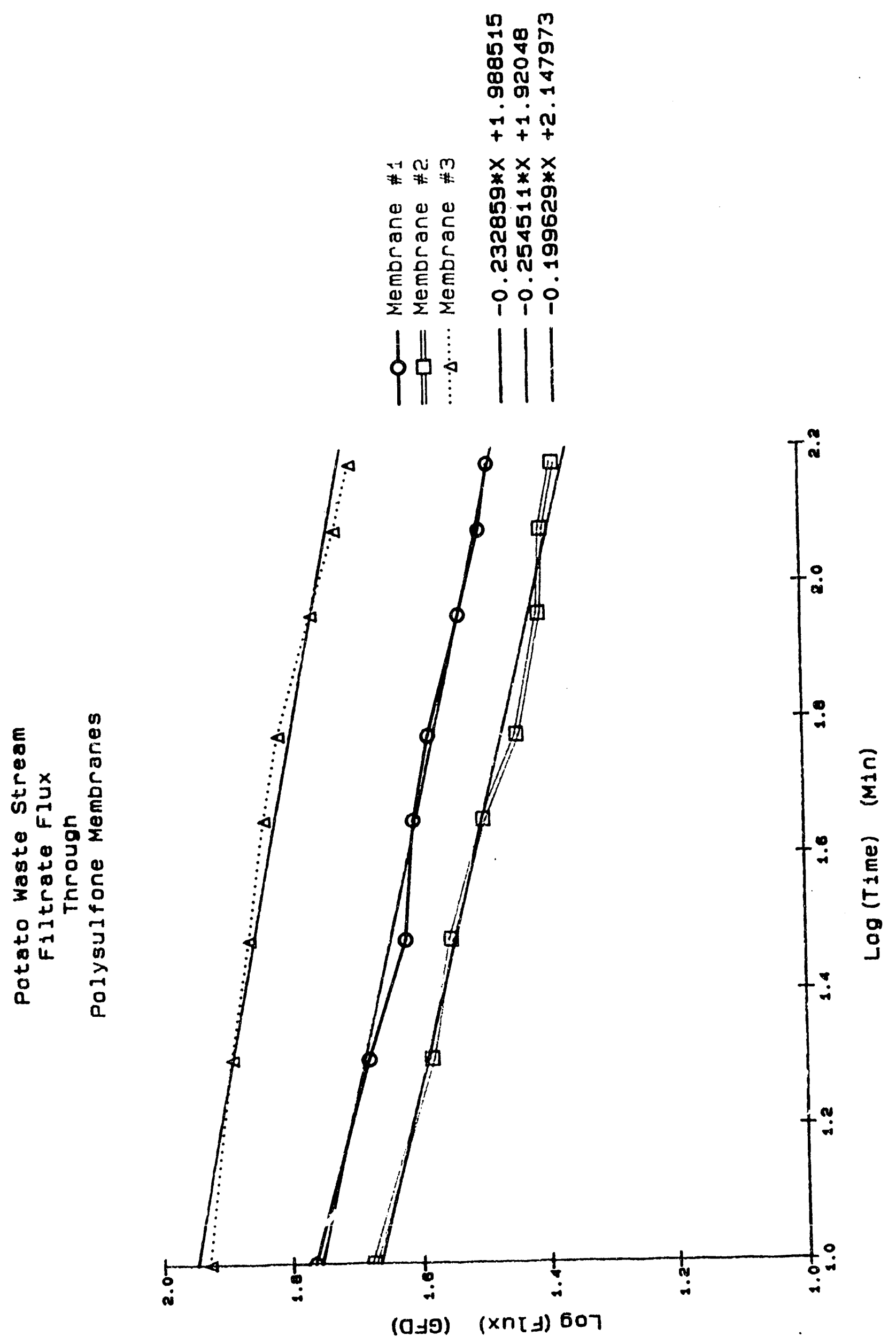


Date of Run - 04-12-90

Membrane \#1 - Wet PS (as delivered)

Membrane \#2 - Fluorinated PS with 0.025 vol $\% \mathrm{~F}_{2}$ in $\mathrm{N}_{2}$ for $60 \mathrm{Min}$

Membrane \#3 - Fluorinated PS with 0.025 vol $\% \mathrm{~F}_{2}^{2}$ in $\mathrm{N}_{2}$ for $30 \mathrm{Min}$

Membrane \#4 - Fluorinated PS with 0.025 vol $\% \mathrm{~F}_{2}$ in $\mathrm{N}_{2}$ for $5 \mathrm{Min}$

Membrane \#5 - Fluorinated PS with 0.050 vol $\% \mathrm{~F}_{2}^{2}$ in $\mathrm{N}_{2}^{2}$ for $5 \mathrm{Min}$

Membrane \#6 - Fluorinated PS with 0.050 vol $\% \mathrm{~F}_{2}^{2}$ in $\mathrm{N}_{2}^{2}$ for $120 \mathrm{Min}$

(where PS = Fluid System's Polysulfone)

Flow Rate $=2500 \mathrm{ml} / \mathrm{minute}$

$\Delta \mathrm{P}($ Cross-membrane $)=100 \mathrm{psi}$

Total Solids in Feed $=0.53 \mathrm{wt} \%$ 


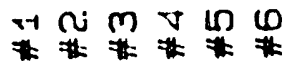

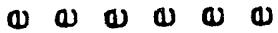

Cᄃ

c C C C C C

C

$\frac{\omega}{\Sigma} \sum_{\Sigma}^{\infty} \sum_{\Sigma}^{\infty} \underset{\Sigma}{\Sigma} \frac{\omega}{\Sigma}$

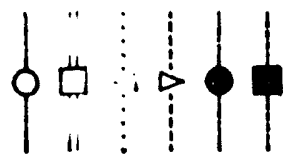

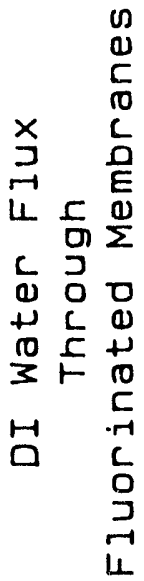

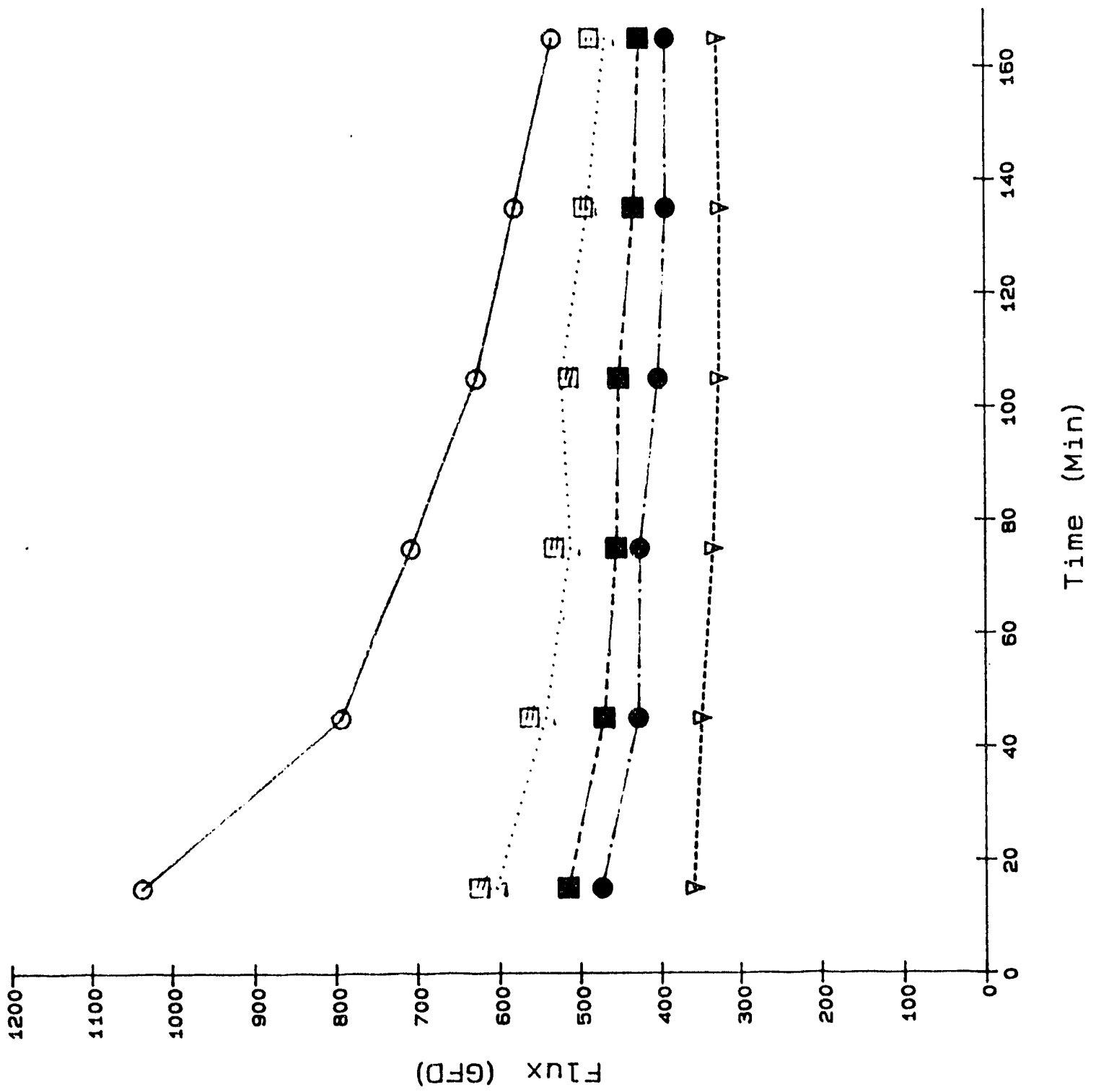




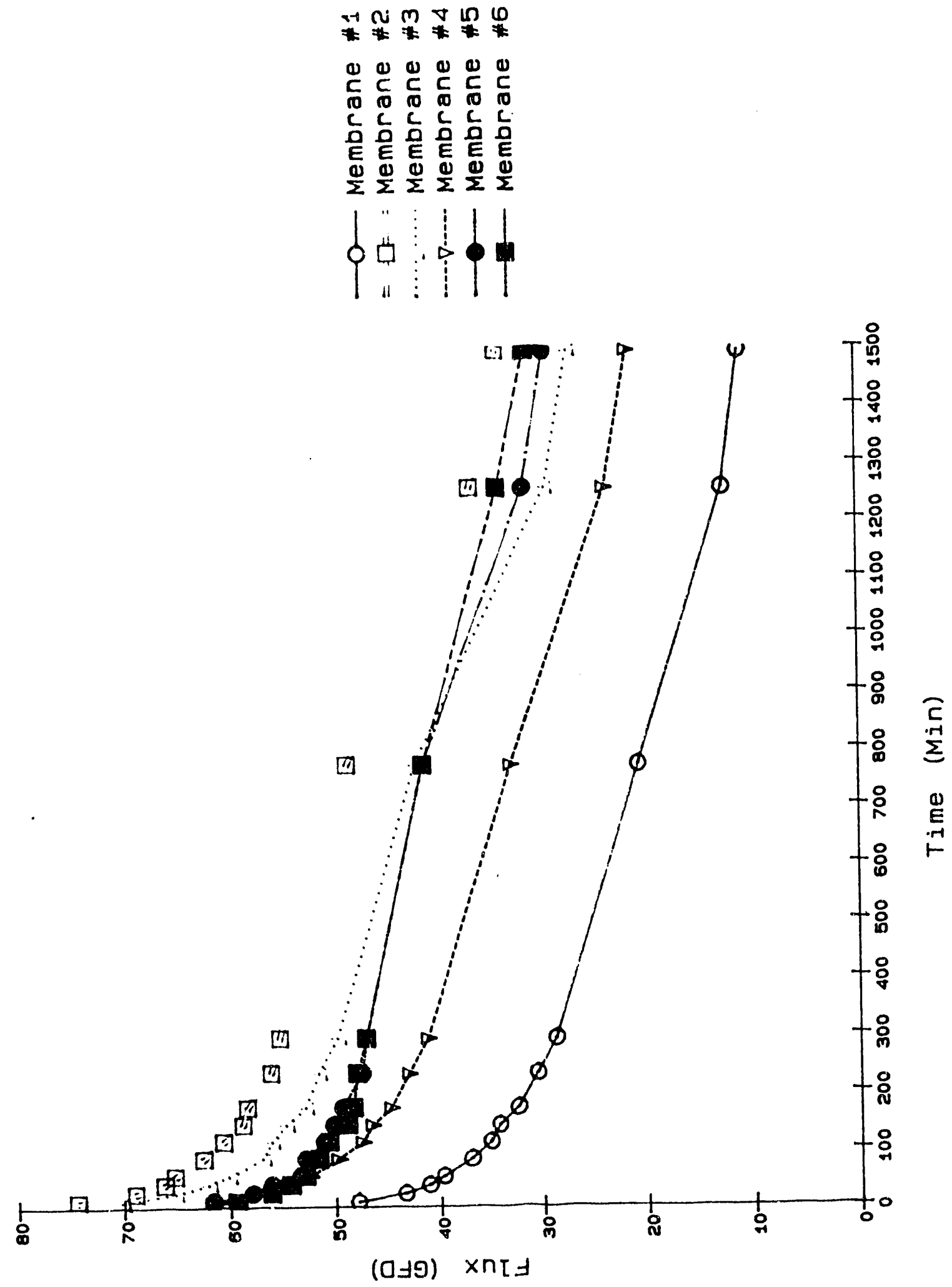

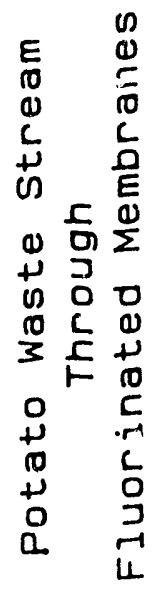




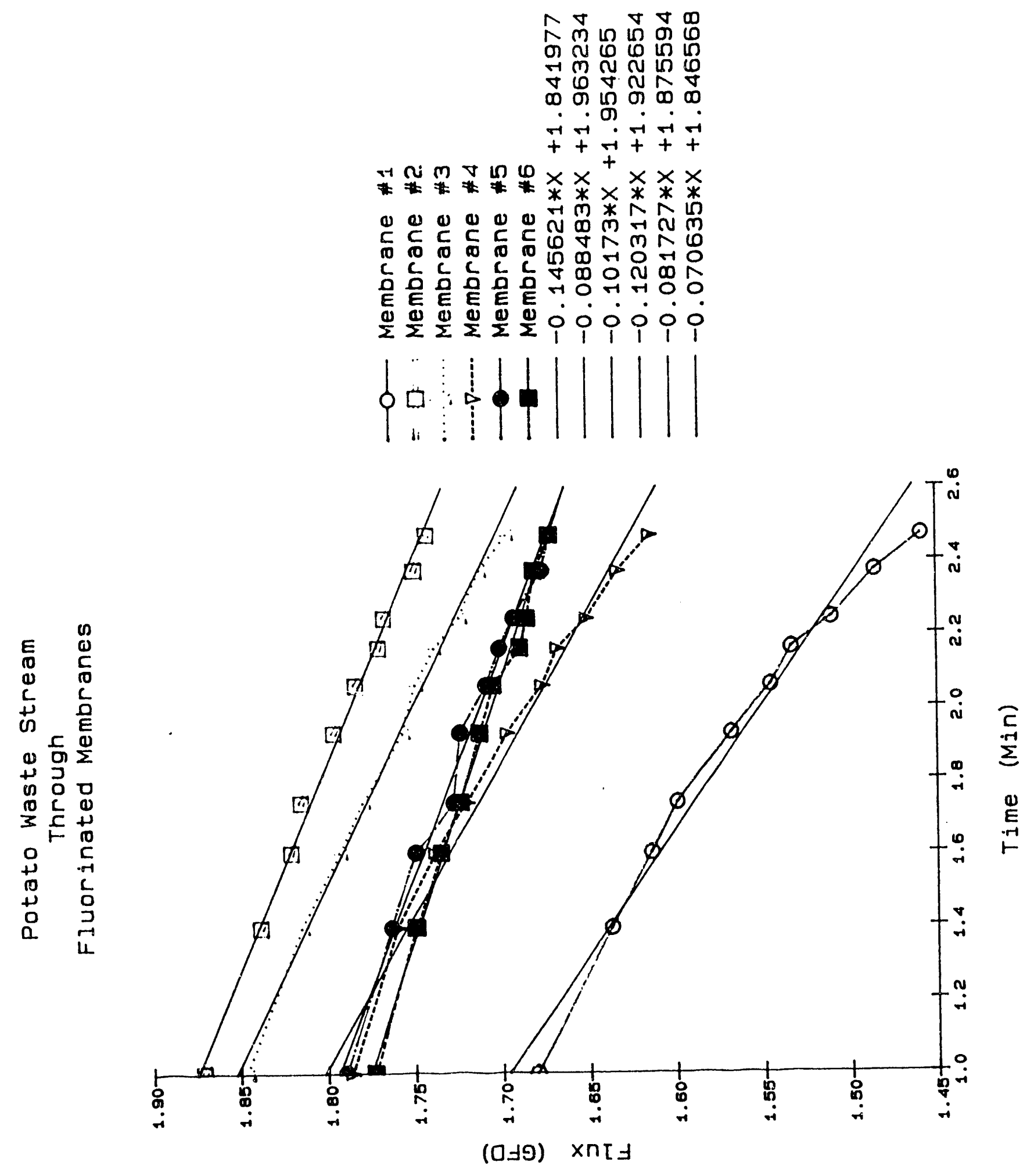




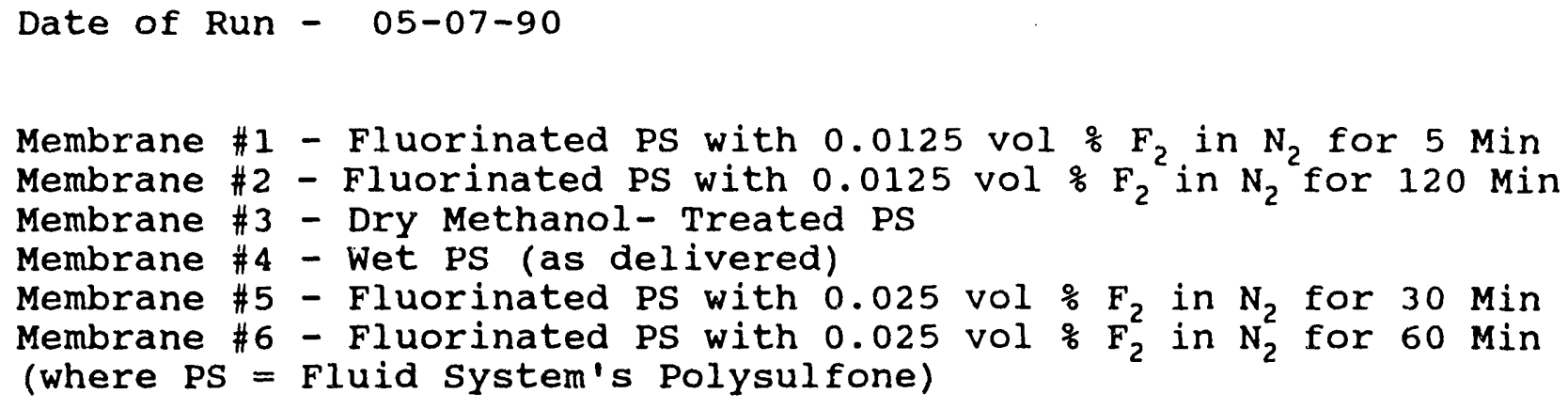

Flow Rate $=2500 \mathrm{ml} /$ minute

$\Delta \mathrm{P}($ Cross-membrane $)=100 \mathrm{psi}$

Total solids in Feed $=0.67 \mathrm{wt} \%$

Note: The membranes fluorinated at $0.0125 \mathrm{vol} \% \mathrm{~F}_{2}$ in $\mathrm{N}_{2}$ did not recover initial flux when subjected to the DI water. Subsequently, these membranes were still wetting out when subjected to the simulated potato feed. The data have been removed from the figures for clarity. 

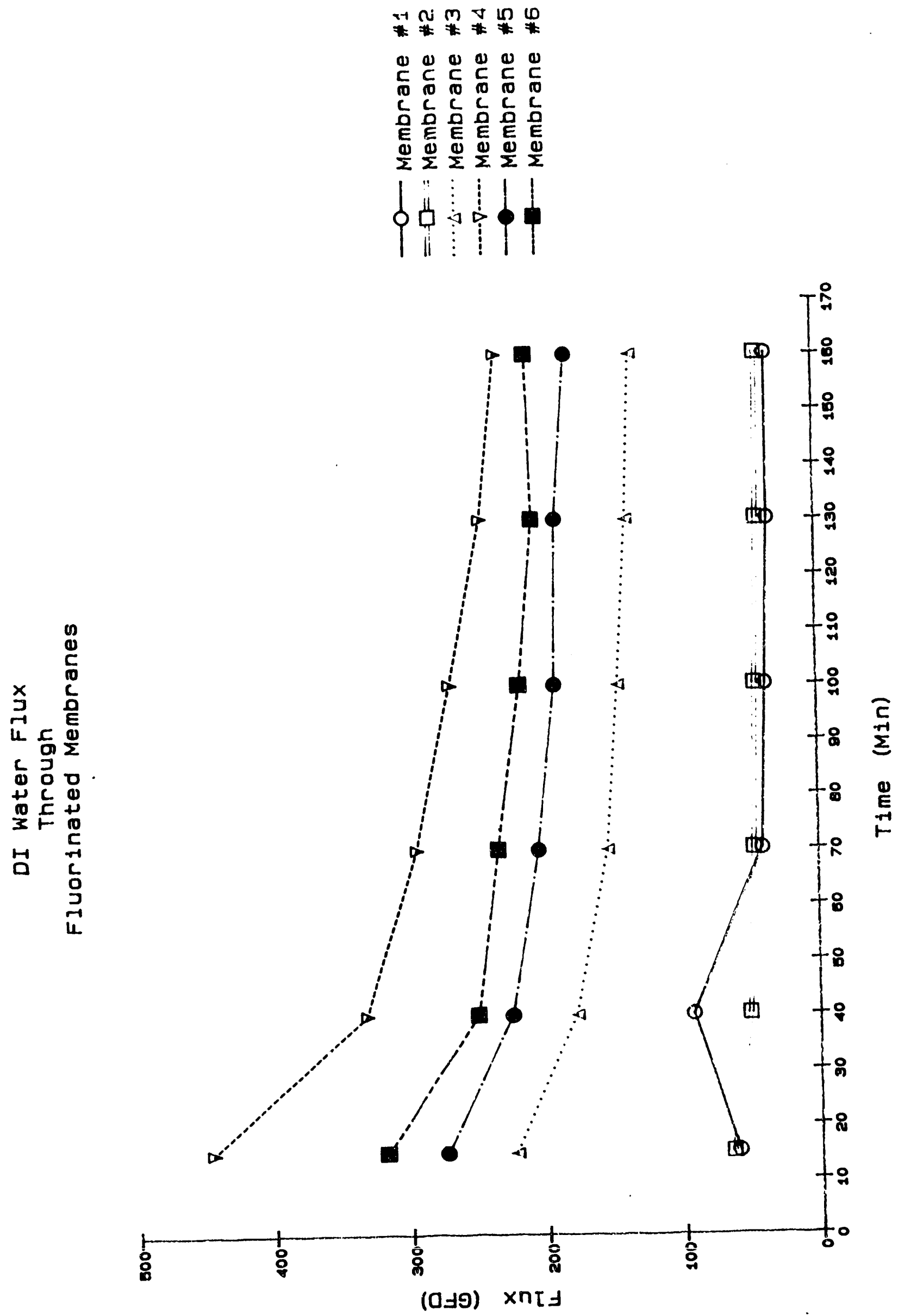


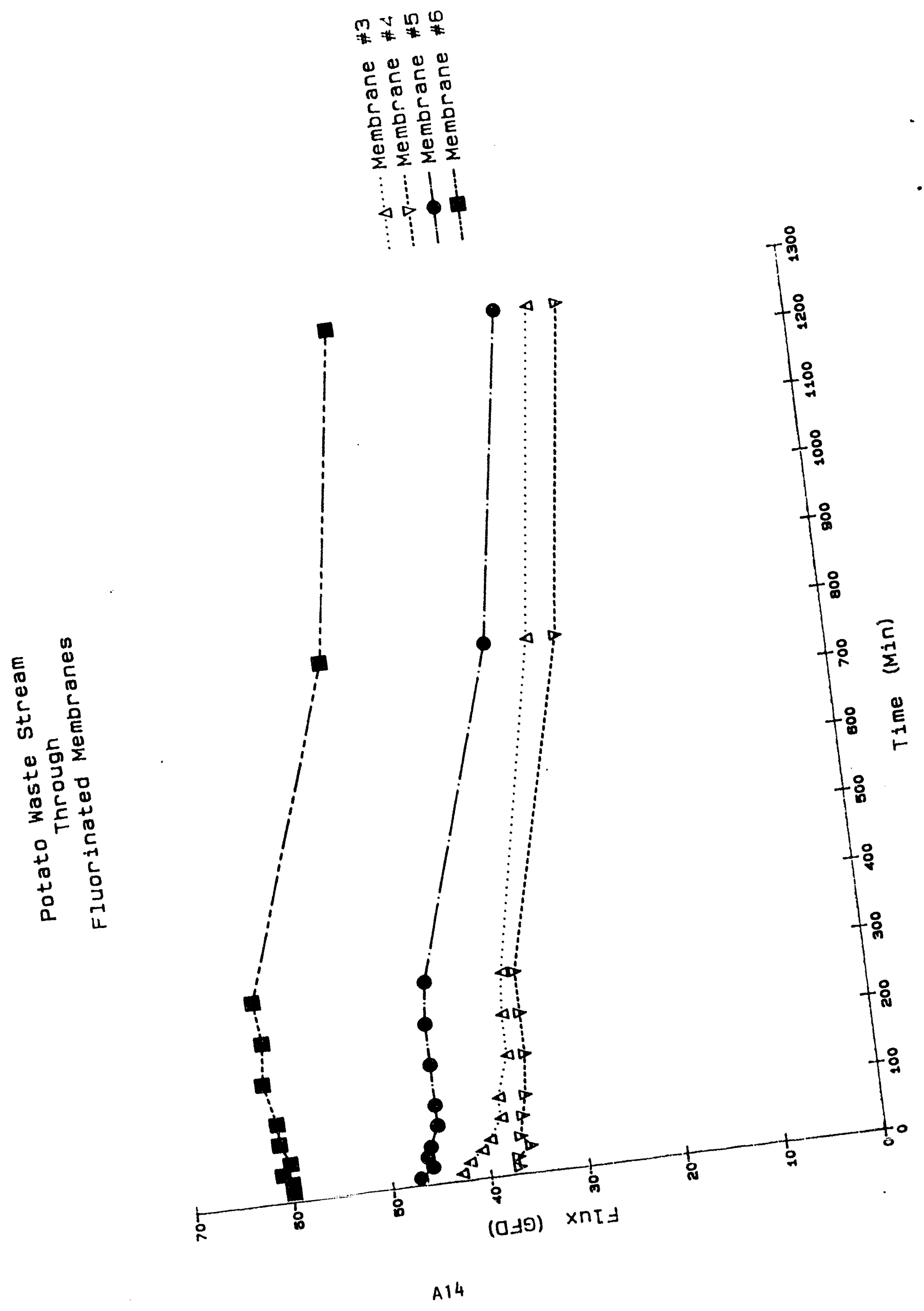




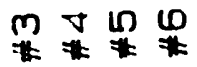

(1) 00

年 $\frac{2}{10} \frac{5}{10}$

ccc

虽虽员

E E

\begin{tabular}{cc|c}
$\vdots$ & $\vdots$ \\
$\vdots$ & $\vdots$ \\
$\vdots$ & $\vdots$ & 1
\end{tabular}

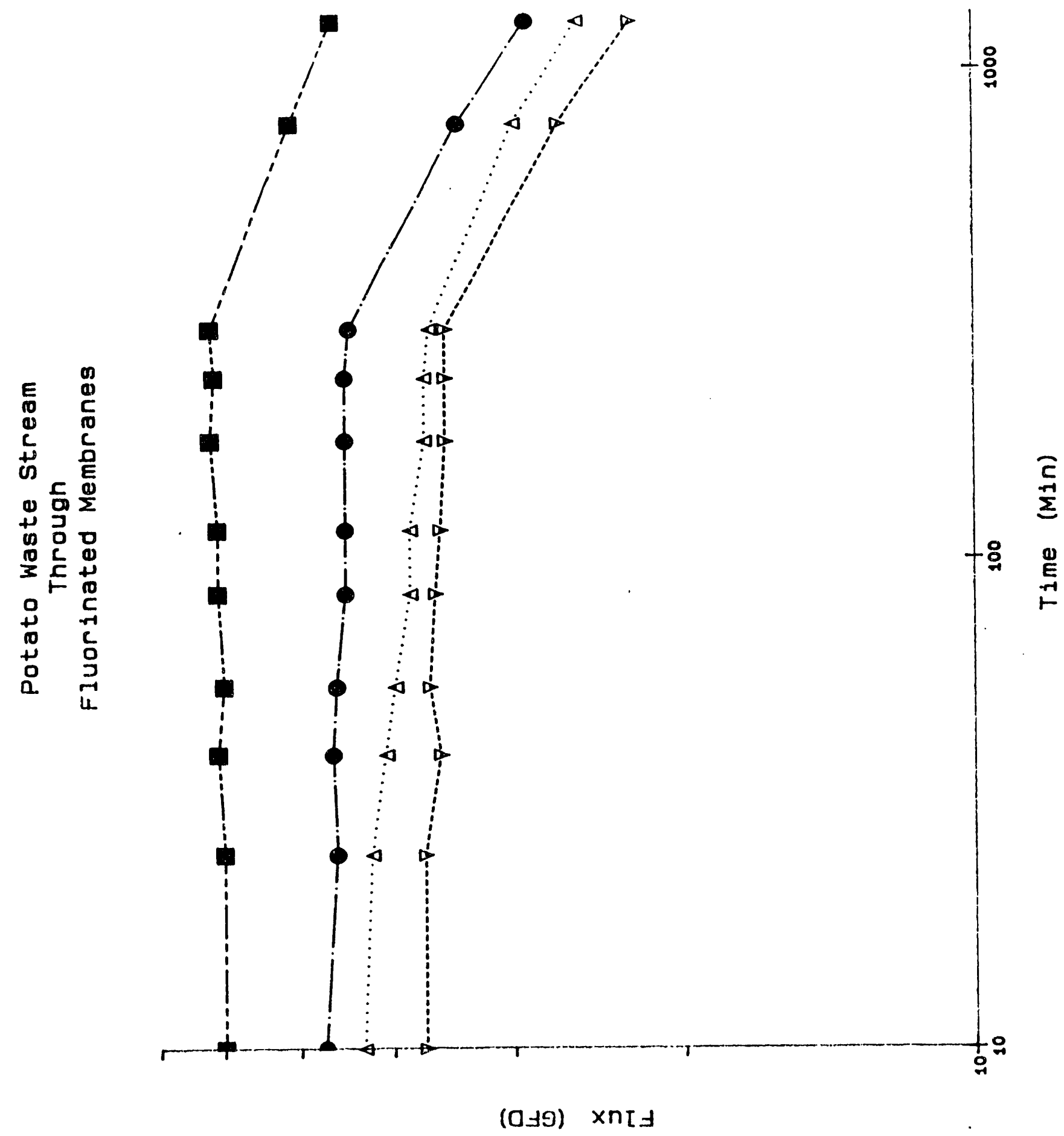




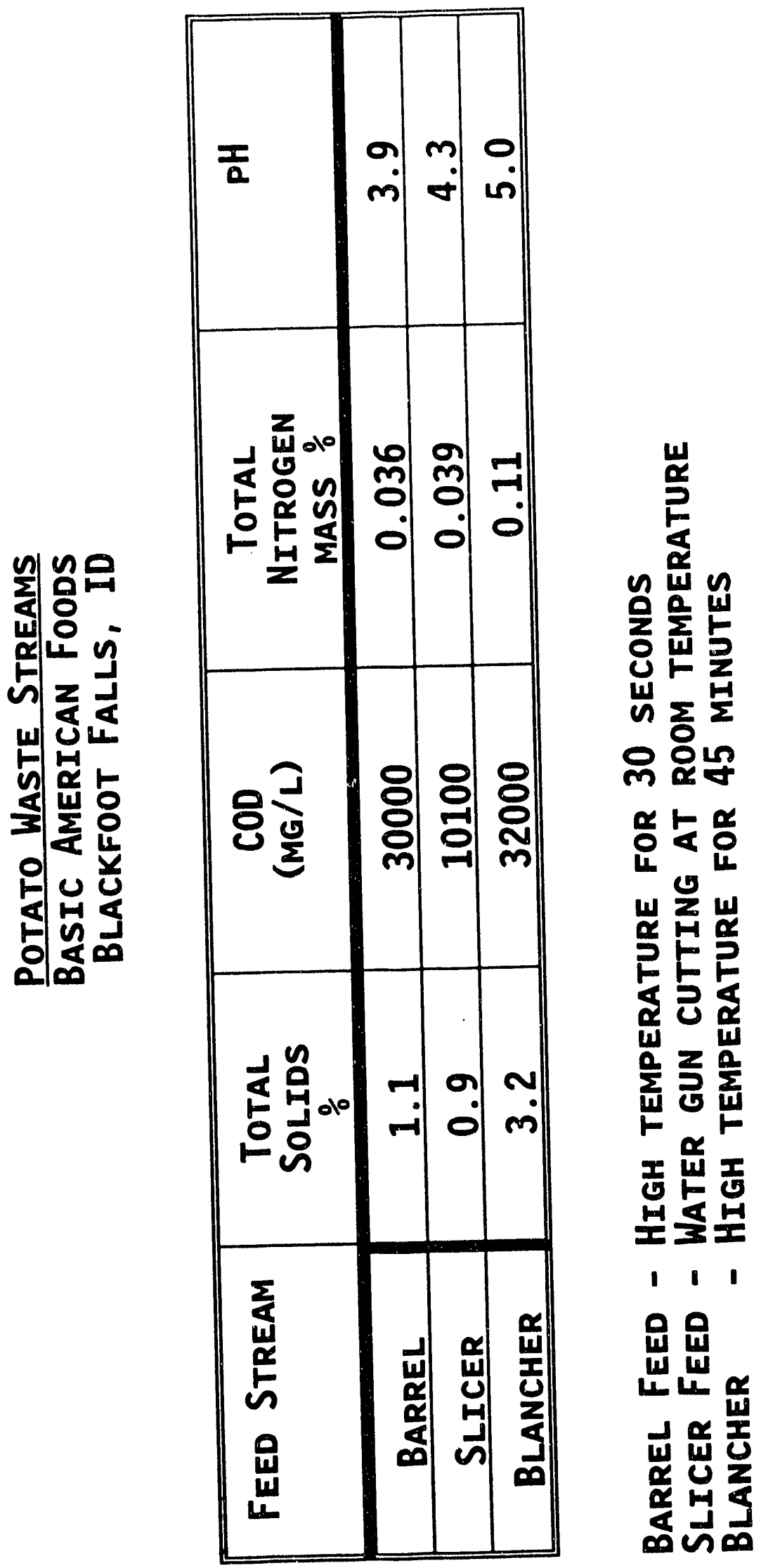


Table A2-1A: Membrane Specifications

(S1icer Stream)

\begin{tabular}{|c|c|}
\hline Membrane & Membrane Treatment \\
\hline$\# 1$ & Wet PS (as delivered) \\
\hline$\# 2$ & Fluorinated PS with 0.025 vol \& $\mathrm{F}_{2}$ in $\mathrm{N}_{2}$ for 60 Min \\
\hline$\# 3$ & Fluorinated PS with 0.025 vol \& $\mathrm{F}_{2}$ in $\mathrm{N}_{2}$ for 30 Min \\
\hline$\# 4$ & Wet PS (as delivered) \\
\hline$\# 5$ & Fluorinated PS with 0.050 vol \& $\mathrm{F}_{2}$ in $\mathrm{N}_{2}$ for 5 Min \\
\hline$\# 6$ & Fluorinated PS with 0.050 vol \& $\mathrm{F}_{2}$ in $\mathrm{N}_{2}$ for 120 Min \\
\hline
\end{tabular}


$\begin{array}{llllll}* & m & \square & 0 & 0 & *\end{array}$
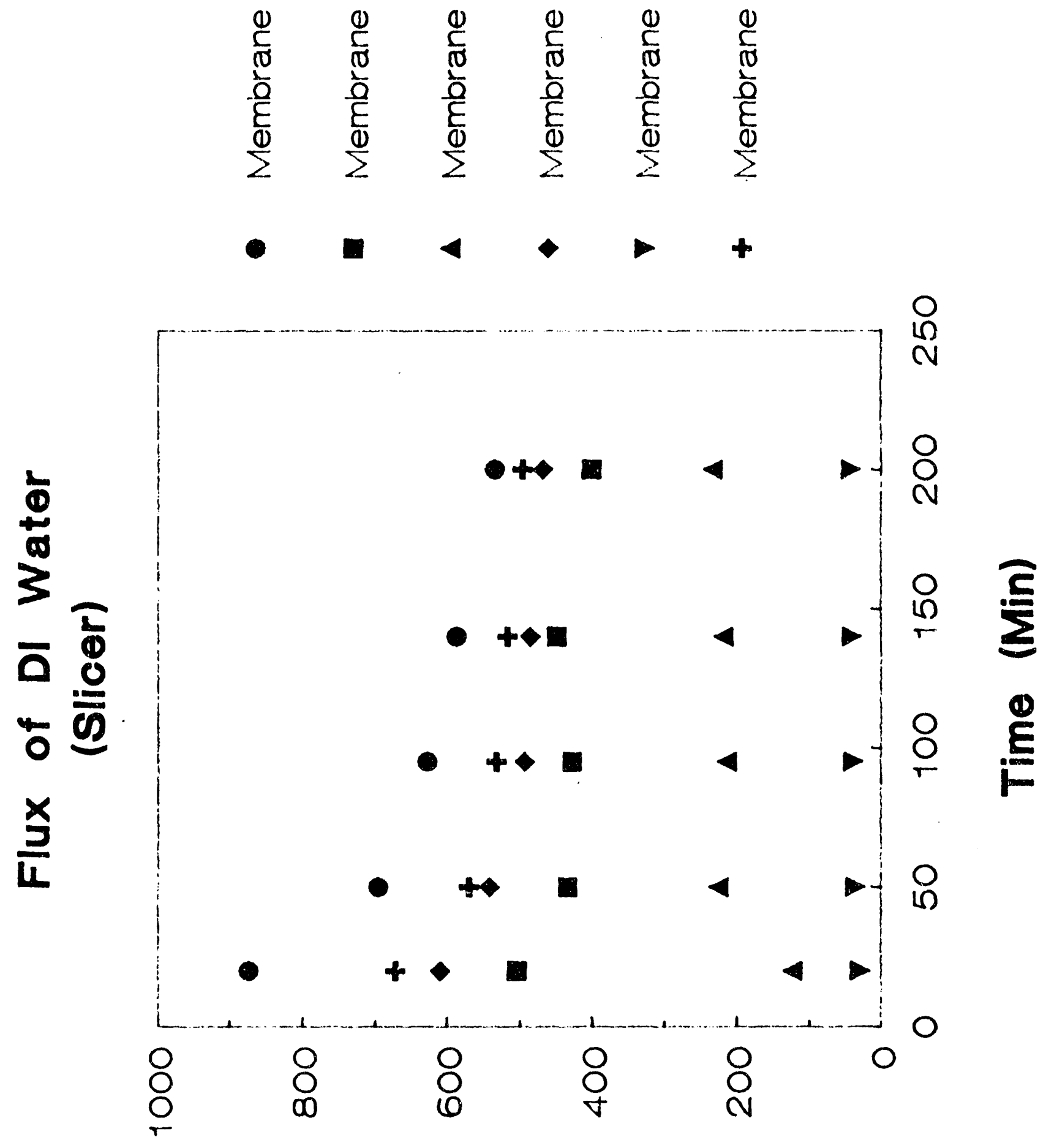

$($ (вp- 


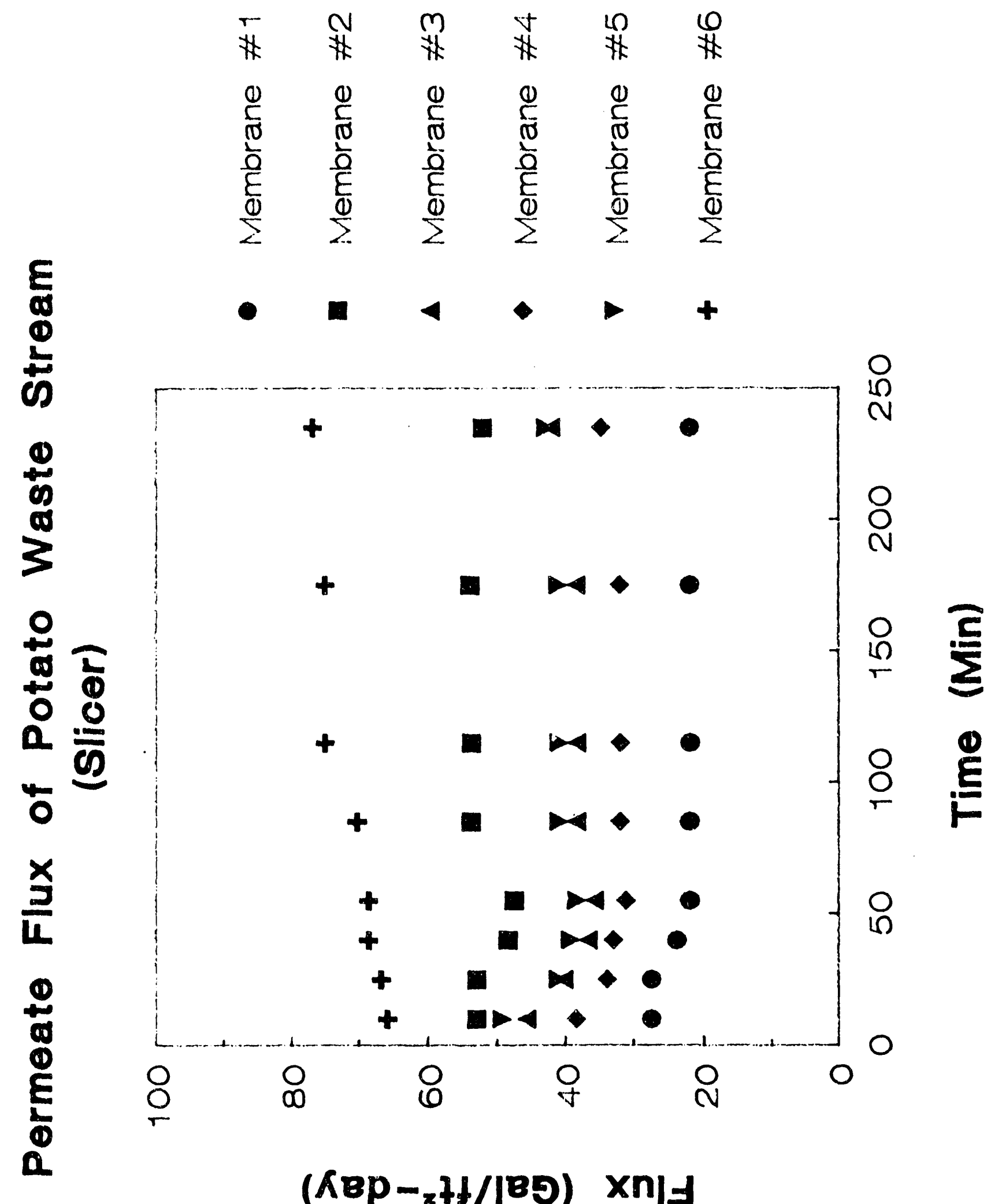


Table A2-1B: COD and Nitrogen Rejection

(Slicer Stream)

Run Date 7-10-90

Start Time 12:00 PM

\begin{tabular}{|c|c|c|c|c|}
\hline Membrane & $\begin{array}{c}\mathrm{COD} \\
(\mathrm{mg} / 1)\end{array}$ & \& Rejection & $\begin{array}{c}\text { Total Nitrogen } \\
\text { Mass \& }\end{array}$ & \& Rejection \\
\hline \multicolumn{5}{|c|}{$12: 15 \mathrm{PM}$} \\
\hline Feed & 10100 & - & $3.9 e-2$ & - \\
\hline 1 & 5300 & 48 & $7.8 e-3$ & 80 \\
\hline 2 & 5500 & 46 & $8.8 e-3$ & 78 \\
\hline 3 & 5700 & 44 & $8.0 e-3$ & 80 \\
\hline 4 & 5100 & 50 & $8.1 e-3$ & 80 \\
\hline 5 & 6500 & 36 & $9.6 e-3$ & 76 \\
\hline 6 & 6000 & 41 & $8.5 e-3$ & 78 \\
\hline \multicolumn{5}{|c|}{$3: 00 \mathrm{PM}$} \\
\hline Feed & 10,000 & - & $3.7 e-2$ & - \\
\hline 1 & 5900 & 41 & $8.2 e-3$ & 78 \\
\hline 2 & 5500 & 45 & $7.9 e-3$ & 79 \\
\hline 3 & 5900 & 41 & $8.4 e-3$ & 78 \\
\hline 4 & 6100 & 38 & $8.2 e-3$ & 78 \\
\hline 5 & 7000 & 30 & $1.0 e-2$ & 73 \\
\hline 6 & 6500 & 35 & $8.0 e-3$ & 79 \\
\hline
\end{tabular}




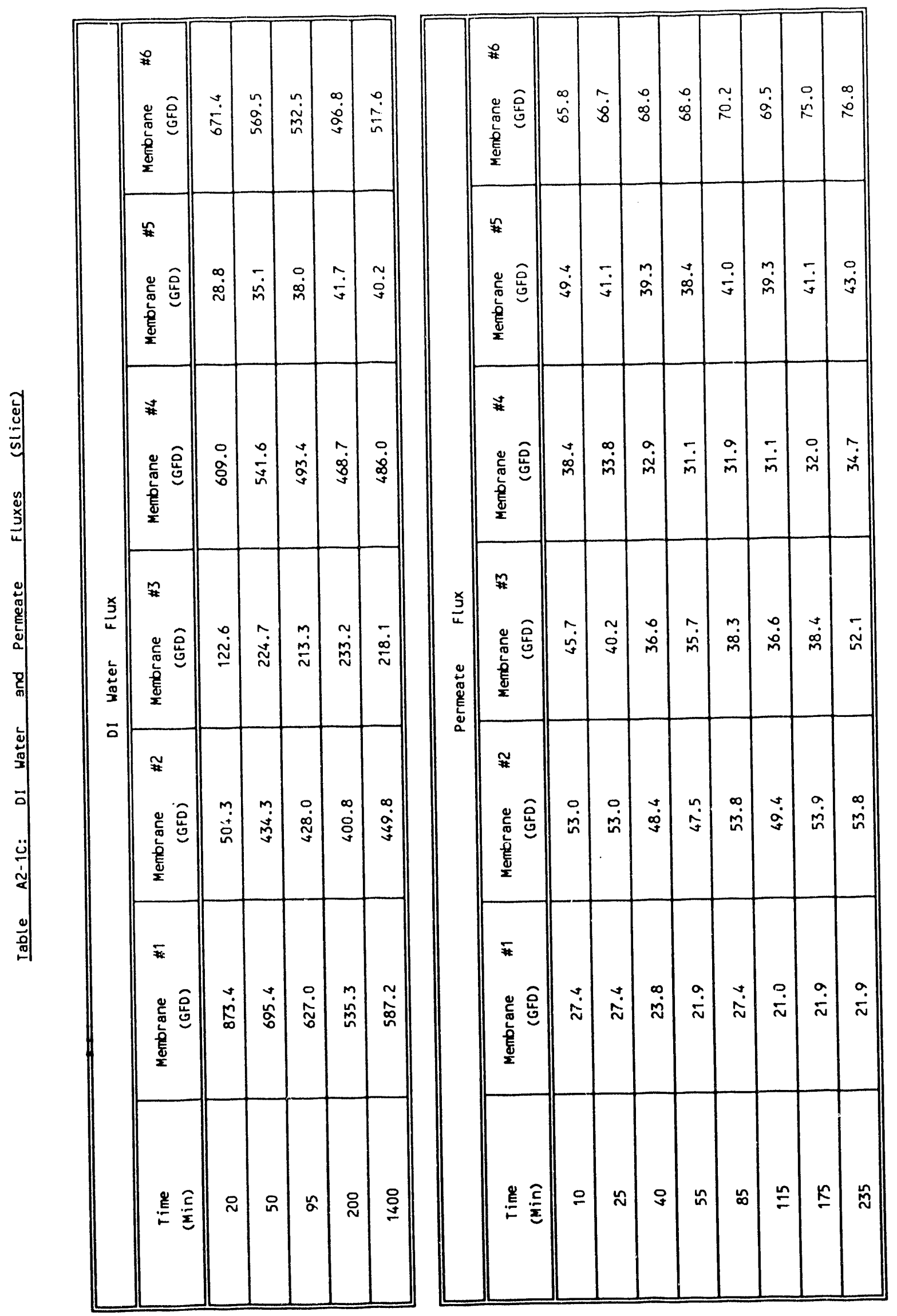


Table A2-2A: Membrané Specifications

(Barrel Stream)

\begin{tabular}{|c|c|}
\hline Membrane & Membrane Treatment \\
\hline$\# 1$ & Wet PS (as delivered) \\
\hline$\# 2$ & Fluorinated PS with 0.025 vol $\& F_{2}$ in $N_{2}$ for 60 Min \\
\hline$\# 3$ & Fluorinated PS with 0.025 vol $\& F_{2}$ in $N_{2}$ for 30 Min \\
\hline$\# 4$ & Wet PS (as delivered) \\
\hline$\# 5$ & Fluorinated PS with 0.050 vol $\& F_{2}$ in $N_{2}$ for 120 Min \\
\hline$\# 6$ &
\end{tabular}




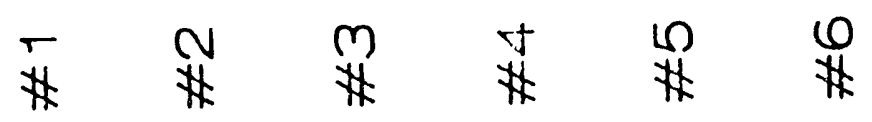
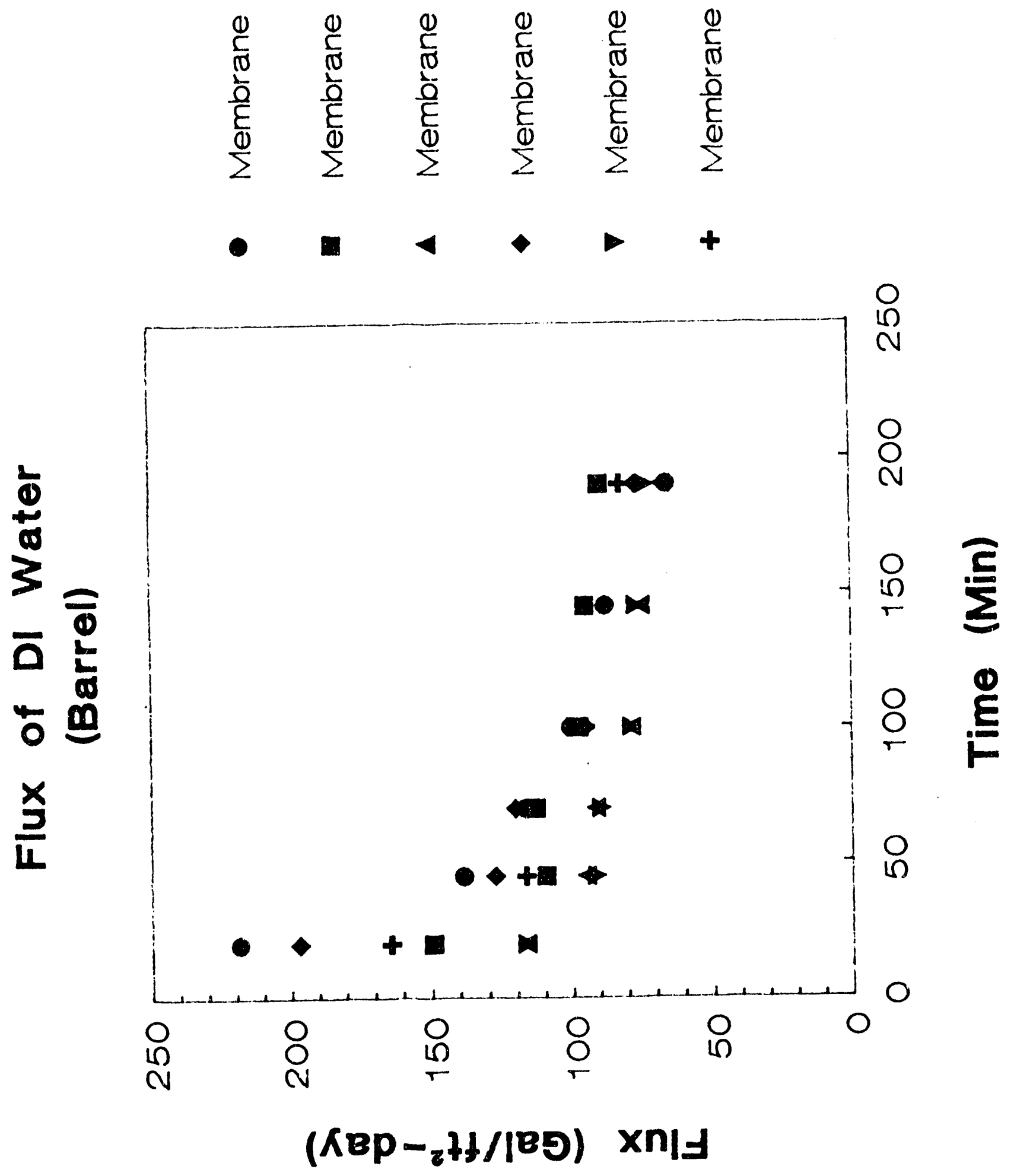


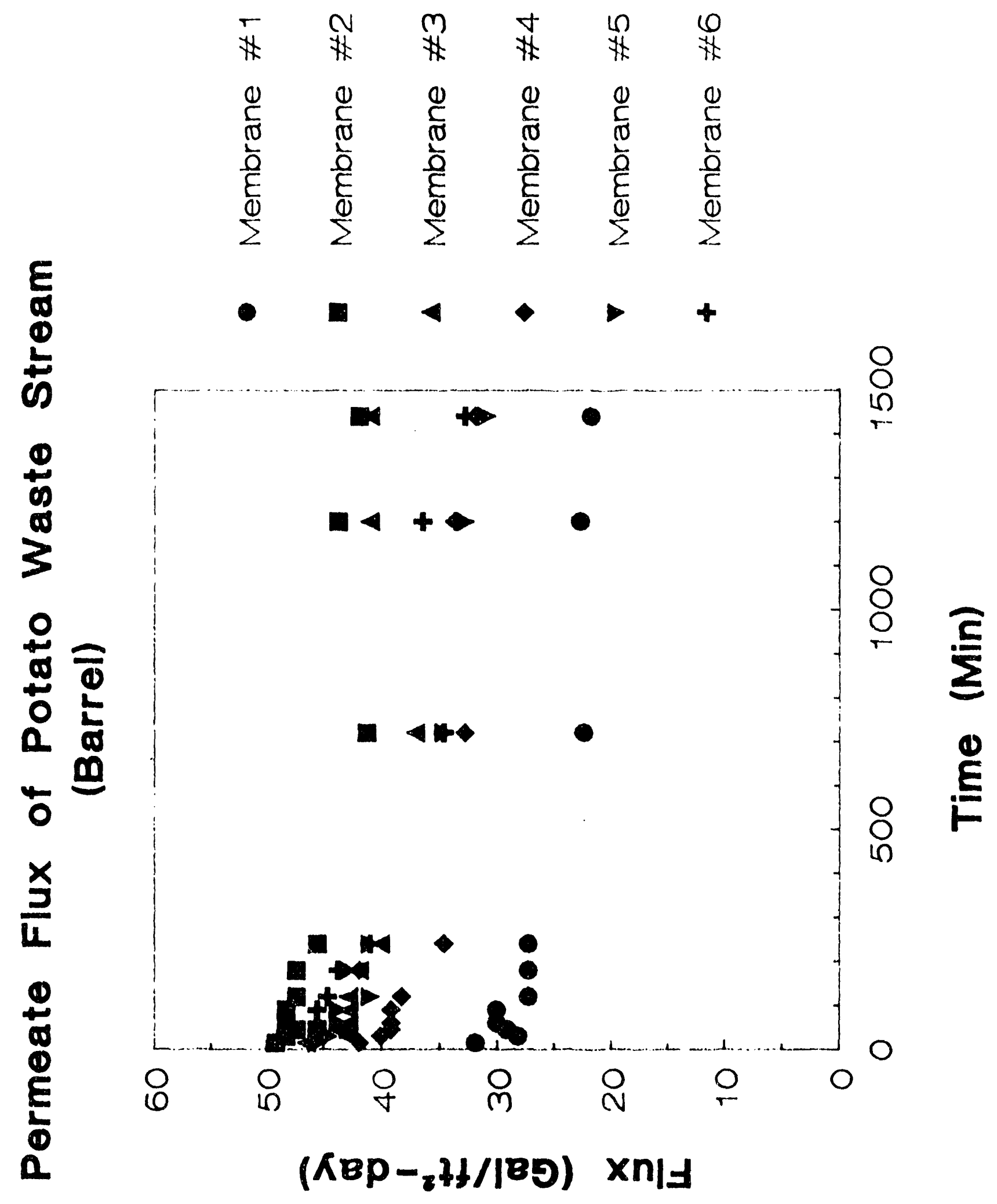


Table A2-2B: COD and Nitrogen Rejection

(Barre1 Stream)

Run Date 7-12-90

Start Time 12:00 PM

\begin{tabular}{|c|c|c|c|c|}
\hline Membrane & COD(mg/l) & \& Rejection & $\begin{array}{c}\text { Total Nitrogen } \\
\text { Mass } 8\end{array}$ & \& Rejection \\
\hline \hline \multicolumn{5}{|c|}{$12: 15$ PM (7-13-90) } \\
\hline Feed & 30000 & - & $3.6 \mathrm{e}-2$ & - \\
\hline 1 & 7500 & 75 & $6.2 \mathrm{e}-3$ & 83 \\
\hline 2 & 6100 & 80 & $8.6 \mathrm{e}-3$ & 76 \\
\hline 3 & 6200 & 79 & $8.5 \mathrm{e}-3$ & 76 \\
\hline 4 & 5900 & 80 & $8.1 \mathrm{e}-3$ & 78 \\
\hline 5 & 8400 & 72 & $9.5 \mathrm{e}-3$ & 74 \\
\hline 6 & 6900 & 77 & $9.8 \mathrm{e}-3$ & 73 \\
\hline \hline
\end{tabular}




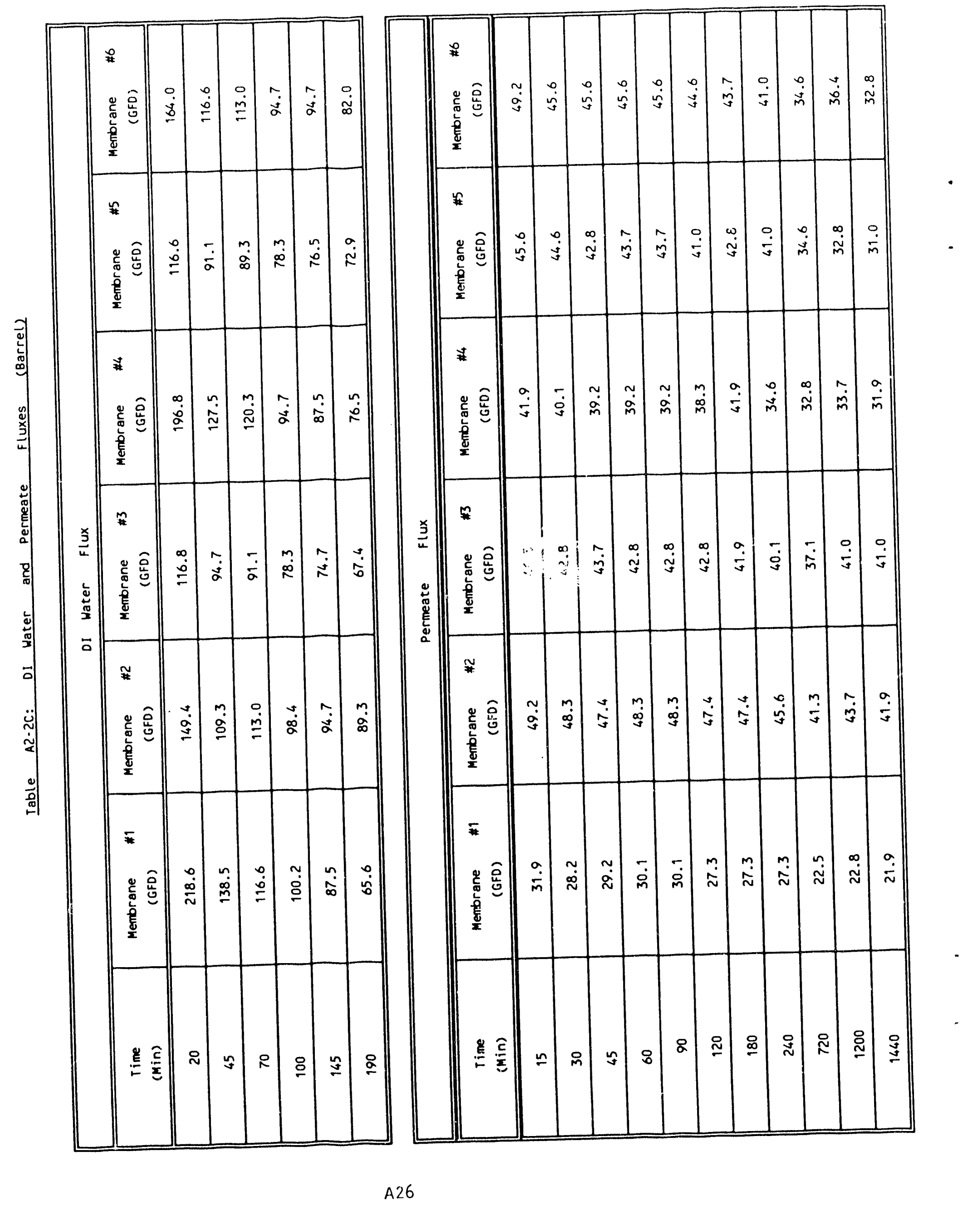


Table A2-3A: Membrane Specifications

(Blancher Stream)

\begin{tabular}{|c|c|}
\hline Membrane & Membrane Treatment \\
\hline$\# 1$ & Wet PS (as delivered) \\
\hline$\# 2$ & Fluorinated PS with 0.025 vol $\& \mathrm{~F}_{2}$ in $\mathrm{N}_{2}$ for $60 \mathrm{Min}$ \\
\hline$\# 3$ & Fluorinated PS with 0.025 vol $\& \mathrm{~F}_{2}$ in $\mathrm{N}_{2}$ for $30 \mathrm{Min}$ \\
\hline$\# 4$ & wet PS (as delivered) \\
\hline$\# 5$ & Fluorinated PS with 0.050 vol $\& \mathrm{~F}_{2}$ in $\mathrm{N}_{2}$ for $5 \mathrm{Min}$ \\
\hline$\# 6$ & Fluorinated PS with 0.025 vol $\& \mathrm{~F}_{2}$ in $\mathrm{N}_{2}$ for $5 \mathrm{Min}$ \\
\hline
\end{tabular}


\

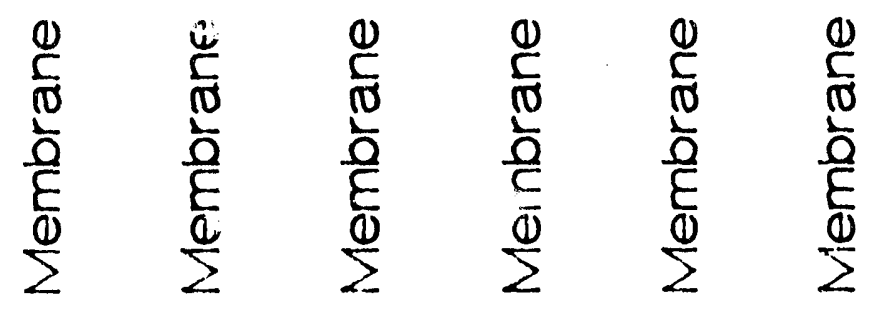

- $\quad 4 \quad \rightarrow+$

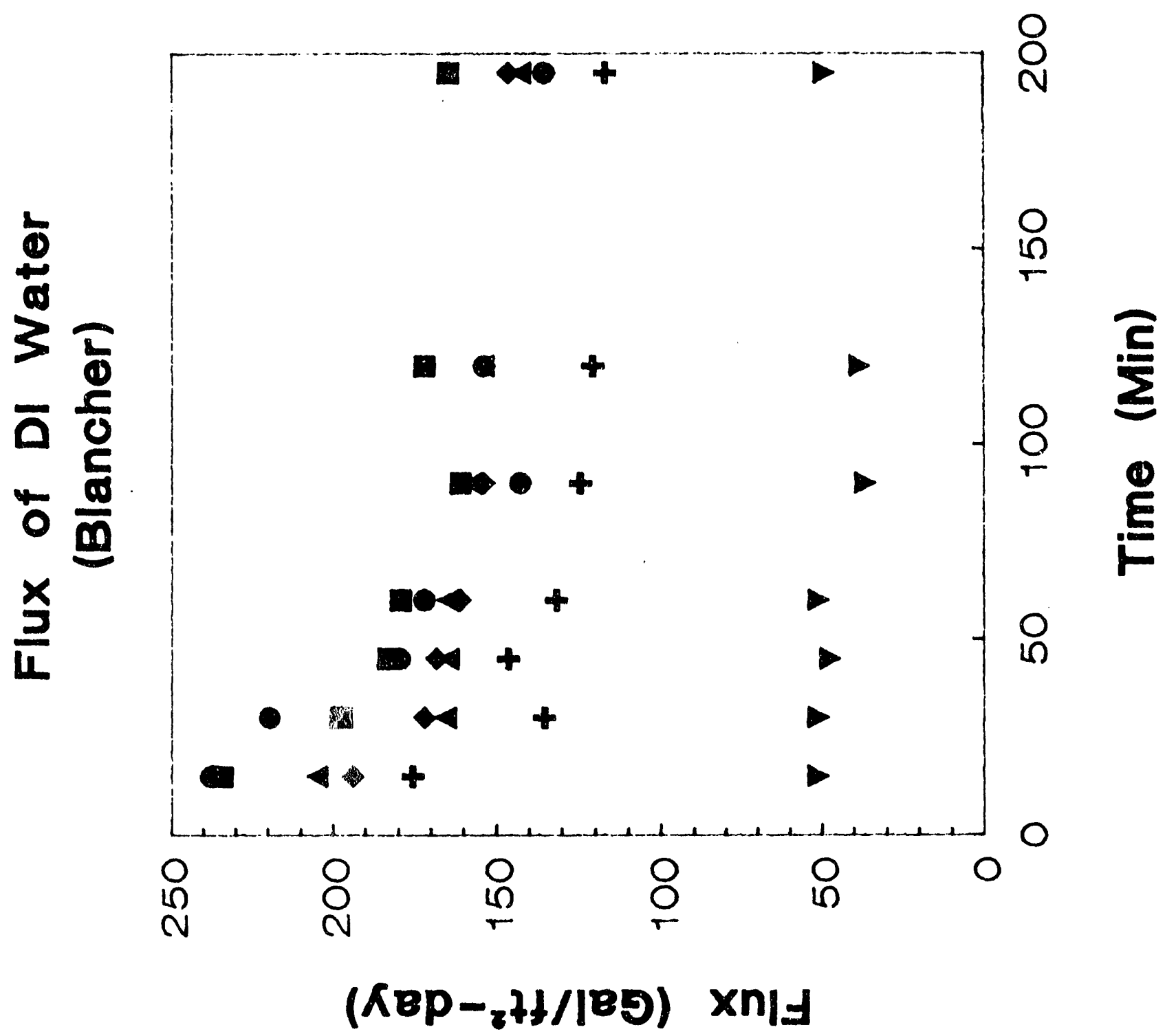




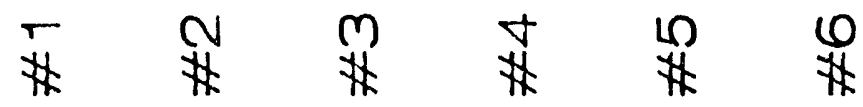

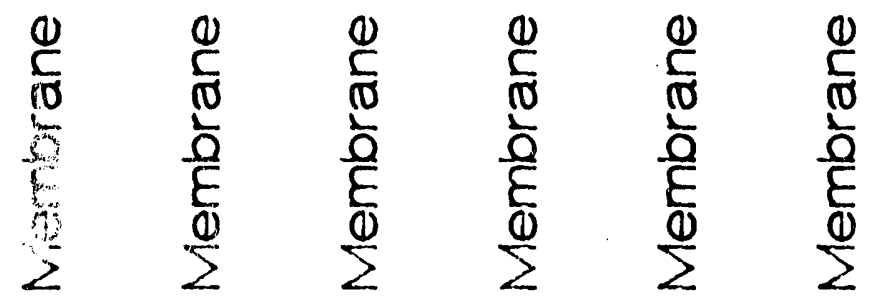

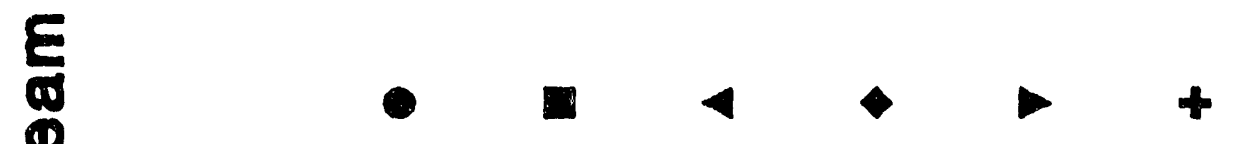

눈

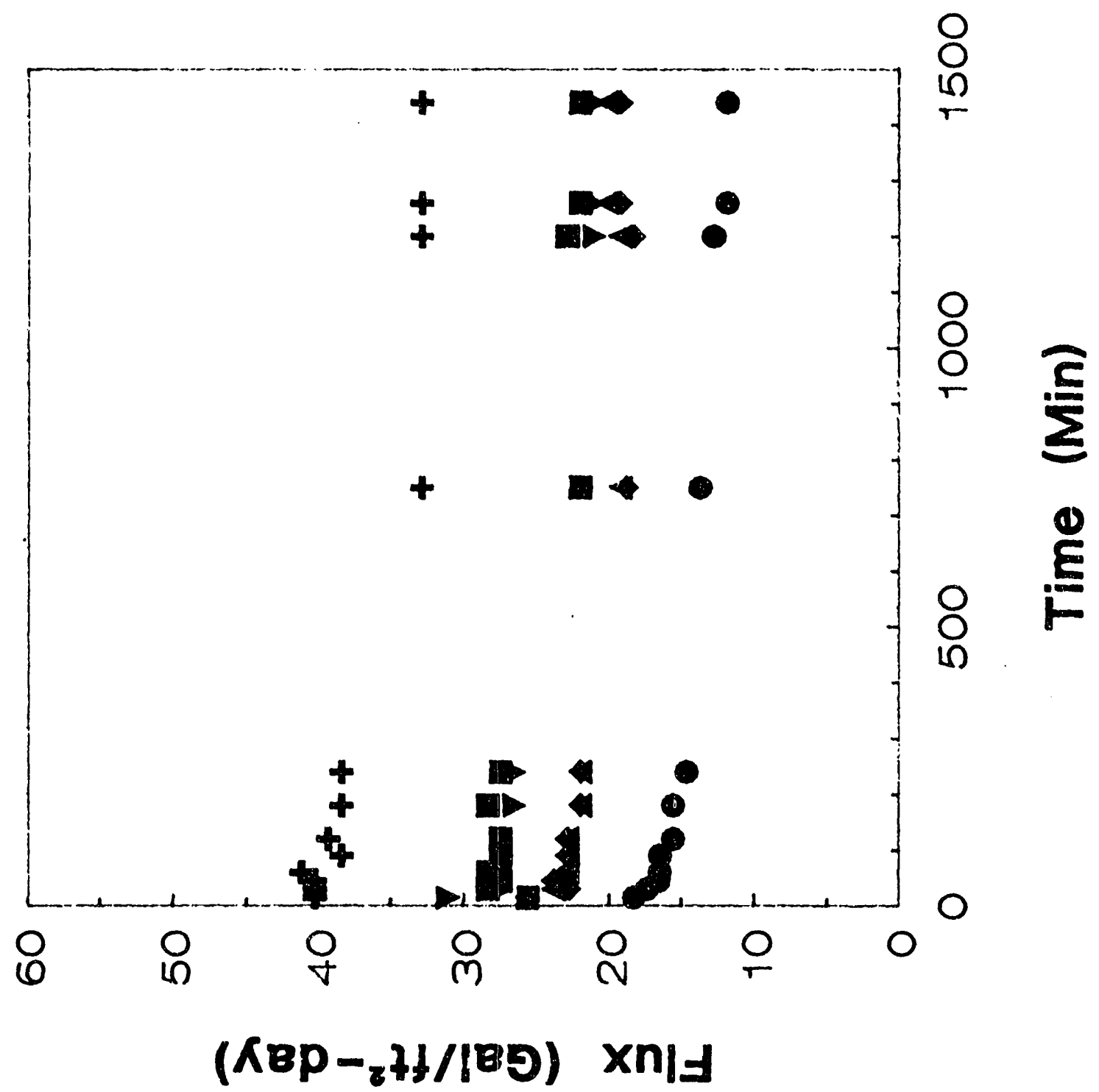


Table A2-3B: COD and Nitrogen Rejection

(Blancher Stream)

Run Date 7-19-90

Start Time 12:00 PM

\begin{tabular}{|c|c|c|c|c|}
\hline Membrane & $\begin{array}{c}\mathrm{COD} \\
(\mathrm{mg} / 1) \\
\end{array}$ & $\&$ Rejection & $\begin{array}{c}\text { Total Nitrogen } \\
\text { Mass } 8 \\
\end{array}$ & \& Rejection \\
\hline \multicolumn{5}{|c|}{$2: 00 \mathrm{PM}$} \\
\hline Feed & 31500 & - & 0.110 & - \\
\hline 1 & 6500 & 79 & 0.069 & 33 \\
\hline 2 & 10500 & 67 & 0.066 & 34 \\
\hline 3 & 8750 & 72 & 0.067 & 34 \\
\hline 4 & 10500 & 67 & 0.059 & 42 \\
\hline 5 & 10000 & 68 & 0.063 & 38 \\
\hline 6 & 10000 & 68 & 0.067 & 34 \\
\hline \multicolumn{5}{|c|}{$8: 00$ AM $(7-20-90)$} \\
\hline Feed & 35000 & - & 0.110 & - \\
\hline 1 & 9500 & 73 & $1.1 \mathrm{e}-2$ & 90 \\
\hline 2 & 9100 & 74 & $1.4 \mathrm{e}-2$ & 87 \\
\hline 3 & 8900 & 75 & $1.2 \mathrm{e}-2$ & 89 \\
\hline 4 & 9200 & 74 & $1.5 \mathrm{e}-2$ & 86 \\
\hline 5 & 7000 & 80 & $1.3 e-2$ & 88 \\
\hline 6 & 10000 & 71 & $1.1 \mathrm{e}-2$ & 90 \\
\hline
\end{tabular}




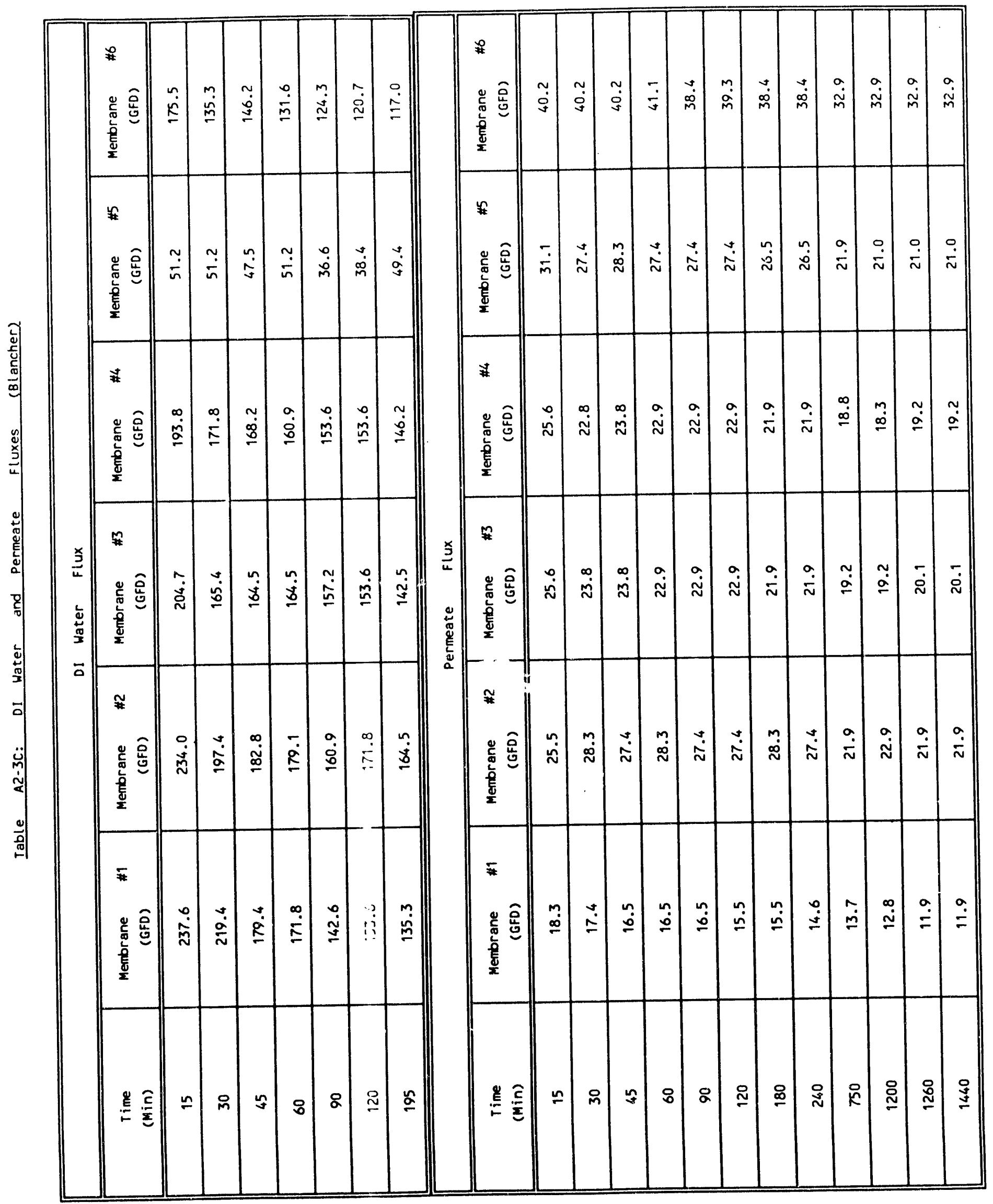


APPENDIX B 


\begin{abstract}
Appendix B
Appendix B1: Pilot Plant Permeate Flux Data Sheets

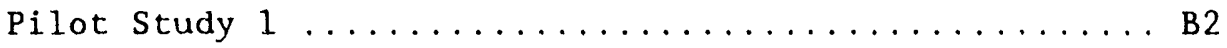

Pilot Study $2 \ldots \ldots \ldots \ldots \ldots \ldots \ldots \ldots \ldots \ldots \ldots \ldots \ldots \ldots$

Appendix B2: COD, Total Solids, Organic Nitrogen and Turbidity Measurements

Appendix B2 Nomenclature ................. B16

Pilot Study 1

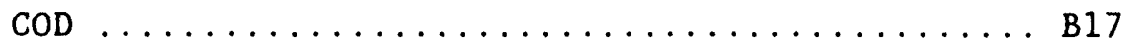

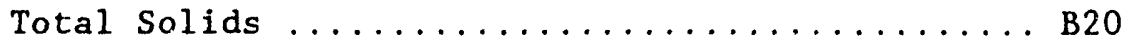

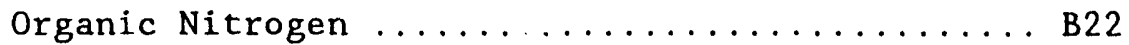

Turbidity $\ldots \ldots \ldots \ldots \ldots \ldots \ldots \ldots \ldots \ldots \ldots \ldots \ldots \ldots \ldots$
\end{abstract}

Pilot Study 2

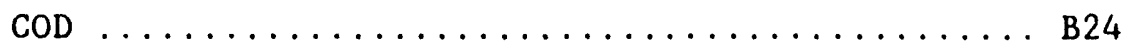

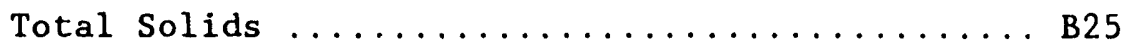

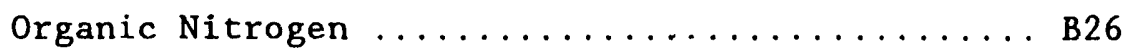

Turbidity $\ldots \ldots \ldots \ldots \ldots \ldots \ldots \ldots \ldots \ldots \ldots \ldots \ldots \ldots \ldots \ldots$ 
ULTRAFILTRATION MEMBRANES: PILOT STUDY \#1

21-DAY PILOT RUN: SEPTEMBER 4 - OCTOBER 3, 1991

\begin{tabular}{|c|c|c|c|}
\hline & $\begin{array}{c}\text { TIME } \\
\text { (Min.) } \\
\end{array}$ & $\begin{array}{c}\text { MEMBRANE A } \\
(\text { GFD })\end{array}$ & $\begin{array}{c}\text { MEMBRANE B } \\
(G F D)\end{array}$ \\
\hline \multirow{11}{*}{$\begin{array}{l}\text { SEPT 4: } \\
(\text { DAY 1) }\end{array}$} & 0 & 17.48 & 48.25 \\
\hline & 15 & 2.18 & 6.45 \\
\hline & 30 & 1.91 & 5.51 \\
\hline & 45 & 1.73 & 4.90 \\
\hline & 60 & 1.64 & 4.42 \\
\hline & 120 & 1.22 & 3.40 \\
\hline & 240 & 1.08 & 3.22 \\
\hline & 360 & 1.02 & 3.19 \\
\hline & 600 & 0.78 & 2.89 \\
\hline & 990 & 0.67 & 2.67 \\
\hline & 1365 & 0.67 & 2.67 \\
\hline \multirow{11}{*}{$\begin{array}{l}\text { SEPT 5: } \\
\text { (DAY 2) }\end{array}$} & 0 & - & - \\
\hline & 15 & 3.12 & 7.88 \\
\hline & 30 & 2.62 & 6.02 \\
\hline & 45 & 2.38 & 5.04 \\
\hline & 60 & 2.17 & 4.48 \\
\hline & 120 & 1.72 & 3.50 \\
\hline & 210 & 1.35 & 2.76 \\
\hline & 330 & 1.19 & 2.75 \\
\hline & 570 & 0.95 & 2.44 \\
\hline & 930 & 0.90 & 2.26 \\
\hline & 1320 & 0.87 & 2.20 \\
\hline
\end{tabular}


ULTRAFILTRATION MEMBRANES: PILOT STUDY \#1 (CONT)

21-DAY PILOT PLAN RUN: SEPTEMBER 4-OCTOBER 3, 1991

\begin{tabular}{|c|c|c|c|}
\hline & $\begin{array}{c}\text { TIME } \\
\text { (Min.) }\end{array}$ & $\begin{array}{c}\text { MEMBRANE A } \\
(G F D)\end{array}$ & $\begin{array}{c}\text { MEMBRANE B } \\
(\text { GFD })\end{array}$ \\
\hline \multirow{11}{*}{$\begin{array}{l}\text { SEPT 6: } \\
\text { (DAY 3) }\end{array}$} & 0 & - & - \\
\hline & 15 & 2.97 & 7.35 \\
\hline & 30 & 2.67 & 5.49 \\
\hline & 45 & 2.37 & 4.68 \\
\hline & 60 & 2.24 & 4.28 \\
\hline & 120 & 1.88 & 3.42 \\
\hline & 240 & 1.49 & 2.85 \\
\hline & 350 & 1.24 & 2.55 \\
\hline & 615 & 1.13 & 2.59 \\
\hline & 990 & 0.97 & 2.28 \\
\hline & 1350 & 0.89 & 2.13 \\
\hline \multirow{11}{*}{$\begin{array}{l}\text { SEPT 9: } \\
\text { (DAY 4) }\end{array}$} & 0 & - & - \\
\hline & 15 & 3.12 & 6.01 \\
\hline & 30 & 2.60 & 5.05 \\
\hline & 45 & 2.39 & 4.55 \\
\hline & 60 & 2.27 & 4.31 \\
\hline & 105 & 1.94 & 3.71 \\
\hline & 225 & 1.72 & 3.29 \\
\hline & 335 & 1.58 & 3.08 \\
\hline & 585 & 1.46 & 2.68 \\
\hline & 945 & 1.38 & 2.47 \\
\hline & 1335 & 1.24 & 2.44 \\
\hline
\end{tabular}


ULTRAFILTRATION MEMBRANES: PILOT STUDY \#1 (CONT)

21-DAY PILOT PLAN RUN: SEPTEMBER 4-OCTOBER 3, 1991

\begin{tabular}{|c|c|c|c|}
\hline & $\begin{array}{c}\text { TIME } \\
\text { (Min.) }\end{array}$ & $\begin{array}{c}\text { MEMBRANE A } \\
(\text { GFD })\end{array}$ & $\begin{array}{c}\text { MEMBRANE B } \\
(\text { GFD })\end{array}$ \\
\hline \multirow{11}{*}{$\begin{array}{l}\text { SEPT 10: } \\
\text { (DAY 5) }\end{array}$} & 0 & - & - \\
\hline & 15 & 2.39 & 5.54 \\
\hline & 30 & 2.10 & 4.70 \\
\hline & 45 & 2.00 & 4.31 \\
\hline & 60 & 1.85 & 4.00 \\
\hline & 120 & 1.59 & 3.37 \\
\hline & 310 & 1.57 & 3.14 \\
\hline & 430 & 1.47 & 2.97 \\
\hline & 675 & 1.41 & 2.63 \\
\hline & 1035 & 1.30 & 2.38 \\
\hline & 1320 & 1.13 & 2.14 \\
\hline \multirow{11}{*}{$\begin{array}{l}\text { SEPT 11: } \\
\text { (DAY 6) }\end{array}$} & 0 & - & - \\
\hline & 15 & 1.16 & 4.26 \\
\hline & 30 & 0.96 & 4.00 \\
\hline & 45 & 0.86 & 3.75 \\
\hline & 60 & 0.86 & 3.55 \\
\hline & 105 & 0.71 & 3.24 \\
\hline & 225 & 0.54 & 2.82 \\
\hline & 335 & 0.46 & 2.60 \\
\hline & 705 & 0.32 & 2.24 \\
\hline & 955 & 0.20 & 2.02 \\
\hline & 1305 & 0.13 & 1.82 \\
\hline
\end{tabular}


ULTRAFILTRATION MEMBRANES: PILOT STUDY \#1 (CONT)

21-DAY PILOT PLAN RUN: SEPTEMBER 4-OCTOBER 3, 1991

\begin{tabular}{|c|c|c|c|}
\hline & $\begin{array}{c}\text { TIME } \\
\text { (Min.) } \\
\end{array}$ & $\begin{array}{c}\text { MEMBRANE A } \\
\text { (GFD) }\end{array}$ & $\begin{array}{c}\text { MEMBRANE B } \\
(\text { GFD })\end{array}$ \\
\hline \multirow{10}{*}{$\begin{array}{l}\text { SEPT 12: } \\
(\text { DAY } 7)\end{array}$} & 0 & 0.91 & 17.65 \\
\hline & 15 & 0.40 & 3.93 \\
\hline & 45 & 0.34 & 3.34 \\
\hline & 60 & 0.29 & 3.13 \\
\hline & 120 & 0.30 & 2.89 \\
\hline & 210 & 0.24 & 2.66 \\
\hline & 330 & 0.22 & 2.52 \\
\hline & 680 & 0.13 & 2.30 \\
\hline & 965 & 0.11 & 2.10 \\
\hline & 1290 & 0.06 & 1.96 \\
\hline \multirow{10}{*}{$\begin{array}{l}\text { SEPT 13: } \\
\text { (DAY 8) }\end{array}$} & 0 & 0.76 & 17.33 \\
\hline & 15 & 0.23 & 3.35 \\
\hline & 30 & 0.21 & 2.89 \\
\hline & 45 & 0.17 & 2.74 \\
\hline & 60 & 0.15 & 2.49 \\
\hline & 120 & 0.15 & 2.24 \\
\hline & 210 & 0.15 & 2.13 \\
\hline & 305 & 0.15 & 1.98 \\
\hline & 570 & 0.13 & 1.83 \\
\hline & 1350 & 0.04 & 1.57 \\
\hline
\end{tabular}


ULTRAFILTRATION MEMBRANES: PILOT STUDY \#1 (CONT)

21-DAY PILOT PLAN RUN: SEPTEMBER 4-OCTOBER 3, 1991

\begin{tabular}{|c|c|c|c|}
\hline & $\begin{array}{c}\text { TIME } \\
(\operatorname{Min} .) \\
\end{array}$ & $\begin{array}{c}\text { MEMBRANE A } \\
(\mathrm{GFD})\end{array}$ & $\begin{array}{c}\text { MEMBRANE B } \\
(\mathrm{GFD})\end{array}$ \\
\hline \multirow{11}{*}{$\begin{array}{l}\text { SEPT 16: } \\
\text { (DAY 9) }\end{array}$} & 0 & - & - \\
\hline & 15 & 5.40 & 2.85 \\
\hline & 30 & 5.00 & 2.41 \\
\hline & 43 & 4.86 & 2.35 \\
\hline & 60 & 4.75 & 2.28 \\
\hline & 120 & 4.43 & 2.10 \\
\hline & 240 & 4.13 & 1.96 \\
\hline & 345 & 4.01 & 1.96 \\
\hline & 600 & 3.45 & 1.75 \\
\hline & 915 & 3.14 & 1.55 \\
\hline & 1320 & 2.80 & 1.46 \\
\hline \multirow{11}{*}{$\begin{array}{l}\text { SEPT 17: } \\
\text { (DAY 10) }\end{array}$} & 0 & 26.62 & 1.94 \\
\hline & 15 & 5.46 & 2.37 \\
\hline & 30 & 5.06 & 2.13 \\
\hline & 45 & 4.82 & 2.02 \\
\hline & 60 & 4.72 & 1.95 \\
\hline & 120 & 4.46 & 1.88 \\
\hline & 210 & 4.21 & 1.80 \\
\hline & 300 & 4.00 & 1.74 \\
\hline & 585 & 3.57 & 1.57 \\
\hline & 935 & 3.20 & 1.44 \\
\hline & 1290 & 2.96 & 1.40 \\
\hline
\end{tabular}


ULTRAFILTRATION MEMBRANES: PILOT STUDY \#1 (CONT)

21-DAY PILOT PLAN RUN: SEPTEMBER 4-OCTOBER 3, 1991

\begin{tabular}{|c|c|c|c|}
\hline & $\begin{array}{c}\text { TIME } \\
\text { (Min.) }\end{array}$ & $\begin{array}{c}\text { MEMBRANE A } \\
(\text { GFD })\end{array}$ & $\begin{array}{c}\text { MEMBRANE b } \\
(\text { GFD })\end{array}$ \\
\hline \multirow{11}{*}{$\begin{array}{l}\text { SEPT 18: } \\
(\text { DAY 11) }\end{array}$} & 0 & 60.61 & 6.31 \\
\hline & 15 & 4.43 & 2.00 \\
\hline & 30 & 4.22 & 1.94 \\
\hline & 45 & 4.18 & 1.90 \\
\hline & 60 & 3.98 & 1.84 \\
\hline & 105 & 3.93 & 1.77 \\
\hline & 225 & 3.57 & 1.66 \\
\hline & 345 & 3.05 & 1.45 \\
\hline & 585 & 2.43 & 1.20 \\
\hline & 945 & 2.00 & 0.99 \\
\hline & 1305 & 1.77 & 0.84 \\
\hline \multirow{10}{*}{$\begin{array}{l}\text { SEPT } 19 \\
(\text { DAY } 12)\end{array}$} & 0 & 46.08 & 4.46 \\
\hline & 15 & 5.14 & 2.03 \\
\hline & 30 & 4.69 & 1.93 \\
\hline & 45 & 4.53 & 1.85 \\
\hline & 60 & 4.41 & 1.88 \\
\hline & 120 & 4.10 & 1.82 \\
\hline & 360 & 3.22 & 1.43 \\
\hline & 720 & 2.54 & 1.03 \\
\hline & 1050 & 2.24 & .89 \\
\hline & 1350 & 2.24 & .89 \\
\hline
\end{tabular}


ULTRAFILTRATION MEMBRANES: PILOT STUDY \#1 (CONT)

21-DAY PILOT PLAN RUN: SEPTEMBER 4-OCTOBER 3, 1991

\begin{tabular}{|c|c|c|c|}
\hline & $\begin{array}{c}\text { TIME } \\
\text { (Min.) }\end{array}$ & $\begin{array}{l}\text { MEMBRANE A } \\
(\text { GFD })\end{array}$ & $\begin{array}{c}\text { MEMBRANE B } \\
(\text { GFD })\end{array}$ \\
\hline \multirow{8}{*}{$\begin{array}{l}\text { SEPT. } 20 \\
(\text { DAY } 13)\end{array}$} & 0 & - & $\overline{ }$ \\
\hline & 15 & 4.81 & 1.80 \\
\hline & 30 & 4.33 & 1.61 \\
\hline & 45 & 4.28 & 1.58 \\
\hline & 75 & 4.03 & 1.52 \\
\hline & 350 & 2.92 & 1.12 \\
\hline & 715 & 2.38 & .92 \\
\hline & 1295 & 2.00 & .81 \\
\hline \multirow{11}{*}{$\begin{array}{l}\text { SEPT } 23 \\
\text { (DAY } 14)\end{array}$} & 0 & 42.00 & 4.10 \\
\hline & 15 & 4.45 & 1.67 \\
\hline & 30 & 4.16 & 1.56 \\
\hline & 45 & 4.06 & 1.56 \\
\hline & 60 & 3.95 & 1.52 \\
\hline & 120 & 3.80 & 1.48 \\
\hline & 240 & 3.53 & 1.41 \\
\hline & 360 & 3.34 & 1.32 \\
\hline & 595 & 3.42 & 1.13 \\
\hline & 970 & 2.44 & 0.98 \\
\hline & 1320 & 2.11 & 0.86 \\
\hline
\end{tabular}


ULTRAFILTRATION MEMBRANES: PILOT STUDY \#1 (CONT)

21-DAY PILOT PLAN RUN: SEPTEMBER 4-OCTOBER 3, 1991

\begin{tabular}{|c|c|c|c|}
\hline & $\begin{array}{l}\text { TIME } \\
\text { (Min.) }\end{array}$ & $\begin{array}{c}\text { MEMBRANE A } \\
(\text { GFD })\end{array}$ & $\begin{array}{c}\text { MEMBRANE B } \\
\text { (GFD) }\end{array}$ \\
\hline \multirow{11}{*}{$\begin{array}{l}\text { SEPT 24: } \\
\text { (DAY 15) }\end{array}$} & 0 & 38.92 & 3.33 \\
\hline & 15 & 5.16 & 1.58 \\
\hline & 30 & 4.98 & 1.58 \\
\hline & 45 & 4.79 & 1.58 \\
\hline & 60 & 4.70 & 1.47 \\
\hline & 120 & 4.40 & 1.49 \\
\hline & 240 & 3.95 & 1.16 \\
\hline & 330 & 3.73 & 1.29 \\
\hline & 600 & 3.01 & 0.99 \\
\hline & 990 & 2.55 & 0.89 \\
\hline & 1320 & 2.34 & 0.82 \\
\hline \multirow{11}{*}{$\begin{array}{l}\text { SEPT: } 25 \\
\text { (DAY } 16)\end{array}$} & 0 & 34.82 & 3.21 \\
\hline & 15 & 5.46 & 1.20 \\
\hline & 30 & 4.06 & 1.09 \\
\hline & 45 & 3.70 & 1.04 \\
\hline & 60 & 3.56 & 1.02 \\
\hline & 105 & 3.47 & 1.02 \\
\hline & 225 & 3.20 & 0.95 \\
\hline & 345 & 2.99 & 0.87 \\
\hline & 585 & 2.69 & 0.86 \\
\hline & 945 & 2.03 & 0.74 \\
\hline & 1305 & 1.55 & 0.61 \\
\hline
\end{tabular}


ULTRAFILTRATION MEMBRANES: PILOT STUDY \#1 (CONT)

21-DAY PILOT PLAN RUN: SEPTEMBER 4-OCTOBER 3, 1991

\begin{tabular}{|c|c|c|c|}
\hline & $\begin{array}{c}\text { TIME } \\
\text { (Min.) }\end{array}$ & $\begin{array}{l}\text { MEMBRANE A } \\
(\mathrm{GFD})\end{array}$ & $\begin{array}{l}\text { MEMBRANE B } \\
(\mathrm{GFD})\end{array}$ \\
\hline \multirow{11}{*}{$\begin{array}{l}\text { SEPT: } 26 \\
(\text { DAY } 17)\end{array}$} & 0 & - & - \\
\hline & 15 & 4.20 & 1.29 \\
\hline & 30 & 3.64 & 1.15 \\
\hline & 45 & 3.32 & 1.12 \\
\hline & 60 & 3.13 & 1.12 \\
\hline & 90 & 2.91 & 1.08 \\
\hline & 210 & 2.11 & 0.98 \\
\hline & 330 & 1.78 & 0. \\
\hline & 570 & 1.47 & $0 . \therefore$ \\
\hline & 930 & 1.28 & 0.65 \\
\hline & 1290 & 1.18 & 0.60 \\
\hline \multirow{10}{*}{$\begin{array}{l}\text { SEPT: } 27 \\
\text { (DAY 18) }\end{array}$} & 0 & 35.01 & 2.89 \\
\hline & 15 & 4.86 & 1.43 \\
\hline & 30 & 4.39 & 1.34 \\
\hline & 45 & 4.04 & 1.33 \\
\hline & 60 & 3.85 & 1.30 \\
\hline & 180 & 3.22 & 1.12 \\
\hline & 300 & 2.66 & 1.00 \\
\hline & 545 & 2.15 & 0.80 \\
\hline & 905 & 1.84 & 0.70 \\
\hline & 1335 & 1.68 & 0.65 \\
\hline
\end{tabular}


ULTRAFILTRATION MEMBRANES: PILOT STUDY \#1 (CONT)

21-DAY PILOT PLAN RUN: SEPTEMBER 4-OCTOBER 3, 1991

\begin{tabular}{|c|c|c|c|}
\hline & $\begin{array}{l}\text { TIME } \\
\text { (Min.) }\end{array}$ & $\begin{array}{c}\text { MEMBRANE A } \\
\text { (GFD) }\end{array}$ & $\begin{array}{c}\text { MEMBRANE B } \\
\text { (GFD) }\end{array}$ \\
\hline \multirow{10}{*}{$\begin{array}{l}\text { SEPT: } 30 \\
\text { (DAY } 19)\end{array}$} & 0 & 40.64 & 4.46 \\
\hline & 15 & 4.85 & 1.52 \\
\hline & 30 & 4.49 & 1.48 \\
\hline & 45 & 3.97 & 1.26 \\
\hline & 60 & 3.68 & 1.29 \\
\hline & 120 & 3.78 & 1.27 \\
\hline & 245 & 3.51 & 1.22 \\
\hline & 360 & 3.41 & 1.19 \\
\hline & 780 & 2.85 & 0.93 \\
\hline & 1320 & 2.76 & 0.82 \\
\hline \multirow{10}{*}{$\begin{array}{l}\text { OCT: } 1 \\
(\text { DAY } 20)\end{array}$} & 0 & 42.47 & 4.56 \\
\hline & 15 & 5.45 & 1.72 \\
\hline & 30 & 4.81 & 1.60 \\
\hline & 45 & 4.48 & 1.51 \\
\hline & 60 & 4.43 & 1.49 \\
\hline & 120 & 4.20 & 1.42 \\
\hline & 240 & 3.90 & 1.37 \\
\hline & 360 & $3: 72$ & 1.31 \\
\hline & 780 & 2.94 & 1.02 \\
\hline & 1320 & 2.33 & 0.86 \\
\hline
\end{tabular}


ULTRAFILTRATION MEMBRANES: PILOT STUDY \#1 (CONT)

21-DAY PILOT PLAN RUN: SEPTEMBER 4-OCTOBER 3, 1991

\begin{tabular}{||c|c|c|c|}
\hline \multirow{4}{*}{$\begin{array}{c}\text { OCT : } 2 \\
\text { (DAY } 21)\end{array}$} & 0 & 44.49 & 4.51 \\
\cline { 2 - 4 } & 15 & 5.01 & 1.47 \\
\cline { 2 - 4 } & 30 & 4.63 & 1.42 \\
\hline 45 & 4.54 & 1.42 \\
\hline 60 & 4.40 & 1.39 \\
\hline 120 & 4.16 & 1.37 \\
\hline 240 & 3.45 & 1.32 \\
\hline 360 & 2.69 & 1.14 \\
\hline & 780 & 1.34 & 0.64 \\
\hline & 1270 & 0.88 & 0.41 \\
\hline
\end{tabular}


5-DAY PILOT RUN: OCT 11 - OCT 17, 1991: STUDY \#2

\begin{tabular}{|c|c|c|c|}
\hline & $\begin{array}{c}\text { TIME } \\
\text { (Min.) }\end{array}$ & $\begin{array}{c}\text { MEMBRANE A } \\
(\mathrm{GFD})\end{array}$ & $\begin{array}{c}\text { MEMBRANE B } \\
(\mathrm{GFD}) \\
\end{array}$ \\
\hline \multirow{10}{*}{$\begin{array}{ll}\text { OCT: } & 11 \\
(\text { DAY } & 1)\end{array}$} & 0 & 31.50 & 5.99 \\
\hline & 20 & 16.83 & 3.98 \\
\hline & 30 & 14.96 & 3.86 \\
\hline & 45 & 13.64 & 4.00 \\
\hline & 60 & 12.51 & 3.98 \\
\hline & 90 & 11.43 & 4.28 \\
\hline & 345 & 7.83 & 5.83 \\
\hline & 585 & 7.58 & 5.86 \\
\hline & 1035 & 10.08 & 5.81 \\
\hline & 1310 & 9.18 & 5.81 \\
\hline \multirow{11}{*}{$\begin{array}{l}\text { OCT: } 14 \\
\text { (DAY } 2)\end{array}$} & 0 & 92.27 & 20.29 \\
\hline & 15 & 22.23 & 9.12 \\
\hline & 30 & 21.61 & 9.27 \\
\hline & 45 & 21.30 & 9.34 \\
\hline & 60 & 19.94 & 9.21 \\
\hline & 120 & 12.90 & 8.21 \\
\hline & 240 & 6.33 & 5.74 \\
\hline & 360 & 5.03 & 4.39 \\
\hline & 972 & 5.10 & 3.53 \\
\hline & 1325 & 6.33 & 3.96 \\
\hline & 1330 & 6.33 & 3.9 \\
\hline
\end{tabular}


5-DAY PILOT RUN: OCT 11 - OCT 17, 1991: PLANT \#2 (CONT)

\begin{tabular}{|c|c|c|c|}
\hline & $\begin{array}{c}\text { TIME } \\
\text { (Min.) }\end{array}$ & $\begin{array}{c}\text { MEMBRANE A } \\
(G F D) \\
\end{array}$ & $\begin{array}{c}\text { MEMBRANE B } \\
(G F D)\end{array}$ \\
\hline \multirow{11}{*}{$\begin{array}{c}\text { OCT: } 15 \\
(\text { DAY } 3)\end{array}$} & 0 & 95.14 & 20.19 \\
\hline & 15 & 16.68 & 9.21 \\
\hline & 30 & 16.56 & 9.06 \\
\hline & 45 & 16.38 & 9.34 \\
\hline & 60 & 15.92 & 9.24 \\
\hline & 120 & 14.08 & 9.29 \\
\hline & 180 & 12.83 & 8.41 \\
\hline & 426 & 8.04 & 5.34 \\
\hline & 736 & 6.35 & 4.48 \\
\hline & 1085 & 5.98 & 4.30 \\
\hline & 1140 & 6.04 & 4.33 \\
\hline \multirow{12}{*}{$\begin{array}{l}\text { OCT: } 16 \\
\text { (DAY } 4 \text { ) }\end{array}$} & 0 & 98.97 & 18.43 \\
\hline & 15 & 14.97 & 8.26 \\
\hline & 30 & 15.11 & 8.29 \\
\hline & 45 & 15.40 & 8.61 \\
\hline & 60 & 15.77 & 8.77 \\
\hline & 115 & 17.03 & 9.22 \\
\hline & 240 & 17.27 & 9.07 \\
\hline & 335 & 14.25 & 8.01 \\
\hline & 607 & 6.96 & 4.20 \\
\hline & 940 & 6.48 & 3.50 \\
\hline & 1265 & 9.94 & 3.61 \\
\hline & 1305 & 7.04 & 3.71 \\
\hline
\end{tabular}


5-DAY PILO'T RUN: OCT 11 - OCT 17, 1991: PLANT \#2 (CONT)

\begin{tabular}{|c|c|c|c|}
\hline & $\begin{array}{l}\text { TIME } \\
\text { (Min.) }\end{array}$ & $\begin{array}{l}\text { MEMBRANE A } \\
(\text { GFD })\end{array}$ & $\begin{array}{c}\text { MEMBRANE B } \\
(\text { GFD })\end{array}$ \\
\hline \multirow{11}{*}{$\begin{array}{l}\text { OCT: } 17 \\
\text { (DAY } 5)\end{array}$} & 0 & 93.74 & 14.05 \\
\hline & 15 & 18.57 & 7.62 \\
\hline & 30 & 18.54 & 7.86 \\
\hline & 45 & 17.69 & 7.77 \\
\hline & 60 & 16.78 & 7.81 \\
\hline & 110 & 14.96 & 7.46 \\
\hline & 240 & 9.45 & 5.68 \\
\hline & 330 & 7.73 & 4.33 \\
\hline & 1000 & 4.91 & 3.05 \\
\hline & 1275 & 5.27 & 3.25 \\
\hline & 1320 & 5.35 & 3.31 \\
\hline
\end{tabular}




\section{Appendix B2 Nomenclature}

\section{Sample Type}
A - Permeate Sample (Untreated Spiral Module)
B - Permeate Sample (Fluorinated Spiral Module)
$F=$ Feed Sample

Time Interval
$1=30$ minutes into experiment
2 - 60 minutes into experiment
3 - 360 minutes into experiment
4 - Final reading 


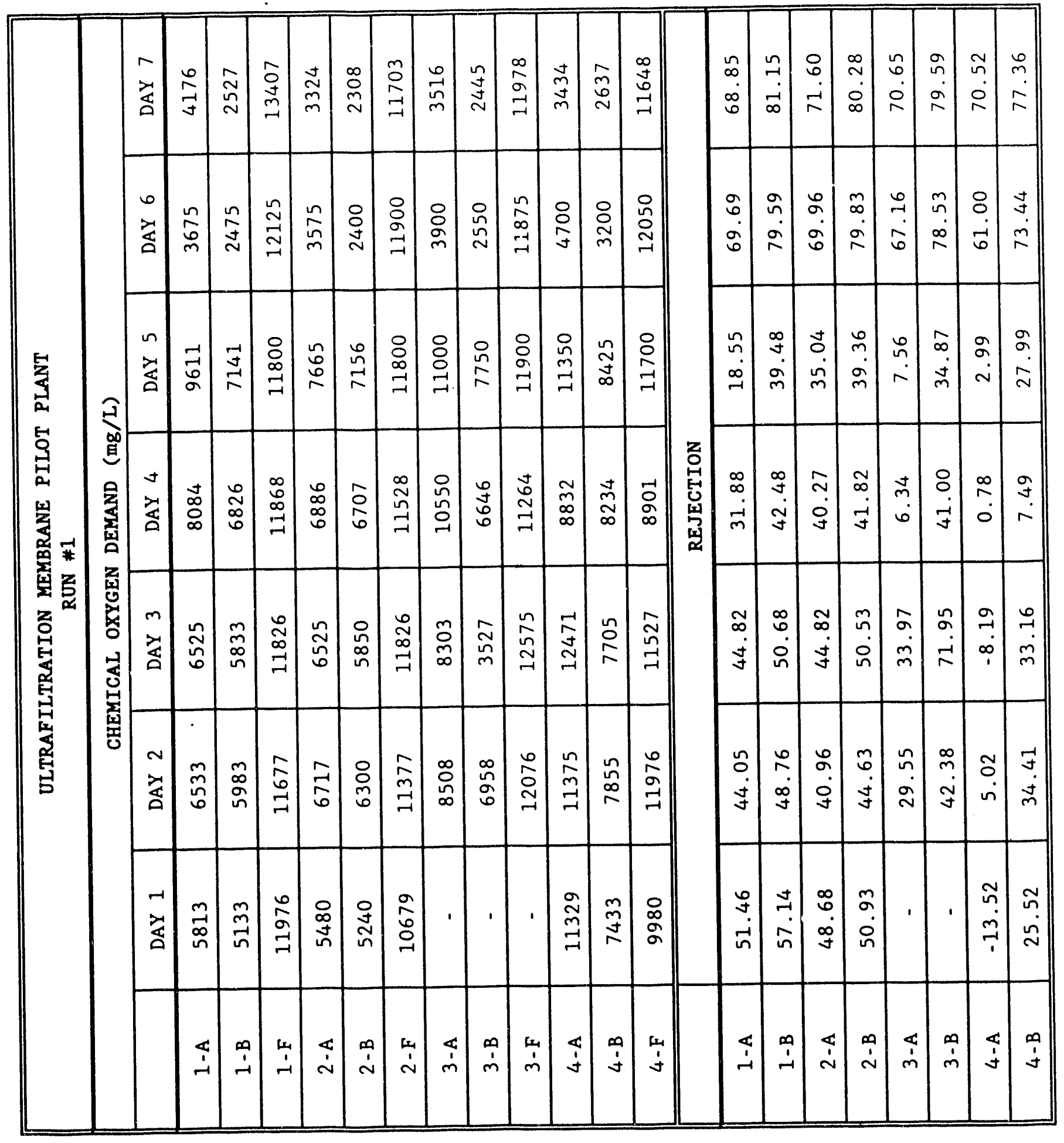




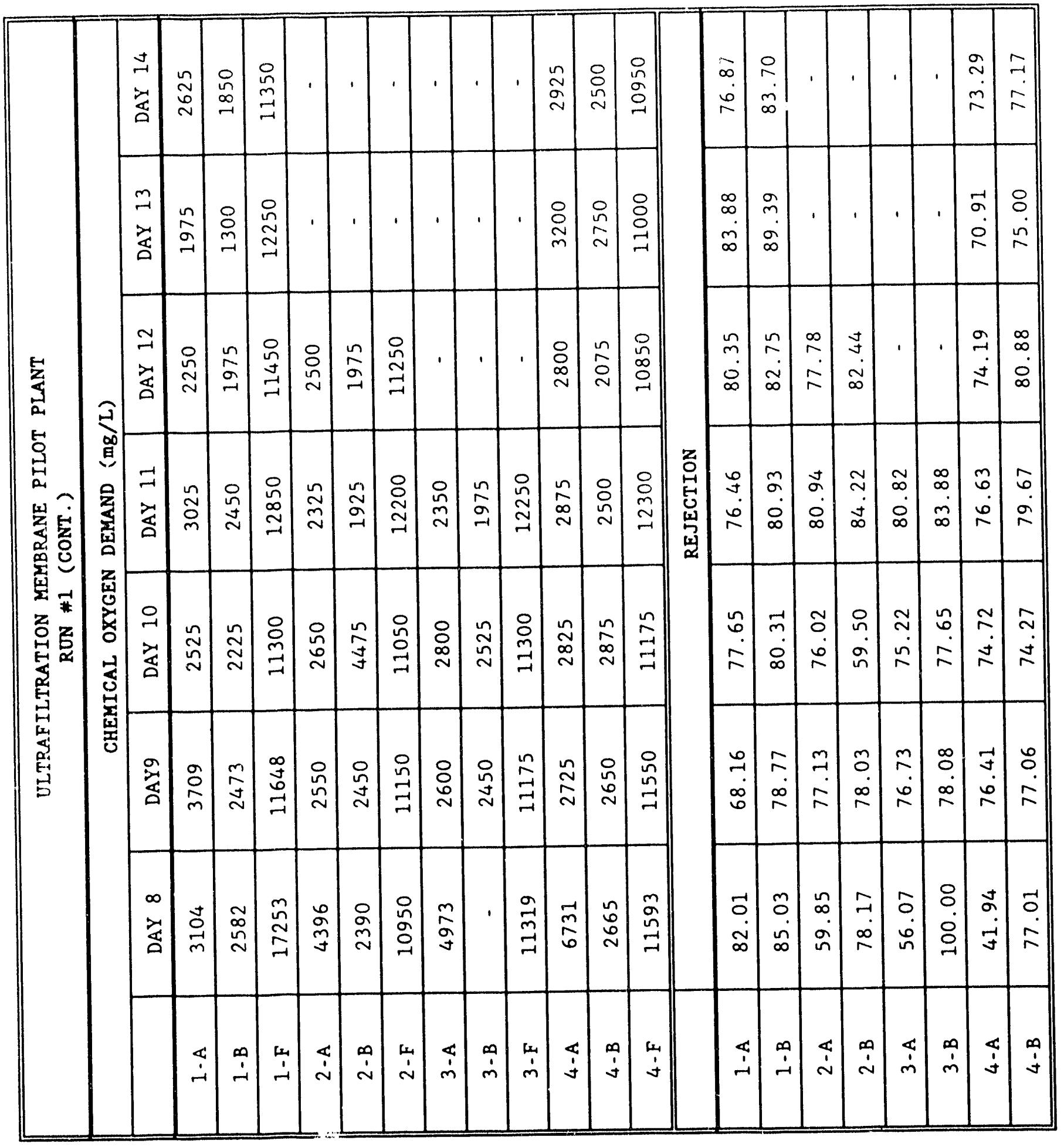




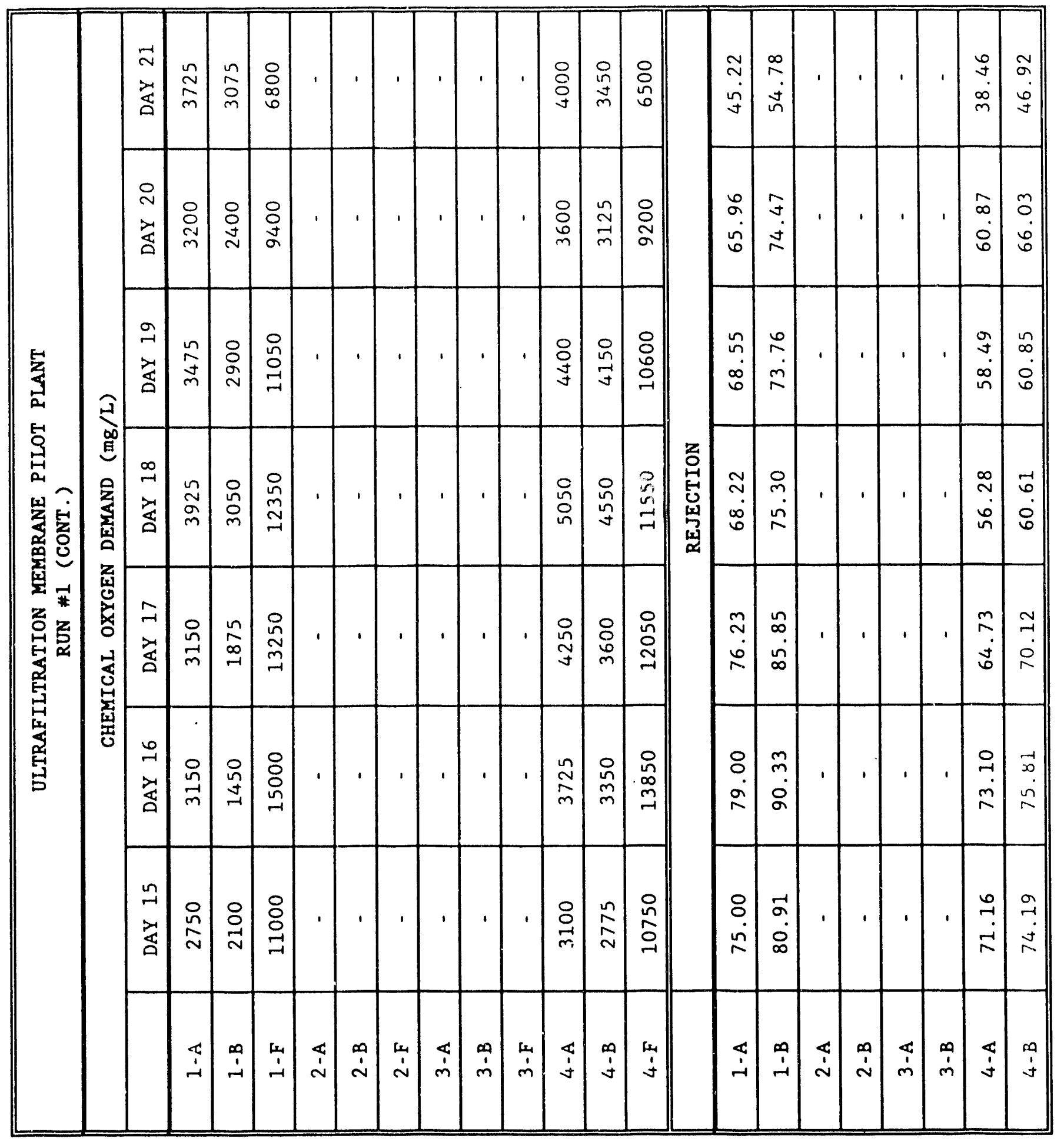



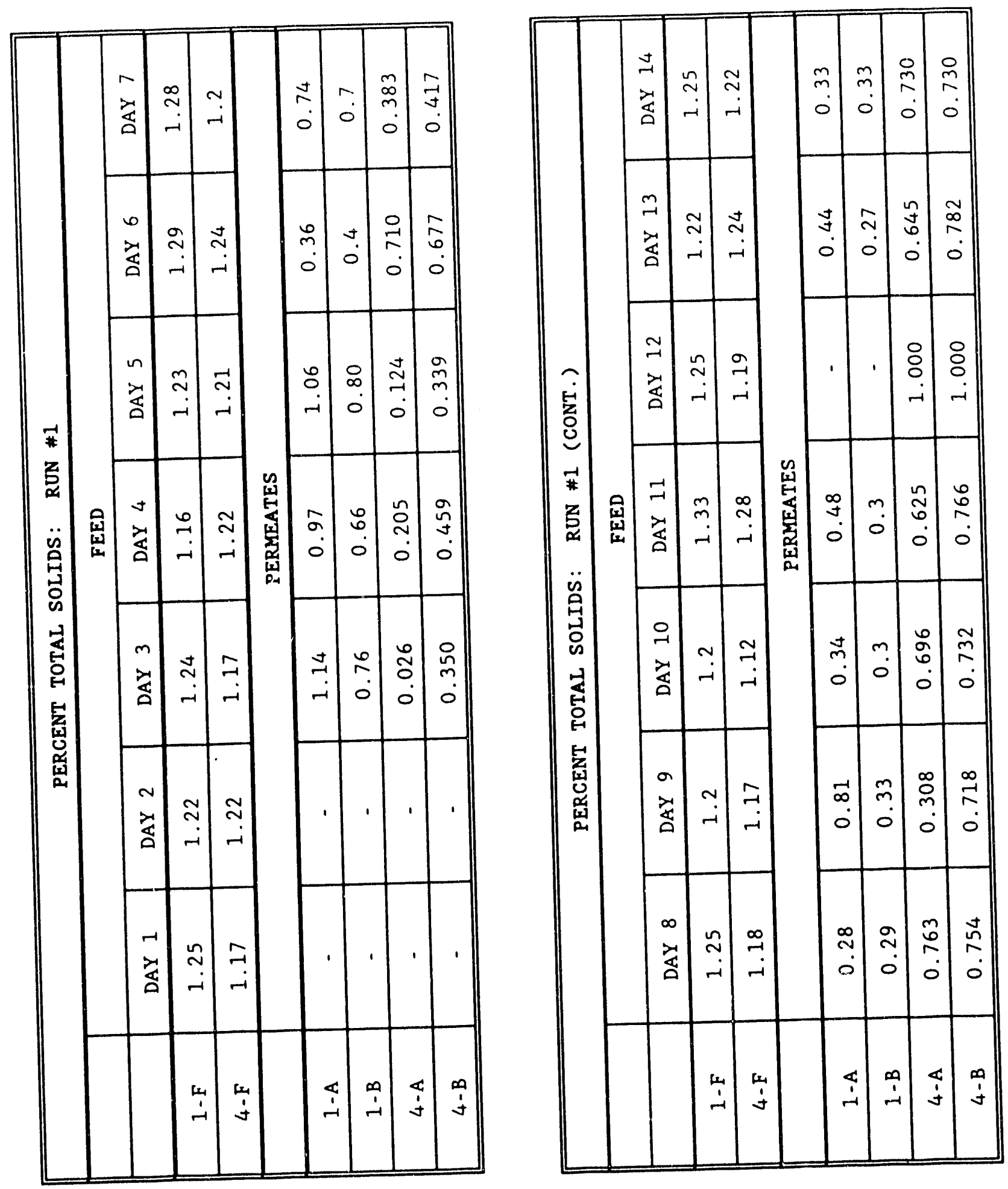


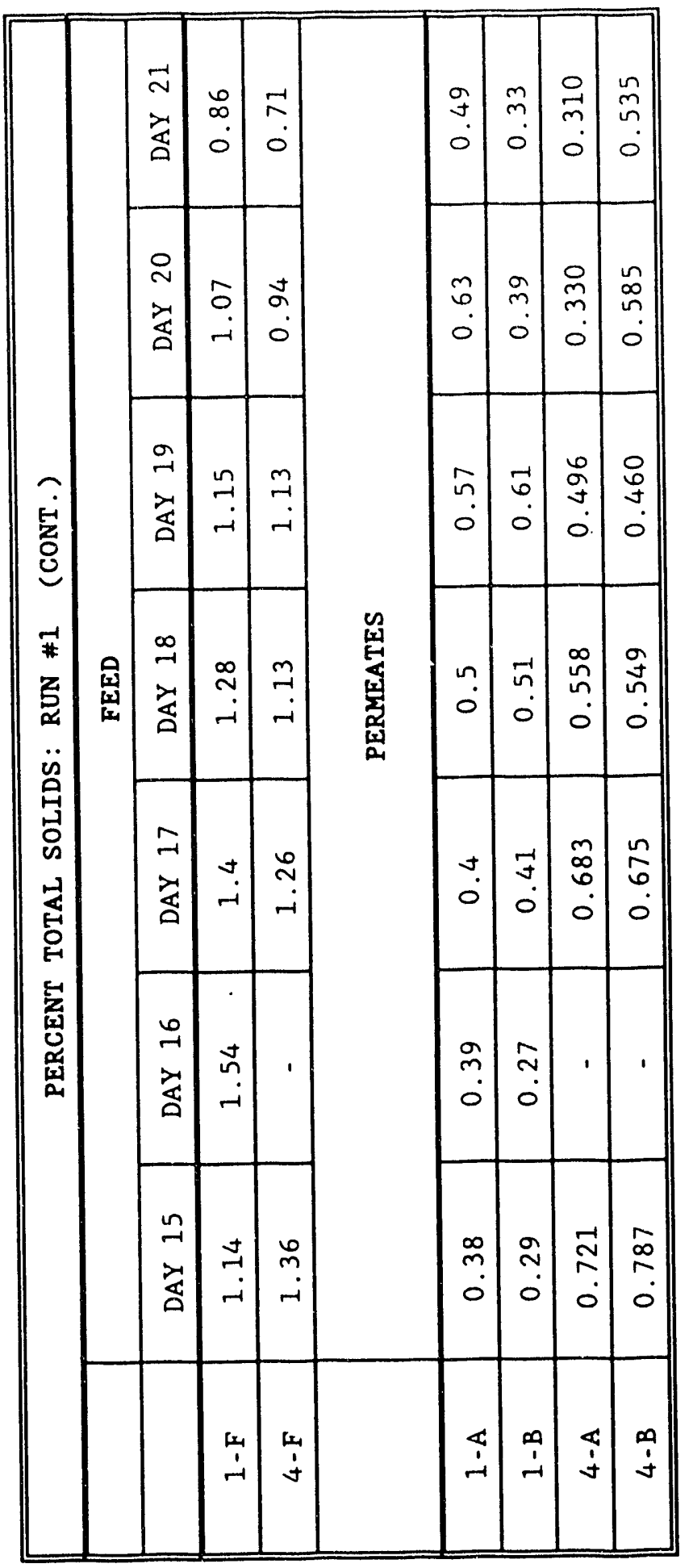




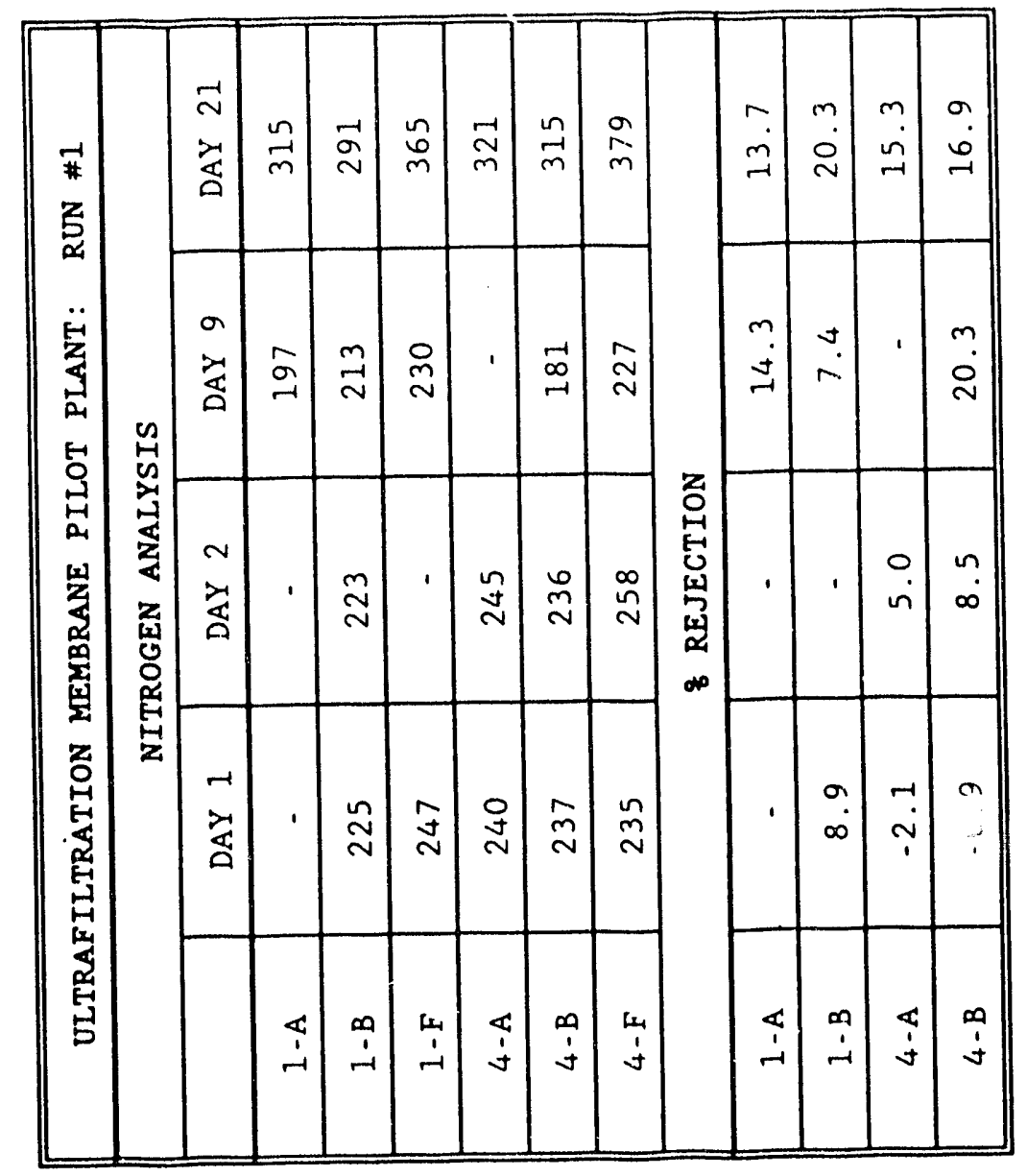




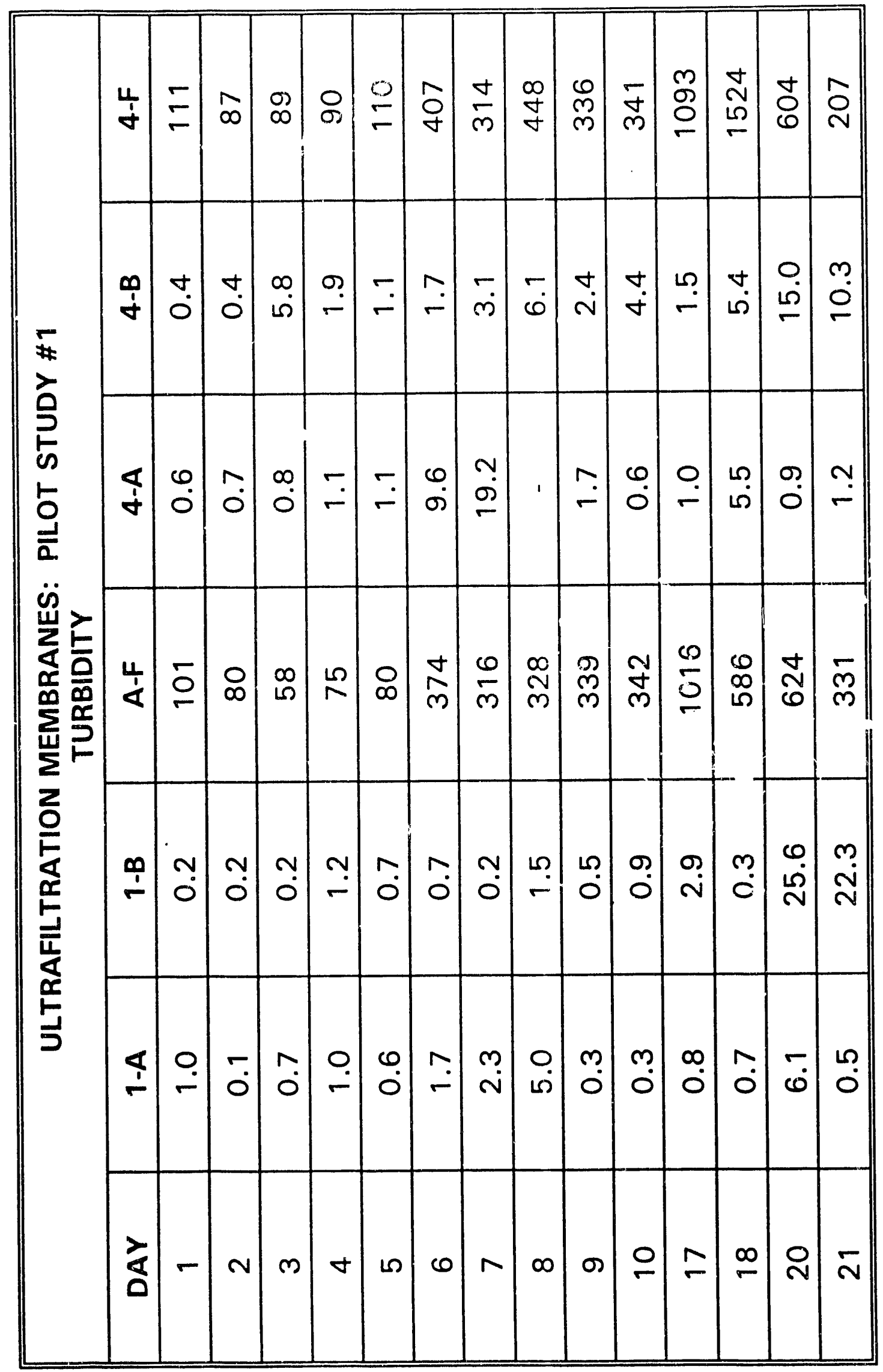




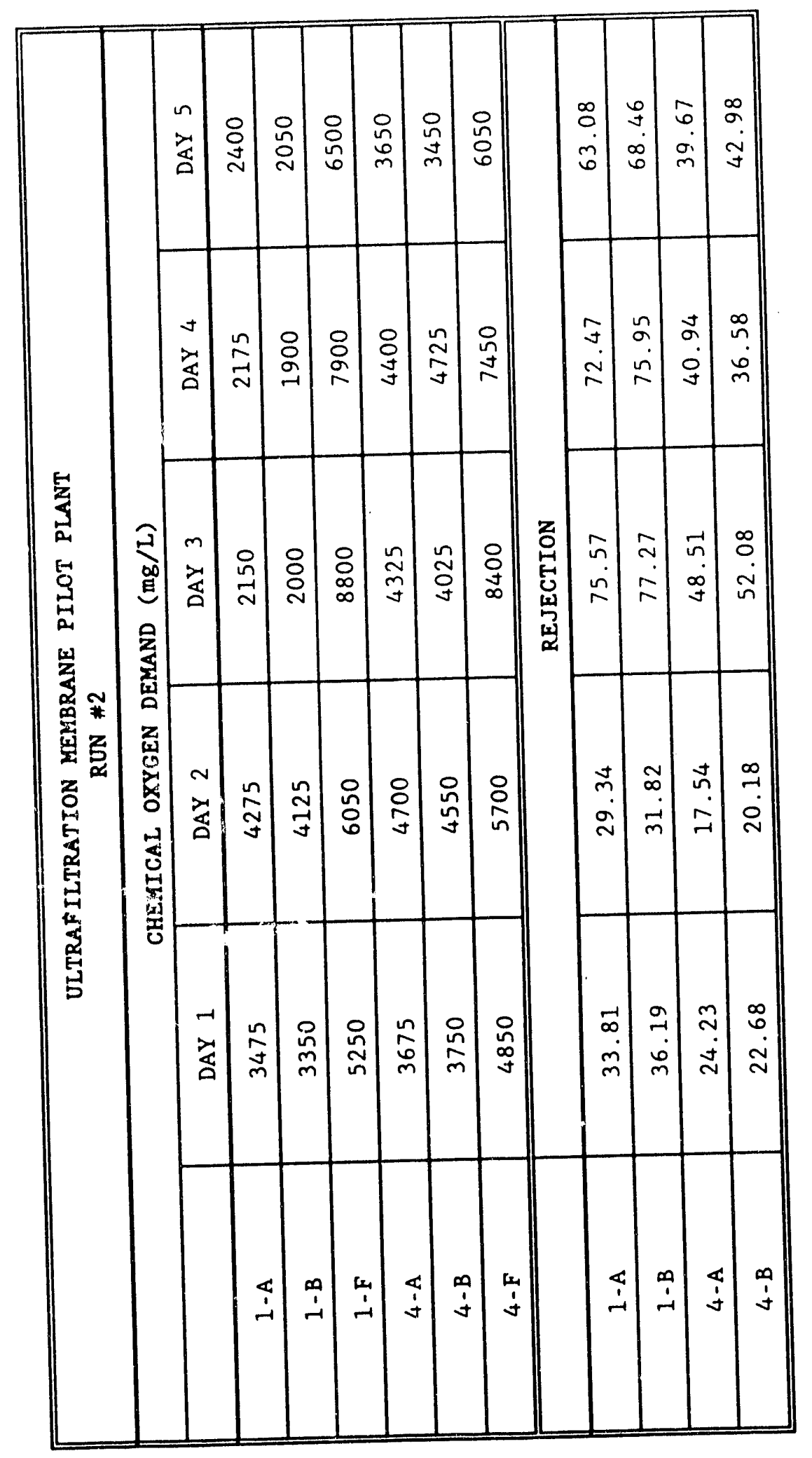




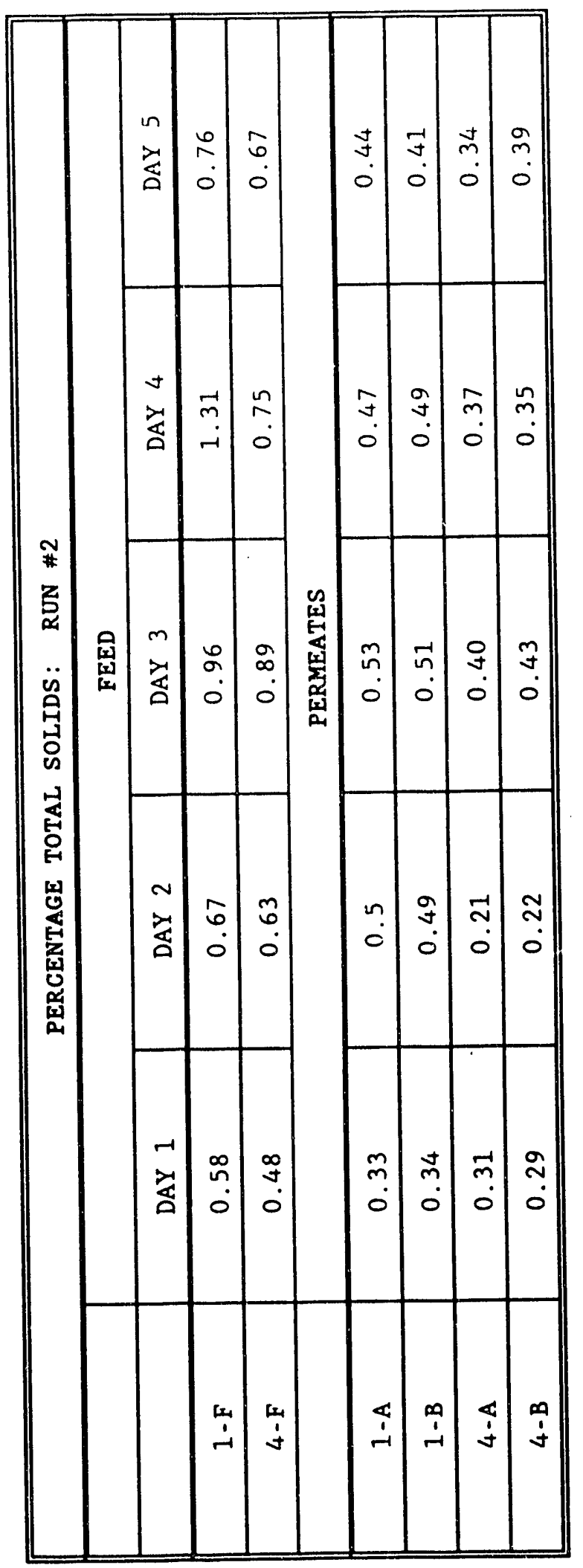




\begin{tabular}{||c|c|c|c|c|c||}
\hline \multicolumn{7}{||c||}{ ULTRAFILTRATION MEMBRANE PILOT PLANT: RUN \#2 } \\
\hline \multicolumn{7}{|c|}{ NITROGEN ANALYSIS } \\
\hline DAY 1 & DAY 2 & DAY 3 & DAY 4 & DAY 5 \\
\hline 1-A & 355 & 446 & 269 & 227 & 276 \\
\hline 1-B & 373 & 446 & 219 & 544 & 268 \\
\hline 1-F & 369 & 443 & 360 & 359 & 345 \\
\hline 4-A & 367 & 313 & 298 & 228 & 199 \\
\hline 4-B & 359 & 314 & 294 & 301 & 208 \\
\hline 4-F & 352 & 346 & 372 & 306 & 252 \\
\hline \multicolumn{7}{|c|}{$\%$ REJECTION } \\
\hline 1-A & 3.8 & -0.7 & 25.3 & 36.8 & 20.0 \\
\hline 1-B & -1.1 & -0.7 & 39.2 & -51.5 & 22.3 \\
\hline 4-A & -4.3 & 9.5 & 19.9 & 25.5 & 21.0 \\
\hline 4-B & -2.0 & 9.2 & 21.0 & 1.6 & 17.5 \\
\hline
\end{tabular}




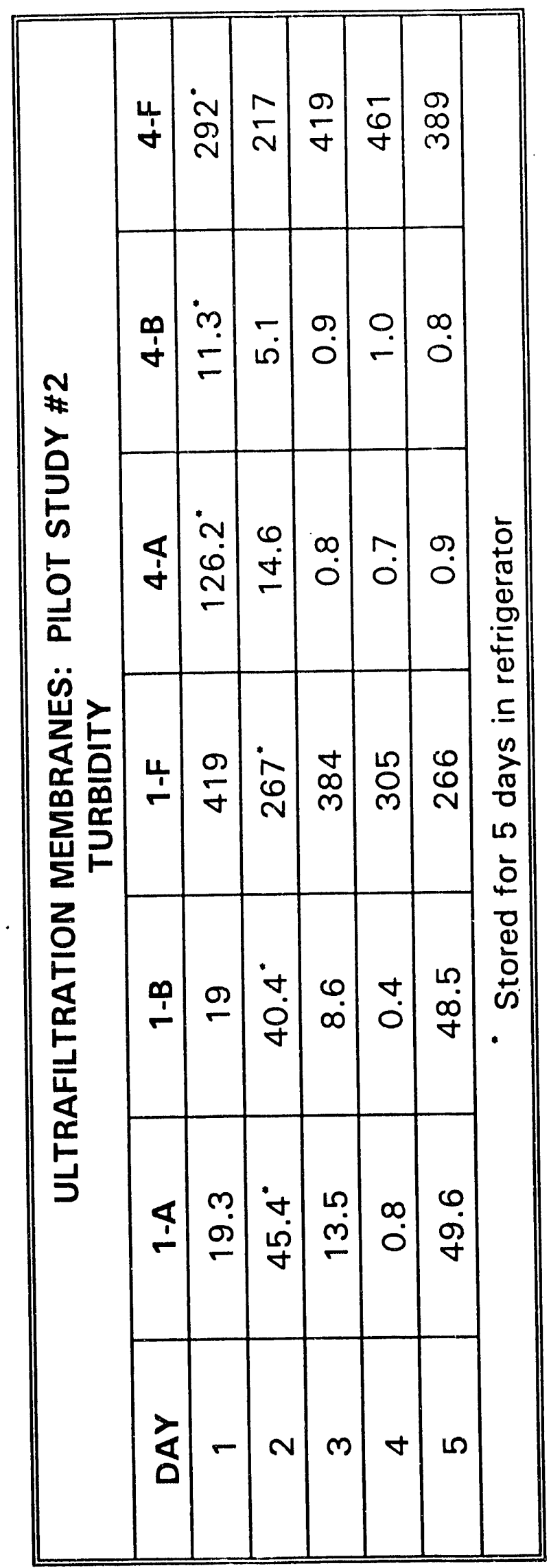


Appendix C 
I. ESCA Survey Spectra of Untreated and Fluorinated Polysulfone Membranes

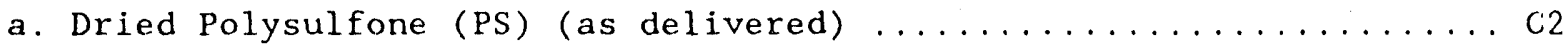

b. Fluorinated PS with 0.025 vol \& $\mathrm{F}_{2}$ in $\mathrm{N}_{2}$ for $5 \mathrm{Min} \ldots \ldots \ldots$

c. Fluorinated PS with 0.025 vol \& $\mathrm{F}_{2}$ in $\mathrm{N}_{2}$ for $30 \mathrm{Min} \ldots \ldots \ldots$

d. Fluorinated PS with 0.025 vol \& $\mathrm{F}_{2}$ in $\mathrm{N}_{2}$ for $60 \mathrm{Min} \ldots \ldots \ldots$

e. Fluorinated PS with 0.050 vol \& $\mathrm{F}_{2}$ in $\mathrm{N}_{2}$ for $120 \mathrm{Min} \ldots \ldots \ldots$

Table C1: Summary of Atomic Percentages and Binding Energies (PS) .... C7

II. ESCA Survey Spectra of Untreated and Fluorinated Polyethylene Membranes

a. Untreated Polyethlyene $(\mathrm{PE}) \ldots \ldots \ldots \ldots \ldots \ldots \ldots \ldots$

b. Fluorinated $P E$ with 0.025 vol \& $F_{2}$ in $\mathrm{N}_{2}$ for $30 \mathrm{Min} \ldots \ldots \ldots$

c. Fluorinated $\mathrm{PE}$ with 0.250 vol \& $\mathrm{F}_{2}$ in $\mathrm{N}_{2}$ for $30 \mathrm{Min} \ldots \ldots \ldots$

Table C2: Summary of Atomic Percentages and Binding Energies (PE) . . . C11

III. ESCA Survey Spectra of Untreated and Fluorinated Cellulose Acetate Membranes

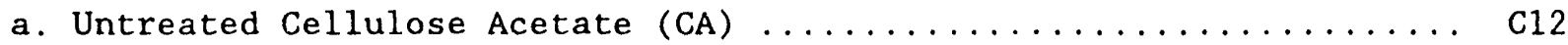

b. Fluoxinated $\mathrm{CA}$ with 0.025 vol \& $\mathrm{F}_{2}$ in $\mathrm{N}_{2}$ for $30 \mathrm{Min} \ldots \ldots \ldots 13$

Table C3: Summary of Atomic Percentages and Binding Energies (C. . . C14

IV. ESCA Survey Spectra of Cleaning Study Samples

a. Dried Polysulfone (PS) (as delivered) $\ldots \ldots \ldots \ldots \ldots \ldots \ldots$

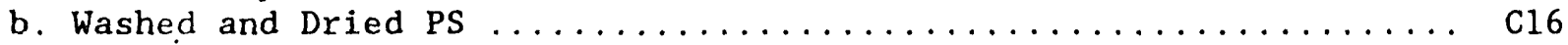

c. Fluorinated ${ }^{\star}$ PS washed with $0.88 \mathrm{H}_{2} \mathrm{SO}_{4} \ldots \ldots \ldots \ldots \ldots \ldots$

d. Fluorinated ${ }^{\star}$ PS washed with $0.88 \mathrm{NaOH} \ldots \ldots \ldots \ldots \ldots$

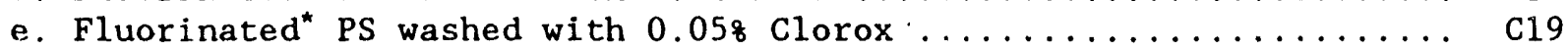

Table C4: Summary of Atomic Percentages and Binding Energies

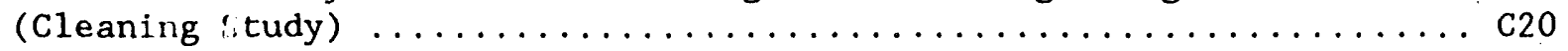

* Fluorinated PS with 0.025 vol \& $\mathrm{F}_{2}$ in $\mathrm{N}_{2}$ for $30 \mathrm{Min}$

V. ESCA Survey Spectra of Final Spiral Module Membrane Surfaces

a. Fouled Untreated Polysulfone ........................ C21

b. Fouled Fluorinated PS with 0.025 vol \& $\mathrm{F}_{2}$ in $\mathrm{N}_{2}$ for $30 \mathrm{Min} \ldots \ldots \mathrm{C} 22$

Table C5: Summary of Atomic Percentages and Binding Energies

(Pilot Plant Study) 


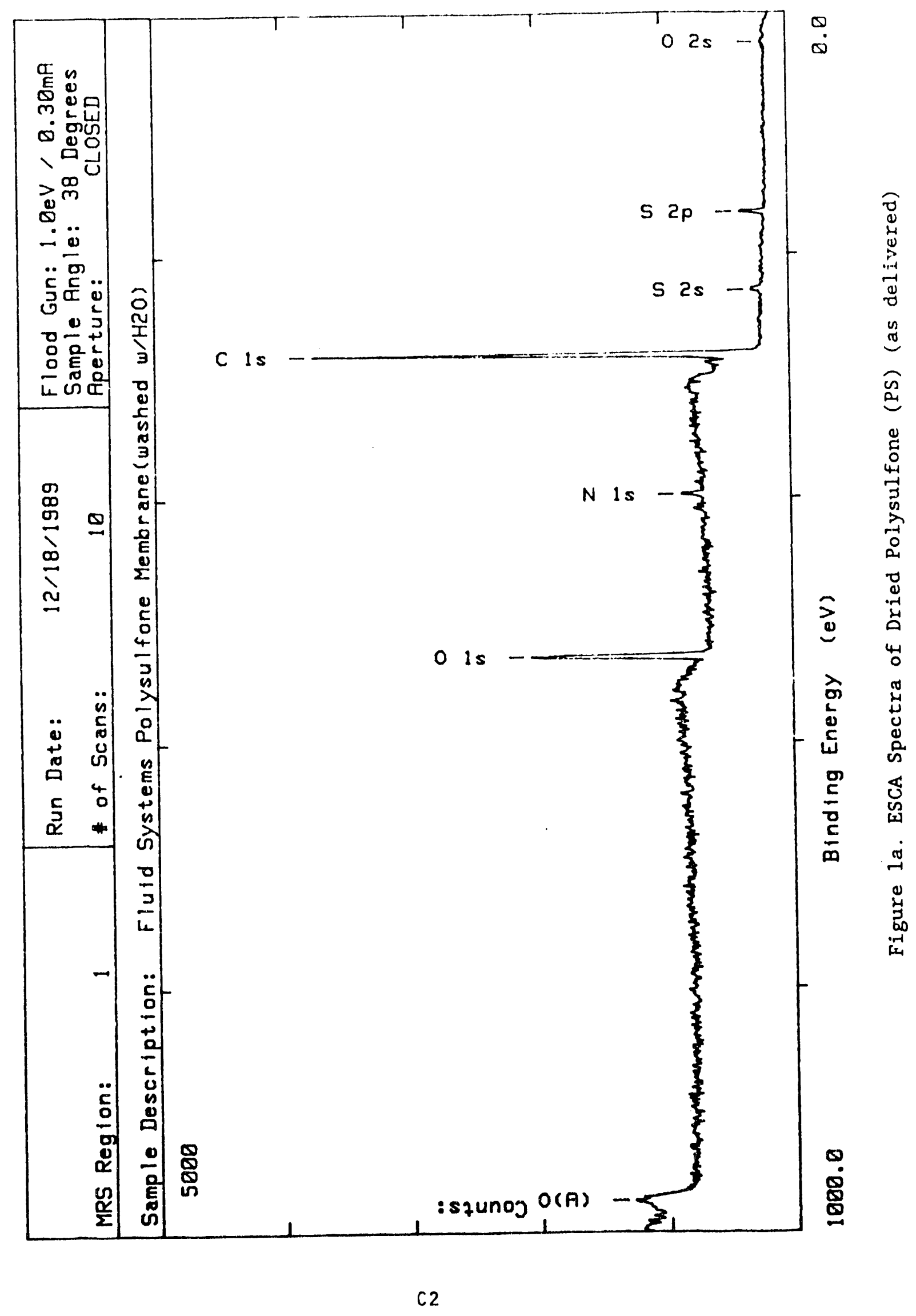




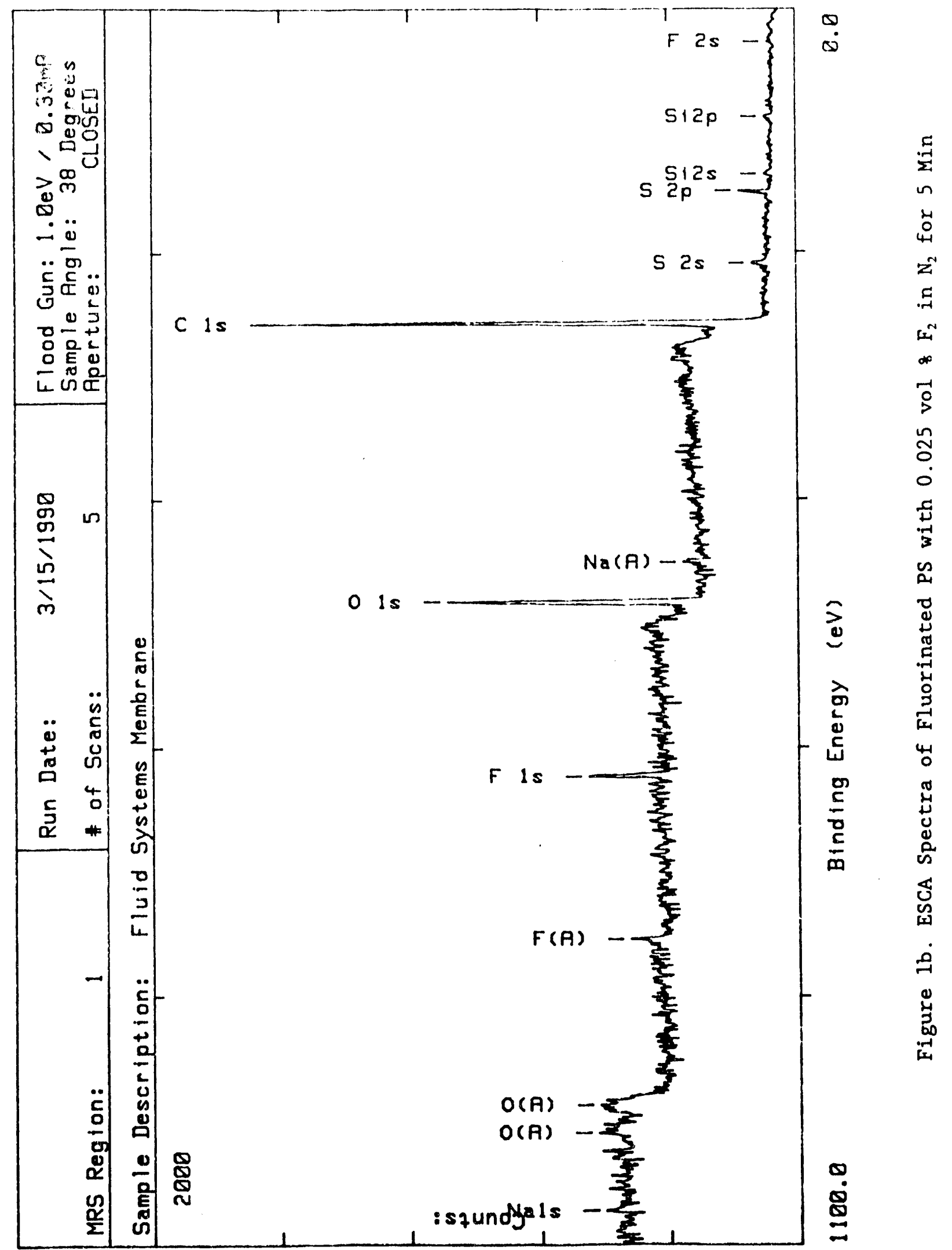




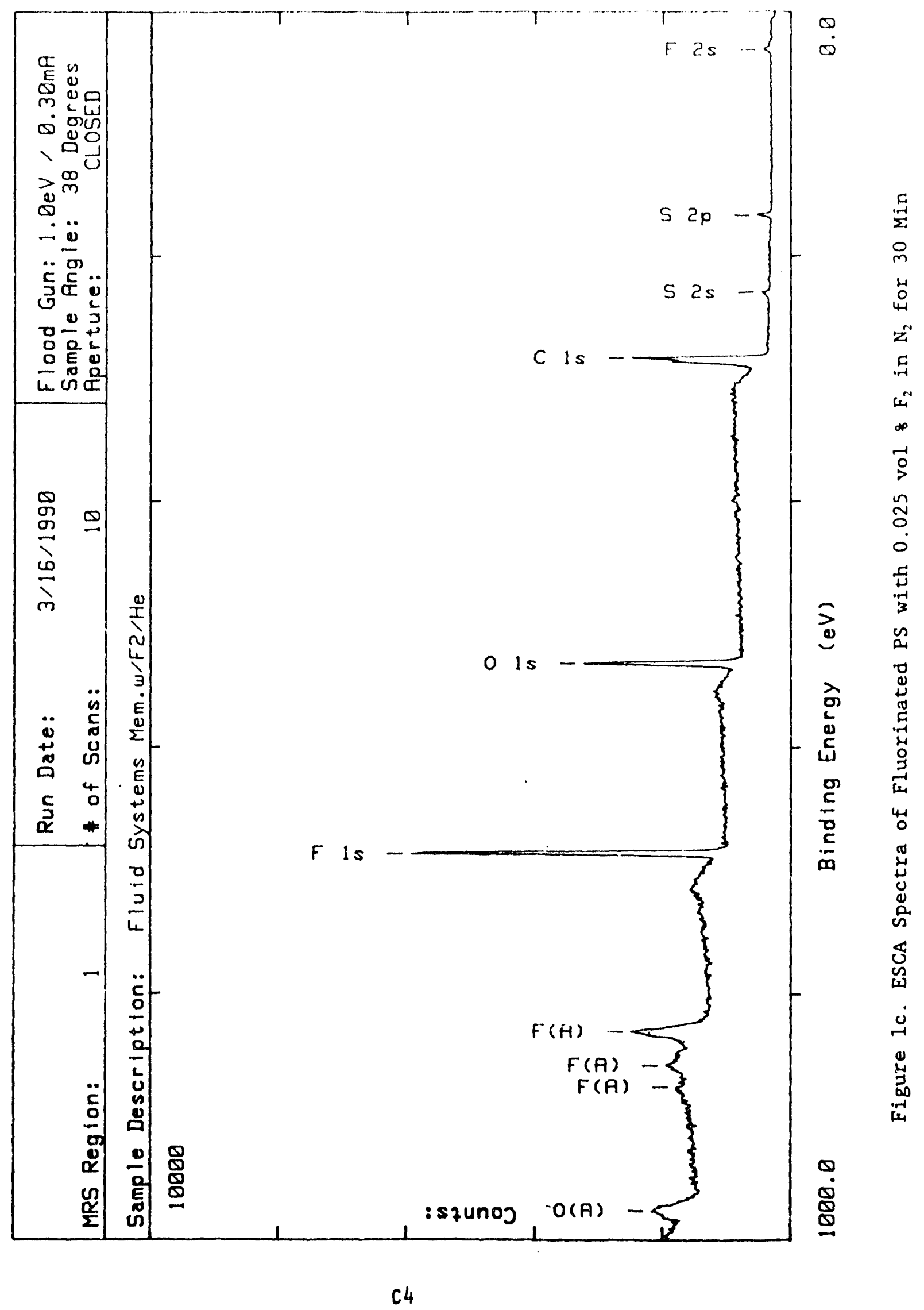




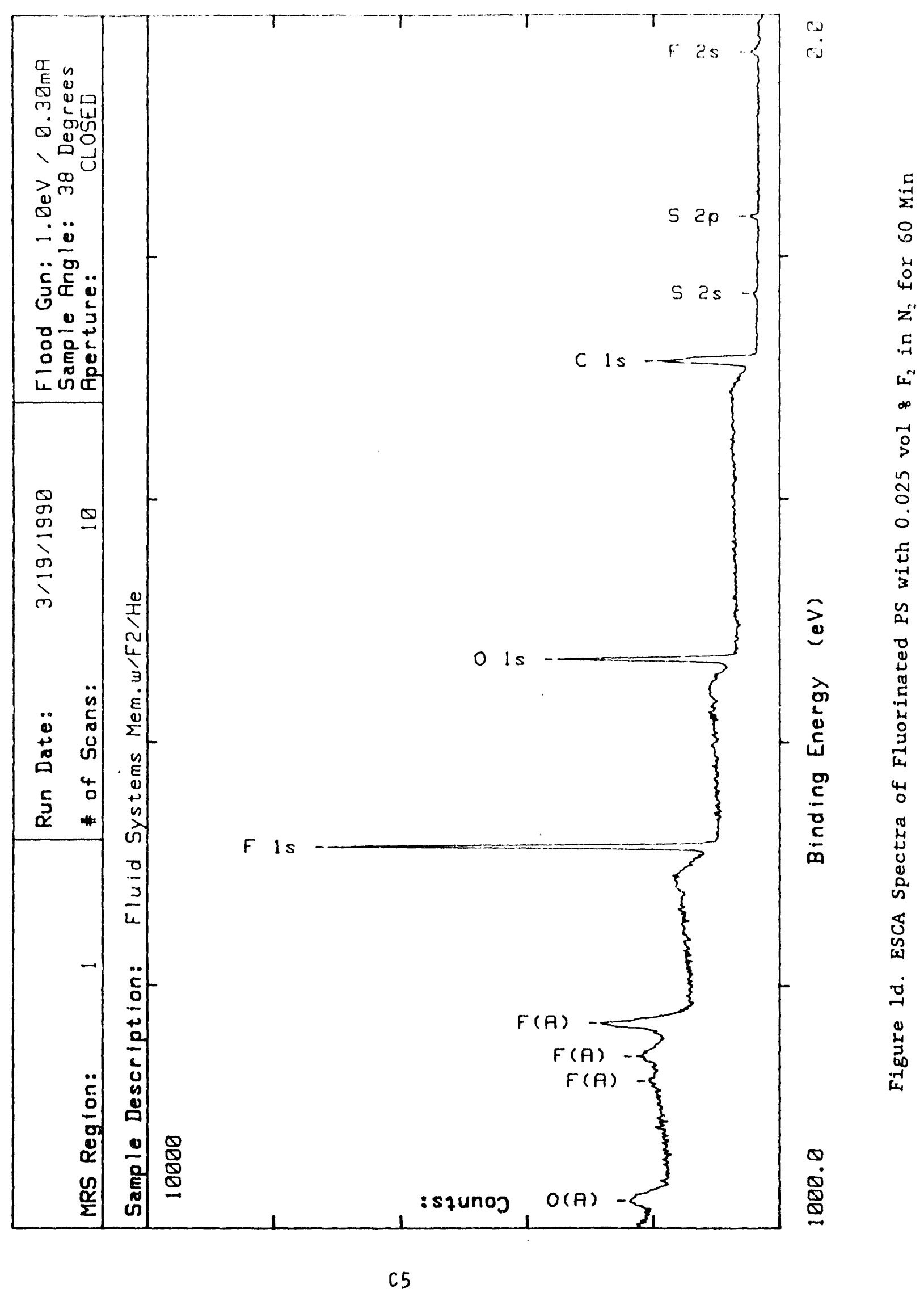




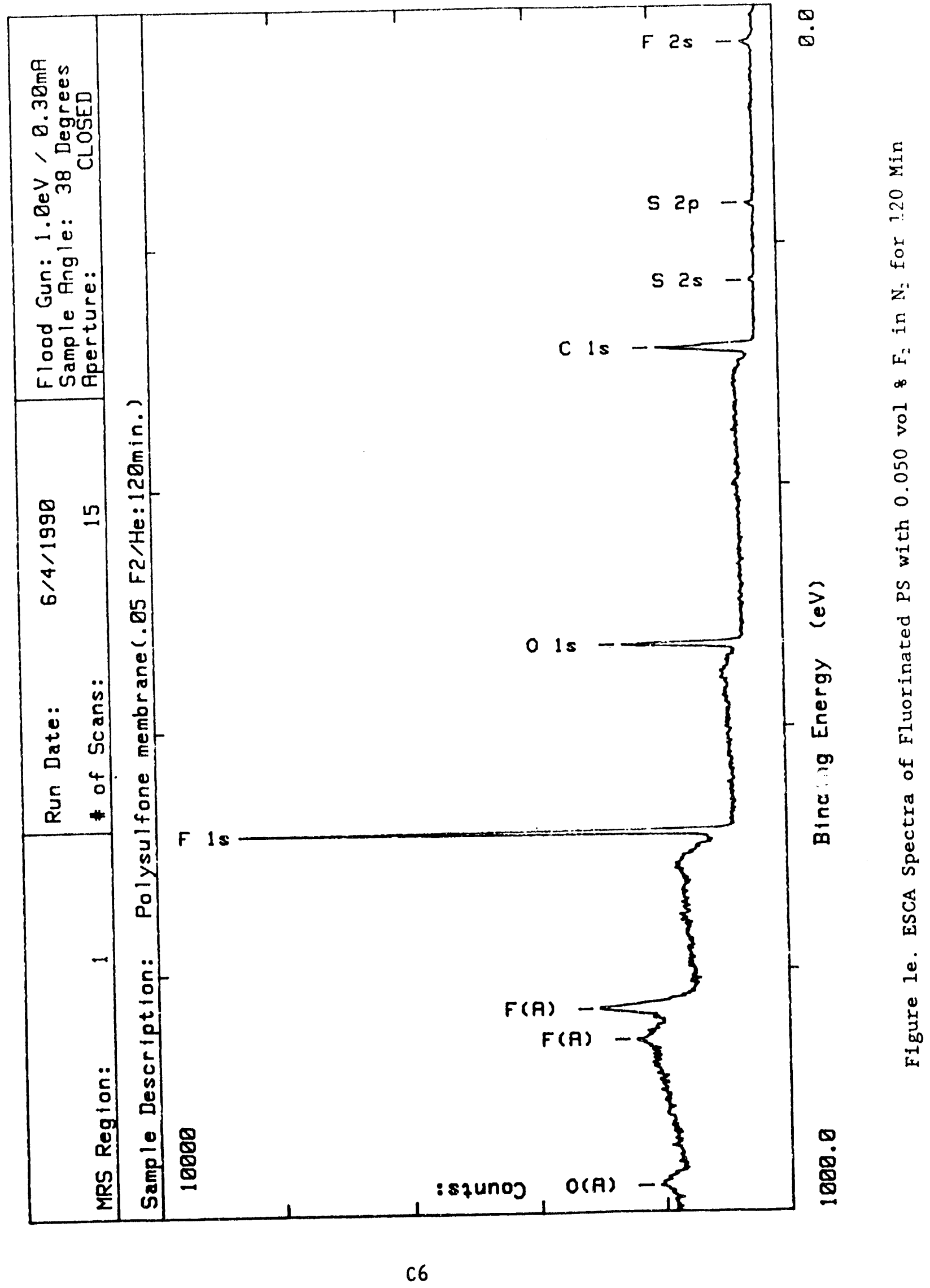


Table Cl: Summary of Atonic Percentages and Binding Energies (PS)

\begin{tabular}{|c|c|c|c|c|c|}
\hline \multicolumn{6}{|c|}{ Atomic Percents } \\
\hline Membrane & la & Ib & Ic & Id & $\mathrm{Ie}$ \\
\hline S $2 p$ & $2 \therefore 1$ & 2.13 & 1.90 & 1.46 & 1.31 \\
\hline C $1 \mathrm{~s}$ & 58.20 & 59.19 & 29.35 & 17.93 & 16.79 \\
\hline C $1 \mathrm{~s}$ & 22.62 & 18.16 & 25.09 & 27.58 & 24.29 \\
\hline C $1 \mathrm{~s}$ & - & - & 6.20 & 9.31 & 10.09 \\
\hline $\mathrm{N} 1 \mathrm{~s}$ & 1.92 & - & - & - & - \\
\hline $01 s$ & 14.85 & 8.08 & 17.55 & 19.69 & 3.42 \\
\hline $01 \mathrm{~s}$ & - & 9.32 & - & - & 12.76 \\
\hline F 1s & - & 3.11 & 19.91 & 17.08 & - \\
\hline F 1s & - & - & - & 6.95 & 31.34 \\
\hline
\end{tabular}

\begin{tabular}{|c|c|c|c|c|c|}
\hline \multicolumn{6}{|c|}{ Corrected Binding Energies } \\
\hline Membrane & Ia & $\mathrm{Ib}$ & Ic & Id & Ie \\
\hline Offset & 1.16 & 0.87 & 0.07 & -0.24 & -0.89 \\
\hline S $2 p$ & 168.29 & 168.19 & 168.24 & 168.28 & 167.87 \\
\hline C $1 \mathrm{~s}$ & 284.60 & 284.60 & 284.60 & 284.60 & 284.60 \\
\hline C $1 \mathrm{~s}$ & 286.04 & 286.08 & 287.23 & 287.26 & 287.03 \\
\hline C 1s & - & - & $289.46^{\circ}$ & 289.35 & 289.09 \\
\hline $\mathrm{N} 1 \mathrm{~s}$ & 399.65 & - & - & - & - \\
\hline 0 1s & 532.05 & 531.55 & 532.62 & 532.49 & 530.70 \\
\hline $01 \mathrm{~s}$ & - & 533.08 & - & - & 532.22 \\
\hline F 1s & - & 686.45 & 686.67 & 686.23 & - \\
\hline$F$ 1s & - & - & - & 687.32 & 686.13 \\
\hline
\end{tabular}




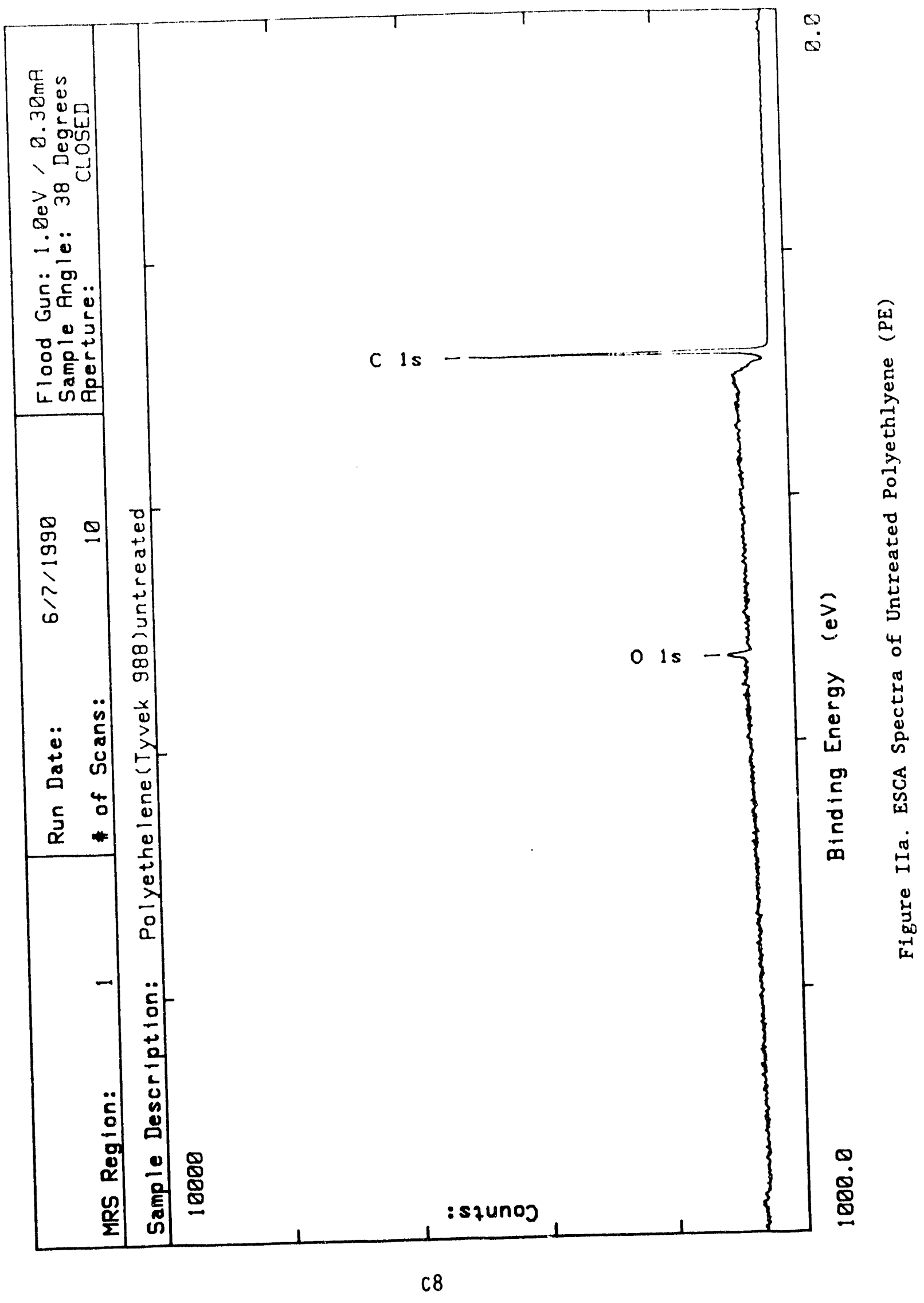




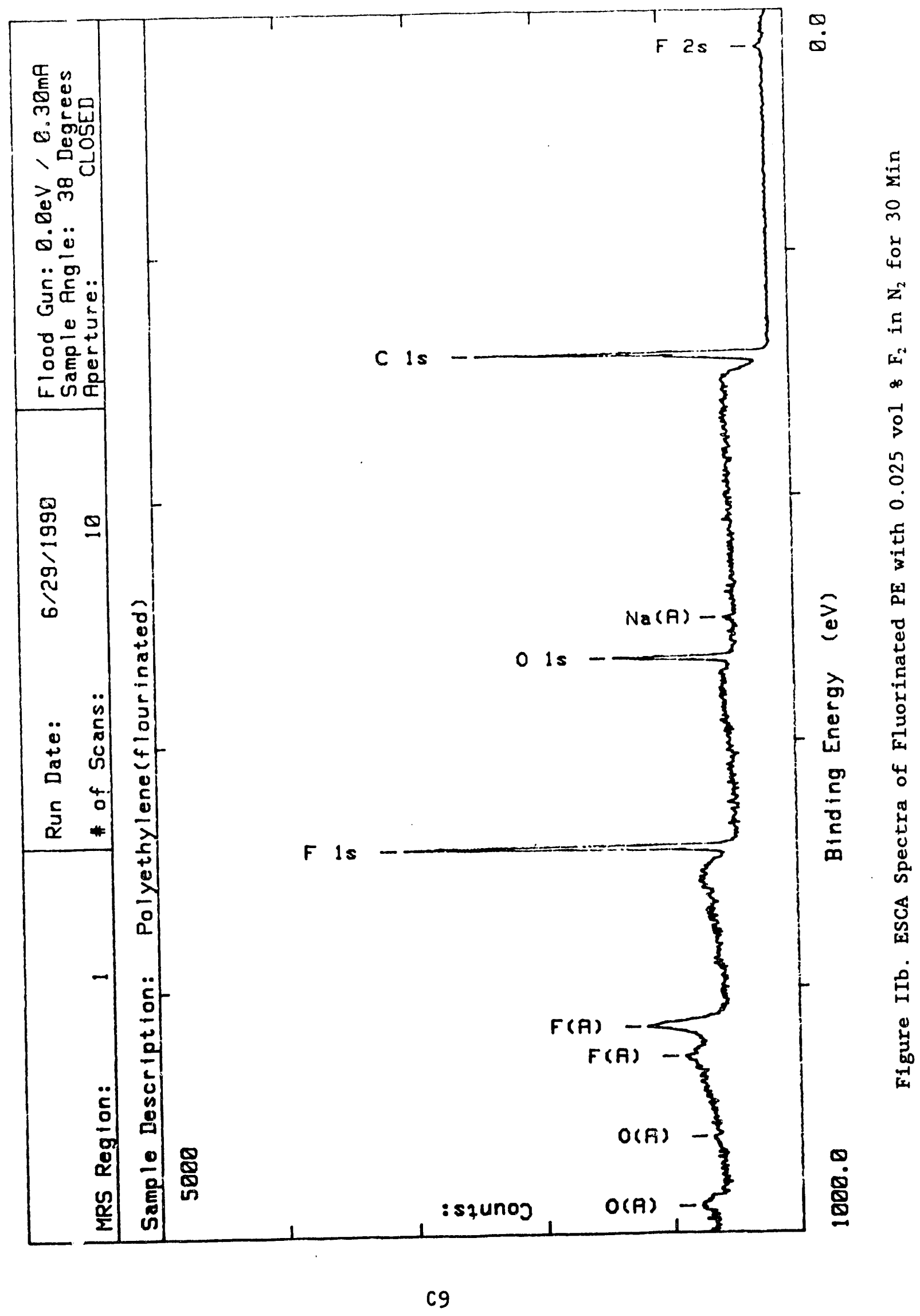




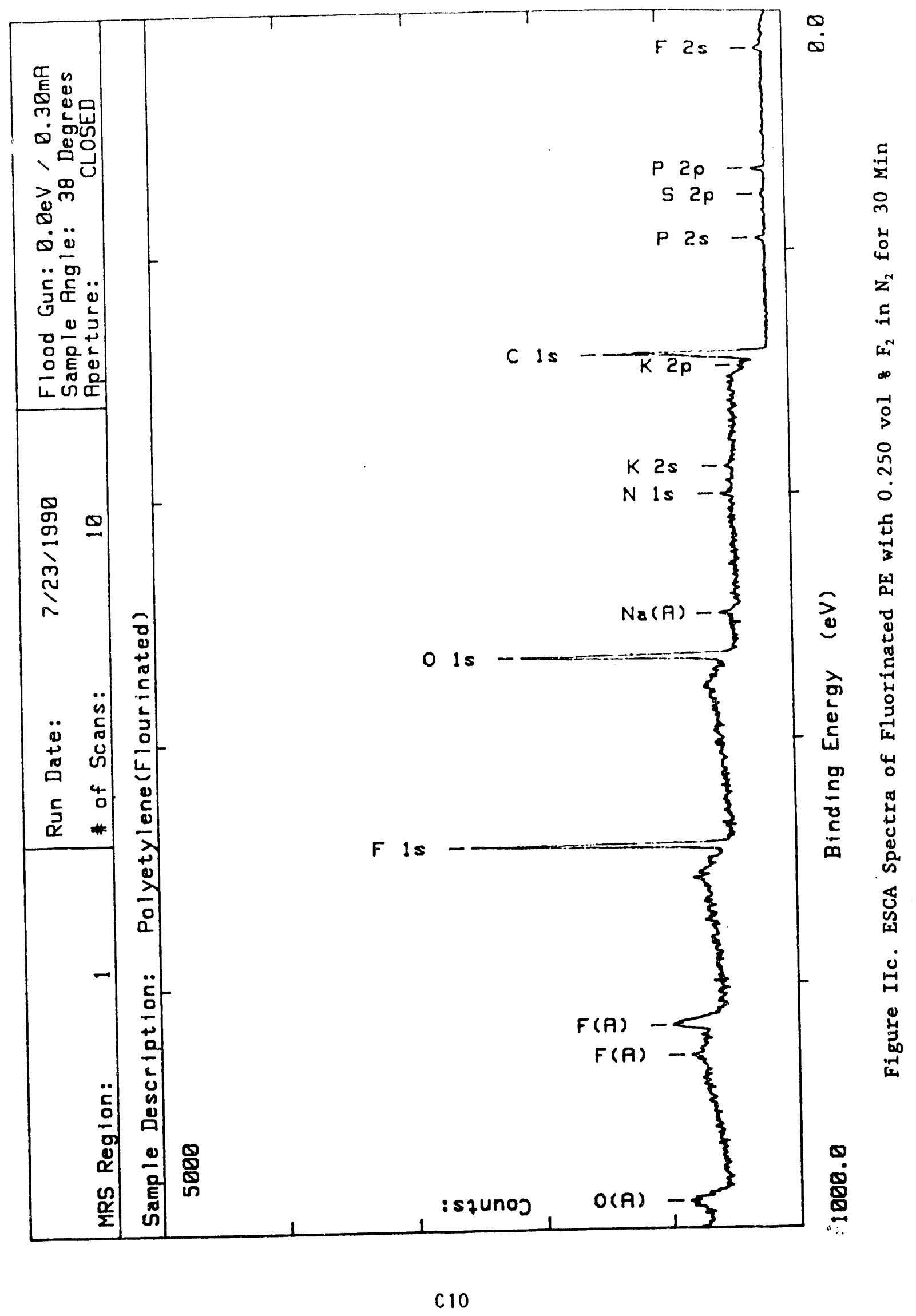


Table C2: Summary of Atomic Percentages and Binding Energies (PE)

\begin{tabular}{|c|c|c|c|}
\hline \multicolumn{4}{|c|}{ Atomic Percents } \\
\hline Membrane & I Ia & I Ib & I Ic \\
\hline S 2p & 0.07 & - & 0.14 \\
\hline C 1s & 83.59 & 44.19 & 35.70 \\
\hline C 1s & 11.77 & 25.67 & 20.74 \\
\hline C 1s & - & 3.36 & 4.03 \\
\hline O 1s & 4.57 & 9.61 & 3.64 \\
\hline O 1s & - & - & 19.17 \\
\hline F 1s & - & 14.7 & 13.84 \\
\hline F 1s & - & 2.47 & 2.74 \\
\hline
\end{tabular}

\begin{tabular}{||c|c|c|c||}
\hline \multicolumn{4}{|c|}{ Corrected Binding Energies } \\
\hline \hline Membrane & I a & I Ib & I Ic \\
\hline Offset & 1.02 & 0.90 & 0.30 \\
\hline S 2p & 169.9 & - & 169.01 \\
\hline C 1s & 284.60 & 284.60 & 284.60 \\
\hline C 1s & 285.56 & 287.14 & 287.07 \\
\hline C 1s & - & 289.74 & 289.39 \\
\hline O 1s & 532.25 & 532.75 & 530.99 \\
\hline O 1s & - & - & 532.53 \\
\hline F 1s & - & 686.44 & 686.52 \\
\hline F 1s & - & 687.85 & 687.92 \\
\hline
\end{tabular}




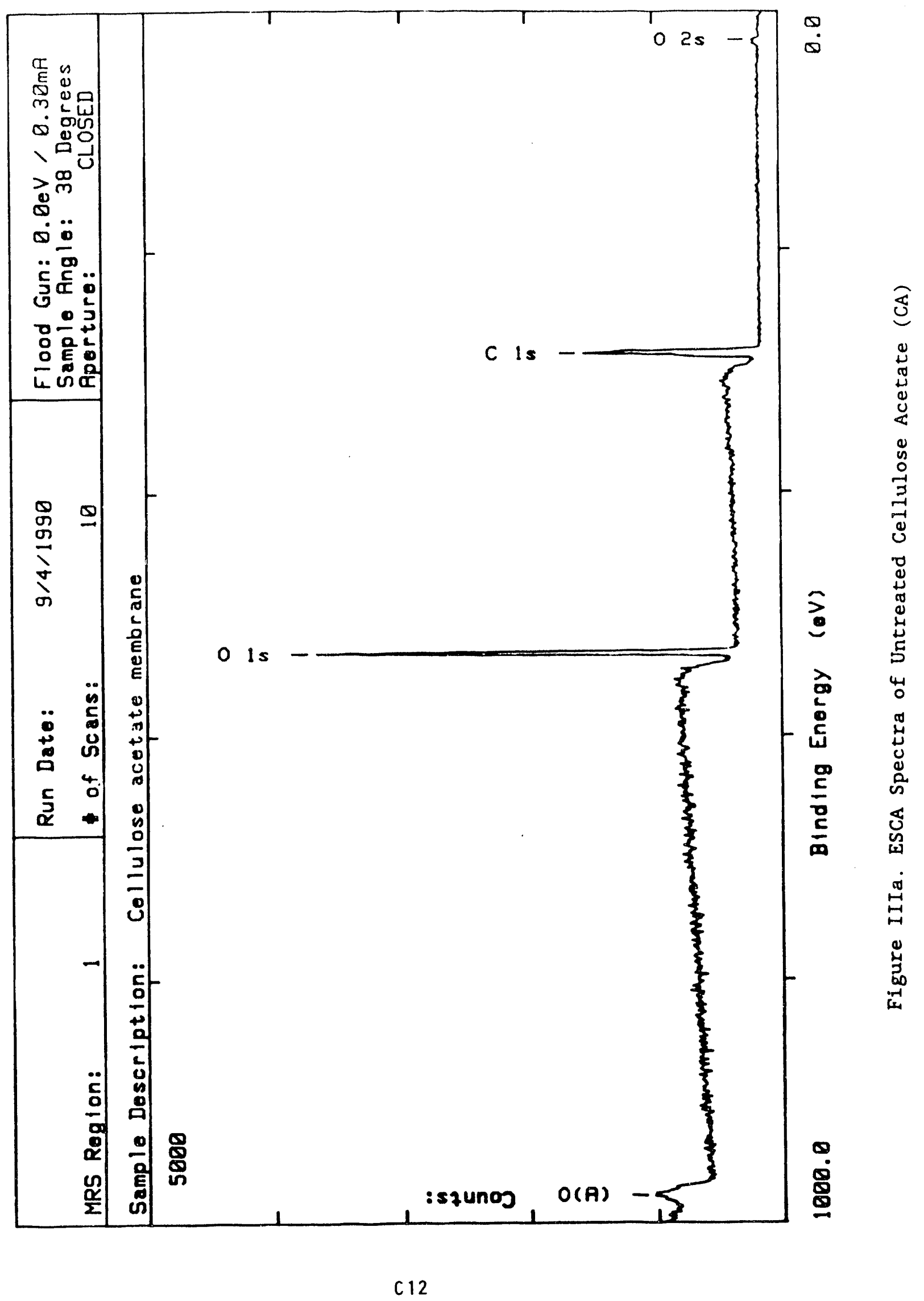




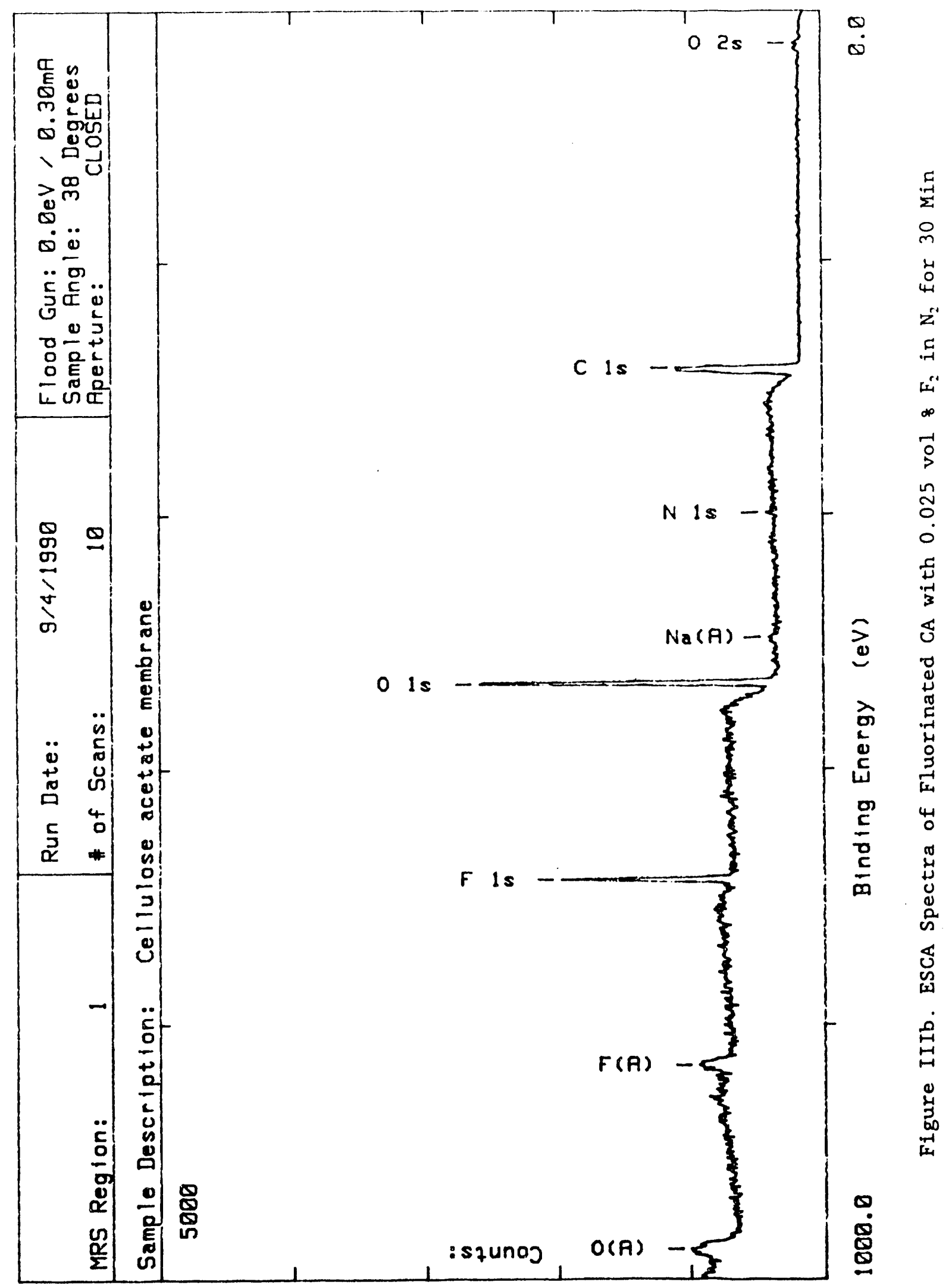


Table C3: Summary of Atomic Percentages and Binding Energies (CA)

\begin{tabular}{||c|c|c||}
\hline \multicolumn{3}{|c|}{ Atomic Percents } \\
\hline \hline Membrane & IIIa & IIIb \\
\hline C Is & 19.94 & 21.90 \\
\hline C Is & 31.90 & 24.53 \\
\hline C 1s & 15.33 & 15.70 \\
\hline O 1s & 32.82 & 7.47 \\
\hline O 1s & - & 20.98 \\
\hline F Is & - & 9.42 \\
\hline
\end{tabular}

\begin{tabular}{||c|c|c||}
\hline \multicolumn{3}{|c|}{ Corrected Binding Energies } \\
\hline Membrane & IIIa & IIIb \\
\hline Offset & 0.81 & 0.41 \\
\hline C Is & 284.60 & 284.60 \\
\hline C Is & 286.35 & 286.55 \\
\hline C Is & 288.76 & 288.70 \\
\hline O Is & 532.62 & 531.54 \\
\hline O Is & - & 532.84 \\
\hline F Is & - & 686.50 \\
\hline
\end{tabular}




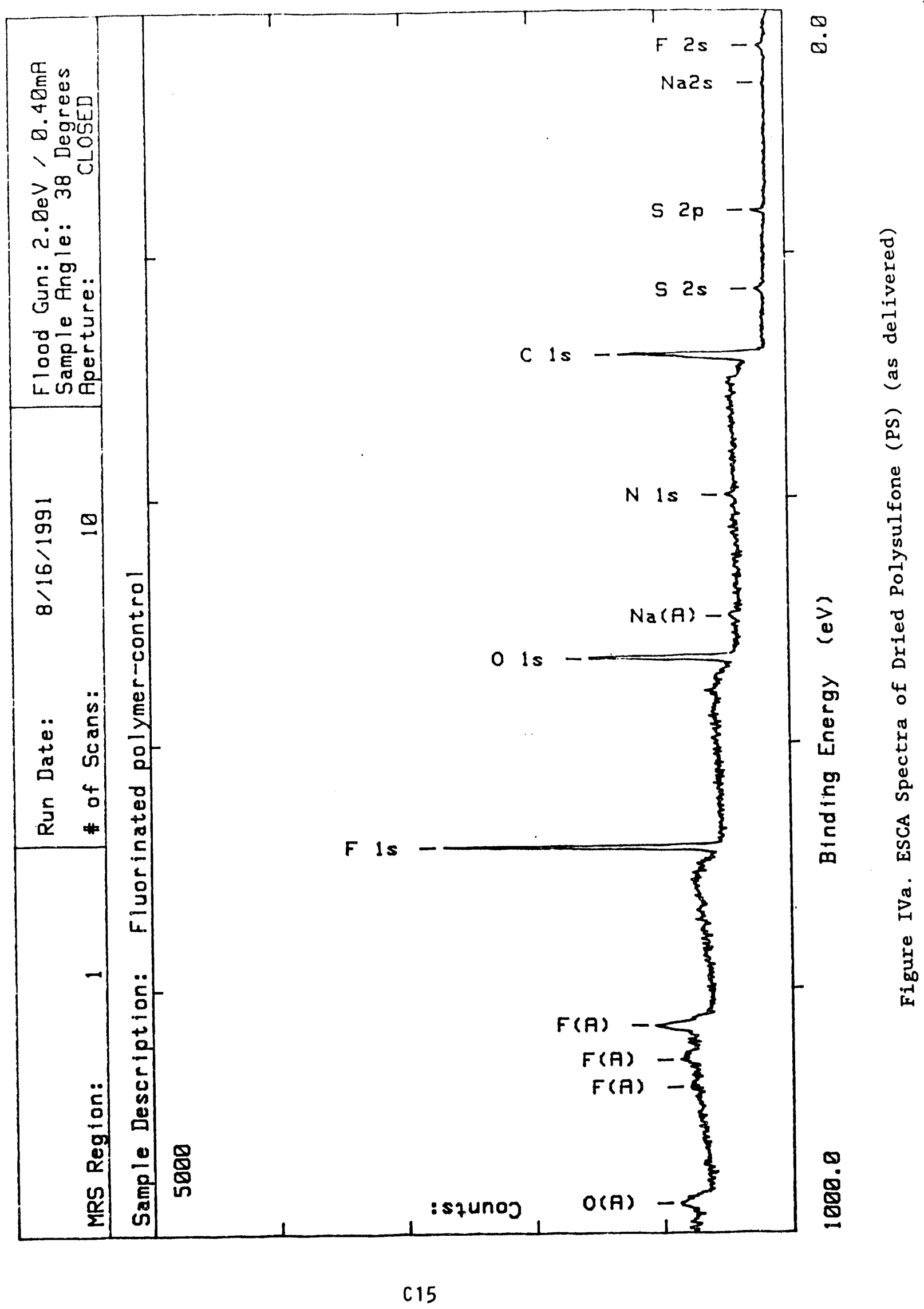




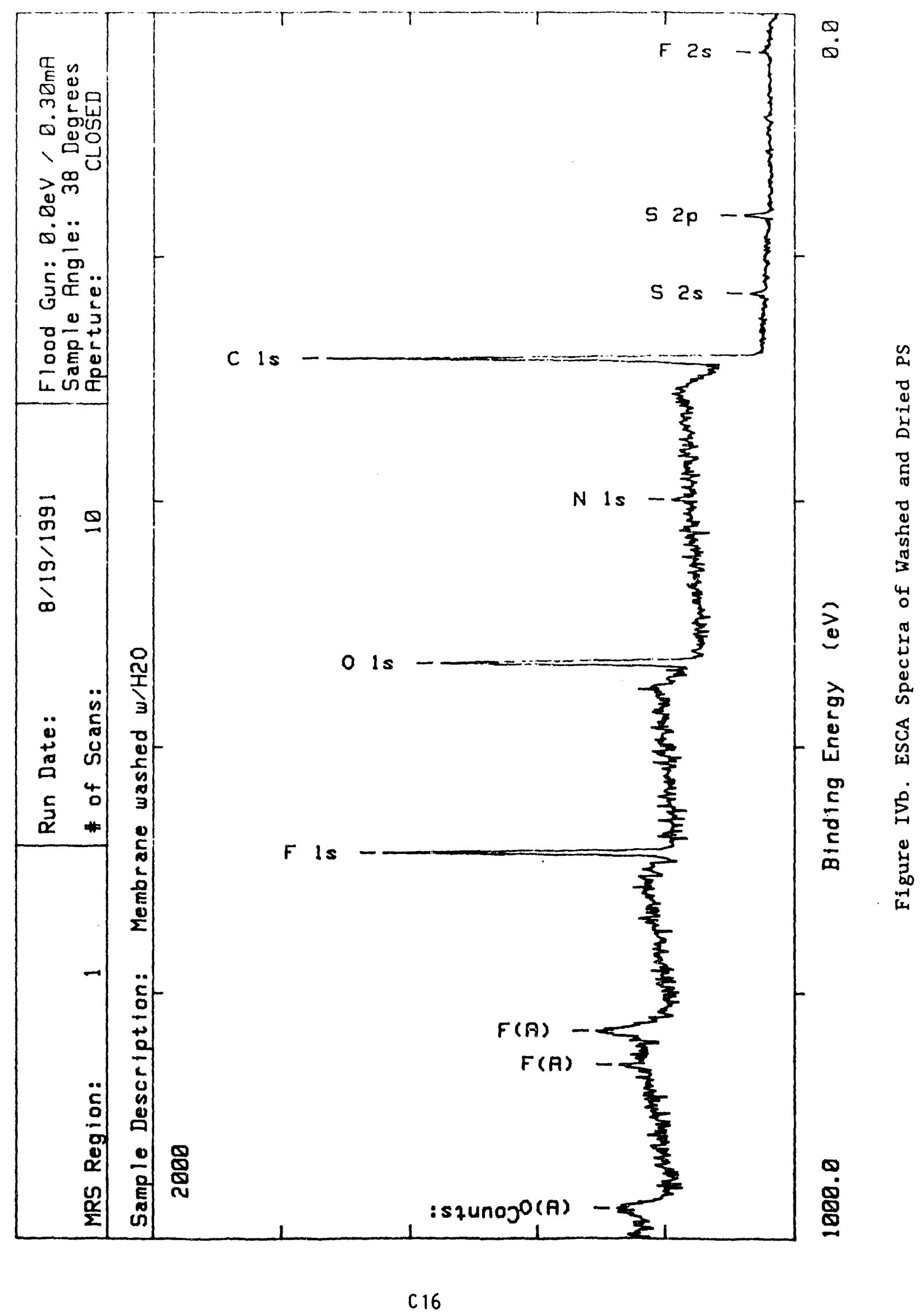




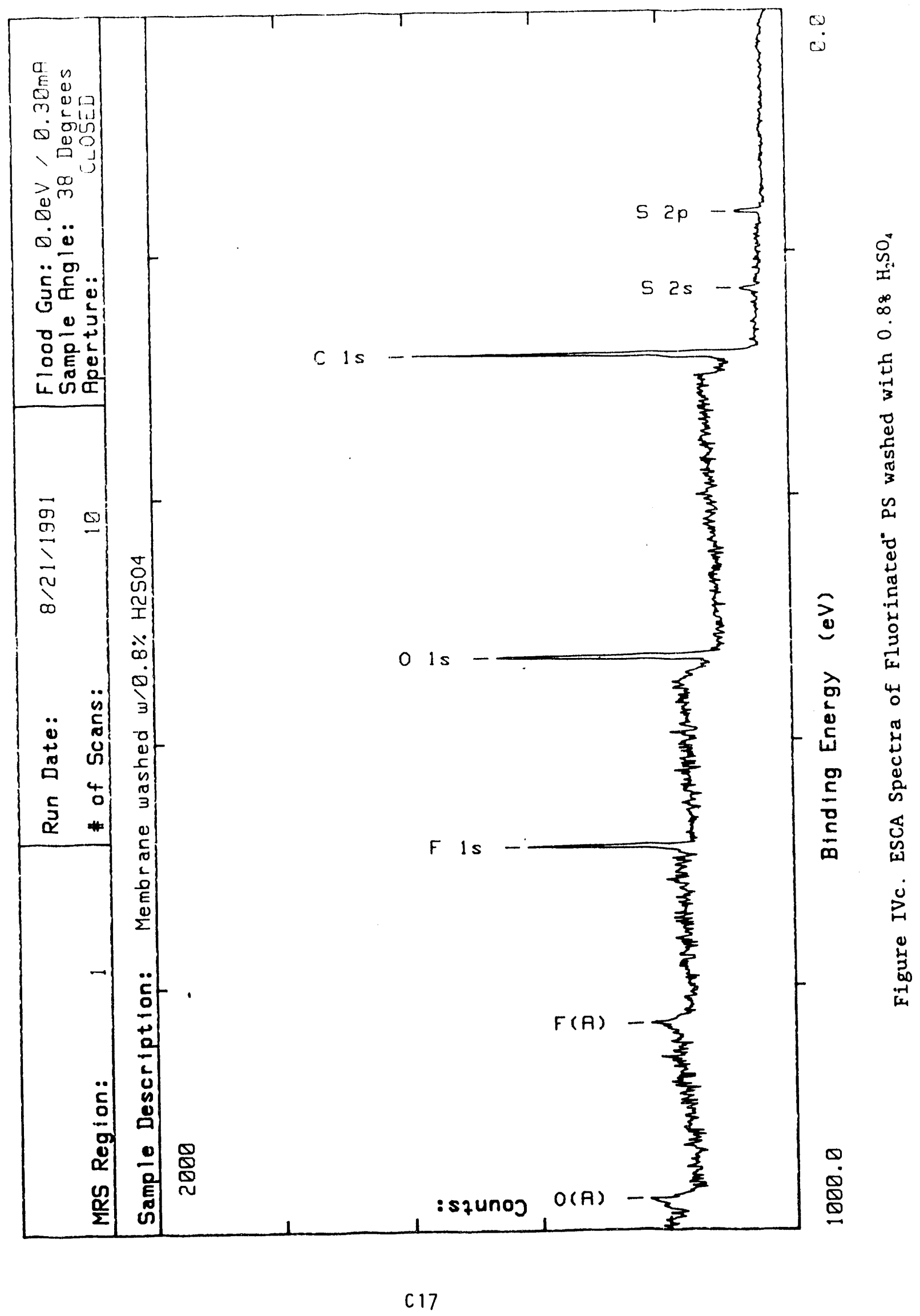




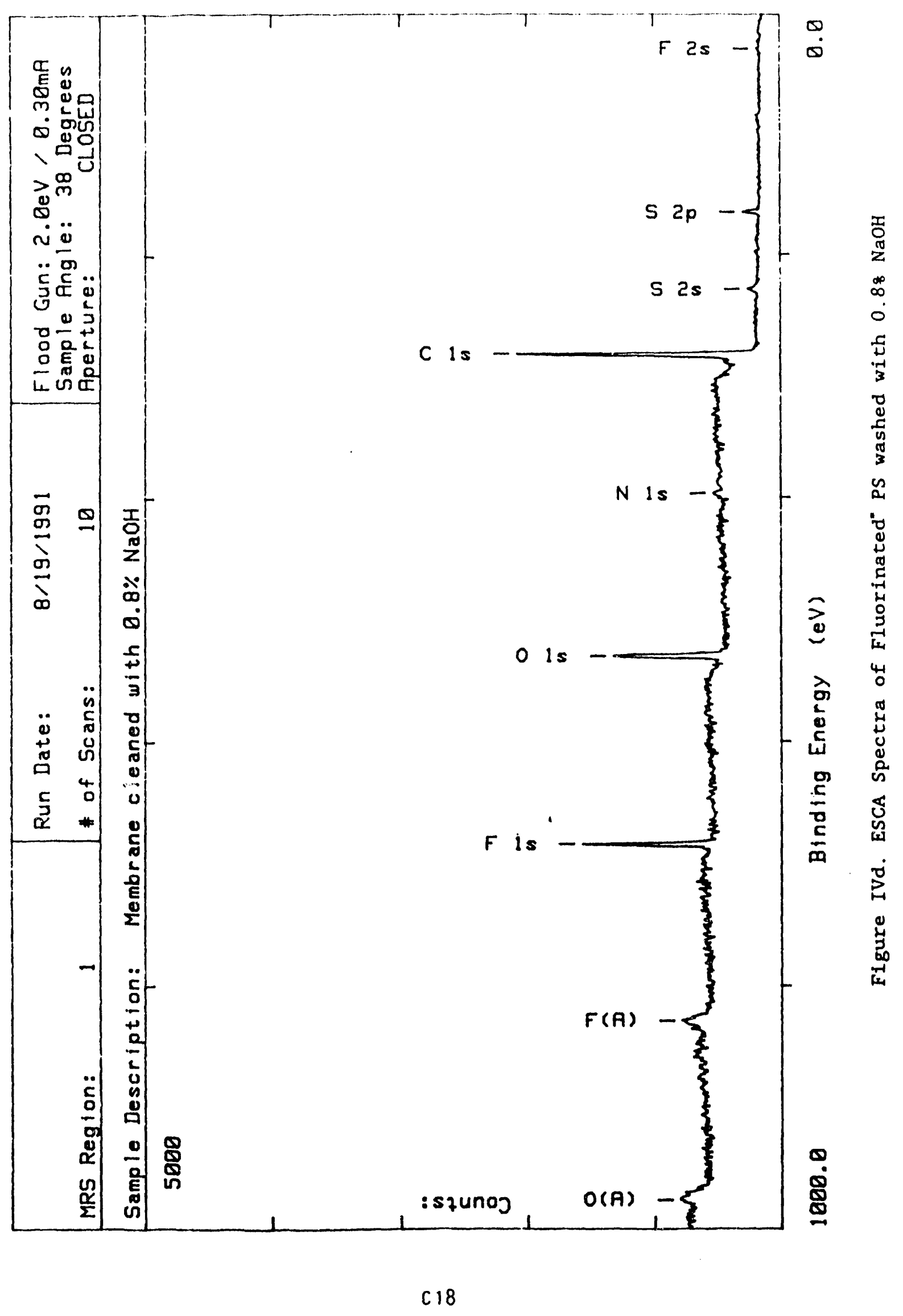




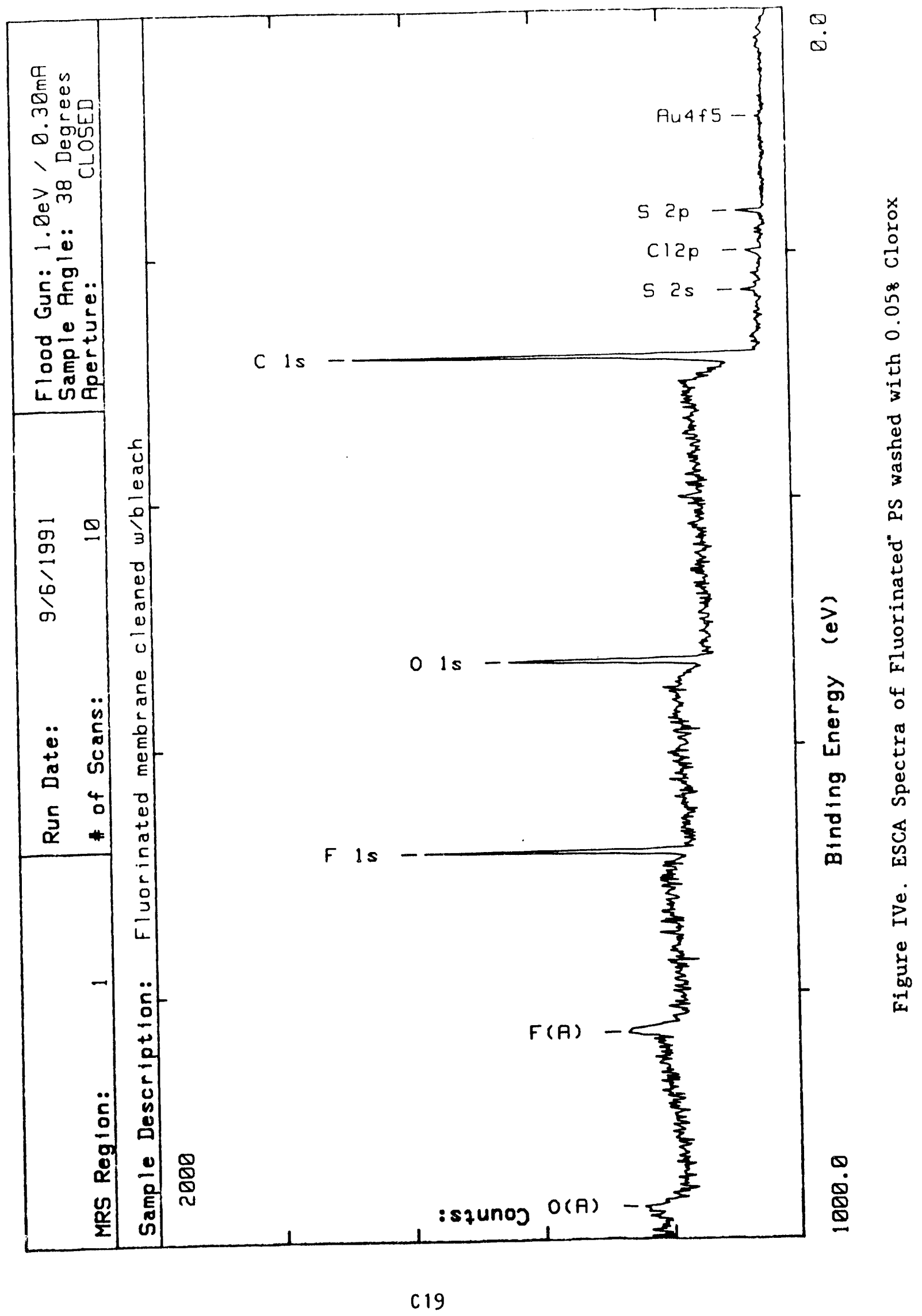


Table C4: Summary of Atomic Percentages and Binding Energies (Cleaning Study)

\begin{tabular}{|c|c|c|c|c|c|}
\hline \multicolumn{6}{|c|}{ Atomic Percents } \\
\hline Membrane & IVa & IVb & IVe & IVd & IVe \\
\hline S 2p & 1.74 & 2.01 & 0.24 & 2.44 & 2.03 \\
\hline$S 2 p$ & - & - & 3.41 & - & - \\
\hline $\mathrm{Cl} 2 \mathrm{p}$ & - & - & - & - & 0.99 \\
\hline C $1 s$ & 34.39 & 41.13 & 37.47 & 47.23 & 45.11 \\
\hline C $1 \mathrm{~s}$ & 22.62 & 27.95 & 30.61 & 24.83 & 25.79 \\
\hline C $1 \mathrm{~s}$ & 4.02 & - & - & - & - \\
\hline $\mathrm{N} 1 \mathrm{~s}$ & 1.49 & 1.74 & 1.24 & 1.36 & 1.65 \\
\hline $01 \mathrm{~s}$ & 9.78 & 8.44 & 8.55 & 7.88 & 6.95 \\
\hline $01 \mathrm{~s}$ & 8.36 & 8.27 & 11.03 & 7.52 & 8.60 \\
\hline F 1s & 17.6 & 10.46 & 7.46 & 8.74 & 8.89 \\
\hline
\end{tabular}

\begin{tabular}{|c|c|c|c|c|c|}
\hline \multicolumn{6}{|c|}{ Corrected Binding Energies } \\
\hline Membrane & IVa & IVb & IVc & IVd & IVe \\
\hline offset & 0.38 & 1.01 & 1.21 & 0.59 & 0.67 \\
\hline s $2 p$ & 168.28 & 168.25 & 165.12 & 168.19 & 168.19 \\
\hline s 2p & - & - & 168.62 & - & - \\
\hline C.1 2p & - & - & - & - & 201.01 \\
\hline C $1 \mathrm{~s}$ & 284.60 & 284.60 & 284.60 & 284.60 & 284.60 \\
\hline C $1 s$ & 287.01 & 286.28 & 285.81 & 286.05 & 286.32 \\
\hline C $1 s$ & 289.26 & - & - & - & - \\
\hline $\mathrm{N}$ is & 399.40 & 399.58 & 400.70 & 399.71 & 399.55 \\
\hline $01 s$ & 531.73 & 531.75 & 531.76 & 531.63 & 531.72 \\
\hline $01 s$ & 533.11 & 533.21 & 533.16 & 533.16 & 533.19 \\
\hline F 1s & 686.74 & 686.83 & 687.00 & 686.83 & 686.91 \\
\hline
\end{tabular}




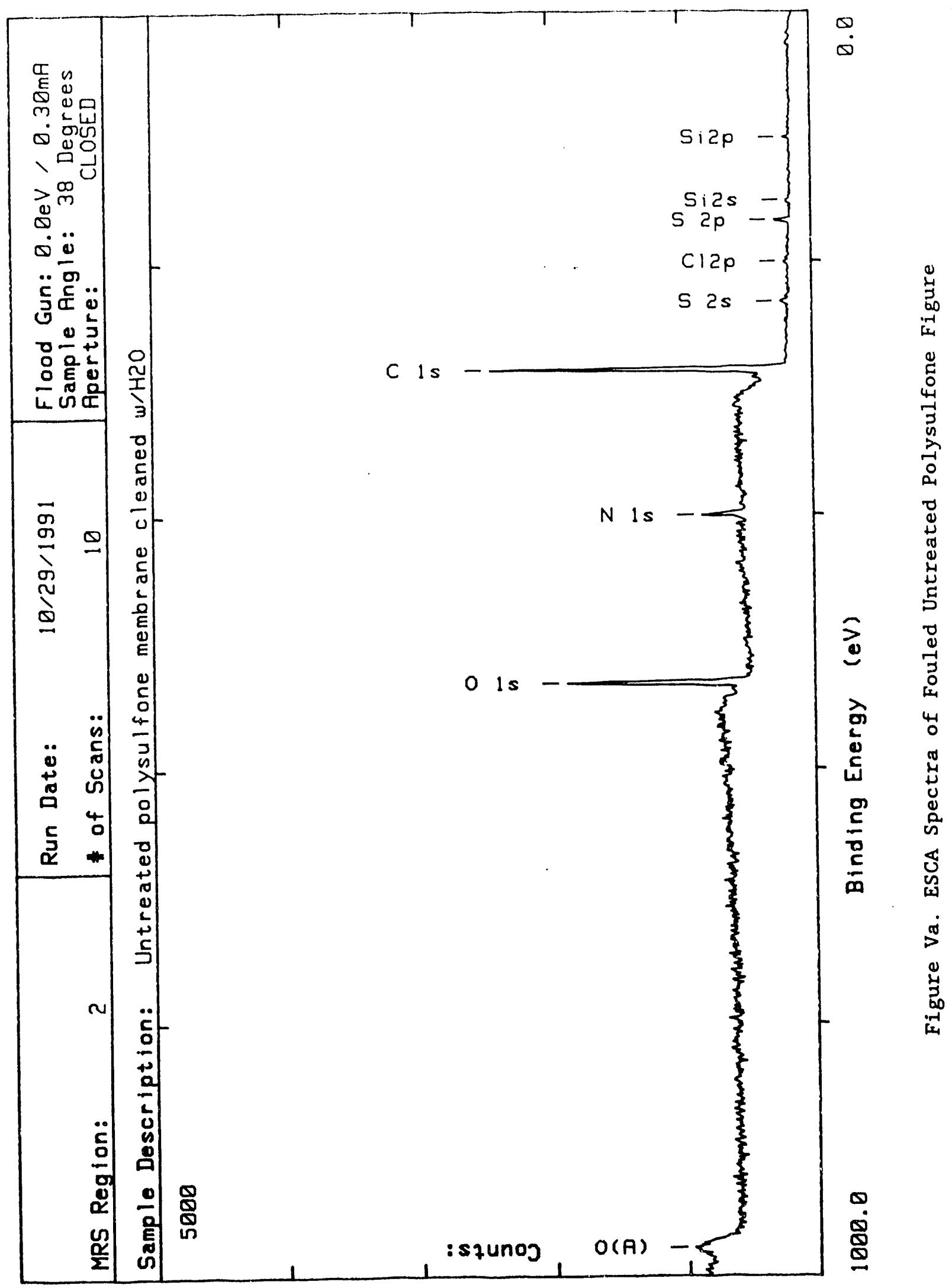




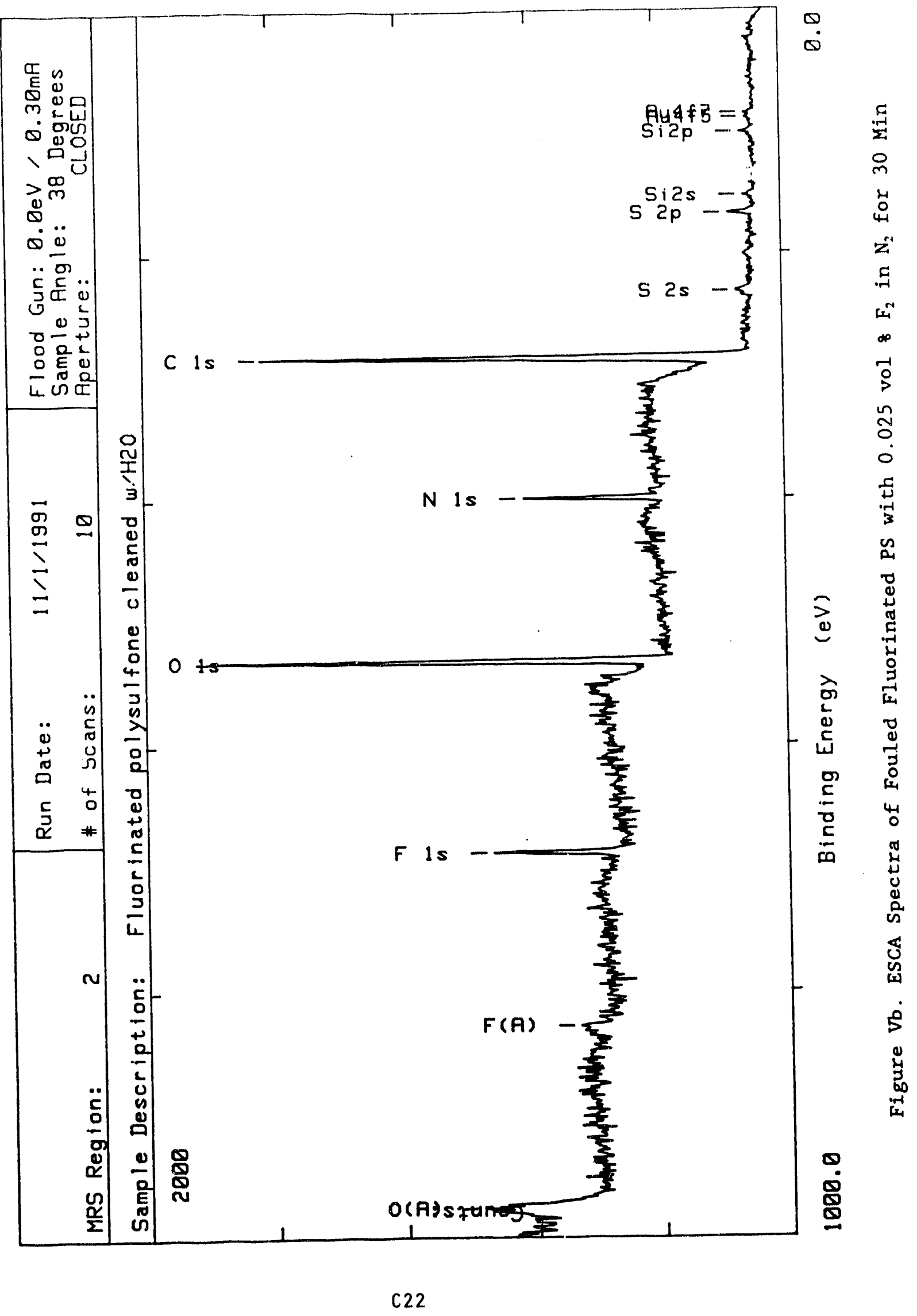


Table C5: Summary of Atomic Percentages and Binding Energies (Pilot Plant Studies)

\begin{tabular}{|c|c|c|}
\hline \multicolumn{3}{|c|}{ Atomic Percents } \\
\hline Membrane & $\mathrm{Va}$ & $\mathrm{Vb}$ \\
\hline $\mathrm{S} \mathrm{2p}$ & 1.85 & 1.18 \\
\hline $\mathrm{C} 1 \mathrm{~s}$ & 51.28 & 41.72 \\
\hline $\mathrm{C} 1 \mathrm{~s}$ & 15.61 & 11.52 \\
\hline C 1s & 8.36 & 15.26 \\
\hline N is & 6.30 & 7.94 \\
\hline O 1s & 12.59 & 17.78 \\
\hline O 1s & 4.01 & 1.77 \\
\hline F 1s & - & 2.83 \\
\hline
\end{tabular}

\begin{tabular}{|c|c|c||}
\hline \multicolumn{2}{|c|}{ Corrected Binding Energies } \\
\hline Membrane & $\mathrm{Va}$ & $\mathrm{Vb}$ \\
\hline Offset & 0.22 & 0 \\
\hline S 2p & 168.79 & 168.07 \\
\hline C 1s & 284.60 & 284.60 \\
\hline C 1s & 286.02 & 285.97 \\
\hline C 1s & 287.47 & 287.47 \\
\hline N 1s & 400.33 & 399.71 \\
\hline O 1s & 531.81 & 531.72 \\
\hline O 1s & 533.41 & 533.49 \\
\hline F 1s & & 686.27 \\
\hline
\end{tabular}


APPEndix D 
Appendix D: Economic Analysis of Ultrafiltration Systems

1. Capital Costs of U1trafiltration System $\ldots \ldots \ldots \ldots \ldots$ D2

2. Annual Operating Costs of Ultrafiltration System ....... D3 


\section{Capital Costs of Ultrafiltration System}

(5.5-FOLD CONCENTRATION OF PROTEIN IN $1,500,000$ POUNDS OF WHOLE WHEY)

Present ultrafiltration membranes:

\begin{tabular}{|c|c|c|}
\hline $\begin{array}{c}\text { Equipment } \\
\text { Type }\end{array}$ & $\begin{array}{c}\text { Costs } \\
(\$)\end{array}$ & $\begin{array}{c}\text { Percentage of } \\
\text { Total Cost (8) }\end{array}$ \\
\hline \hline Membranes & 77,000 & 24 \\
\hline $\begin{array}{c}\text { Hardware } \\
\text { (Pressure tubes, pumps, etc.) }\end{array}$ & 215,000 & 66 \\
\hline $\begin{array}{c}\text { Peripherals } \\
\text { (Controls, instrumentation, etc.) }\end{array}$ & 35,000 & 10 \\
\hline Total Costs & 327,000 & 100 \\
\hline
\end{tabular}

Improved ultrafiltration membrane with 258 increase in permeate flux:

\begin{tabular}{|c|c|c|}
\hline $\begin{array}{c}\text { Equipment } \\
\text { Type }\end{array}$ & $\begin{array}{c}\text { Costs } \\
(\$)\end{array}$ & $\begin{array}{c}\text { Percentage of } \\
\text { Total Costs (8) }\end{array}$ \\
\hline Membranes & 57,500 & 22 \\
\hline $\begin{array}{c}\text { Hardware } \\
\text { (Pressure tubes, pumps, etc.) }\end{array}$ & 161,000 & 64 \\
\hline $\begin{array}{c}\text { Peripherals } \\
\text { (Controls, } \text { instrumentation, etc.) }\end{array}$ & 35,000 & 14 \\
\hline Total Costs & 253,500 & 100 \\
\hline \hline Savings in Capital Costs & 73,500 & 2.3 \\
\hline
\end{tabular}




\section{Annual Operating Costs of Ultrafiltration System}

(5.5-FOLD CONCENTRATION OF PROTEIN IN 1,500,000 POUNDS OF WHOLE WHEY)

\begin{tabular}{|c|c|c|}
\hline $\begin{array}{c}\text { Operating } \\
\text { Costs }\end{array}$ & $\begin{array}{c}\text { Standard } \\
\text { Membrane }\end{array}$ & $\begin{array}{c}\text { Improved } \\
\text { Membrane }\end{array}$ \\
\hline $\begin{array}{c}\text { Electrical } \\
(\$ 0.038 / \mathrm{kw})\end{array}$ & $\$ 52,700$ & $\$ 39,500$ \\
\hline Steam & $438,000 \mathrm{lbs}$ & No Change \\
\hline Cleaning Water & $5,400,000 \mathrm{gal}$ & $4,320,000 \mathrm{gal}$ \\
\hline Cleaning Chemicals & $\$ 60,000$ & $\$ 48,000$ \\
\hline Membrane Replacement & $\$ 60,000$ & $\$ 45,015$ \\
\hline Labor & 1095 hours & No change \\
\hline
\end{tabular}



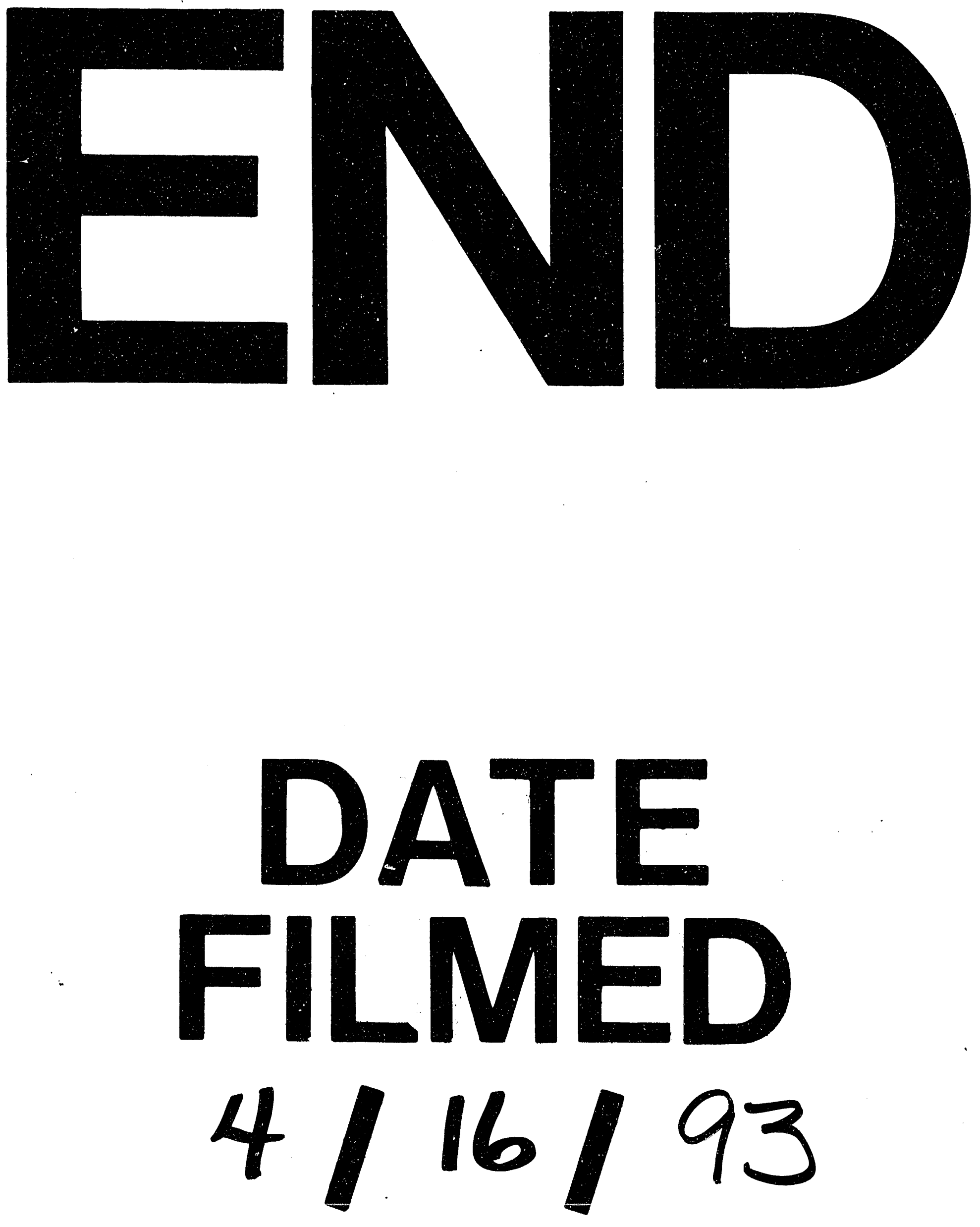
